University of Louisville

ThinkIR: The University of Louisville's Institutional Repository

Electronic Theses and Dissertations

8-2020

\title{
Getting up: an ethnography of hip hop graffiti writers, their art, and perceptions of society's reactions.
}

Theodore Malone

University of Louisville

Follow this and additional works at: https://ir.library.louisville.edu/etd

Part of the Criminology Commons, Criminology and Criminal Justice Commons, Quantitative, Qualitative, Comparative, and Historical Methodologies Commons, Social Control, Law, Crime, and Deviance Commons, Social Psychology and Interaction Commons, Sociology of Culture Commons, and the Urban Studies and Planning Commons

\section{Recommended Citation}

Malone, Theodore, "Getting up: an ethnography of hip hop graffiti writers, their art, and perceptions of society's reactions." (2020). Electronic Theses and Dissertations. Paper 3524.

https://doi.org/10.18297/etd/3524

This Doctoral Dissertation is brought to you for free and open access by ThinkIR: The University of Louisville's Institutional Repository. It has been accepted for inclusion in Electronic Theses and Dissertations by an authorized administrator of ThinkIR: The University of Louisville's Institutional Repository. This title appears here courtesy of the author, who has retained all other copyrights. For more information, please contact thinkir@louisville.edu. 
GETTING UP: AN ETHNOGRAPHY OF HIP HOP GRAFFITI WRITERS, THEIR ART, AND PERCEPTIONS OF SOCIETY'S REACTIONS

\title{
By
}

\author{
Theodore Malone \\ B.A., West Virginia University, 2002 \\ M.A., West Virginia University, 2015

\begin{abstract}
A Dissertation
Submitted to the Faculty of the

College of Arts and Sciences of the University of Louisville

in Partial Fulfillment of the Requirements

for the Degree of
\end{abstract}

Doctor of Philosophy in Applied Sociology

\author{
Department of Sociology \\ University of Louisville \\ Louisville, Kentucky
}

August 2020 

GETTING UP: AN ETHNOGRAPHY OF HIP HOP GRAFFITI WRITERS, THEIR ART, AND PERCEPTIONS OF SOCIETY'S REACTIONS

\section{By}

Theodore Malone

B.A., West Virginia University, 2002

M.A., West Virginia University, 2015

\section{A Dissertation Approved on}

July 27,2020

by the following Dissertation Committee:

Patricia Gagné, Ph.D.

Robert Carini, Ph.D.

Ryan Schroeder, Ph.D.

Jason Gainous, Ph.D.

Jeff Ferrell, Ph.D. 


\section{ACKNOWLEDGEMENTS}

A special thanks goes to my colleagues at the University of Louisville, and to a wonderful Committee and Chair, Dr. Pat Gagné, for her ever productive feedback in developing and refining this dissertation, and for showing me how to do qualitative research. I also thank Dr. Ryan Schroeder for inspiring me to think deeper on all things criminology and deviance and for supporting me in this project from its inception. I thank my colleagues, Brandon and Adam, for helping me to see the potential of this project, and for the infrequent "refueling" sessions at Wendy's while working at the Center for Environmental Policy and Management at UofL. A big shout out goes out to all the writers who welcomed me into their world and often treated me as one of their own and often as part of the crew. I learned a great deal from everyone who I was fortunate enough to meet, and my life has improved vastly because of our many experiences. This project would also not have been as informative without the help of the dedicated city officials who accommodated my many meetings, calls, and emails, and showed me the ways graffiti and municipal practices meet at the policy level. A huge thanks goes to my unnamed friends who welcomed me in to graffiti and reminded me to trust my instincts. I would like to thank Jeff for showing us places to find sparks in life. I thank my family for their continued love and support, and a tremendous thanks goes to TC, my favorite person and truest of homies, who has always inspired me to go beyond limits. 


\section{ABSTRACT \\ GETTING UP: AN ETHNOGRAPHY OF HIP HOP GRAFFITI WRITERS, THEIR ART, AND PERCEPTIONS OF SOCIETY'S REACTIONS}

Theodore Malone

July 27,2020

This ethnographic analysis of the modern hip hop graffiti writing subculture connects the separate but complementary theoretical constructs of serious leisure (Stebbins 1982), dark leisure (Smith and Raymen 2016), recreational specialization theory (Bryan 1977), and edgework (Lyng 1990) and situates the writer "standpoint" (Smith 1987) in terms of interrelations of policy and written discourse. Past research found that writers were motivated by recognition and status, to express artistic skills, and to control and destroy space (Brewer and Miller 1990). Others found that writers sought to express contestant notions of style and resist economic and political authority (Ferrell 1996; 2006), and some emphasize affective aspects of accomplishment and desire in graffiti (Halsey and Young 2006). Policy research indicates wide misunderstandings of graffiti and its inclusion under a 'gang' label (Ferrell 1996), and cities increasingly favor "wars on graffiti" (Iveson 2010) where ineffective anti-graffiti campaigns justified in "broken windows" ideals often result in increasing illegal graffiti (Haworth, Bruce, and Iveson 2013). Interviews of policy officials of a mid-sized Midwestern city revealed varying views, preferences, and understandings of graffiti, and city ordinance criminalized all unsanctioned graffiti. Interview data from a snowball sample of writers indicated dynamic motives, views, and practices and three writer classes. A key finding is as writers specialized on a career trajectory, a shift in focus occurred from writing for thrill to writing for flow.

Motives were consistent with past research, and the subculture regulated its membership via social control and mentoring. Further, socialization was a central part of progression, and writing occurred as "everyday forms of resistance" (Scott 1984), edgework, serious leisure, and recreation specialization. To acknowledge these nuances through policy may benefit the public, engage writer voices, and reduce fear by increasing awareness and public exposure to graffiti, potentially disassociating it from 'master vandal' or gang status. 


\section{TABLE OF CONTENTS}

PAGE

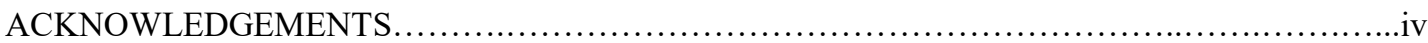

ABSTRACT ....

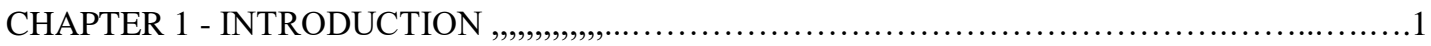

A Brief Overview of Graffiti and the Current Research Study ..........................................1

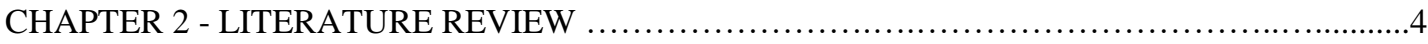

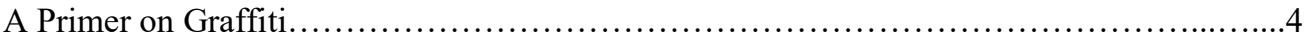

Historical Traditions of Graffiti: From Cave Scratching to Train Piecing...............................5

Distinguishing Hip Hop Graffiti Writing from Other Types of Graffiti........................7

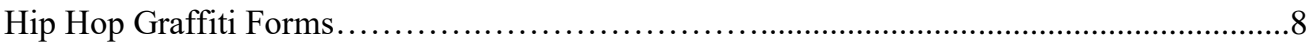

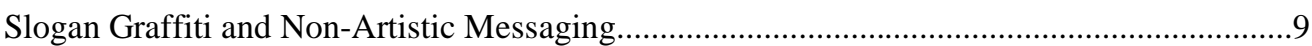

Political Graffiti and Street Art .............................................................

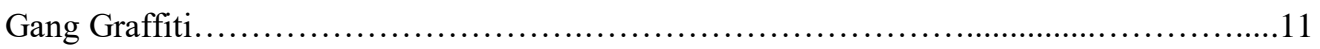

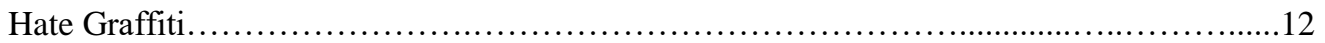

Studies on Hip Hop Graffiti Writing .............................................................

Public Attitudes Toward Hip Hop Graffiti..........................................................14

Writer Preferences and Graffiti Policy and Practices....................................................16

CHAPTER 3 - THEORETICAL FRAMEWORK AND RELATED RESEARCH.....................21

Cultural Criminology, Moral Entrepreneurship, and Hip Hop Graffiti..............................21

Standpoint Theory, Institutional Ethnography, and "Everyday Forms of Resistance" ...........23 


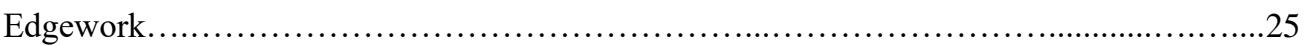

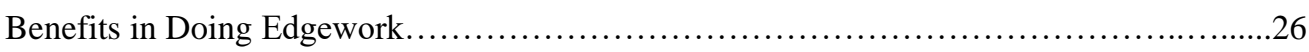

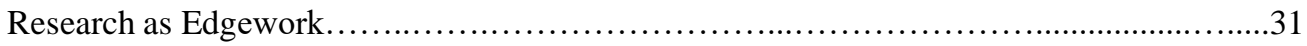

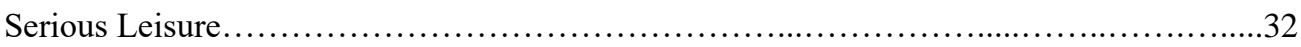

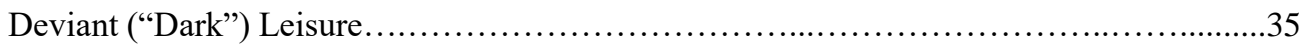

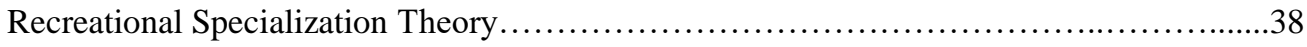

Studies in Recreational Specialization Theory and Related Research......................39

Recreational Specialization Theory and the Serious Leisure Perspective...................44

Gender, Substitution, Identity, and Other Factors in Recreation Specialization................45

What the Current Study Aims to Do.............................................46

Policy Implications of Wrongly Theorizing Hip Hop Graffiti............................48

Urban Planning, Reducing Crime, and Place-based Urban Space Policies..................49

"Broken Windows," Rational Choice, and "Getting Tough on Crime".....................50

Expanding Policy, Coordinating Efforts, and Celebrating Unheard Voices.................54

"Smart Cities," the Creative City, and Alternative Graffiti Policy ........................56

A Note on Legal Graffiti Policy Administration......................................58

CHAPTER 4 - RESEARCH METHODS............................................................60

Geographical Location, Unit of Analysis, and Sample...........................................60

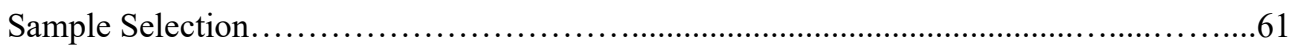

Gaining Entrée and Building Rapport............................................64

Researcher Membership Status and Criminological Verstehen...................................65

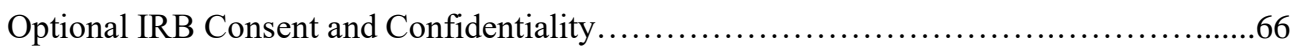

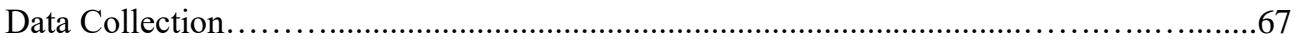


Data Analysis

Data Storage.

Insider Researcher Focus.

The Research Process and Edgework.

Research Questions

Overview: Research on Policy Officials and the Written Discourse

Theoretical Framework Revisited: Graffiti, Serious Leisure, RST, Edgework, and Policy

Prioritizing Removal of Illegal Graffiti Forms....................................96

Prioritizing Graffiti and Other Crime............................................. 97

Perceptions of Efficacy: Graffiti Policy and Practices..................................99

Views and Ideals of Priorities and Best Practices for Addressing Graffiti..................100

Desire for Increased Departmental and Community Collaboration......................101

Alternatives to Conventional Deterrence Policy: Murals and Sanctioned Graffiti...............103 


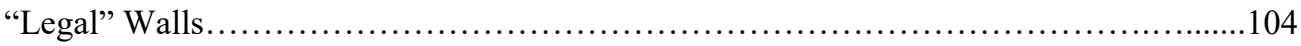

Softening the Approach: Restorative Justice and Engagement Strategies..........................106

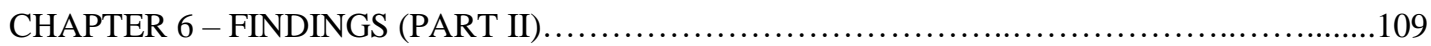

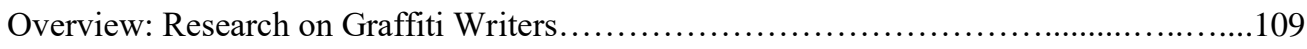

A Day in the Life of Graffiti Research: A “Thick Description”.................................110

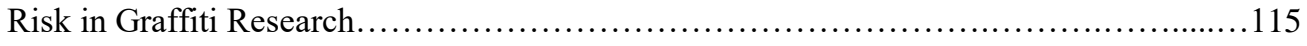

Socialization, Mentorship, and Identity in the Graffiti Subculture...................................116

Subcultural Values and Practices and The Hip Hop Orientation in Graffiti.................129

Efficiency Norms: A “No-hollow Zone"................................................120

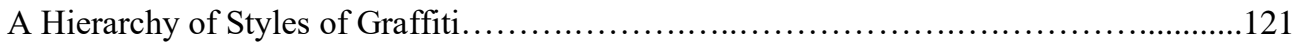

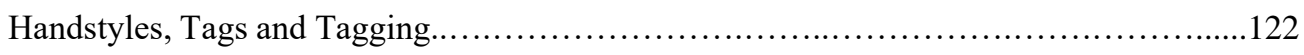

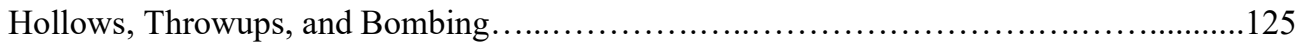

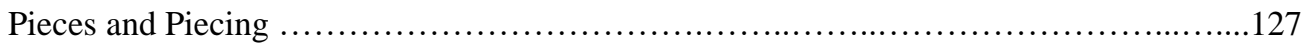

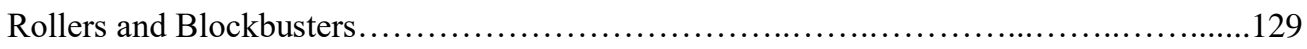

Experience Levels, Mentorship, Progression and Social Control in Graffiti Subculture......131

Snitches Get Stiches: A Blue Line of Silence, Ousting, and Respect Lost (and Regained?)

Everyday Forms of Resistance: Contesting Use of Space, Private Property, and Advertising

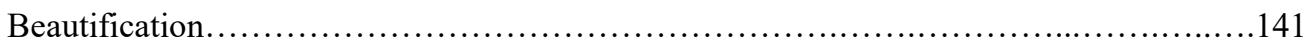

Choosing Graffiti Spots, Risks, and Constraints..........................................142

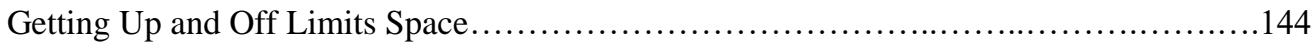

Style in Hip Hop Graffiti, Developing Individual Style, and Learning from Others...........146

Respect and Doing “Consistent, Quality Vandalism”..................................... 148

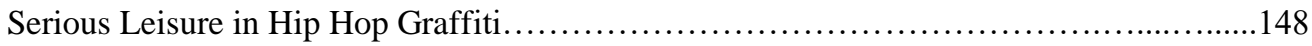

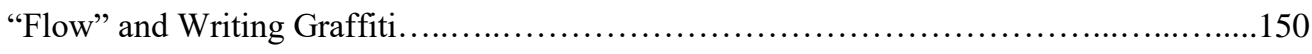

Serious Leisure Commitment and Producing "Saleable" Graffiti...........................151 
Auxiliary Activities: Social Media, Sketching, Benching, and Homework

RST in Graffiti Writing: Experience Levels, Progression, and the Career Trajectory.... .154

“Quality” and “Quantity” Orientations in Graffiti, Supplies, and Paint Spot Preferences....157

Investment and "Side Bets" in Graffiti as Recreation.

"Paying Dues": Deterrence Policy, Jail Time, and Writer Commitment.

Abatement as a Challenge. 164

Edgework, Thrill, "Crowding the Edge" and Improving Skills 166

Career Trajectory: Dark Leisure Edgework Recreation to Professional Pursuits. 169

Discontinuing the Writing Career. 171

A Caution to Alternative and Legal Graffiti Policy.

Policy Standpoint and Conflicting Images: Quality of Life and Illegal Graffiti .173

CHAPTER 7 - DISCUSSION AND CONCLUSIONS. .175

Synopsis. 175

Subcultural Influences and the Graffiti Career Trajectory: From Toy to OG .176

Policy Implications: Dark Leisure, Serious Leisure, and Recreational Specialization in Graffiti

Policy Recommendations: Expanding Practices through Alternatives.....................182

Alternatives in Restorative Justice............................................... 185

"Mainstreaming" Graffiti and Writer Resistance....................................... 187

Limitations and Directions for Future Research...................................... 189

Concluding Statements ...................................................... 192

REFERENCES. 194

APPENDIX A (INTERVIEW GUIDE - GRAFFITI WRITERS)............................................201

FOCUS GROUP INTERVIEW GUIDE - GRAFFITI WRITERS .............................................204 


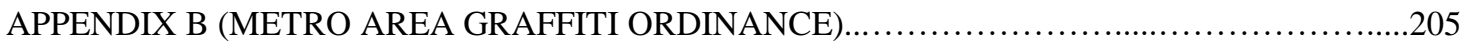

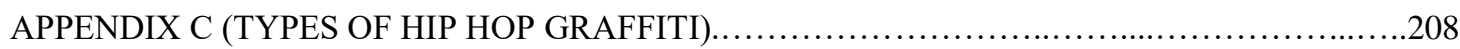

APPENDIX D (OTHER PRACTICES IN HIP HOP GRAFFITI) ..............................216

APPENDIX E (INTERVIEW GUIDE - POLICYMAKERS AND ENFORCERS............................218

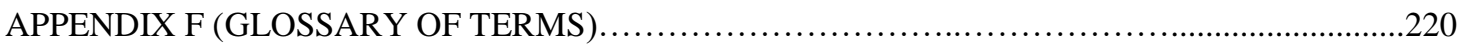

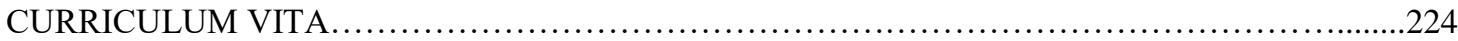




\section{CHAPTER 1}

\section{INTRODUCTION}

\section{A Brief Overview of Graffiti and the Current Research Study}

Most past research on hip hop graffiti has been conducted in the ethnographic tradition, and findings indicate that graffiti "writing" entails a form of resistance and subcultural expression (Ferrell 1995), a means to gain fame and demonstrate one's artistic skills (Brewer 1992; Ducuyunan 2000; Halsey and Young 2006), an anarchist form of resistance to political and economic control (Ferrell 1996:187), and an ongoing dialogue of members of a deviant subculture (Austin 2001; Ferrell 2006). Other research shows that graffiti can be a process of communication and protest of marginalized groups expressing (often) controversial issues of race, gender, and sexual orientation through amateur graffiti (Rodriquez and Clair 1999). Other studies examined graffiti within alternative contexts, including anti-Semitic graffiti that arose in relation to soccer team rivalry (Sinnreich 2004), and, in another instance, examined fear and non-fear reactions to different spatio-temporal variations in graffiti (Vanderveen and Ejik 2015). Still other research examined municipal responses to graffiti, finding that most cities favor a "criminalizing" policy approach (Halsey and Young 2002; Ross 2016); others note a militarizing trend in graffiti policy (Iveson 2010). The current research frames graffiti as a subset of dark leisure (Stebbins 1996) with theoretical and conceptual intersections in edgework (Lyng 1990), the serious leisure perspective (Stebbins 1982), recreational specialization theory (Bryan 1977, 2008), and standpoint theory. This study locates its methodological approach in institutional ethnography (Smith 2005, 2006), and looks within the graffiti subculture to situate the world of writers in terms of the often-politicized social institutions in which they practice their transgressive and stylistic form of recreation. The analysis addresses gaps in the graffiti literature by providing an updated and theoretical understanding of graffiti writing in relation to the terms of municipal graffiti policy and related criminal justice practices in a mid-sized metropolitan area. 
The theoretical connections and deeper understandings offered here seek to explain why artists risk stigmatization, fines, and jail time in doing their craft. A goal of this research is to open discussion with graffiti policymakers and enforcers to reconsider conventional policy understandings that frame all graffiti art or vandalism. Current (mis)understandings of graffiti writing manifest in policy that implies penalties for practitioners, as well as prohibitions and fines for owners of (usually) commercial or abandoned properties where hip hop graffiti is typically done, if it is not removed according to municipal protocols. While numerous studies have utilized combined research methods in assessing graffiti writing and related policy practices, little known research examines graffiti writer standpoints in their experiences with and perceptions about their practices in relation to the terms of institutional discourse, policy design and practice, and reactions of local government, business, the news media, and community members.

In the next two chapters I outline a brief history of graffiti, key literatures, and several bodies of theory relevant to historical and contemporary understandings of graffiti. This discussion will include related literature on edgework, the serious leisure perspective and deviant leisure, recreational specialization theory, cultural criminology, and municipal graffiti policy. The current analysis seeks to offer a deeper and current understanding of the motives, meanings, and rewards of illegal artistic graffiti writing. The central contribution of this study is to describe graffiti writing in terms of intersections of the theories discussed above to offer a framework of graffiti and writers' standpoints in terms of their experiences, perceptions about their art, outsider reactions, and ways that social institutions and discourses (primarily urban graffiti policy and criminal justice practices) affect their work.

This current study aims to debunk stereotypes and myths about hip hop graffiti that pervade the public consciousness, and to provide a "thick description," a detailed and deeper examination (Geertz 1973), of a poorly understood subculture through immersive research methods. In my research I conducted semi-structured interviews and participant observations of graffiti being painted in the "naturalistic environments" of writers, and observations involving non-structured socializing and related interactions and conversations. The sample of writers originated from a friendship that I developed with an initial key research participant, eventually expanding into a cohort of 31 active writers, some of whom were willing to invite me along on painting excursions as an observer. My role as such was initially restricted to observing 
and "looking out" for possible intruders and later developed into a more involved capacity to assist in creating graffiti.

In my research design, I also set out to answer research questions1 that investigate municipal policymaker and enforcer practices and preferences toward graffiti and policy officials' understandings and views of the modern hip hop graffiti subculture. Thus, a separate set of interviews with five key graffiti policy officials elucidates the interrelated institutional features and written discourses that affect the practice of hip hop style graffiti and the experiences of writers. Additionally, I sought to assess writer views and subcultural values and practices and the ways that graffiti may take form as edgework, serious leisure, recreational specialization, or resistant dark leisure to compare findings with other studies and identify ways that policy and publics may benefit from a better understanding of graffiti as a form of skilled and rewarding recreation. Through grounded analytical analysis of qualitative data (Charmaz 2006; Jorgensen 1989), new theoretical insights realized from addressing these questions aids in an expanded theoretical understanding of illegal hip hop graffiti. Such an understanding may allow a re-conceptualization of graffiti within the public policy discourse, which constructs artistic graffiti as art or crime classified with hate speech, obscenity, or other un-skilled forms. Below, I explore some of the key literature related to hip hop style graffiti writing and public policy practices.

1 Also, see CHAPTER 4 - RESEARCH METHODS for a full listing of research questions and the methodology used in this study. 


\section{CHAPTER 2}

\section{LITERATURE REVIEW}

\section{A Primer on Graffiti}

Urban graffiti writing originates in a millennia-old cultural tradition of writing on, painting, and inscribing walls and other surfaces with messages, art, knowledge systems, and other relics. Hip hop graffiti is often miscategorized with "street art," which refers to a similar form of non-graffiti art using (often politicized) stickers, stencils, or murals (Chalfont and Prigoff 1987), usually directed toward a public audience (Austin 2010; Ferrell 1996; McAuliffe 2012). Austin characterized "graffiti art" as the types of graffiti that began appearing in the late 1960s and early 1970s on New York City walls and train cars, and postulated that it is out of this form of graffiti that street art really emerged (2010:34). The root of the word 'graffiti' loosely means to scratch a mark or picture onto or into a surface (MacDonald 2013). Accordingly, human society has maintained much of its history and cultural heritage via inscriptions, cave paintings, petroglyphs, and other forms of graffiti visible in museum artifacts and on surfaces throughout the world. "Hip hop" graffiti 'writing' is usually done illegally and is specific to its own distinct style codes, finding its roots in lettering and names. Graffiti writing is also specific to the use of markers and ink, aerosol and other paint, etching devices, and improvised writing tools, to serially create a quickly-executed and stylistic “tag” (one's graffiti name or signature), drawing, or message. Writing is also accomplished with bucket paint, stickers, and occasionally by using fire extinguishers to leave one's signature on a myriad of surfaces chosen specifically for the type of graffiti and intent of the artist (Brewer and Miller 1990; Ferrell 1996; Halsey and Young 2006).

Modern graffiti writing began in Philadelphia (Halsey and Young 2002) and New York in the 1960s and 1970s (Mailer and Narr 1974; Ferrell 1996), later diffusing beyond New York’s Bronx and Harlem boroughs, where "hip hop" culture largely originates. Hip hop includes dance forms, rapping, turntable DJing, and graffiti, as well as a style of clothing and skateboarding (MacDonald 2013; Ferrell 
1996). From its early origins, hip hop graffiti has found its way to cityscapes, highway walls, and the miles upon miles of New York City subway cars. This resistant and artistic form of graffiti later expanded physically and culturally by way of interstate freight trains into cities throughout the United States and Canada, Latin America, Europe, Australia, and New Zealand (Chalfont and Prigoff 1987). Modern day hip hop graffiti is the largest form of illegal graffiti, practiced throughout major cities and towns, wherever there are parked train cars or urban landscapes that offer expansive canvasses.

While illegal hip hop graffiti writing has become a popular subcultural pursuit, it remains outside of the understanding of most non-affiliates. This is likely due to urban graffiti's illegality, the elusive nature of practitioners, perhaps racialized assumptions about writers, and the relative dearth of in-depth research conducted following its emergence from the streets of Philadelphia and the subways of New York. Since its early popularity in films like Wild Style (1983) and in magazines and MTV productions, hip hop graffiti has diffused into mainstream culture, often commodified and sold in various forms to eager consumers, including graffiti-style Coach products, Apple iPads, video games, and graffiti lettering on H\&M clothing and other brands. Hip hop graffiti has also become commonplace through the musical works of artists including LL Cool J, The Typical Cats, A Tribe Called Quest, and the Beastie Boys. Despite some evidence of a gradually increasing cultural appeal, the realities of the graffiti subculture in the United States and in many other international locations remains a mystery to most, while simultaneously facing mixed reactions from police, political authorities, the media, and the general public.

\section{Historical Traditions of Graffiti: From Cave Scratching to Train Piecing}

The modern English word 'graffiti' finds its etymological origin in the Italian word, "graffitos," to scratch a surface or leave a mark (MacDonald 2013). By this definition, graffiti may be one of the oldest forms of human cultural communication. Before its more recent appearance on highway walls, freight trains, billboards, signs, and the long list of other surfaces on which modern graffiti is "written," graffiti could be observed in the form of inscriptions, pictographs, hieroglyphs, Celtic runes, and other means, on six of the seven continents (Baird and Taylor 2016; MacDonald 2013). Archeologists used early forms of graffiti to retell the histories of the ancient cultures of Pompeii and Athens (Abel \& Buckley 1977:4), and graffiti can also be traced to primeval Egyptian society, which developed one of the oldest and most remarkable forms of writing in its hieroglyphics (Shillington 1989:97). Additionally, indigenous cultures of 
the Americas, Europe, Asia, and Australia scratched or painted graffiti in caves and on rock walls to mark their presence and relay stories (MacDonald 2013). By all accounts, these early precursors to modern graffiti were not illegal, and have been very helpful in aiding in historical interpretations of past cultures and societies.

The American railroads are another chapter in the history of modern graffiti. One need look no further than to the sides of passing freight trains to see a variety of art: elaborate graffiti "pieces" (masterpieces) or monikers and messages left on the sides of train cars by graffiti writers, hobos, and rail workers alike. The modern-day train moniker, or personalized signature and sometimes pictorial message drawn on the sides of freights using paint markers, was thought by some to be utilized in an earlier form by friends, families, and other illicit freight train riders to mark travel itineraries, send warnings or notices about food or resources, or to otherwise communicate. The historical and modern train moniker likely comprises a means of communication amongst subcultural members and displaced travelers, but recent research has indicated monikers are often a declaration of presence of marginalized workers and others taking shape as a pseudonym, date, and location, rather than as some hidden form of communication (Weide 2016). While monikers historically have been the product of hobos and train workers, gutter punks (illicit modern day train riders) often 'sign-in' on trains or in areas around train yards and stopped train lines (Ferrell 2019). Additionally, hobo and other train graffiti are thought to be a sub-niche within the larger phenomenon of the graffiti subculture (Lennon 2016).

The artistic movement of the 1970s helped graffiti find its way into the public sphere on subway cars and city walls (and eventually to freight trains) while the popularity of street artists like Keith Haring and Jean Michel Basquiat in the 1980s helped bring graffiti-style art into international focus (McAuliffe 2012:202). It was also during the 1980s that intensified hostility occurred between graffiti writers and authorities (Austin 2010), though early declarations of war on graffiti initially conducted in the 1970s in "zero tolerance" practices may have inspired this resultant hostility much earlier (Mailer and Naar 1974). The modern-day hip hop movement that evolved during this era includes graffiti, DJing, break dancing, skateboarding, and emcee style rapping (Ferrell 1996). Films like Style Wars (1984), and others helped to bring hip hop graffiti into the mainstream, and arguably helped to diffuse its practice from the boroughs of 
New York City across the United States, and simultaneously on to Europe, Central America, South America, Asia, Australia, and Africa (MacDonald 2013; McAuliffe 2012) where other forms of graffiti had already been in place.

\section{Distinguishing Hip Hop Graffiti Writing from Other Types of Graffiti}

Conventional graffiti ordinances tend to blanket non-commissioned graffiti under policies defining it as illegal, while the opposite may be true when permission is sought beforehand (Halsey and Young 2002, 2006). In the United States and in most industrialized nations, legality in graffiti implies having permission to paint a publicly or privately owned fixture or structure. Nonetheless, most artistic graffiti that are publicly visible in metropolitan areas across the United States and internationally are done illegally (Ferrell 1996; Halsey and Young 2002, 2006; McAuliffe 2012). It thus is important to distinguish artistic "hip hop" graffiti writing from gang graffiti, hate graffiti, political graffiti, and "civilian" (or amateur) graffiti. Generally, conventional policies categorize artistic hip hop graffiti with racial and ethnic slurs, obscenity, political statements, graffiti intended purely to deface public and private property, or gang markers (Brewer and Miller 1990; Halsey and Young 2002). This trend in policy to characterize most or all graffiti as gang activity has persisted to the modern day, and some time during the late 1990s, many also began to frame illegal graffiti more broadly as a quality of life issue (Bloch 2016a).

Style is a key element in distinguishing hip hop graffiti from other forms with which it is often confused. With hip hop's early (and ongoing) influence, artistic graffiti has become more than just writing one's name in as many locations as possible. "Style" is a unique element of "graffiti art" (Austin 2010) shared with the hip hop cultural movement that emerged in the 1970s as a central component of the graffiti subculture. Hip hop includes lyricism, music, clothing, dance, and expression (Ferrell 1996). Style in graffiti is a certain artistic je ne sais quoi, and is a way of "making one's letters sing" (Ferrell 1996:7).

Thus, today's hip hop graffiti is a form of illegal art to some degree associated with the hip hop style, however many argue that hip hop and graffiti are not significantly related. Nonetheless, hip hop-influenced spelling and lettering styles within graffiti are key features which may aid in distinguishing the artistic forms of graffiti from territorial gang graffiti or other forms which may pose a perceived immediate threat to public perceptions of safety (Phillips 2016). With an eye for artistic style, one can often identify hip hop graffiti (Brewer 1992; Ferrell 1996). Still, graffiti policy tends to favor approaches that lack any distinction 
made between 'graffiti art' (works that possess characteristics of folk art or high art) and 'graffiti vandalism' that is done to express defiance to authority, control territory, or to maintain some degree of infamy (Gomez 1993). Additionally, municipal graffiti policy narratives often intentionally fail to distinguish hip hop graffiti from gang graffiti, and as such may implicitly include the former under the 'gang' label (Bloch 2016a; Ferrell 1996; Phillips 2016).

\section{Hip Hop Graffiti Forms}

Hip hop graffiti is usually carefully executed in an artistic manner and is often seen on surfaces within the confines of metropolitan and suburban spaces, and on passing freight and passenger trains (MacDonald 2013). This form of urban graffiti may be a solo or group venture, and its practice is governed by loosely-structured, semi-hierarchical groups, or "crews," who enforce blanket rules for members and individual writers based on a standard of respect (Brewer 1992; Halsey and Young 2002). Should hip hop graffiti writers not adhere to this code, they often will lose respect, or fail to obtain it in the first place (Brewer 1992; Gomez 1993).2

Some basic terminology applies to hip hop-style graffiti. "Tagging," sometimes called "hand style," refers to a simple two-dimensional form of graffiti, which consists of writing one's stylistic name, or "tag." "Tagging" is usually intended for creating fame through repeated application, (Brewer 1992; Halsey and Young 2002), and writers often may agree out of respect for their code of ethics not to tag clean walls, statues, or sculptures (Ferrell 1996). While this may be the case in some locations, other research found writers expressly wanted to tag blank walls. One interviewed writer said, "You see a blank wall, you want to be the one to get up there first" (Halsey and Young 2006:286). To some, tagging is not (always) thought of as art and may sometimes be perceived as an activity of those who are at an early stage in their graffiti careers (Halsey and Young 2006). In contrast, many writers argue that since graffiti is about lettering, tagging is a key part of doing graffiti (Ferrell 1996), and that highly artistic piecing would not be possible if not for the original practice of tagging, which is discussed by well-known writer, Toomer, in the graffiti documentary, Infamy (2005). A relative of tagging referred to as "scratchiti," consists of etching one's tag onto mirrors or glass surfaces (McAuliffe 2012:204). Incidentally, much of the graffiti one may see appears

2 (See APPENDIX F for a glossary of graffiti terminology, which includes some definitions for the types of hip hop graffiti and related terminology, which was encountered in this study; See also APPENDICES C and $\mathrm{D}$ for descriptions and pictorial examples of the different types of graffiti). 
in some form such as tagging, etching, or simple writing, and many non-graffiti writers and municipalities tend to strongly disfavor tagging over other forms of illegal graffiti (Halsey and Young 2002; Snyder 2009). Another variant of the tag, train monikers can be seen on sides of freight cars or other surfaces in and around railyards, often done by rail workers themselves, but some graffiti writers create similar train car tags, messages, or sketches (Lennon 2016; Weide 2016). Significantly, tags and "throwups" were noted among the earliest documented research on hip hop graffiti (Mailer and Naar 1974).

“Throwups," also called "bubble letters," or sometimes "hollows," or "fill-ins," are usually twodimensional, but sometimes have a type of added shadowing that gives the letters a three-dimensional appeal and vanishing point. Often executed in 2 or 3 colors, throw-ups, like tags, generally are intended to be frequently executed to establish notoriety and fame (Brewer 1992; Halsey and Young 2006; McAuliffe 2012). Throwups are thought to be less labor intensive or require less skill than "pieces" (Halsey and Young 2006; Haworth, Bruce, and Iveson 2013).

"Pieces," short for "masterpieces," are usually highly artistic and elaborate, multi-colored, and highly stylistic creations. Piecing is usually intended for artistic development and to convey one's personal style, which is distinguishable in letter structure, color scheme, overall complexity, and (sometimes) characters, or renditions of people, cartoon characters, or other artistic features. Pieces having simple, 'straight' lettering are referred to as "straight-letters" or sometimes "blockbusters." Blockbusters are designed in large format, often in highly-visible locations, where they may better establish one's notoriety and skill within the graffiti community or outsiders. More complex pieces are thought to be intended to demonstrate advanced style and artistic ability (Ducuyunan 2000; Ferrell 1996; Halsey and Young 2006).

These forms and stylistic aspects of graffiti will be revisited later in a "hierarchy of forms" which graffiti takes, aside from the tag (See CHAPTER 6 "Hierarchy of Graffiti Styles"). The complexity of forms and style that must be learned and practiced within hip hop graffiti and the coexistence of different types of non-hip hop graffiti speaks to the common confusion or lack of understanding about hip hop graffiti. As Austin (2010:34) noted, "graffiti art is very poorly understood as vandalism." To attempt to redress this poor understanding, some of the forms of graffiti are reviewed in greater detail below.

\section{Slogan Graffiti and Non-Artistic Messaging}


Slogan graffiti, sometimes called "messaging" (See also Austin and Sanders 2007), usually aligns with amateurs or non-artists whose intent may be to engage social topics, expressions of love (Haworth, Bruce, and Iveson 2013), to deface public and private property, or to convey some politicized or nonpoliticized message. Most readers have witnessed this form of non-artistic graffiti on bathroom walls or other surfaces (See also Trahan 2016 on "latrinalia, or "bathroom stall" graffiti) perhaps inscribed into tree bark or picnic tables at rest areas in poorly-executed and crude renditions of human anatomy or written profanity. Amateur messaging or slogans may fit the stereotype of a bored twelve-year old who discovered their parent's spray paint collection.

\section{Political Graffiti and Street Art}

Ferrell noted that people "employ particular forms of graffiti as a means of resisting particular constellations of legal, political, and religious authority" (1995:77). Political graffiti paintings, and some protest-style street art, are often placed in a resistant manner in highly visible locations, and these displays may be artistic or non-artistic in nature. One may note that despite the different designations I have drawn with these sections on forms of graffiti, there is some overlap between political and slogan graffiti, both of which may be politically-oriented. McAuliffe (2012) notes that there is no specific distinction between hip hop graffiti and street art, where both are done without permission. However, street art often more directly addresses the public, while graffiti is likened as an "ego-centric private communication" solely done for and among writers (McAuliffe 2012:190). Historically, political graffiti and street art typically commented on social issues in a voice that may otherwise be unheard (or less heard). As such, these graffiti forms may convey some notion of resistance through commentary about current social conditions intended for a public audience. Perhaps among the best known modern political graffiti appeared on the Berlin Wall prior to its dismantling in 1989.

Research notes that political graffiti has "given voice" to the unheard about relevant social issues which affect them (Waclawek 2016). In a notable instance, 'unsigned' non-hip hop style graffiti occurred in Quebec through public dialogues since the mid-Twentieth Century in response to social issues threatening francophone cultural autonomy. These exchanges of non-artistic graffiti centered on topics such as gender

equality, anarchism, tribal nation rights, and religion. Eventually, public signage was mandated in French in Quebec, and in this manner, political graffiti was thought to have been instrumental in sustaining 
indigenous cultural values (Waclawek 2016). Research on the graffiti writing of Native Americans reveals that graffiti has historically been a way to educate outside society on social issues pervading reservation life, including the marginalization, inequality, and disenfranchisement residents experience (Martín 2016).

Other research has noted that Santiago, Chile's Mapucho River wall has long been a site of political propaganda in graffiti written for communist regimes, in protest of social and economic conditions, and as anti-regime dissent. Interestingly, a long history of protest and propaganda graffiti precipitated what is now an atmosphere of acceptance of graffiti and brigadista style murals in Santiago (Palmer 2016). Such studies perhaps emphasize that political graffiti is not exclusively used for subversive purposes, however, hate groups and gang members often use graffiti to invoke fear or claim control of urban areas.

\section{Gang Graffiti}

Criminal gangs have often utilized graffiti to mark territorial boundaries and to sometimes indicate affiliation with prison gangs (Phillips 2016), often in a non-stylized or non-artistic manner. However, some of the earliest gang graffiti was observed after World War II in Los Angeles, California in very precise and intricate cholo hand styles (fonts) and detailed wall murals (Alonso 1998). Latino varieties of highly artistic gang piecing, referred to as "placas" (Romotsky and Romotsky 1975), have historically related Mexican cultural themes, while African American gangs since the 1960s often have painted artistic "hit ups," originally formed in response to pressure from white hate groups (Alonso 1999; Phillips 2016). Interestingly, the dualistic treatment of graffiti as art or crime is not limited to hip hop graffiti, as gang graffiti is also partially celebrated for its artistic character, while at the same time discouraged for its threatening presence. While gang graffiti is often not executed in the same artistic hip hop stylized manner as is hip hop graffiti, the sophisticated cholo style of lettering that represents a fusion of Los Angeles Latino gang writing style has been exhibited in public art exhibits and galleries in the same city. Perhaps somewhat ironically, Los Angeles police department websites express to the public that gangs create graffiti to intimidate, and as such that community members are subjected to violence by its presence (Phillips 2016:57). Early research on the placement of Philadelphia graffiti of the 1960s and 1970s indicated graffiti's intent was either in contesting space (as in the case of hip hop graffiti "writing"), or alternately functioned to show one's gang presence (as indicated by physical territorial markers at the edges of gang territories) (Ley and Cibriwski 2010). While gang activity (and other graffiti) is often associated 
with fear and violence, hate speech or racialized graffiti shares this association, though is generally thought to be produced by individuals or members of hate groups, not by criminal gangs.

\section{Hate Graffiti}

Hate graffiti may be the most fear-inspiring form of graffiti, though more research may need to be conducted to better differentiate reactions to gang graffiti, hate graffiti, and other form to better examine trends in different levels of fear. Hate graffiti is often placed at sacred spaces or places of worship in plain view of the public (Alonso 1998; Halsey and Young 2002). The purpose of hate graffiti may be to spread hate or violence and invoke fear, as well as to deface or vandalize property, often places of worship. In most cases, hate graffiti targets individuals according race, sexuality, gender, or ethnicity. Hate graffiti is not thought to be a product of any known hip hop graffiti writers, and may be produced by amateurs in a non-artistic manner taking form in expletives, derogatory terms, or in symbolism, such as in swastikas.

\section{Studies on Hip Hop Graffiti Writing}

Research trends have generally shown that graffiti writer motivations tend to include a desire to be part of a group and to be known and recognized, both for one's artistic skill and for one's willingness to do illegal graffiti (Brewer 1992; Ducuyunan 2000; Ferrell 1996; Halsey and Young 2006; Mailer and Naar 1974). As well, in terms of public opinion, mixed reactions toward hip hop graffiti writing emerge from research, with some support for progressive policies that partially allow its occurrence and sometimes celebrate it as a form of cultural and artistic commodity (Halsey and Young 2002, 2006; McAuliffe 2012). Consistently, studies note adversarial municipal graffiti practices that attempt to entirely eliminate graffiti and punish its practitioners (Brewer 1992; Halsey and Young 2002; Mailer and Narr 1974; McAuliffe 2012).

Most studies on graffiti have been framed from an outside-looking-in vantage, with some research touching on writer perspectives through interview and observation. Other graffiti research has functioned to combine interview data with assessment of public opinion and graffiti policies and practices via discourse analysis (Alonso 1998; Brewer 1992; Halsey and Young 2002, 2006; Haworth, and Iveson 2013). Some research has utilized photojournalistic methodologies (Mailer and Naar 1974; Chalfont and Prigoff 1987); photography and discourse analysis (Ferrell 2006); immersive ethnography, discourse analysis, and interviewing (Ferrell 1996); and municipal GIS data of distributions of graffiti combined with assessments 
of the efficacy of municipal abatement practices (Haworth, Bruce, and Iveson 2013). While several studies have utilized combined research methods, few have examined graffiti writer standpoints via their perceptions about doing graffiti and its related practices situated in terms of institutional relations and discourse, namely municipal and criminal justice policy and practices. Nonetheless, Ferrell (1996) demonstrated the ways that aggressive graffiti policies changed writers' behavior, perhaps pushing them toward countercultural acts and language.

One of the earliest known examinations of hip hop graffiti writing, a photo-journalistic investigation, occurred in New York City in the 1970s to document the then emerging phenomenon. Mailer and Naar (1974) report a motivational notion of "faith" in one's graffiti name and in doing graffiti, which contrasts with other "faiths" endorsed by society, whether faith in religion or in other beliefs and practices that are evident in the diversity of modern lifestyles. Graffiti faith motivates the continual practice of transgressively writing one's stylistic name, not to destroy but to proliferate this self-identity everywhere possible. One young writer highlighted this: "Graffiti writing is a way to gain status in a society where to own property is to have an identity" (Mailer and Naar 1974:30). Remarkably, early graffiti art began entering fine art galleries, selling from $\$ 200$ to $\$ 3000$. Yet despite the demand for graffiti from high society or art enthusiasts, graffiti's notable spread from streetscapes to walls of newly constructed housing and fresh subway cars caught political attention. New York City Mayor John Lindsay, who boasted the completion of the subway system and other city improvements, including new housing complexes in ghetto neighborhoods, also initiated a "war on graffiti" (See also Iveson 2010, Ferrell 1996 on wars on graffiti and other crime and the historical and simultaneous militarization of police organizations). For writers, this "war" consisted of higher fines, increasingly severe beatings from police (according to graffiti writers), and bans on sales of spray paint and art supplies (Mailer and Naar 1974:7-8). Historical graffiti policy practices, such as Mayor Lindsay's abatement campaign that drove graffiti from subways to city walls, may have set the tone for modern "zero tolerance" policies and practices adopted by other city governments, particularly in terms of dedicated abatement strategies. Joe Austin (2001) relates this in his tracing of graffiti's history in New York, noting the ways that a cash-strapped metropolis arguably neglected other public needs in its heavily-funded response to graffiti as an urban crisis. 
Later studies on urban graffiti policy emphasized the importance of an improved analysis of graffiti writing and a focus on municipal processes to better conceptualize graffiti and to advise policy designs to accommodate more stakeholders, including city councils, transit authorities, urban planners, businesses, arts councils, the general public, and graffiti artists themselves (Haworth, Bruce, and Iveson 2013; McAuliffe 2012). Halsey and Young (2006) examined hidden aspects of graffiti culture through interviews with writers and public administrators and found four emergent themes: motivations of writers, distinctions between 'art' and 'vandalism,' writer reactions to 'blank' walls, and graffiti crime's relationship to other forms of crime. Findings suggest that little, if any, distinction is made in city abatement policies between art or vandalism, and that graffiti writers may prefer to illegally paint on "buffed" walls (those repainted by city personnel), or those that are already painted (e.g. murals, signs, or other such surfaces), reflecting the notion that already-painted surfaces often hold paint better than unpainted ones. As well, most graffiti writers did not fit the profile of "hardened" criminals, drug addicts, or those expressly engaged in the destruction of property, and writers preferred doing illegal graffiti if also willing to utilize legal spaces (Brewer 1992; Halsey and Young 2006; McAuliffe 2012). The current study is consistent with other research according to how writers chose graffiti spots according to policies (See also Ferrell and Weide 2010), and as such it offers important implications for policy officials and urban planning.

More recent studies that utilized structured interviews with graffiti writers and city administrators noted that "wars on graffiti" (Iveson 2010) are often manifested in zero tolerance policy and practices, which have also coincided with a militarization of local policing. The notion of war in graffiti policy converges with the ideal of "moral geographies," or spaces that reflect physical locations where a continual battle occurs in graffiti writers and street artists illegally painting public spaces which city authorities continue in repainting (McAuliffe 2012). While research has shown that the presence of graffiti can be used by policymakers to generate "moral panics" (Ferrell 1996), wars on graffiti sometimes result in the partial allowance of graffiti in designated locations ("legal walls"), without policymakers appearing to be too "soft" on crime (McAuliffe 2012). Yet, while many graffiti writers utilize legal spaces, they continue to do illegal graffiti for desires that cannot be satisfied by legalized graffiti (Halsey and Young 2002, 2006).

\section{Public Attitudes toward Hip Hop Graffiti}


Much of the research on graffiti (and street art) that has been conducted from the 1990s to the present time has occurred outside the United States in several Australian metropolitan areas, documenting both writer and public attitudes (Halsey and Young 2002, 2006; Haworth, Bruce, and Iveson 2013; McAuliffe 2012). Graffiti writers have faced resistance from traditional abatement and beautification organizations and government, but nonetheless have also found growing public support, particularly for hip hop graffiti and street art in legal (and sometimes illegal) forms. For instance, an illegally painted mural featuring a moonscape and image of Martin Luther King, Jr. along with the slogan in gothic lettering, "I Have a Dream," located on a highly visible building off a main thoroughfare in the Marrickville suburbs of Sydney has been untouched by abatement crews where other graffiti was consistently repainted (McAuliffe 2012). Many initiatives have appeared in and around the city of Sydney where municipal authorities have become more permissive of street artists and graffiti writers, many of whom have advocated for these alternatives. A small survey ( $\mathrm{n}=93$ ) administered to local citizens in the Marrickville suburb in 2010 indicated that a large majority of residents supported local arts initiatives coordinated between writers, street artists, and local government, and 80 percent of those surveyed viewed street art and some graffiti as cultural attractions that encourage tourist visits (McAuliffe 2012:198).

An exploratory study examined perceptions of safety in terms of different types of graffiti occurring in different locations suggests that different graffiti invokes varying responses. Survey results of a convenience sample of university students who were showed photographs of gang graffiti, message graffiti, graffiti commissioned in legal murals, and illegal hip hop graffiti showed varying reactions. Notably, perceptions of safety were highest when individuals viewed the murals and lowest upon seeing gang graffiti (Austin and Sanders 2007). This research offers support to the notion that nuances among different types of graffiti are discernable by the public, who may view some illegal graffiti positively.

Another recent study assessed public opinion according to photographs and descriptions of different types of graffiti (tags, throw-ups, and pieces) at different locations (public streets, near schools or churches, or on highway walls). Results indicated ambiguity in the perceptions of fear of most graffiti because it is illegal (despite not causing actual harm), other forms because it is unattractive, and others because it provoked perceptions of fear (Vanderveen and Ejik 2015). In all the opinion assessments, in addition to the form or style, the placement of graffiti was a key determinant of its approval or disapproval. 
Photographs of different graffiti were assigned a positive or negative value judgement in affecting one's quality of life, in the sense of detracting from the visual aesthetic, or neutral, and respondents were asked to prioritize examples for removal (Vanderveen and Ejik 2015). Since different evaluations occurred among respondents that comprised the same population who report different forms of illegal graffiti to metropolitan authorities, the researchers emphasize that policy officials should be explicit to the public about priorities in dealing with different forms of graffiti that occur in public space, so that policy may be transparent and aligned with public values (Vanderveen and Ejik 2015). These results and others may imply the need for policy officials to better understand and acknowledge the different types of graffiti, and their separate intentions and meanings, in order for policy outcomes to better align with the desires of stakeholders. The importance of the placement and type of graffiti as evident in public opinion emphasizes the notion of "moral geographies" of what is acceptable and where in terms of policies dealing with the use of public space and sanctioning of graffiti (See also McAuliffe 2012).

In another study on urban graffiti policy, researchers surveyed police perceptions of illegal graffiti in a mid-Atlantic city, and results indicated that significant differences may occur in the way officers treat illegal graffiti, dependent on the officer's race and shift working. Specifically, officers on late night shifts appeared to be impartial as to whether or not graffiti writers should face mandatory sentencing for illegal graffiti. Additionally, white officers were likely to take a similar neutral stance on several questions, notably indicating that they may be more likely to use discretion before taking a hard line on enforcing arrest and incarceration protocols for individuals caught for doing illegal graffiti (Ross and Wright 2014).

Alison Young's research on graffiti described the viewing of illegal graffiti as an experience of enchantment--immaterial of whether the graffiti were viewed with favor or dislike--where alternate understandings of the city, private, and public space can occur (2014). This study raises the notion that the presence of some forms of graffiti may carry the potential to alter the ways in which we perceive the built environment and our relationships to it.

\section{Writer Preferences and Graffiti Policy and Practices}

Early interviews of West Coast North American graffiti writers, magazine staff, and graffiti enthusiasts in the 1980s identified policy preferences in how interviewees felt cities could best address graffiti writing, based partly on Brewer's and Miller's (1990) study of writer subculture and practices. 
Findings revealed that graffiti writers were more interested in two main practices that include "bombing," or "burning." Bombing was described as painting one's art as frequently as possible, usually in "tag" or "throw-up" forms (See above discussion and APPENDICES C through E), while "burning" was a means of painting more detailed, elaborate, and artistic "pieces," also known as "masterpieces." Key motives for doing graffiti included obtaining "fame" through repeated public displays of one's work, and "artistic expression," or showing off one's talent in "burning." To a lesser extent these artists reported motives of "power," by occupying large amounts of space with their art, and (less frequently) "rebellion," or painting with the express purpose of destroying property (Brewer 1992)3. This typology of practice and motive is consistent in the extant graffiti literature as a generalized dichotomy of graffiti practices between quick and frequent productions and less-frequent but more involved ones (Ferrell 1996; Halsey and Young 2006; McAuliffe 2012). Other noteworthy findings in Brewer's study suggest that, in terms of social policies, writers desired opportunities for artistic expression and fame, where most writers preferred policies that would allow more legal spaces to practice graffiti writing and forums or studios where writers can display their work and collaborate with others interested in improving their skills (Brewer 1992:364). These findings are consistent with policy preferences alluded to in other research wherein writers desired fame and recognition and the ability to fulfill their desire to shape public space (Ducuyunan 2000; Halsey and Young 2006).

In other research, through immersive ethnography, graffiti writing was described as an expressive and subversive practice, a means of "resistance to authority," and as an act of "subverting pop culture imagery" to alternately convey stylistic elements of hip hop culture (Ferrell 1995, 1996). Here, "style" is an artistic quality that is demonstrated, critiqued, and re-defined over time through subcultural mediation and interaction (Ferrell 1996:170-172) and shared in a transient process of subcultural communication in train graffiti (Ferrell 2006). Other studies indicate that graffiti writers practice for a sense of accomplishment and out of a desire for illicit expression and resistance to orthodox values (Halsey and Young 2002, 2006).

Many argue that conventional graffiti policy is inefficient because it overlooks the cultural and social nuances of graffiti practices (Gomez 1993; Brewer 1992; Halsey and Young 2006), and that

\footnotetext{
3 As will be revealed in later chapters, the current study data did not indicate that writers choose to damage personal property, private residences, places of worship, cemeteries, schools, playgrounds, or small businesses.
} 
policymakers fail to acknowledge writer motives, attitudes, and preferences or the desires of communities (Young 2010). Instead, the assumption is made that all stakeholders view graffiti as a problem, thus defining all graffiti as vandalism to maintain urban geographies of ordered space. Furthermore, anti-graffiti campaigns often perpetuate the same behaviors that they target, ignoring completely the opportunity to assess writer attitudes (Halsey and Young 2006:97; Ferrell 1996). Additionally, "moral panics" (Cohen 2002) are often conveyed in anti-graffiti campaigns conducted to advance the ideal that all graffiti is destruction, defiance, or otherwise harmful and negative activity. An instance of such a moral panic was evident while Ferrell (1996) was conducting research on the Denver graffiti scene. Mayor Federico Peńa had a "real problem" with graffiti, and beginning in 1983 and later continuing in 1988, initiated a major crackdown, heavily involving police, city abatement crews, and the media to mobilize public support to eliminate all graffiti. At the height of this. the city created an abatement initiative forcing regular inmates together with incarcerated graffiti offenders to clean up city graffiti, having the effect of pitting other inmates against graffiti writers. Argued by graffiti writers as a degradation ceremony (Ferrell 1996), the mayor's initiative essentially epitomized moral entrepreneurship (See also Becker 1963) against hip hop graffiti, designating all graffiti as blatant vandalism and a threat to public safety. Despite the mayor's admission of its failure to reduce graffiti after 5 years, this zero-tolerance approach had the unintended effect of proliferating graffiti's occurrence via increased media focus and, hence, more public visibility to those favorable to graffiti, manifesting in a greater demand for writers' artistic services at skate shops, media distribution channels, book vendors, and other outlets. Further, new graffiti writers began emerging at higher than usual rates (Ferrell 1996). One interviewed writer said: “...In a way, it's about the best thing they could have done. I mean, I've gotten from the crackdown, 100\% of my art sales, 100\% higher" (Ferrell 1996:147). Such moral panic campaigns on graffiti, despite being failures in practice, reflect predominant policy utilized in the United States and in many other parts of the world (Halsey and Young 2006; Haworth, Bruce, and Iveson 2013).

A later examination of South Australian city council policies revealed that taking an alternative municipal stance on graffiti writing (e.g. a shift away from zero tolerance practices) can be successful via engaging and promoting types of graffiti art while not appearing soft on crime or authorizing a growth in its illegal form. Halsey and Young interviewed policy makers and examined written discourse on graffiti and 
established a typology of municipal practices including removal, criminalization, welfarism, and acceptance (2002). Criminalization, including punishment of offenders who mark buildings or structures, usually is paired with costly removal practices, and abatement programs may use surveillance and photodocumentation of tags and other graffiti in hopes of matching them to apprehended writers. Abatement programs aim to reappropriate public space that has been "claimed" by illegal graffiti, and such efforts also may require that apprehended offenders remove their own graffiti and that of others., where the notion of deterrence is conveyed in costs to writers (Halsey and Young 2002). In contrast, welfarist policy programs use youth outreach and community initiatives to redirect apprehended writers away from doing illegal graffiti and toward other practices, often by mandating reparation, employment, and re-education terms in sentencing. Acceptance policies attempt to commission graffiti writers for murals, educate community youth on graffiti, and provide legal walls and art workshops to help writers improve skills, in hopes of decreasing tagging and encouraging more aesthetically desirable "pieces" (Halsey and Young 2002:174178; See also APPENDICES C through E). While the welfarist and acceptance policy models described by Halsey and Young (2002) are often combined with varying levels of criminalization and removal, the use of such alternatives has drawn community and artist support and shown promise in sustainable abatement cost reduction. Nonetheless, the administration of such programs that appropriated legal walls often failed due to differential enforcement of alternative policies (Halsey and Young 2002). Additionally, legal wall initiatives usually fail because they are not regularly or adequately maintained or because they are not writer-managed (Ross 2016), and often undesirable non-artistic forms of graffiti appear, resulting in the closing of legal spaces. Such alternatives are typically abandoned and replaced by conventional combined policy approaches of removal and criminalization (Halsey and Young 2006). Failures of new policy initiatives are often less a result of poor policy design than one of policy implementation (Pressman and Wildavsky 1984; Lipsky 2010).

A closer examination of abatement practices and their efficacies was conducted in a cluster analysis of Sydney city government GIS data documenting abatement activity and types of graffiti (tags, throw-ups, or pieces; See APPENDICES C through E) along with different surface types (e.g. painted, brick, substrate). Results indicated over 18,000 reported instances of graffiti in 6 months with roughly 17 instances of abatement per day, and concluded that city abatement efforts showed no signs of reducing 
targeted graffiti "hotspots." Perhaps indicating the inefficiency of organized abatement efforts, results found that "hotspot" abatement practices did not effectively reduce graffiti. Instead these efforts appeared to displace it to other areas, resulting sometimes in an increased occurrence of illegal graffiti. (Haworth, Bruce, and Iveson 2013). Specifically, instances of "quick and dirty" graffiti, mainly tags and throwups, tended to increase (Haworth, Bruce, and Iveson 2013). Interestingly, the more elaborate and artistic forms of graffiti (i.e. skilled "pieces") were not frequently the targets of abatement (Haworth, Bruce, and Iveson 2013:55-60). This may be an indication that some city abatement practices are prioritized toward less artistic graffiti styles like tags and throwups, or perhaps these types of graffiti are reported more frequently. One may argue that this last finding could reiterate a need to more deeply understand and conceptualize the different forms of not only graffiti in general, but this is perhaps especially the case with hip hop graffiti and the various levels of artistic ability that may be evident in its production (See also Vanderveen and Ejik 2015). Halsey and Young (2006) aptly noted:

"(to writers) the act of writing feels right... writers... see public/urban space differently than outsiders: It is a series of surfaces waiting to be painted to writers" (2006:283).

Given misunderstandings of the types of graffiti and research that indicates that conventional graffiti policies are often ineffective (Gomez 1993; Ferrell 1996; Halsey and Young 2002, 2006; Haworth, Bruce, and Iveson 2013), a goal of the current study is to better identify some of the nuances within graffiti and distinguish hip hop graffiti writing from other forms that are targeted and prioritized in abatement practices. To achieve this goal, I will now discuss several sociological and criminological theories that can aid in enhancing current understandings of hip hop graffiti. 


\section{CHAPTER 3}

\section{THEORETICAL FRAMEWORK AND RELATED RESEARCH}

Prior to gathering and analyzing data from the written discourse on graffiti, interviews with policy officials, and interviews, focus groups, and participant observations of graffiti writers, I considered and integrated several theoretical components into the theoretical framework employed in this analysis. These have not been known to have been used conjunctively in other known research to date, and, as will be discussed later, additional theoretical explanations of graffiti resultantly emerged. Notably, these theoretical components are utilized to show the ways that hip hop graffiti is nuanced and may be a legitimate form of recreation that offers regular benefits to its practitioners. Additionally, the theoretical and conceptual components were selected with an intention to more closely identify in the writer experience the elements of edgework, the serious leisure perspective, deviant leisure, and recreational specialization. In addition, the current analysis attempts to situate the standpoints of graffiti writers and policy officials in the interest of offering options for expanding graffiti policy. As will be discussed, a notion of "moral geography" occurs in the interaction of writers and policymakers and enforcers where illegal graffiti meets the challenge of abatement. Both parties make an effort to define and redefine the boundaries of what is deemed appropriate use of public space (McAuliffe 2012; Smith 1997). By using the theoretical framework to examine graffiti as recreational specialization, serious leisure, and dark leisure, I sought to offer an alternative view of artistic graffiti that may shift public and policymaker awareness to decrease misunderstandings and perceptions of fear.

\section{Cultural Criminology, Moral Entrepreneurship, and Hip Hop Graffiti}

Cultural criminology considers meanings, symbols, and interpretation, emphasizing cultural aspects of crime and crime control that are located within the interactional process of different social 
groups. It looks past conventional understandings of crime and criminal justice by focusing on subcultures, transgressive acts, media depictions of criminality and victimization, instances of public anger and elatedness, and acts of justice and injustice (Ferrell 2014; Ferrell et al. 2014). Cultural criminology examines sociological and criminological phenomena, focusing on the cultural and institutional origins of the social construction of crime and deviance and the systems that enforce and regulate them in the interest of removing constraining structures that cause oppression, while at the same time acknowledging the difficulty in doing so (Ferrell et al. 2014). Cultural criminology builds upon numerous older traditions of criminology in deviance theories, labeling theory, and conflict theories, which found their origins with contemporary American sociologists of the 1950s and 1960s (Ferrell 2014; Ferrell et al. 2014). Specific to the current study, labeling theory generally involves an identified behavior that violates law, norms, or conventional morality; this behavior is referred to as primary deviance. Following the occurrence and social observation of such behavior is the application of a formal label, after which either acceptance or rejection of the label occurs by the labeled individual. If a label is accepted, it is internalized, and individuals so labeled may commit more deviant behavior or other socially undesirable behaviors that pertain to the label, a process known as secondary deviance (Becker 1963; Lemert 1951, 1967). A key point of labeling theory emphasized by cultural criminologists is that the degree of a behavior's violation of laws or norms may be determined by the reaction to the behavior. In this way, many behaviors can be labeled as deviant, as long as there is a power relationship wherein this reaction can be framed (Ferrell et al. 2014; Also, see Becker 1963, Lemert 1951, and Lemert 1967 on deviance and labeling).

Research notes that individuals in power and opponents of graffiti, along with the media, influence public understandings of its practice, in effect clouding distinctions between graffiti vandalism and artistic graffiti writing, resulting in the assumption that all graffiti is criminal and constitutes vandalism (Ferrell 1996:5). This is part of the process of moral entrepreneurship (Becker 1963), wherein moral entrepreneurs, usually policy makers or political representatives, carry out public campaigns to identify and control undesirable behavior. A necessary step that must occur prior to the application of a label happens when certain behaviors get defined as deviant, indicating to the public that there is a problem. This can go the other way, as well, as when the public, sometimes through social movements (for instance with the battered women's movement when doctors influenced public perceptions and influenced policy makers about a 
serious social problem). As such, change can be a democratized process, or sometimes not, as may be the case in labeling or moral entrepreneurship.

Moral entrepreneurs may go to great lengths to eliminate targeted behaviors, embarking on political campaigns designed to degrade certain groups of "outsiders," mobilizing the public against the behavior. During such campaigning, moral entrepreneurs attempt to persuade the public, campaigning their own version of social reality by designating certain behaviors as deviant and problematic. As such, the moral campaigning process tends to focalize opposition of a larger group against some designated group of "outsiders" who are a subset of the larger population. Instead of accepting the labeling that occurs, the outsiders may reject the ideals and rules held by moral entrepreneurs and their advocates, who are then identified as outsiders by the label, and a secondary designation of 'outsiders' occurs (Becker 1963). At some point, however, the behavior targeted and labeled by moral entrepreneurs may intensify or increase, and many argue that this is a predictable consequence. Similar to moral entrepreneurship is the notion of “moral panics" (Cohen 2002), processes whereby public spectacle is generated over a particular behavior characterized as a social problem, often distorted by media and powerful individuals who influence the public reactions to certain issues, often exaggerating their severity and creating misconceptions or myths about certain groups. Such false perceptions or "generalized belief systems" are designed based on already known public perceptions and views and inspire "hyper-representation" of symbolic and deviant images to generate meaning by coercing social hysteria over an issue (Cohen 2002). This is an important tool for moral entrepreneurs delivered through speech and written discourse and conveyed to the public through media outlets (Cohen 2002). In such practices, change can occur through mobilizing community and policy officials around awareness and perceptions of a social problem. This may also apply to the treatment of hip hop graffiti, although as will be discussed later, a lack of nuance in policy tends to lump together the practices of graffiti writers (and hence also their experiences) with those of producers of hate graffiti, violent speech, obscenity, and so forth. I will later argue that in this way, conventional policy overlooks the realities of illegal hip hop graffiti.

\section{Standpoint Theory, Institutional Ethnography, and "Everyday Forms of Resistance"}

Cultural criminology and labeling theories highlight the power of elites to determine what is considered deviant or illegal and sometimes seek an emancipatory solution to oppression (See also Halsey 
and Young 2006) for a discussion of this. Another approach may better reveal the perspectives of labeled and policed individuals and the institutional practices and discourses that affect them. Standpoint theory goes beyond emancipation as a 'solution' by offering instead an opportunity for the reconceptualization of the experience of oppressed groups, by situating their experience within the institutional order (Smith 1987; 2005). According to standpoint theory, society is ruled not by localized experience or by kinship and familial standards, but by unseen institutional "relations of ruling" that include government, business, educational, and legal ideals framed within textual "discourses" or "texts" (Smith 1987). A term borrowed from Michel Foucault (1974), discourse includes documents, laws, and policies that may be likened to a "conversation" in which the spoken words originate from specific individuals at certain points in time and space (Smith 1987:61). Particularly, textual discourses are designed by and from the perspectives of powerful dominant groups who systematically disregard the voice and perspective of those not fitting the same demographic. Standpoint theory seeks to improve group experiences by locating oppressed individuals' standpoints and then begins a critique of the institutional relations that affect and shape individual experiences, working from specific events toward theoretical propositions. Stated another way, this location of standpoint is not achieved by designing research from theoretical origins, but by beginning in the observation of the daily experiences and practices of unheard individuals and groups to locate potential remediation of problematic institutional interactions. Taking Smith's position in terms of hip hop graffiti writing, I would argue that the perspectives and voices of graffiti writers are rarely, if ever, considered in the discourses within policy and legal practices. It is my intent to utilize Smith's $(2005,2006)$ theory to examine the standpoints of hip hop graffiti writers using institutional ethnography. Institutional ethnography begins in the everyday lives of individuals, their perspectives, problems, and issues (standpoint) in terms of their relationship to an unseen institutional order. Additionally, institutional ethnography locates what is to be analyzed in the institutional order by first mapping the standpoint of oppressed populations in terms of the larger social organization that is revealed during ongoing research and also considers the institutional context in which behavior and standpoints exist (Smith 2005:34-35).

Smith noted that explaining institutional relationships via institutional ethnography will illuminate the "common bases of experience" of those studied and will identify uncommon bases existing within the social and institutional order (1987:177). The current study aims to highlight these relationships and bases 
of experience within the hip hop graffiti writer's experience, to not only observe, explain, and understand in the Weberian sense (i.e. verstehen), but to locate a specific social reality and map it in terms of social and institutional forces (such as policing practices and policy discourses) that validate certain theories and justify value judgements that define art and crime.

Collins (1989) advocates the standpoint theoretical approach in terms of Black feminist thought, noting that Black women's experiences are excluded from the domain of knowledge and social science by male and "Eurocentric" power structures. In answer to institutional oppression and the inequality it creates, Black women (and other oppressed groups) are thought to commit everyday acts of resistance, in defiance of hegemonic institutional structures $(1989 ; 2000)$. The repeated act of doing illegal hip hop graffiti, which may be framed within labeling theory as a form of primary or secondary deviance, may also be conceptualized as everyday acts of resistance. It is my intent to expand upon this concept by situating the standpoint of graffiti writers in terms of institutional practices and textual discourse. While illegal hip hop graffiti writing could be a variant $\backslash$ everyday act of resistance, it may also be a form of "edgework" (Lyng 1990) (explained further below). Following Collins's position, I will take a "both/and" approach to analyzing which, if either (or both) of these theories, might explain graffiti writers' motivations for their work.

\section{Edgework}

"Edgework" is a phrase initially coined by Hunter S. Thompson (1966) in his groundbreaking book, Hells Angels: The Strange and Terrible Saga of Outlaw Motorcycle Gangs, in which he wrote of his observations as a participant in the 'Big Four' criminal motorcycle gang, the Hell's Angels. As Thompson stated, "the edge" is a place that cannot be explained because the only people to know it are those who have gone past it, pushing the limits of control beyond the comfort zone (2003:530). Though not a sociologist, Thompson offered the world a journalistic work that is very important in that, up to the date of its writing, no one had yet studied outlaw motorcycle culture, nor had they in the process joined its members' ranks. Thompson's work highlights the importance of research that goes deeper than an outsider perspective on deviant or criminalized subcultures.

Early thinkers conceptualized voluntary risk-taking as a solitary and aberrant activity (Jung 1964), sometimes associating it with a need for thrill, which was further associated with a propensity for 
criminality (Sales 1971). Zuckerman (2007) and others built upon the decades-old "thrill seeker" type, continuing the tradition by describing a predisposition toward risky activities per biological response; however, such a formulation is limited as a unified explanation of risk-taking. To paraphrase Lyng, conventional understandings assume a predisposition toward risky behavior, but there is no biological account that establishes this relationship (1990:853). In justifying the sociological study of voluntary risktaking, Lyng queried why the supposed "thrill seeker trait" is not statistically predictable and distributed accordingly in human populations. The concept of edgework locates social-psychological and social structural factors in voluntary risk taking, alternately situating such pursuits within the realm of sociological inquiry, not limiting its study to the confines of psychology or biochemistry. Lyng (1990) thus expanded the field of risk sociology within the concept of edgework.

Edgework is defined as any voluntary and controlled activity where practitioners navigate risk and an imaginary or real boundary, or edge, between extremes such as chaos and order, life and death, harm and safety, or sanity and insanity (Lyng 1990, 2005). Edgework involves deliberately entering into situations wherein there exists a grave threat to one's physical or psychological wellbeing, while subsequently obtaining tangible benefits gained from voluntary self-exposure to danger. A central theme in edgework is skill that is obtained by continual practice of risk taking, which in turn allows greater risk taking and repeats the process of more obtained skill. Lyng (1990) noted that edgework also involves practiced spontaneity and impulsivity, notions that contrast sharply with the ideals of rationality and control that are emphasized in modern society's movement to delimit risk and regulate factors of harm through a rational ordering of life. Such notions of impulse and spontaneity highlight the ad hoc nature of edgework that most distinguishes it from other practices (Lyng 1990). Edgework as a sociological construct follows the sociological paradigm, which seeks to understand human social relationships and behavior within structural and cultural terms.

\section{Benefits in Doing Edgework}

Lyng's theory describes edgework as "experiential anarchy" in that its practice contrasts with conventional institutional behavior (1990). Involuntarily and spontaneously exposing oneself to grave danger, such as in safely climbing over a highway sign or up a roadside billboard, and subsequently surviving the incident, edgeworkers are thought to obtain tangible personal benefits. These include thrill, 
deep satisfaction, a sensation of the slowing-down of time, opportunities for skill building, shared peer/social time, and personal identity formation. Since a key theme in edgework is a continual process of risk taking and skill building, it is thought that engaging in practice allowed the regaining of self-control by constant skill building and risk experience. According early edgework theory, the benefits from practice aid in relieving alienation experienced in mundane and over-rationalized modern lifestyle (Lyng 1990). A theoretical synthesis of George Mead's and Karl Marx's perspectives, a Marx-Mead synthesis, represents this dialectic of alienation and spontaneous expression, wherein the "I," described by Mead as the underexpressed spontaneous version of self is freely expressed in edgework. Conventional modern life in most industrialized societies, promotes this rational self, or Mead's notion of the "me" is the dominant mode of self-awareness, and, much like Freud's notion of superego, is largely socialized and dependent on the social expectations and established norms of one's primary peer groups. In doing voluntary risk in edgework, Mead's notion of self, the "I," finds an opportunity for expression: Namely, when one's key concern is for survival, or in maintaining personal safety, an element of many edgework scenarios, conventional values associated with the everyday notion of self ("the me") are subjugated. In this situation, improvisation and spontaneity replace rationality and constraint. The "I" exists only in the immediacy of the present moment. It has awareness of itself only as a memory image, after it has been re-integrated back into the everyday self, the "me" (Mead 1950:177; Lyng 1990). The edgework experience provides the conditions where an awareness of the "I" is possible: This under-expression of the "I" that is characteristic of an increasingly rationalized existence of modern-day life, thus resolves itself through edgework practice (Lyng 1990). One interviewed edgeworker said "my colleagues...think I'm a nut: But I tell them, look, I go home (stressed) from working eight hours a day...(and) when I (BASE) jump, I totally forget that stuff" (Celsi, Rose, and Leigh 1993:19-21;9). Another study examined a cohort of extreme BMX riders and found that riders unanimously take the risks that they do "for fun" (Scott and Austin 2016). This finding was also the case according to some interviews conducted with illegal BASE jumpers (Ferrell, Milovanic, and Lyng 2001). Other edgework research on BASE jumpers found through semi-structured interviewing that jumpers performed their sport to enhance life quality and to become "positively transformed" in the experience, suggesting that edgework is a necessary activity in the lives of practitioners (Allman et al. 2009). 
Edgework research was initially conducted in the case of skydivers (Lyng and Snow 1986) and later BASE jumpers (Lyng 1990; Celsi, Rose, and Leigh 1993; Ferrell et al. 2001), as well as with illegal bicycle racers (Kidder 2006b), within youth gang culture (Garot 2003), motorcycle riders (Gagné and Austin 2010), BMX riders (Scott and Austin 2016), and Parkour “free runners," a form of urban gymnastics originating with French special forces soldiers (Kidder 2013). Lyng and Snow's (1986) early study of skydivers assisted in the development of the edgework concept, helping to bring voluntary high risk activity out of the realm of psychology and into that of sociology. Edgework was also established in early (and recent) studies that note its existence within work, including that of firefighters (Lyng 1990; Desmond 2007), female street hustlers (Miller 1989), professional bicycle messengers (Kidder 2006a), financial traders (Wexler 2010), juvenile justice personnel (Stout, Dadich, Hosseinzadeh, and Herbert 2018), and ambulance drivers (Granter et al. 2019). Lyng's (1990) early skydiving research also revealed that many jumpers reported deliberately engaging in high risk pursuits for obtaining personal benefits such as the often-experienced "rush," deep satisfaction from overcoming personal limits and fears, and "flow," an extreme level of wellbeing that results from personal pursuits when one's skills match the challenges involved in the activity (See also Csikszentmihalyi 1990 on "flow"). Such experiential benefits were found to also carry over into regular daily life (Gagne and Austin 2010). Some edgeworkers "increase the stakes" by smoking marijuana or drinking alcohol on the flight before the jump (Lyng and Snow 1986; Lyng 1990). These practices are a way to maximize the experience by "crowding the edge," or seeing how close one can get to losing control without doing so.

Several studies following Lyng's early research similarly supported the notion of sociological foundations in voluntary risk-taking, and for the theoretical Marx-Mead edgework dialectic of occupational alienation and mediated experiential rewards gained through risky practices. One such study revealed that risk-taking through BASE jumping was not always valued as the end itself, or to achieve a thrill, as psychological research portends (see also Zuckerman 2007); instead, jumps were performed for their transformative effects, where edgework risk-taking was a means to an end (Allman et al. 2009). Other edgework research analyzed advertisements targeting skydivers and revealed that media imagery likened drop zones to a stage where skydivers gain identity, dissolve fears, display control in life and in the face of danger, obtain and maintain exclusive friendships, and experience experiential benefits that entail thrill, 
self-actualization, and flow (Celsi, Rose, and Leigh 1993). This dramaturgical approach to edgework study found that advertisements emphasized skydiver values depicting imagery displaying a disconnect from work and alienation experienced from mundane life activity, persuading skydivers to accept the disconnect and seek out prescribed alternatives to enhance the edgework experience. This could be achieved by purchasing expensive products that offered new technologies in parachutes, altimeters, streamlined jump suits and attire, and other technical gear. The study may suggest that the media portray edgework skydiving (and other risky pursuits) as practices reserved for privileged members of the middle class who engage in a specialized alternative available to elites (Celsi, Rose, and Leigh 1993:11-14).

Other edgework research revealed that different motivations and rewards occur for individuals at different skill levels in the extreme sport of mountaineering, and may also support the notion that the edgework experience is mainly available to professional middle class, whose positions in society allow them an advantage in participation vis á vis economic means where other classes are excluded.

Interestingly, some of these athletes claimed to reject middle class values by doing edgework, yet the study showed that the middle-class values that were supposedly rejected were in fact embedded into the practice of mountaineering, and included intensive dedication, deferred gratification, displaying individualism, calculated risk-taking, and a persistent and ongoing commitment (Fletcher 2008:323). These and other findings may be taken to suggest that, normatively and economically, those of the middle class are differentially predisposed to participation in edgework, while non-middle class individuals experience barriers to the same activities based on a lack of such privilege.

Another related study offered support to this suggestion. Structured interview data $(n=54)$ on experienced4 BASE jumpers who attended an annual "Bridge Day" event (a legal BASE jumping event conducted since the early 1980s where the West Virginia Department of Highways closes vehicle access to the New River Gorge bridge, which offers jumpers an 876 foot free fall), revealed that Bridge Day participants were often of the middle class, and many were professional students, medical practitioners, engineers, air traffic controllers, or specialized mechanics (Allman et al. 2009).

4 Bridge Day coordinators require registered BASE jumpers to provide a verifiable record of past skydiving jumps before jumps are permitted, and generally within the BASE jumping community this ideal is enforced (Forsey 2012). 
Despite its richness as a research topic, many critics claim that edgework studies have the tendency to bias the extant literature by framing and researching edgework topics as practices of the wealthy and (often) of white males (Miller 1989; Lois 2001). Indeed, many of the sports (e.g. skydiving, base jumping, mountaineering, etc.) studied within edgework require costly gear in order to practice, and as such pose barriers to entry to many except for the wealthy, or often younger individuals who do not have children and are willing to trade conventional norms like buying a home or having a committed career for being able to afford the expensive lifestyle of doing many of these activities. Such individuals may "couch surf" (i.e. move from one friend's couch to the next without having a permanent residence), live in their cars, and otherwise improvise funds to purchase the expensive equipment required of backcountry mountaineering, skiing and snowboarding, skydiving, BASE jumping, and so on. This critique that edgework studies have been confined to the wealthy and middle class male has been addressed in ongoing edgework research and in the expansion of the edgework concept.

One such study closely examined the demographic characteristics of edgeworkers. Interview and observational data gathered recently at the Bridge Day event, and at a "BASE camp" training school in Idaho, indicated a low number of female athletes, about 10 percent of the 500 registered Bridge Day jumpers (who were again largely white and middle-class), and a similar proportion of females at the training school (Forsey 2012). At both venues, hegemonic masculinity appeared to be prevalent in BASE practices, and male athletes often called each other "females, "fags," and "homos" or made other sexist and homophobic insults in situations where full confidence was not displayed. Similarly, being cautious was often debased, and at times some males affirmed their masculinity by saying "we're not gay" after giving hugs (Forsey 2012:60-61). These gestures suggest a devaluing of feminine characteristics and slander toward male homosexuality, in contrast to the "badass" ethos of "toughness" espoused by many male BASE jumpers. Elucidating these rites of hegemonic masculinity is an important contribution to the literature and demonstrates that edgework often has disproportionately been framed as a practice dominated by male heterosexual whites.

Another study examined edgework and serious leisure in travel motorcycling and debunked notions of edgework being a pastime of only men, and finding that edgework can very much be a gendered activity. Results further suggest that engaging in edgework motorcycling is a form of serious leisure, and 
that facing the fears and challenges of motorcycling and utilizing developed riding skills is an empowering experience for female riders (Gagné and Austin 2010).

Other research further debunks the notion that edgework participation is limited to the middleclass. Interviews with inner city youth gang members found that edgework is not just a practice of middle class individuals (or of only whites) (Garot 2003). Inner city gang youth engage in edgework when encountering other rival gang members on the street in a territorial process called "hitting up," when one youth confronts another asks where he or she is from. This challenge is answered either with violent retaliation, or by backing down. To do the latter would be to forfeit one's respect, and to many such youth, this "respect," or "juice" (See also Anderson 1999) is the only thing of value they possess. As such, Garot describes hitting up as a process of "creating something out of nothing," where members of the gang subculture gained highly-valued respect as a previously unknown edgework benefit (2003).

I will later explore more deeply the notion that hip hop graffiti writers regularly confront risk in the way of implicit adversity from criminal justice and municipal discourses that ban their practice, and face tangible elements of opposition and danger as they navigate the fine line between doing graffiti and getting caught (Ferrell 1996). Writers risk potential capture by police, attacks from angry citizens, property owners, dogs, and territorial gang members who may mistake them for rival gang members while they traverse inner-city neighborhoods and private property. Graffiti writers navigate these risks while attempting to surreptitiously create stylistic illegal art, and they face additional physical dangers such as falling from highway signs or dilapidated structures, or being struck by passing vehicles and freight trains. Hip hop graffiti, as in edgework and other forms of serious leisure, requires the learning, development, and practice of specialized skills and a simultaneous exercise of control while managing an array of constraints (Ferrell 1996; Halsey and Young 2006). I would argue that the "edge" located in illegal hip hop graffiti occurs between grace and error, stealth and discovery, and in a broader sense, as is also the case in other edgework practices, control and chaos.

\section{Research as Edgework}

Some also posit that edgework is not confined to those whose practices are studied by researchers, but experiencing edgework may become a part of the research process itself (Lyng 1998; Ferrell and Hamm 
1998). It is thus thought to be necessary to experience edgework and take extreme risks within the research process to gain a sense of "criminological verstehen" (Ferrell 1997; Ferrell et al. 2014). This is a Weberian understanding of the everyday reality of crime and an accurate sense of emotional and affective aspects of doing crime, which can be obtained only through situating oneself in very close proximity to what is studied. Olsen noted that an illegal BASE jumper once said, "You can never fully appreciate it, until you do it yourself" (2001:144). Or, as Feyerabend stated, "It is conceited to assume that one has solutions for people whose lives one does not share and whose problems one does not know" (1975:280). Being willing to do edgework to facilitate the research process involves going against the norm in research practices. I would venture to say that this is a significant step further but in the same vein of thinking in what was instructed by Parks in the early Chicago School, to get away from the office, the classroom, and the books, to inspire participation in research in getting out on the streets and doing it (Becker 1986). Studying edgework, experiencing it as research subjects do, may become a fundamental part of analysis (Lyng 1998; Ferrell and Hamm 1998; Ferrell 1997).

One thing that may not receive enough emphasis in the literature on edgework is that often edgework is a specialized form of leisure; truly, its practice parallels many of the characteristics and benefits of "serious leisure" (Stebbins 1982). It is here that a discussion of the extant literature on the forms of leisure explores this connection.

\section{Serious Leisure}

The serious leisure perspective proposes that modern life and post-industrialism offer fewer job opportunities and hours on the job for individuals to express their abilities, fulfill potentials, and self-realize at work (Stebbins 1982). Further, it posits that since leisure is becoming a more fulfilling and effective means "to personal fulfillment, identity enhancement, and self-expression" than work, people will increasingly continue to seek out leisure opportunities. Where casual leisure differs from serious leisure is that the former requires little or no skill but is still a pleasurable activity suited to immediate free time. In contrast, serious leisure requires significant skill, repeat practice, some organization or planning, and provides significant and long-lasting experiential benefits that cannot be obtained from doing casual leisure (Stebbins 1997). Serious leisure may be becoming a main route for meeting personal needs (Stebbins 1982: 251-254) and is further distinguished from casual leisure (like watching television or walking the dog) on 
several key criteria, notably: a need to persevere; a propensity for the learning of skills and specialized knowledge or training; an array of experiential benefits, including actualization of self, recreation and renewal, enrichment of self, self-expression, social interaction, self-gratification, and enhanced self-image, a unique subculture and ethos, and a tendency to identify with a pursuit and be enthusiastic over it (Stebbins 1982:254-258). Casual leisure is a satisfying and otherwise rewarding activity, though usually short in duration and requiring no special skills (Stebbins 1997:17), such as in listening to podcasts. Conversely, serious leisure is an organized and ongoing regular activity that includes "amateurism, hobbyism, or volunteerism," and compels participants to continue practice and potentially find a profession that uses the specialized skills and experiences gained from doing the activity (Stebbins 1992:3-4). Serious leisure demands increasing one's knowledge and skills base through continual effort and practice (Stebbins 1982:267).

Amateurism includes semi-professional activities involving a system of interdependent public and professional relationships that may entail sports or entertainment and a desire to become involved in some occupational pursuit. Amateurism is largely motivated by self-interest. Hobbyism may include non-work activities like body building, running, playing bridge, fishing and hunting, and is generally driven by selfinterest and sometimes pecuniary benefits. Volunteerism includes delegated work activity motivated by both altruism and self-interest and tends to be a socially helpful activity that is specific in its contribution. This may be the case in pursuits such as search and rescue or picking up litter. In contrast, both amateurism and hobbyism often tend to contribute to the cultural areas to which they pertain (Stebbins 1982).

Early ethnographic studies examined serious leisure in a variety of leisure pursuits. These studies succeeded in locating a conceptual structure by which the theory could be advanced. Intermediate studies on serious leisure, largely qualitative in nature, examined athletic swimmers (Hastings et al. 1995), fishermen (Yoder 1997), PC gamers (Bryce and Rutter 2003), sports spectators (Jones 2000), and museum volunteers (Orr 2006), to name a few. Enduring themes and outcomes that emerged among early studies were later included in the construction of a serious leisure psychometric model to be used in distinguishing serious leisure from casual leisure (Gould et al. 2009). This model considers factor items such as "perseverance, personal effort, career course, identity, unique ethos" and outcomes of "personal enrichment, self-actualization, self-expression, enhanced self-image, self-gratification, recreation..., and 
financial return," and others, for a total of 18 different serious leisure factors. This self-report assessment, known as the "Serious Leisure Inventory and Measurement" (SLIM), was initially tested using convenience and target sampling of various leisure practitioners, and results indicated that the SLIM tool exhibited reliability and validity as an inclusive assessment across several serious leisure pursuits (Gould et al. 2009). Later confirmatory tests of the SLIM tool, conducted on a large sample of chess players, succeeded in confirming reliable serious leisure items for the 18 serious leisure factors, with results also noting some problematic bias in the SLIM tool and other self-report measures (Gould et al. 2009). Nonetheless, these shortcomings have more recently been improved, and the SLIM tool has proven a significant advance in the field, helping to consistently distinguish between serious and casual leisure, and offering the field a powerful diagnostic tool.

A recent study expanded the serious leisure literature in terms of gender and found that women's work, childbearing, sexuality, gender identification, and parenting all played key roles in motivation and commitment for women in recreational climbing (Dilley and Scraton 2009). Another study on aging populations similarly advanced the scope of serious leisure studies and produced findings supporting the notion that subjective wellbeing results from serious leisure practice (Heo et al. 2010). A further study on serious leisure and aging populations found significant support for the idea that positive relationships exist between serious leisure practice, life satisfaction, and health in older adults (Heo et al. 2013).

One may infer that the alienation experienced in day-to-day life that is discussed within edgework literature may coincide with the serious leisure position that a modern imbalance that exists between work and leisure will result in increased leisure pursuits; indeed, this is acknowledged in the serious leisure literature. Serious leisure theory maintains that people will increasingly seek out leisure to provide benefits their daily careers cannot (Stebbins 1982, 2007). The serious leisure experience offers an array of benefits obtained from engaging in leisure pursuits, and it may thus shift the focus of importance in one's life from work to leisure (Stebbins 1982:254). Serious leisure's potential to lead to related careers that utilize the skills and experiences obtained through its practice may be evident in the case of a person who engages in motorcycling and eventually professionally races motorcycles, a person who does needlepoint as serious leisure and then opens a business specializing in sewing and fabrics, or perhaps in the case of a hip hop graffiti artist becomes a successful muralist or gallery artist. Notably, the extant body of leisure research 
has not as yet framed illegal hip hop graffiti as a form of serious leisure, though much research has been conducted on other forms of non-sanctioned leisure or "purple recreation" (Curtis 1988), generally described as "deviant" leisure, which I will discuss next.

\section{Deviant ("Dark") Leisure}

Durkheim noted that there will always be deviance where there is society because defining and enforcing deviance is a universal practice of society (1979). Deviant leisure, in earlier studies referred to by the term "purple recreation," referring to "off color" or non-socially acceptable forms of leisure (Curtis 1988), is a subtopic in leisure studies that examines activities that explore and re-explore taboos and push the boundaries of assumed morality (Stone and Sharpley 2013). Smith and Raymen (2016) utilize a deviant leisure perspective that allows the examination of increasingly diverse commodified forms of deviant leisure that are growing in popularity. Where some such types of deviant leisure might be socially discouraged but still considered harmless, such as dumpster diving or urban exploration of abandoned or condemned buildings, others may be socially accepted but lack immediate prosocial value, often instead posing inherent harms to oneself or society (Smith and Raymen 2016). This raises an important notion of tolerability in deviant leisure forms, as emphasized by Stebbins (1997) (and discussed further below). For instance, some forms of culturally approved and commodified leisure in activities like bar hopping (or "pub

crawling”), gambling, and sports spectator hooliganism pose high risk for societal harm (Smith and Raymen 2016). Other non-culturally approved, uncommodified forms of deviant leisure may include graffiti writing or parkour, also called "free running," a form of urban gymnastics developed by French special forces that involves climbing dangerous urban walls, jumping off high ledges, or "building jumping" (hopping gaps between tops of buildings), and may carry less potential for harm to others than culturally approved and commodified forms. Put more plainly, some widely-sanctioned leisure activities may include heavy alcohol consumption, which is often associated with domestic violence, physical or verbal assault, sexual assault, over-consumption, drunk driving, and related accidental fatality, while gambling can result in financial disaster (Smith and Raymen 2016). It might be noted that graffiti writing can involve accidental self-harm, trespassing, and defacement of public and private property, though the scope of property damage may be selective. A substantial body of research notes that graffiti practitioners tend to adhere to a code whereby personal property, places of worship, sculptures and monuments, schools, 
hospitals, or cemeteries are often largely avoided in the selection by hip hop graffiti writers of appropriate canvas on which to paint (Brewer 1992; Ferrell 1996; Halsey and Young 2006).

Some aspects of deviant leisure may require the learning of auxiliary skills and engaging in “supportive leisure" practices, which, as Smith and Raymen (2016) suggest, may also constitute serious leisure activity. For instance, drag racers may need to learn mechanical or welding skills, computer hackers may also have to become informed about different hardware and network protocols that are used, in addition to being skilled at cryptography. It is likely that becoming skilled at related 'serious leisure' forms may also occur in doing hip hop graffiti, where accessing some locations to paint trains may require handling construction tools to grind out door locks, cut through metal bars, penetrate barrier fences, sever razor wire, or create passages through block walls.

In terms situating deviant leisure forms within the parameters of the serious leisure perspective, Stebbins expanded his original serious leisure typology, acknowledging that leisure behaviors can be designated according to deviance in terms of socio-cultural constructions of leisure forms as being "tolerable" or "intolerable." "Tolerable" deviant leisure is distinguished by the notion that public welfare is maintained in its practice, while "intolerable" deviant leisure occurs where there is significant agreement that a leisure practice is morally wrong, harshly discouraged, and carries potential negative effects for public welfare (Stebbins 1996). According to this, many forms of socially approved and commodified leisure forms may be characterized as "intolerable," as may be the case several forms of "nightlife" activities that were discussed above, which may involve high levels of alcohol consumption. Stebbins noted there is likely some overlap between tolerable and intolerable deviant leisure, and that these designations differ according to time and place (1996:19). This is worth noting because some forms of deviant leisure are not considered deviant (or vice versa); for instance, writing graffiti on public walls in most of North America is criminalized often as unless some authority (via permit) says it is ok, while doing so in parts of South America (and elsewhere) is often viewed as art. Perhaps relevant to Stebbin's tolerable/intolerable distinction, Mcauliffe (2012) noted that certain moral geographies occur in graffiti's place or location and in the form graffiti assumes (i.e. tagging or artistic masterpiece), and, this involves a politics of public preference for what is considered appropriate art and appropriate place. 
Despite distinctions between serious and non-serious leisure, and between deviant and non-deviant leisure, deviant leisure may be difficult to conceptualize in terms of criminality. Acknowledging this challenge, a recent expansion on Stebbins' work incorporates tolerable and intolerable deviant leisure into a typology designating "legitimate" and "criminal" dimensions of deviant leisure forms (Williams and Walker 2010). According to this framework, twelve separate subtypes of leisure forms may be classified according to intensity (serious versus casual leisure), tolerability (tolerable versus intolerable leisure), and legitimacy (criminal versus legitimate leisure) (See also Williams and Walker 2010). For the benefit of the current discussion, I will emphasize four such features of deviant leisure within Williams' and Walker's typology that I believe are relevant to hip hop graffiti writing.

Tolerable legitimate deviant leisure includes behaviors that are legal but may violate some element of consensus morality. This may occur in behaviors such as reading erotic literature (identified as casual leisure) or being in a cult (identified as serious leisure) (Williams and Walker 2010). Additionally, the typology establishes intolerable criminal deviant leisure to include behaviors such as shoplifting, vandalism, and viewing child or violent pornography (casual leisure forms), or computer hacking and serial murder (serious leisure forms). The typology further designates tolerable criminal serious leisure to include activities like street racing (Williams and Walker 2010:204).

At once, one may see that many leisure pursuits, including the painting of illegal graffiti, could fit both within both tolerable and intolerable forms of deviant leisure, as well as having potential overlap between categories of criminal and legitimate forms. While vandalism was designated in Williams' and Walker's (2006) framework as an example of intolerable criminal casual leisure, no known studies have attempted to categorize illegal hip hop graffiti within such a typology. Such a categorization of graffiti writing may be somewhere between tolerable criminal serious leisure and intolerable criminal serious leisure, depending on the perspectives or standpoints of those involved. In terms of the authors' examples of these latter two types, for which they offer examples of street racing and computer hacking/serial murder, respectively, I would argue that illegal hip hop graffiti not only fits within both of categories, but that street racing, serial murder, and computer hacking carry far greater potential harms to society than spray painting large, stylistic letters and pictures, whether on public or private property. In terms of labeling theory, it is important to note that, characterizations of deviance (or as deviant leisure in this case) are 
constructed according to features of tolerability not inherent in the act. Rather, the latter find roots in a separate and culturally-dependent labeling process that occurs (Becker 1963; Lemert 1967). Similarly, aspects of dark leisure are not evident in the practice of the deviant activity alone, but rather become clear in the cultural reaction and the labeling of the act as deviant. This raises an important connection between labeling theory and the cultural construction of notions of tolerability and legitimacy in "dark" (deviant) leisure forms. Additionally, it is important to emphasize that simple categorizing of deviance or other social acts is not entirely productive without also identifying the social processes and written discourses which characterize these acts as deviant (See also Ferrell et al. 2014).

Thus in terms of dark leisure activity or labeled recreational forms, it may be useful to discuss such activities according to Williams' and Walker's (2006) typology of deviant leisure, as many risky practices also converge upon notions of intensity, tolerability, and criminality, which again are socially defined (See also Stebbins 1996). Illegal hip hop graffiti violates specific norms and laws that similarly vary according to time and place. In one sense, these violations may include the respect for private property and in another the consensus notions of what constitutes the proper use of public space, and perhaps another on decency or what is considered free speech, civil discourse, or civil disobedience. In addition to this, widely agreed-upon notions of personal safety may also be violated in the deliberate act of putting oneself at risk of injury and other harm while doing illegal graffiti. Deviance research may further examine these distinctions within edgework or serious leisure practice and the relative dimensions of deviant leisure in terms of legitimacy and tolerability. It may benefit studies that attempt to grasp aspects of leisure and recreation to also consider differences among recreation specialists exhibiting varying levels of “seriousness." Such differing levels of practice may similarly occur among graffiti writers of advanced, intermediate, or novice levels, as discussed in the sections below.

\section{Recreational Specialization Theory}

It is important to emphasize that scholars and researchers distinguish between leisure and recreation, noting that some may at times conflate these terms and their separate meanings. To cite early research, recreation is recognized for its being a form of leisure of differing degrees of seriousness, that is practiced for ensuing positive benefits. Recreational specialization theory (RST) assumes that recreational practitioners are heterogeneous in their practices, and that homogenous subgroups exist within populations 
of those who practice different forms of recreation (Bryan 1977). On the other hand, the serious leisure perspective simply dichotomizes leisure types into regular "serious leisure" forms, and casual or nonserious ones (Stebbins 1982). Though the criteria for distinguishing serious from non-serious leisure are specified and well-established through research, referring to RST in the study of certain populations allows going beyond a simplified typology of practices as serious versus non-serious leisure. RST may identify degrees of seriousness (See also Scott 2012 and section below, titled "Recreational Specialization Theory and the Serious Leisure Perspective") and different subtypes of practitioners within a population engaged in a recreational pursuit, where values, practices, and motivations may vary according to some degree of specialization that changes over time. As is further discussed below, progression does not necessarily occur in a linear (forward) direction (Kuentzel and Heberlein 2006; Scott and Shafer 2001a), and progression in recreational forms may also vary by different life contingencies (Oh, Sorice, and Ditton 2010; Scott 2001b).

RST theory was early applied to studies of trout fisherman (Bryan 1977), recreational canoeists (Bryan 2008; Wellman, Roggenbuck, and Smith 1982), backcountry hikers (Bryan 2008; Virden and Schreyer 1988), photographers (Bryan 2008), mountain climbers (Bryan 2008), outdoor recreation students such as canoers, rock climbers, spelunkers, wilderness campers (Ewert and Hollenhurst 1989), and, later, freshwater and saltwater kayakers, rock climbers, and canoeists (Ewert et al. 2013), bridge players (Scott and Godby 1992, 1994), recreational baseball players (Jaehyun et al.. 2019), and mountaineering specialists and adventure tourists (Pomfret and Bramwell 2016). Applying RST in the theoretical framework of the current study reveals patterns of different specialization levels and corresponding practices, motivations, and values among members of a sample cohort of graffiti writers. Knowledge of such patterns may carry potential implications for policy officials who engage in practices targeting graffiti, and municipalities may benefit from adjusting policies according to an awareness of the diversity in practices within illegal graffiti.

\section{Studies in Recreational Specialization Theory and Related Research}

Early Recreational Specialization Theory (Bryan 1977, 2008) research was conducted in conversational interviewing and participant observation of freshwater anglers in their naturalistic environments. Bryan (1977) established a conceptual framework identifying a continuum of recreation practices thought to occur from the general to the specific, and according to skill, equipment used, 
experience, and values. Bryan's research went beyond serious leisure theory to devise a recreation specialization variable important in identifying heterogeneous behaviors and attitudes among different subgroups of recreational participants (1977). Bryan's (1977) angler study noted that as specialization level differs, so also do consumption practices, attitudes on conservation, and career preferences. Anglers were characterized as occasional practitioners, generalists, equipment specialists, and setting specialists who pursue specialized fishing locations on extended vacations or make career and life changes suitable to the practice (like taking a lower paying job to be able to live close to choice angling destinations). Bryan (1977) found that anglers (or other recreationists) increase their frequency of practice, knowledge, skill level, awareness and attitude in terms of nature and conservation, different equipment used, vacationing and socialization patterns (specialist anglers often casually chatted with others and regularly frequented tackle shops, bars, and campfire sessions). Additionally, differences occurred in types of settings and different bodies of water chosen (i.e. stocked ponds and streams or less-accessible rivers and subsidiaries having native fish), as well as in consumption practices (beginners ate more caught fish than advanced anglers who often practiced 'catch and release'). These distinctions represent values differences, for instance in whether one simply enjoys the process of fishing, or, perhaps more so, the volume of product. Thus, such differences may be acknowledged by recreation managers, to the extent that such knowledge is useful in planning, maintenance, and development of recreation resources. For instance, Bryan aptly noted that RST is a useful conceptual framework for use by conservation managers to better understand diversity within recreational pursuits among different types of practitioners, in order to better advise the drafting and implementation of recreation and natural resource management policies (Bryan 1977; Scott 2012). RST research continued and identified different specialization levels among hikers, backpackers, hunters, and recreational canoeists (Bryan 2008).

As noted in Bryan's $(1977 ; 2008)$ and others' works, RST predicts that there will be diversity in conservation attitudes and practices among anglers and other recreational specialists. For example, this may be evident in different personal views on creel limits, or temporarily limiting access to certain locations to allow for overfished species to regenerate. Nonetheless, some studies have failed to garner support for RST in terms of these differences. A survey study of Virginia canoeists assessed behaviors and attitudes in terms of conservation, particularly toward appropriate and depreciative river practices, and found little difference 
between subtypes of canoeists in terms of conservation practices and attitudes. Where RST predicts that specialists will be more conservation-oriented (and beginners less so and thus more depreciative or damaging to rivers), results showed that beginners devalued depreciative behaviors and practices roughly the same as do specialists (Wellman, Roggenbuck, and Smith 1982). Another study similarly failed to identify significant differences in conservation attitudes in terms of preferences for fishing regulations and for protected areas among angler specialist subgroups of more and less specialized anglers (Salz and Loomis 2005).

Other research gathered support for RST in terms of differences in conservation attitudes and preferred practices in different recreation setting types. One study surveyed backcountry hikers on their general and recent experiences, equipment preferences, monetary investment levels, and value for the importance of backcountry hiking compared to their other life commitments. Findings showed that one's level of hiking experience influences their environmental perceptions and awareness, and their desire for more diverse settings (Virden and Shreyer 1988). Additionally, as specialization level increased, hikers exhibited a decreased tolerance for encountering directional signs, motorized vehicles, or other hikers on the trail, instead preferring rugged environments, the presence of bears and wildlife, sustainable management practices, and limits to hiker party size (Virden and Shreyer 1988).

A later study garnered support for RST and tested the "adventure recreation model" with a convenience sample of outdoor recreation students who specialized in canoeing, wilderness camping, rock climbing, and spelunking (caving) (Ewert and Hollenhorst 1989). The adventure recreation model proposes that leisure practitioners can be classified into three engagement levels: introduction (amateur), development (intermediate skill), and commitment (advanced and highly-skilled). These levels were assigned in part by increasingly more difficult and challenging environments chosen by outdoor adventure practitioners (Ewert and Hollenhorst 1989). The model specifies that greater engagement levels predict increased skill and frequency of practice, higher risk levels sought, and increased awareness of internal "locus of control" (Ewert et al. 2013:92-93). Results confirmed that as experience level increases, so also do skill, frequency of participation, level of risk, and perceived locus of control. Additionally, practitioners continually sought out more "natural" and untouched wilderness conditions. Though the sample was not large or representative, both elements of RST and the adventure recreation model were supported by data 
that suggest that there are different levels of preference for risk and different environmental conditions for recreationists according to increasing levels of specialization (Ewert and Hollenhorst 1989). This increased risk taking and difference in choice of environments may also occur in graffiti writing or in other risky practices framed as recreational pursuits.

Ewert et al. (2013) retested the adventure recreation model by using an expanded questionnaire examining key motivations and attitudinal differences among freshwater and saltwater kayakers, canoeists, and rock climbers. The "level of experience" index used with this large sample indicated that gender, experience, and type of activity differently affect motivations of recreationists. The results showed social motives as being most important to specialists in all four practices, especially so for canoeists, while social motives were also more important to females than males. These social motives included being part of a team, having friendships, and closely interacting with others (Ewert et al. 2013:104). Another motivation reported was sensation-seeking, highest among rock climbers, and increasing with level of experience, while less important to more experienced canoeists. Additionally, self-image was the greatest motivation among experienced rock climbers and beginner kayakers (Ewert et al. 2013:104). This research emphasizes the notion that risk-taking and challenge are important aspects on which recreational planners may focus, but that these are not the only motives among diverse groups of recreationists. Thus, recreational planners and managers may aptly take note of such diversity (Ewert et al. 2013:107). It is possible that this notion also has implications for policy construction or planning designed in response to other pursuits, such as in graffiti writing.

Kuentzel and Heberlein (2006) conducted a closer examination of commitment, identity, and social factors related to specialization, importantly noting that forward progression is not a guarantee based on an increased investment of time or frequency within a recreational pursuit. Using time series data to examine progression from novice to specialist among recreational boaters, the authors noted that no significant forward progression occurred in terms of skill and advanced levels of experience and engagement. Significantly, most recreational boaters maintained lower levels of "casual" leisure participation or viewed boating as a form of entertainment rather than recreation, and did not significantly progress over time (Kuentzel and Heberlein 2006). These findings and others suggest that commitment and specialization in leisure practices may be more complicated than theory predicts, and that researchers 
should endorse alternative conceptual frameworks and methodologies to advance beyond the limitations of cross-sectional studies in RST research. Perhaps heeding this counsel to use longitudinal data in RST research, a panel study on Texas anglers also showed recreational progression does not always occur in a forward direction (Kuentzel and Heberlein 2006; Oh et al. 2010). Taken together, these and other findings suggest that recreational practitioners may not progress in a traditional direction (Scott and Shafer 2001; Kuentzel and Heberlein 2006). This reaffirms the notion that a time-series approach may better model recreational progression and specialization, as life course factors and other contingencies more likely moderate one's level of commitment and progress.

The notion of commitment is central to the designation of a serious or casual leisure form (if compared to perseverance and personal effort; See also Stebbins 1982), and may determine an increase in skill level and involvement. In a theoretical discussion of recreational specialization, Buchanan (1985) examined commitment in terms of several components, including consistent and focused behavior, "side bets" (financial interests and other resources invested in maintaining a leisure activity, where the notion of losing this investment compels continued involvement in recreation; See also Salz, Loomis, and Finn 2001), and behavioral consistency with objectives and values related to the activity. These include affective attachment to groups or other participants, level of cognitive commitment involved in maintaining practice as an alternative to the costs of discontinuing, and control, or normative dedication to values and beliefs of key actors within a recreational network (Buchanan 1985). Other research using a sample of contract bridge players further explored commitment and the conditions under which individuals progress, with findings revealing two subgroups of players, who played "social bridge" and who played "serious bridge" (Scott and Godby 1994). This distinct categorization of involvement levels among participants parallels Stebbins' serious and casual leisure typology $(1982,2007)$. In terms of empirical support for progression and RST, data suggest that most bridge players did not achieve an elite stage of specialization, and often instead remained in lower, less-serious, levels of practice. A follow-up study of bridge players also found support for RST, identifying non-homogenous attitudes and behaviors among players, where participation, desired setting, commitment level, social relationships, and degree of competitiveness distinguished four player subtypes. These included highly-involved "serious bridge" players (socially motivated and dedicated to skill building), "regular social players" (who may eschew rigid playing rules in favor of more friendly 
play), and occasional players (less-involved marginal members who play for social purposes) (Scott and Godby 1994). These research studies garnered significant support for specialization in recreational forms, and urge the importance for researchers to look closely at how recreational specialization subtypes vary according to different recreational forms and in terms of differing social practices, attitudes, and behaviors.

\section{Recreational Specialization Theory and the Serious Leisure Perspective}

Many argue that the serious leisure perspective and RST have potentially useful connections, where RST can extend a continuum of serious leisure. Referring to the serious leisure perspective, Stebbins early stated that a "more sophisticated, research-informed construct will likely abandon eventually this primitive terminology for terminology conveying continuousness" (1982:255). Some research discusses aspects of recreational specialization theory that may be utilized to improve the serious leisure perspective. Tsaur and Liang (2008) modeled a significant positive relationship between serious leisure practice and recreational specialization, and found that five of six serious leisure criteria (all except having a unique ethos; See also Stebbins 1982, 2007) are significantly and positively related to both past experience and level of importance of a leisure practice in terms of one's other life pursuits (Tsaur and Liang 2008).

Acknowledging the claim that serious leisure and recreation specialization are incompatible, Scott notes that styles of participation in serious leisure can vary along a continuum of involvement in degrees of seriousness that can be located among recreation specialization subgroups (2012). This line of thinking may imply that there is important variation within recreational activities that cannot be adequately captured by a binary specification of serious versus casual leisure (or by the forms of serious leisure). Scott importantly notes that levels of serious leisure vary according to "gradations" of heterogeneity within leisure populations (2012). He further highlights the applications of recreational specialization theory within serious leisure that are evident in the distinct levels of seriousness, quantifiable numbers of participants in different seriousness levels, and diversity of participation styles (Scott 2012:369). The connection between past experience and centrality of importance of a leisure practice to other life pursuits was re-examined by Lee and Scott (2013) who reported that personal and behavioral commitment (RST concepts) are significantly connected to identity, related career potential, invested efforts, and perseverance (serious leisure concepts) in leisure practices, all of which were aggregated into a composite measure of 
"seriousness" (Lee and Scott 2013). Taken together, these studies offer some evidence that serious leisure and RST are compatible and complementary.

\section{Gender, Substitution, Identity, and Other Factors in Recreational Specialization}

A recent study examined motivational differences in gender, age, and experience level in outdoor adventure tourists and recreational adventurers (mountaineers). The authors suggest that adventure tourists are more motivated by "pulls" of the destination (including natural environment type and tourism-specific products and services) than were beginners (Pomfret and Bramwell 2016:26). This research showed that experienced mountaineers reported experiencing euphoria and "flow" while engaged in practice, and that experienced mountaineers as recreational specialists are different from typical adventure tourists, whose practices are largely safeguarded (i.e. associated risks are "assumed" by industry representatives who sell "packaged" adventures and facilitate events). Kim et al. (2019) examined social influences in RST in terms of specialization among Korean baseball players. Findings revealed that as specialization increased, a greater negotiation of social constraints occurred for many players. Additionally, the authors suggest that managers who act to reduce negative social constraints for players, may increase participation by increasing incentives and consumables to players, such as providing regular team events and meetings to encourage cohesion and social bonding among players (Kim et al. 2019). This research has important implications for applying RST to pursuits outside of the realm of (generally) outdoor or wilderness-oriented recreation.

Needham, Scott, and Vaske (2013) summarize recent research in RST, noting several studies with factors of note. Some of these focalized the social psychological concept of "flow" (extreme sense of wellbeing or satisfaction; See also Csikczentmihalyi 1990), substitutional recreational practices, addiction, identity in specialization, and multi-directional progression. In another study, the concepts of flow (See also Csikczentmihalyi 1990) and addiction were examined within online role play gaming (Wu, Scott, and Yang 2013), and results showed that more specialized gamers experience more flow and levels of addiction.

Other research shows that waterfowl hunters may or may not attain a specialized identity through practice, and that some were observed to have relinquished this identity over time (Schroeder et al 2013). In another study, deer hunters and elk hunters were reported to substitute these forms of hunting for other activities (like fishing or other game hunting), as specialization increased. Additionally, when substitutions are made, 
more specialized hunters resorted to hunting other game, while less-specialized ones favored toward fishing as a substitution activity (Schroeder et al. 2013).

To date, no known research studies have examined aspects of recreational specialization within illegal activities (or among hip hop graffiti writers) in terms of differences in practice according to experience categories of specialization levels. The current study seeks to identify differences in graffiti practices and mindsets in terms of specialization, and to identify standpoints of graffiti writers in terms of the constraints of dominant social institutions and written discourse. Revealing the standpoint and diversity in writer, views, preferences and practices may offer directions for existing policy structures and designs, that could be utilized similarly to the way that recreation and natural resources administrators have historically utilized RST research findings to manage resources. Understanding that some writers value risk and thrill features in practice, where others may favor different practices, benefits, and motives, could offer evidence-based data on which policy makers may efficiently revise current practices. Identifying differences in practices among writers may benefit RST research by showing there is not only a spectrum of specialization within graffiti, but practices may also differ according to varying degrees of criminality.

\section{What the Current Study Aims to Do}

Foucault famously stated, "Where there is authority, there will be resistance" (1978: 95-96). While graffiti has not always been illegal, or even necessarily defined as deviant, modern consensus is often such that graffiti is an act of defiance, destruction, or immorality, and should be illegal (Ducuyunan 2000). Though most hip hop graffiti is prohibited, graffiti writers look for and find ways to continue to do their art, risking stigmatization, imprisonment, physical harm, and in some cases, accidental death in doing so. It

may be the case that a focus on such non-prosocial outcomes, coupled with myths and stereotypes about the risks and realities of graffiti writing, serves to situate and constrain its practice. Certainly dominant discourses and institutional interrelations determine and shape graffiti's practice and public understandings of artistic graffiti. Nonetheless, graffiti writing continually defies dominant institutional values and constraints, and it persists in the re-ordering of public space and expression of contestant notions of style (Ferrell 1996; Halsey and Young 2006). In light of these points, the current study aims to situate the standpoint of graffiti writers and their resistance practices in terms of these authority structures, institutional relationships, and related social forces as evident from discussions with policy makers and in 
an examination of city ordinances and how these affect both writers and property owners. Additionally, the current research seeks to examine aspects of serious leisure, recreational specialization, dark leisure, and edgework within the practice of illegal hip hop graffiti. The purpose of utilizing these conceptual and theoretical components is to illustrate the various nuances within graffiti, as it occurs in various forms. By utilizing this theoretical framework, I offer a conceptualization of graffiti that highlights its similarities to legitimate forms of recreation, and illustrate the ways that graffiti writing may be conceived of as occurring as a career trajectory with different practices. benefits, attitudes, and views that change over time, as writers accumulate knowledge, skills, and experience. As such, I will argue throughout the final few chapters that graffiti is a legitimate form of recreation having planned positive benefits, and that policy officials and publics may beneficially reconceptualize graffiti in ways that benefit writers and other stakeholders.

Several research studies have pointed to hip hop graffiti's stigmatization in policy and policing practices, where hip hop graffiti is characterized as and treated with hate graffiti, political statements, and violent gang graffiti. Nonetheless, few projects have gone proceeded beyond an exploration of graffiti writing, municipal policy, and writer motives. As well, no known research studies have deeply examined graffiti writers' experiences, practices, perceptions of adversity, or standpoints within institutional interrelations, to locate "common grounds of oppression" (Smith 1987:176). What is more, no known research has analyzed hip hop graffiti as a form of deviant serious leisure, recreation specialization, or edgework. A key goal of the current analysis is to utilize a combined theoretical framework to address the gaps in research and to gather more information on what is still unknown about hip hop graffiti culture and how practitioners' experiences relate to the larger policy discourse. I believe such a formulation will lead to a deeper and more nuanced understanding of the graffiti writing subculture, highlighting the potential benefits graffiti offers to communities. To provide such an understanding may carry the potential to open discussion to inform conventional social policy practices for the benefit of all stakeholders.

It is necessary to henceforth discuss some of the forms of conventional graffiti policy and policing strategies utilized in public administration and criminal justice, and to highlight the theories upon which these are based. To illustrate the potential value to municipalities in considering conventional policy alternatives, the following discussion emphasizes the implications of wrongly theorizing policies directed toward hip hop graffiti writing, 


\section{Policy Implications of Wrongly Theorizing Hip Hop Graffiti}

The danger in characterizing all forms of graffiti as deliberately destructive or fear- and hateinspiring activities is to ignore the different degrees of artistic and expressive value found within hip hop graffiti. Such characterizations for the most part punish all illegal graffiti equally, overlooking contextual factors that could assist in keeping separate minor property criminals from more serious offenders, and prevent adding potential cultural capital to communities. Misunderstanding the hip hop form of graffiti, or miscategorizing it with gang graffiti, hate graffiti, political graffiti, or amateur vandalism, is a common tendency in conventional policy which often deliberately blurs distinctions between different types of graffiti. Below, I review some key municipal graffiti practices, and the rationales upon which zero tolerance policies are based, followed by a discussion of alternatives that may promote or engage graffiti in positive ways without conveying an ideal of being "soft" on crime. These latter "engagement" policies (McAuliffe 2012) have realized great potential for hip hop graffiti as a form of alternative cultural capital. Additionally, their use has shown promise in some districts in a move away from zero tolerance policies that, as previously discussed, tend to move the practice of illegal graffiti from one geographical place to another, and may inadvertently increase graffiti's occurrence (Haworth et al 2013).

It was estimated that, internationally, "zero tolerance" graffiti policy cost nearly $\$ 6.8$ billion in annual expenditures in 2005 (Halsey and Young 2006:292), and the cost of worldwide abatement in 2013 exceeded $\$ 12$ billion (Ross 2016). The city of Sydney, Australia, listed in the top 5 international locations to see hip hop graffiti, reported spending about "\$2.9 million per year on graffiti management" in 2010 (McAuliffe 2012; City of Sydney 2010), and even in the 1980s, abatement costs in Los Angeles and San Francisco were in the tens of millions annually (Brewer 1992). Practices in graffiti administration include types characterized as enforcement, removal, and engagement (McAuliffe 2012), which loosely equate to policing, abatement, and partial legalization, respectively. The former two policy practices (enforcement and removal) are often embodied in zero tolerance policy that designates all non-commissioned graffiti and street art as illegal, along with all other forms of graffiti. These practices are often described as part of a "new urban militarism" growing out of ongoing declarations of wars on crime by public officials since the 1970s, a trend that parallels another one in urban policy, referred to as "war on graffiti" (Iveson 2010).

Municipal efforts are generally centered at the very least on abatement and police involvement in 
deterring graffiti, often described as a "criminalizing" (Halsey and Young 2002) graffiti policy. In such policy designs these two features cooperate to some degree in efforts to deter graffiti through regular abatement and significant penalties for apprehended writers.

"A strongly criminalizing (policy)... is to supply the police with their tag database... to match tags to offenders through video surveillance, handwriting experts and private investigators, who...track writers. The council describes its attitude to graffiti as 'zero tolerance' prosecution of any identified writers” (Halsey and Young 2002:176).

Such approaches are embedded with an assumption that all graffiti is a destructive social problem, as it threatens political and economic ideals, and politicians, media figures, activists, and others often deliberately distort, or perhaps more appropriately, "muddy the boundaries" of understandings of hip hop graffiti as distinct from gang, hate, political, or other graffiti forms (Ferrell 1996:5). This serves to condemn all graffiti as threatening vandalism and tends to ignore the cultural and social contexts from which hip hop graffiti emerges (Gomez 1993; Ferrell 1996). As Ferrell and others noted, such actions represent part of a larger hegemony of the social and cultural realms by elitists or moral entrepreneurs whose efforts disenfranchise minority or diverse groups and centralize and sustain political and economic order (1996:12,15-16; Halsey and Young 2002, 2006; Young 2003).

\section{Urban Planning, Reducing Crime, and Place-based Urban Space Policies}

Early research on city design tailored toward crime prevention included the notion that increased police presence alone is not enough to decrease crimes such as graffiti and drug sales. Instead, the community must take ownership in re-designing neighborhoods so that crime may be more naturally observed, deterred, and ultimately reduced, as a collective community goal (Newman 1972). Though such practices have shown promise and may hold merit in addressing many instances of crime, critics of planning and urban design most frequently allege that such practices miss the mark in crime reduction and pre-determine and control human behavior, while reducing individuals' ability to move freely through public space (Ferrell et al. 2014). Zieleniec (2016) argued that graffiti discussed in terms of Lefebvre's and others' work on urban space, forms a more just model of shared space by its continual, ubiquitous, and contestant nature in terms of the regulation, control, planning of urban space designed chiefly in support of capitalism and the commodification of space and quality of life. The social construction of modern illegal graffiti is thought be complicated by a post-industrial urge toward urban development based on increased 
capital consumption, as well as a movement in space-based urban design strategies such as "crime prevention through environmental design" (CPTED) that increase surveillance, policing, and so forth in an effort to regulate public space (Ferrell 2016). To paraphrase Ferrell, "place-based" urban policies feature ways in which modes of social control are built into the physical environment through urban design and increased surveillance and predicting crime trends based on data gathered in public space (2012:1688). Thus, panhandling, homelessness, and graffiti create image conflicts for communities in urban revitalization where increasing value is attached to "quality of urban life" (Ferrell 2012:1689), which is commodified in policy practices concerned with maintaining good perceptions of the city's image (as related to my previous mention of consumption-based urban development), which is in direct conflict with urban graffiti and the homelessness. The latter are instead seen as threats to community members that will invite violent crime, reaffirming "broken windows" ideals and assumptions of a rational choice or instrumental nature of criminality. Young (2003:391) acknowledged that much of crime is instrumental, perhaps calculating and rational, but still a large amount of crime, like graffiti, is expressive and emotional, indicating a heterogeneity of motive commonly overlooked by policy discourse and practices that assume a rational and instrumental motivation to crime.

\section{"Broken Windows," Rational Choice, and "Getting Tough on Crime"}

Perhaps the most popular justification to neoliberal crime policy is loosely based in deterrence principles and "broken windows" theory, which assumes that visible signs of crime and disorder, such as broken windows and graffiti, must be dealt with quickly or they will lead to other serious crime and lowered community morale and general moral decay (Ferrell 2016; Wilson and Kelling 1982). "Broken windows" theory gained popularity during the 1980 s and formed the justification for intensified policing and punitive measures advanced in "get tough" crime policies that have evolved since the Nixon administration. Such theorizing carries far less empirical support than at first was proposed (Ferrell et al. 2014; Police Foundation of the United States of America 1981).

Hip hop graffiti may be as targeted as other forms of graffiti, and be associated with general disorder or gang activity and other serious threats, such as hate crime (Ferrell 1996; Halsey and Young 2000). As well, some research highlights institutional racism in some practices in targeted policing of inner city neighborhoods, which are disproportionately populated by black and Latino populations (Alexander 
2012). A common methodology in broken windows theory is a heavy reliance on official data gathering that enhances justifications for zero tolerance policing and policy practices which may have limited theoretical bases. Such a method is sometimes termed "jailhouse criminology" (Ferrell and Hamm 1998), a hegemonic methodological process whereby the mass collection of statistics and figures precipitates a reporting of crime rates in such a way that may advance certain policies. Such a reporting method may ignore other valid forms of data, theory, and knowledge as may be provided by demographic and other background factors examined in empirically tested quantitative and qualitative research (Ferrell and Hamm 1998; Ferrell et al. 2014:105-106). For example, many suicides may initially be reported by police as homicides, and the changes in dispositions of such crimes may go unreported to FBI databases which aggregate these data; additionally, not all police departments participate (at all or regularly) in UCR data reporting, posing significant accuracy and reliability issues (Chambliss and Hass 2012). Despite their popularity in reporting, research methods like jailhouse criminology, and the mis-specified theories such as broken windows theory, often result in a lack of reliable empirical evidence (Ferrell et al. 2014), and this may manifest directly into criminal justice policy shortcomings, such as a resultant over-policing of people of color (Alexander 2012).

The failure to reduce crime (and fear of crime) in the early iterations and modern tests of broken windows theory may be traced back to a lack of empirical support for the theory (Kelling and Coles 1996; Wilson and Kelling 1982). The early Newark Foot Patrol, established in Newark, New Jersey and several nearby cities, initiated increased police "foot patrols" to decrease the frequency of loitering, panhandling, and graffiti, and to lessen local residents' fear of crime, most of which it failed in doing (Police Foundation United States of America 1981; Wilson and Kelling 1996). Recent studies of broken windows' theoretical efficacy also fail to strongly support its key premise that increased attention to small signs of disorder will prevent further crime (Xu, Fiedler, and Flaming 2005). The increasing legal costs and continual expenditures of municipal authorities who engage in zero tolerance practices in graffiti policies parallel broken windows practices and may be another indication that such processes are futile when taken as mainstays in policy and without empirical support (Ferrell 1996; Ferrell 1997; Halsey and Young 2002). Several studies highlight the lacking empirical foundation for broken windows theory. One such study revealed insignificant support for a positive relationship between crime, public disorder, and 
perceptions of fear and increased police presence, with mixed findings supporting the crime-reducing effects of community policing. Advocates of community policing value its potential for community capital gained from more socially cohesive neighborhoods resulting from active, involved and confident residents who collectively assist in decreasing crime, usually in concert with increased policing. Notably, some research fell short in its methodology (Xu et al. 2005), where the unit of analysis under study was an affluent Colorado neighborhood wherein community cohesiveness and social organization that evidence a community policing model were likely already largely present, more so than would be found in neighborhoods comprised of other demographics or located near city centers. Xu et al. acknowledge a failure of their study results to generate a reliable multivariate statistical model measuring public disorder, crime, and perceptions of fear (2005:174). Another study examined assumptions about community disorder that are embedded in broken windows theory, suggesting that more affluent neighborhoods have inherent elements conducive to community policing (i.e. decreased perceptions of disorder and fear and already lowered levels of crime) (Austin, Furr, and Spine 2002). This research may suggest that neighborhood quality and perceptions of safety and disorder may be more related to low crime levels, not by community capital enhanced through the increased presence of police. Other research analyzed telephone interviews and observational data to determine actual and perceived levels of neighborhood disorder, noting the importance of cross-checking observed signs of disorder with perceived ones (Hinkle and Yang 2014:27). Significantly, to do so may lead to differences in perceptions of fear between police or policy designers and researchers and actual residents. This research may imply that important demographic features unique to observers may influence overall perceptions of the status of a neighborhood's objective level of disorder. Hence, policy may wrongly or inconsistently define disorder, simply by using questionable methodologies. Put another way, police and policymakers may be wrongly evaluating targets, by erroneously theorizing about levels of crime and the need to increase police presence (or graffiti abatement activity).

Broken windows theory parallels the logic of rational choice theory and routine activities theory in motivations to commit crime, namely where untended disorder invites rational crime-doers by providing suitable and unprotected targets (Chambliss and Hass 2012), increasing overall criminal activity. Though popular in criminal justice and economics studies, rational choice and routine activities theories overlook other contexts and characteristics of crime in the lived experiences of offenders and the often non-rational 
motivations involved in criminality. Nonetheless, these theories are frequently implicit in crime policy design, and assume that people have a natural tendency toward criminality and are largely motivated by a rational pursuit of material gain and risk avoidance (Copes and Viereitas 2009).

Routine activities theory generally posits that criminal action is motivated by a suitable target, lack of protection, and a willing offender, as well as with a potential pursuit of economic gain (Chambliss and Yass 2012; Copes 2003). According to the principle of bounded rationality, a concept borrowed from economics studies, in terms of the rational choice theory, individuals' actions are constrained by rational choices made to gain some tangible "rational" benefit, such as theft for the acquisition of material gain, or graffiti motivated solely by an interest in obtaining fame or destroying public space. In an examination of rational choice and routine activities theories, this reasoning was essentially debunked; studies of auto thieves and identity thieves determined that motives for crime are not always "rational" or are only committed for material gain or other "rational" outcomes. Instead, offenders may attempt to achieve thrill (Katz 1988; Copes 2003), "stay low" (avoid police detection by using another vehicle) (Copes 2003)," floss" (to flaunt one's wealth via conspicuous consumption), to convey social control or payback (Copes 2003), or to demonstrate a "party" lifestyle (Copes and Veiraitas 2009).

The aforementioned research findings clearly contrast with an assumption that rational decisionmaking occurs predictably within criminality, though this notion is still embedded in policies that theorize that crime occurs as a rational decision making process (Ferrell et al. 2014). This broad assumption may also precipitate policies that treat artistic, hate, obscenity, political speech, and gang graffiti all the same. As Copes' and Viereitas' data reflect, crime may be more often about excitement and kicks, and "street crime" is neither a rational or optimizing experience (2009). This research at once also reflects the limits of basing policy steadfastly in rational choice theories, and as discussed above, research on the efficacy of broken windows-style policing similarly fails to garner consistent support (Austin et al. 2002; Xu et al. 2005; Hinkle and Yang 2014). In terms of research studies of municipal practices reflected in zero tolerance graffiti policies, GIS data of targeted abatement of graffiti "hot spots" showed that such practices were not effective in reducing graffiti (See also Haworth, Bruce, and Iveson 2013). Instead, the opposite often occurred, where graffiti increased, also supporting Ferrell's (1996) study, which noted similar failures in practice. This and other research also may support the ideal that different areas of cities could benefit 
from tailored policy approaches toward illegal graffiti, which look beyond rational choice and broken windows-based policy practices. For example, such practices often occur in combining abatement with promoting sanctioned legal spaces or areas (See also Halsey and Young 2002, 2006). Such efforts may better address the reasons behind graffiti, which are often ignored with failed conventional policy (See also Brewer and Miller 1992 and Gomez 1993).

Policy redesign and the use of alternative justice practice may rely on more holistic approaches, rather than constructing policy solely in broken windows and rational choice models, both of which carry mixed support at best (Ferrell et al. 2014). Alternative theorizing in policy design may also attempt to include the perspectives of community stakeholders, such as residents and graffiti writers, and may enlist their involvement in the selection of areas of cities that could be designated for murals projects.

Furthermore, legal graffiti walls may be best placed to deflect vandalism and offer free spaces to those interested in doing graffiti, while simultaneously lessening legal consequences for writers. Researchers have suggested that that this may be done without city officials appearing to be take a soft tack on crime (Halsey and Young 2002; McAuliffe 2012), and ongoing programs in The United States and other countries may offer such promise (Haworth, Bruce, and Iveson 2013; Ross 2016).

\section{Expanding Policy, Coordinating Efforts, and Celebrating Unheard Voices}

Policy practices centered in part on graffiti deterrence in criminalization and abatement, and partly on graffiti "engagement" strategies (Halsey and Young 2002) focalize on the creation of public murals utilizing graffiti talent, which may deter illegal graffiti (Bloch 2016b). As will be discussed later, this singular engagement practice may be supplemented with other legitimate approaches that utilize artistic graffiti and may result in decreased random tagging or undesired forms of amateur graffiti in areas around strategically placed legal spaces. In other research, skilled artistic graffiti productions can carry community support, making excessive tagging less valued as a practice by beginners who may be encouraged to produce more artistic forms of graffiti (Brewer 1992). An expanded portfolio of graffiti engagement practices may complement other policy components and involve more community members and graffiti writers according to the desires of more stakeholders. If designed and implemented correctly, such programs may satisfy sample policy officials' desire for increased involvement among departments and the 
community in terms of graffiti. Bloch (2016a) noted that muralist Judy Baca emphasized that community voices are often celebrated in mural productions involving illegal graffiti writers:

“...murals visually depict the struggles and triumphs of otherwise hidden communities. Because murals articulate a collective voice in the public sphere, they should be collaboratively produced."

A notable project involved collaboration with hundreds of local youth, some referred by the juvenile justice system, to create a mural on a wall spanning several thousand feet in a city water runoff in Los Angeles (Bloch 2016a). Noting the policy officials' willingness to use graffiti writers in public arts productions, and given the already established involvement of several skilled graffiti writer muralists, similar projects models might offer opportunities for increased involvement of graffiti artists, urban youth, and other community stakeholders.

Perhaps in the fashion of Durkheim's discussion of the functional nature of crime, David Smith claimed that "the unsanctioned presence of graffiti and street art...contributes to the continuous production of new urban moral codes" (1997:204). This may aptly apply to allowance of legal graffiti in policy. Joe Austin noted that illegal graffiti provides a useful "disruption of the authorized visual order" (2010:34) and that the:

“urban social order is, for a great many city leaders, a matter of 'common-sense' visual order...(partially, tenuously) held together by cultural agreements about aesthetic matters" (2010:43).

It appears that such cultural agreements on a public aesthetic may occur in response to the disruption or sustenance of this "common sense" notion of order. Part of maintaining this order is the broken windows policy ideal of rapid abatement, celebrating the notion that quickly addressing disorder or crime prevents more (and more serious) disorder (Wilson and Kelling 1982). Additionally, among policymakers, there is a somewhat common idea that properly executed street art murals can serve as a deterrent to illegal tagging or other graffiti (Ross 2016). While in some cases murals done by big name writers like Amuck and others in Los Angeles did not get painted over by other writers, unfortunately, research does not consistently support the claim that murals prevent other graffiti (Bloch 2016b). Research found that graffiti writers often wrote on murals because it was tacitly advantageous because the city announced they would not perform abatement on murals with the intention of fixing them (Bloch 2016b). To writers, this meant graffiti would "ride" longer if left on murals rather than blank walls. Los Angeles writers continued painting on murals 
and justified their new work when murals had already had been bombed or pieced by other writers. This was a "common sense" decision made by writers, as murals were ideal targets for staying up longer, when city officials had announced plans to prolong or avoid abatement of graffiti done on murals. This instance offers an example where policy officials confounded muralism efforts by maintaining a rapid abatement schedule on other walls, "chasing" graffiti to the murals. This example may imply that graffiti removal may be strategized alongside other graffiti policy measures in order to assure that complementary, and not counterproductive, efforts occur to serve policy goals.

\section{“Smart Cities," The Creative City, and Alternative Graffiti Policy}

As has been noted already, the theoretical dichotomy of art versus vandalism, originally discussed in literature in the 1990s (See also Gomez 1993), fails to recognize nuances and deeper social realities embedded within the subcultural practice of writing graffiti (Ducuyunan 2000:106; Halsey and Young 2006). Conventional "zero tolerance" graffiti policies create legal conditions under which writers face increased fines and jail time. Also, under such policy, writers often are targets of surveillance and are placed under increased risk of discovery by citizen patrols or others who may be motivated to alert authorities through reward and incentive programs (Rainey 1993:123). In contrast, the social and cultural nuances of graffiti writing may potentially be capitalized upon by municipalities in the interests of accumulating community value through utilizing the arts for increasing tourism, youth outreach, and other local initiatives. The "smart cities" concept characterizes municipalities that utilize various themes to boost tourism and development appeal. Such themes include technology, culture, music, and art, where the latter often feature artistic graffiti and street art as focal points (Yenchkin 2013). Some alternative initiatives utilize engaging practices in handling illegal artistic graffiti by enlisting artist talent, while others offer restorative justice measures wherein individuals caught doing illegal graffiti may have an opportunity to participate in graffiti abatement, community service, or youth outreach, in lieu of stiff prison sentences (Halsey and Young 2002, 2006; McAuliffe 2012).

Alternative "acceptance" policy measures (See Halsey and Young 2002:117-118) and smart cities models have utilized legal walls and graffiti beautification projects of cityscapes to encourage tourism and urban development, and to enlist the labor of graffiti writers, street artists, and urban youth. Alternative 
graffiti policies acknowledge the persistence of the many forms of graffiti and its relative, street art, and the potential benefits for involving the community and boosting the urban visual arts aesthetic through public arts programs. Such substitutes to conventional deterrence practices have been utilized to notable success in smart cities models internationally, thus challenging the notion of all graffiti as vandalism (McAuliffe 2012). Programs like MuralsDC in Washington, DC and Wynwood Walls in Miami, as well as others in Atlanta (Living Walls), Philadelphia (neighborhood mural programs), New York, Los Angeles, and Toronto (stArt Toronto) have helped to make many cities popular art destinations. Many such initiatives also provide opportunities for graffiti artists to teach skills to urban youth in mural painting and visual arts, also providing work opportunities to those interested in learning a marketable skill and in displaying their art throughout the city. In the Toronto stART initiative, residents and business owners may obtain municipal permission to allow illegal graffiti to remain on their properties, or to permit the commission of graffiti-style murals on the walls of their homes or businesses (Graffiti Management Plan 2017).

Furthermore, many Latin American countries value stylistic graffiti as art, and may be considered beautification of public space. In such cases, municipal authorities have decriminalized graffiti and street art, and often do not paint over illegal artistic graffiti (Pabón 2016).

Alternative graffiti policy success stories emphasize the importance of elucidating the ways in which graffiti writers as artists perceive and interact with mainstream governance, rules, and policies that shape their creative and rebellious activity. As research has shown, writing graffiti has its own code and values that are distinct from other kinds of graffiti (Ferrell 1996; Gomez 1993). McAuliffe (2012:203) and Austin (2010) emphasized that illegal graffiti's "deviant claim" and its "critical/criminal positionality" has made it "easier to ignore or misrepresent...graffiti art's aesthetic..." by policies targeting graffiti. Gomez and others reiterate that conventional graffiti policies "fail to reduce graffiti vandalism because they fail to address, and... often purposefully ignore, the reasons behind graffiti vandalism" (1993:657). One may argue that to ignore the distinctions evident in artistic graffiti may result the grouping of this form of graffiti with other types of graffiti, placing all forms under the same 'master vandal' status. In policy design, this results in the application of uniform punitive policy features to hip hop graffiti as are assigned to other fear-inspiring graffiti, such as gang communications or hate speech, or other practices addressed by conventional “criminalizing” (Halsey and Young 2002) graffiti policy. 
The existence and popularity of alternative graffiti policy models suggests that artistic graffiti writing may be becoming more valued by society at large. The availability of positive outcomes for writers who pursue legal artistic graffiti alternatives raises the question of whether and how municipalities might implement such alternatives (Snyder 2016). Allowing graffiti walls independently or as additions to skate parks, or using writer and street artist talent for urban revitalization may further challenge the 'master vandal' status of all graffiti, and aid in a reconceptualization of hip hop graffiti as an artistic commodity that can boost creative cities potential (McAuliffe 2012).

\section{A Note on Legal Graffiti Policy Administration}

Alternative or "legal" graffiti policy models find origins in 1980s California, where legal venues were used as a policy feature to contain and regulate illegal graffiti. Singapore has recently reversed its conventional stance on graffiti, and research reminds us that neoliberal governance models have increasingly used legal graffiti to make an inherently and authentically illegal activity more docile, perhaps watering it down (Lombard 2013). Writers have accepted or resisted legal policy initiatives differently in various communities, and many Australian councils, despite recently embracing zero tolerance policy for graffiti, continued to use legal programs to surveil writers, while containing and shaping their practice (Lombard 2013). Many writers may as such be wary of legal initiatives and also certainly recognize that legality waters down the authenticity of illegality, the essence of hip hop graffiti. Nonetheless, writers often see legal walls as an opportunity to "get into" a piece more, to think as one goes, which is less possible if painting illegally (Lombard 2013). This research may advise that policymakers intent on making docile an illegal graffiti subculture through provision of legal venues may be discovered by writers who are already disinclined to reveal too much about their identities or to deligitimate graffiti by "selling out" or discontinuing illegal graffiti.

Some research importantly that found that, as graffiti writers "aged out" of doing illegal graffiti, they also strove to maintain a place within the subculture, often drifting between legitimate and illegal graffiti practices. Macdiarmid and Downing aptly noted,

"political and criminal justice agencies should develop a realistic understanding that graffiti is likely to remain resistant to even the most well intentioned efforts to transition it fully into the public, legal realm" (2012:616). 
It is in the spirit of awareness of this potential that facilitators of legal policy may be cautioned to not expect a transformation of graffiti writer cultural values, practices, or motivations in a direction toward legal practice, simply as a result of there being more "free walls" or legal venues. As writer Keep One stated in an interview with Brewer and Miller,

"This [having legal work] don't change nothing. Even with cash gigs, I'm still going to vandalize [paint illegally]. They [patrons, municipal authorities, and police] can't stop me" (1990:362).

This perhaps reiterates the important caveat that while it is possible that experienced writers may utilize legal spaces (perhaps producing quality graffiti and offering a forum for "younger" writers), policy makers should remain aware that they will not "convert" illegal writers to legal graffiti practices (Brewer 1992).

Furthermore, policymakers should heed other research, and ensure that any policy revisions are not considered too radical by other departments. Where this has been noted to have occurred, such policy designs were often non timplemented in practice, as councils had been convinced by police and others that legal initiatives would loosen restrictions too much (Halsey and Young 200writers.

To make achievable graffiti policy alternatives more evident, this analysis situates writer standpoints in the social order of dominant policy discourse and, to allow writer voices to be heard and their perspectives to be better understood. It is my intent that the results herein will aid in a reconceptualization of the unseen realities of graffiti to debunk some of the misunderstandings supporting improper theorizing of graffiti. Additionally, a goal of the current research is to open discussion with governance on graffiti policy alternatives that may be favorable to all stakeholders. 


\section{CHAPTER 4}

\section{RESEARCH METHODS}

\section{Geographical Location, Unit of Analysis, and Sample}

Most known studies of graffiti writing have taken place in large metropolitan areas, in cities including Sydney, Melbourne, New York, Denver, Los Angeles, Seattle, and others. The focal area under analysis in the current study is a mid-size Midwestern metropolitan area, which makes it unique to the list of cities where past studies of hip hop graffiti have been conducted. Some research has indicated that many graffiti writers in North America and parts of Latin America paint freight trains (Ferrell 1998, 2018). This "trainwriting" movement in graffiti has allowed crews to have members from multiple cities who do not necessarily paint together in the same location but can still represent a crew (Weide 2016: 36-37). Many graffiti writers interviewed in the current study have contacts and fellow crewmembers who paint cityscapes or trains in other locations, and thus crews and the larger graffiti subculture are more widely placed geographically, yet are still connected. Including the interviewees (23), focus group members (5), and observed writers, the sample totaled 31 writers (this equates to 28 , plus three who I observed who did not interview), and was primarily male (27 males, 3 females, and one non binary person) and white (28 white and 3 non-white). In terms of demographics, according to some research, today's graffiti subculture is largely a white and male dominated, yet is also often practiced by individuals of diverse ethnic and racial backgrounds (Bloch 2016a). Some emphasize that under acknowledged female writers compose a significant portion of an inherently male dominated modern graffiti subculture, and many have formed highly successful and cohesive networks, such as Few and Far, an all female street artist, gallery artist, and graffiti writer collective (Pabón 2016). Thus, the current study may offer results that are comparable to the larger population of North American graffiti writers and crews, though not necessarily generalizable to all cities and locations. 


\section{Sample Selection}

The current study utilizes semi-structured interview and participant observational data of a cohort of graffiti writers $(n=31)$ who face potential stigma due to graffiti’s illegality as constructed by written discourse. Additionally, the current analysis examines semi-structured interview data from policymakers and enforcers $(n=5)$ involved in the creation and enforcement of graffiti policy practices that deal with illegal graffiti. An expanded sample of graffiti writers for this study was best established by utilizing snowball sampling, a technique for recruiting research participants wherein one subject refers a researcher to another, who then refers another and so forth (Vogt 1999). Snowball sampling has been shown to be useful to the data gathering process in studies of stigmatized groups and individuals who engage in illegal activities (Heckathorn 1997, 2002) and has been utilized in studies of drug users (Avico et al. 1998;

Griffiths et al. 1993; Kaplan, Korf, and Sterk 1987) and male prostitutes (McNamara 1994). The snowball method of sampling was similarly well-suited to illegal graffiti writers, who are unlikely to be accessible through other means of sample selection.

Further, to gather a sizeable enough sample of graffiti writers for analysis required interviewing members of more than one graffiti crew, a semi-hierarchical group of graffiti writers having common interests, who collectively paint their shared "crew letters." Other research has revealed that crew membership tends to not be permanent, nor are members usually exclusive to a single crew (Ferrell 1996). For instance, in some cases a graffiti writer may represent several crews simultaneously, and they may stop representing one crew while still representing another (or others). To illustrate this, when one sees a "Norm" (the writer's name, "no one rules me") piece, they will notice that this writer would sometimes paint a piece (or throwup) containing his name in addition to one or more sets of crew letters adjacent to it, for instance, "AWR" and "MSK." Each of these sets of letters represents the names of the crews of which Norm was at that point a member. Alternately, one may notice another Norm piece with only one set of the above crew letters (i.e. only one set of the letters "MSK" or "AWR" such as in "Norm-AWR"). Snowball sampling from an initial key graffiti writer respondent and his close associates, whose members belong (mainly) to one graffiti crew, known as $\mathrm{STP}_{5}$ (one $\mathrm{STP}^{*}$ member now represents multiple crews), proved

5 All names given and references made to crews and graffiti writers are pseudonyms. This was an ethical decision that was made to protect individuals' identities. 
quite fruitful in recruiting other graffiti writers for study who were either members of other crews, or who were not affiliated with crews. Other research has indicated that some members of crews reside within the same city or area, while other members may reside and paint graffiti in the distant locations (Ferrell 2006). If research were to examine just one crew of graffiti writers living within one metropolitan area, such as the local graffiti crew recruited in the current study, the obtained sample size could turn out to be very small, perhaps only consisting of six research participants. In the interest of obtaining a sizeable sample, I accordingly conducted interviews and observations of members of several crews and of other graffiti writers who do not belong to crews. It is important to note the ephemeral nature of crew membership. Individuals I interviewed at one point in my research who represented a certain crew shortly thereafter became affiliated with another crew, and, at another point, multiple members of a crew dropped out of the crew in which they had been made members. As such, the current study started with members of STP* crew, which, during my research, had five to six known local members and nearly as many spread out in other areas. Later, as the snowball sample increased in size, I included other graffiti writers who were willing to participate in the study, independent of their crew affiliation. All in all, my interview and observational sample represents active writers from multiple crews (and several who are unaffiliated) who paint graffiti in the metropolitan area under study. This includes graffiti writers of various skill and experience levels, including some who are considered beginners, intermediate writers having between a year and a decade of experience, and advanced writers generally having more than ten years of experience.

\section{Gaining Entrée and Building Rapport}

Building trust and rapport in the field are essential to conducting successful qualitative research, particularly with stigmatized populations, for which snowball sampling is often the choice method of accessing research participants (Atkinson and Flint 2001). The sample utilized in this study developed slowly over time, and first required the cultivation of a unique initial friendship with one graffiti writer. This research project was ongoing from February 2017 to the summer months of 2020, and all interviews and observations were conducted when writers were available, at their choice of locations. Over the course of the research, many graffiti writers who I met tended to already know I was conducting research on graffiti, as often this might be mentioned to them ahead of time by other writers who introduced us. Other respondents were somewhat skittish and avoided contact with me altogether. For instance, one graffiti 
writer scheduled and rescheduled interviews with me several times after an initial observation, but eventually stopped all contact with me and avoided doing an interview altogether. Another writer completely ignored my request for an interview, and others expressed serious interest, but despite many reminders on my part, never ended up doing an interview.

Usually during a first or second encounter after meeting a writer, I tried to make known my intentions of doing research and asked them for consent to confidentially document details about our conversations and my observations. At the same time, I attempted to make tentative plans for future structured interviews, and many of these remain uncompleted. This recruiting process followed from a slowly developed friendship with key initial informant, Frede who I met in a local bar that I frequented during my first two semesters in graduate school. During these times, I would often shoot pool or sit at the bar to have a drink and eat while being entertained by the jovial young bartender named Alex, who often made introductions to newcomers and existing clients, doing everything possible to see that everyone had a good experience at the bar. After Alex one day introduced me to Frede, who was at that time one of the cooks at the establishment, I often sought out conversations when Frede finished work in the kitchen for the night and moved to the bar to drink, chat, or watch a sporting event on the multiple flat screen TVs affixed to the walls above and around the bar area. Frede and I quickly became friends, both being somewhat laid back types who enjoy cold beer, friendly conversation, and skateboarding, among other things. After several encounters and long conversations about skateboarding, extreme sports, and life in general with Frede, he had mentioned in passing that he was a graffiti writer, and he had once given me a small piece of paper entitled "Guest Check" on which he had sketched his "throwup" (a quick rendition of one's graffiti name designed to convey one's signature style to other graffiti writers and to gain renown as discussed in earlier chapters). "Sketching" is a part of the process of graffiti writing that constitutes the legal practice of the art, and usually sketches and hand-made stickers are shared with friends or traded with other graffiti writers (Ferrell 1996). Frede suggested I talk to some of his friends and members of his graffiti crew, known as "STP" or "STPK" (shorthand for "STP "Krew" where "STPK" could mean several things to graffiti writers in acronyms. STP's members had developed some hard-earned rapport with the larger population of graffiti writers, and is likely fairly comparable to some larger population of U.S. graffiti writers, especially in terms of the "code," or unspoken subcultural rules by which most graffiti writers 
operate (this includes places and situations in which it is thought acceptable to paint graffiti, avoiding cemeteries and places of worship, small businesses and personal property, and so on) (Ferrell 1996; Halsey and Young 2002).

After an initial focus group interview with four STP crew members, which I conducted one night while they were writing inside an abandoned warehouse, I was pleased to discover that the group would help me network with other writers to obtain a larger sample for my research. The crew leader indicated that he and other STP members would introduce me to 12 or more other graffiti writers, which consists of members of STP and other crews who are "free agent" writers with no crew affiliation. What I was not aware of at this time is that I would ultimately spend several months "proving myself" and gaining the trust of a few STP graffiti writers before I would be introduced to others in the metropolitan area. As this process has ensued, I spent many hours "following" Frede and sometimes his girlfriend on late night excursions into the less prosperous sections of the city where thriving factories and industrial businesses comingle with the inherent poverty evident in the abundance of liquor stores, abandoned industrial complexes, pawn shops, and modest single family homes. These parts of the city, where a large volume of the illegal graffiti observed in the current study often was done, may be particularly well-suited to doing graffiti due to a lack of the usual means of social control and fixtures of suburbia and city centers. These areas often have a dearth of grocery stores, retail outlets, or other community resources and signs of urban development. In their place are well paved networks of streets adjacent to interstate routes, often uniformly clean rows of fenced front yards lining alternating single level "shotgun" style houses, punctuated on every few blocks or so by either small businesses, churches, occasional shopping centers or fast food, and evidently abandoned industrial buildings or complexes of them towering over street corners with sections of roofing and upper levels slowly falling into overgrown and empty lots alongside busy railroad lines.

These are prime outlets and galleries where graffiti writers looking for a place to leave their mark often venture.

For pragmatic purposes, my role in outings often was to be a "lookout" for the many dangers one might encounter in such impoverished city areas at night, including hostile dogs, sharp and unkempt foliage, stray barbed wire from fences, used syringes, broken glass and spilled garbage, roaming gangbangers, concerned citizens, and patrolling police cars. I soon found that this experience of being a 
lookout may have garnered for me both the confidence of the graffiti community and an integral role shift from that of relative outsider to one of integral member (See also Adler and Adler 1987 on "Research Membership Status").

In addition to following graffiti writers on painting sessions, I often purchased beer, paint, cigars, and cigarettes that I shared with graffiti writers who allowed me a chance to interview them and observe them painting. I also initially enticed graffiti writers to participate in my research by offering them two (or more) cans of premium "Montana 94" brand spray paint, only available in specialty and art stores, or in some cases cheaper "go to" Rustoleum spray paint, which is widely available at most retailers and hardware stores. Also, to gain trust, in the early stages of my research, I spent countless hours alone exploring a well-known abandoned warehouse complex that was slated for demolition, and often walked railroad tracks or waited by stoplines (places where freight trains regularly stop, usually in proximity to train yards), extensively photographing every instance of graffiti I could find. This amounted to accumulating over 300 photographs of graffiti tags, throwups, and pieces that I posted to a social media account visible to many local (and distant) graffiti writers who "followed" my profile. These early actions further generated rapport and conversation with other graffiti writers, and helped me to make new contacts in the graffiti community on my own. Gaining entrée with graffiti writers and earning their trust has required substantial time and pecuniary investment on my part, as well as demanding extreme flexibility and a willingness to spend long hours remaining open to research opportunities, which sometimes came on short notice and at all times of the day and night.

\section{Researcher Membership Status and Criminological Verstehen}

In terms of obtaining a sense of "criminological verstehen" in ethnographic research, Ferrell notes that criminologists need to get as close to the studied phenomena and subculture as possible, to be able to understand the meaning of crime (1997) To obtain this level of understanding during graffiti outings, and often for pragmatic purposes, at first I was sometimes asked to be a "lookout" for passing citizens, police, or city workers who may alert police to graffiti activity. While being a lookout sometimes occurred in a "taking turns" format between writers, this role was primarily assigned to me while conducting observations, and after having done so several times, I began volunteering. Being an "extra" body on graffiti outings, I also was often asked to carry supplies, handle cans or other implements while other 
writers were engaged in painting. In some cases, I assisted in painting graffiti. This has given me a deeper understanding and sense of the experience that I may not have been able to grasp if passively standing by and taking notes.

Being a long-time skateboarder and having several friends who are graffiti writers, I entered into my research already having a membership status in the skateboarding subculture that could be described as "active member" (Adler and Adler 1987), and this initially gave me some status in the graffiti community. Convenient to my doing graffiti research, skateboarding and hip hop graffiti subcultures have definite areas of overlap, as many graffiti writers are also skateboarders (Ferrell 1996). In the sense that my personal interests in skateboarding are shared with many graffiti writers, my entrée with the subculture expanded as I connected with several graffiti writers who are skateboarders. As such, my active member status in the skateboarder subculture (a status designated as one of a functional or integral role to the community initially coincided with having a "peripheral member" status (Adler and Adler 1987) of partial involvement in the graffiti subculture, mainly in terms of regular interaction with active members of this community, particularly given my ongoing friendship and regular "lookout" role with initial research participants. "Joining in" when requested (helping to do individual paintings) was often necessary and helped to maintain the trust and rapport with writers. This trust with writers grew over time, and I eventually obtained "active member" status (one who is frequently involved in the activity under study) (See also Adler and Adler 1987) in the graffiti subculture. Because of my observations becoming more frequent and involved, I became somewhat independently active in the photographing and posting of graffiti on social media, which furthered my rapport and preserved my membership status and was able to speak with writers through a digital platform, some of whom I later met. While more complete involvement in the activity under study may bring one closer to a sense of criminological verstehen (Ferrell 1997) (and standpoint; See also Smith 1987, 2005, 2006), it may serve to help in avoiding the "othering" the activity or its participants, which some argue occurs in policy (McAuliffe 2012). Participating in practices on which research is centered may to some extent bias this research, and I more fully address this in the limitations in the final chapter.

\section{Optional IRB Consent and Confidentiality}

For implied consent of research participants, I requested and was granted a waiver with the University of Louisville's Institutional Review Board (IRB), since concealing names and identities of 
subjects is of key priority due to the illegal aspects of graffiti writing. Graffiti is usually prosecuted as vandalism defined as criminal mischief (misdemeanor or felony) or trespassing (See Ferrell 1996, Halsey and Young 2006). In lieu of requesting such written consent of research participants, and to avoid producing a paper trail of names and identities, I requested that research participants simply provide verbal consent to recorded interviews (emphasizing that giving real names be avoided in dialogues), as well as in reporting dialogues recorded in conversational interviews and observations. Research participants were offered an optional consent release form (See APPENDIX B) prior to using direct quotations or photographs of them engaged in any research related activity, with emphasis on the notion that I do not use legal identities or "tag" names (graffiti names) in any published work, in order to preserve all respondents' confidentiality.

In addition, I was granted a consent for city policymakers and enforcers who I interviewed, and I provided this form to each of these individuals who consented to an interview. For reasons of maintaining the confidentiality of graffiti writers, I also made confidential the location of the city under study, and correspondingly I used job titles to refer to all city personnel whose comments I used in the Findings and Discussion and Conclusions chapters that follow.

\section{Data Collection}

During the approximately three years of research on hip hop graffiti, which began in February 2017, there were some time periods in which I have spent only 8 hours per month with graffiti writers, and other times about 40 hours in a given month, in unstructured recreational activities, conversations, interviews, and participant observations with graffiti writers. At other times, I did not spend any significant time with graffiti writers for periods of between 4 to 6 weeks. This lack of interaction resulted from numerous things, including individuals leaving town on vacation, being busy during holidays, or having increased work hours or other constraints. I devoted upwards of 200 hours to doing observations, semistructured interviews, conversational interviews, and unstructured recreational activities with graffiti writers, and approximately 80 hours doing solitary graffiti-related activities, either looking at social media posts of research participants and non-participants, painting at legal walls or other locations, or in doing "sketching" at home and using social media to post my photographs of graffiti on walls, trains, or other structures. 


\section{Participant Observation of Graffiti Writing and "Naturalistic" Observation}

Observations of individuals in their "naturalistic environment" have proven to be appropriate in conducting qualitative research on stigmatized populations (Bot, Engels, and Knibbe 2005). This method maintains principles of naturalistic, (or "constructivist") inquiry and foregoes the examination of tangible research variables used in quantitative models to locate important social constructions of subjects that are evident in daily life activity. Such social constructions reveal sense-making and meaning-making that occur as a result of interactions with other individuals and institutional processes that may not be evident in experimental and positivist modes of inquiry. As such, these largely hidden aspects of daily experience may offer deeper meaning to research on human subjects (Lincoln 2017). Participant observations of graffiti painting and other activities occur in the naturalistic environment of writers, in locations of their choosing. I believe that using participant observations of graffiti writers in their naturalistic environment, doing illegal graffiti, in concert with semi-structured interviews in concert with conversational interviews provides a deeper and more comprehensive source of data for analysis than simply conducting interviews alone. Conversational interviewing is a legitimate research method in qualitative research and other research argues for using multiple methodologies in institutional ethnography (Taber 2010).

Participant observations were based on opportunity, as some interviewees were not available for my observing them doing graffiti, and similarly, not all those willing to be observed were available for interviews. The participant observational process in this study gathers details on graffiti writing sessions and conversations taking place in the painting of graffiti, and in related unstructured social activities, such as "hanging out" at pizzerias, cafes, other restaurants, art stores, graffiti events, art galleries, homes of graffiti writers, my own apartment, and other locations wherein meetings with graffiti writers were arranged. Choice of such locations tended to occur in an ad-hoc fashion (Ferrell 1996), as the decision regarding a "spot" (or painting location) is often a process subject to unanticipated changes due to variables including unexpected police presence, random citizens' presence, inclement weather, other graffiti writers having already (excessively) painted a spot, mood change of graffiti writers, or various other reasons. As such, I maintained a reflexive research posture, to "go with the flow" and allow the research process to unfold and offer unexpected opportunities and findings, a research methodology referred to as "gonzo sociology" (Wozniak 2014). This reflexive approach carries the potential to capture findings often 
unobtainable in rigidly-structured methodologies and offered a wellspring of information from writers that I might not have otherwise obtained. Accordingly, sometimes I asked permission to audio record specific details of observations and associated conversations, which I later transcribed via word processor for storage and analysis. Taking "jottings" and field notes are useful methods to ethnographic and, particularly, participant observational studies (Emerson, Fretz, and Shaw 2011), and have been beneficial in my own data gathering process. Both methods were utilized in my research.

All in all, I interviewed 27 writers and actively observed 30 or more engaged in painting graffiti, with several interviewees being current or past members of the initially interviewed "STP" crew, and another 20 percent from another crew. The remainder of those observed were affiliated with other crews (roughly 48 percent), with some being "free agents" not affiliated with any (12 percent) crew. About 90 percent of "observed" writers are male, 10 percent female, 97 percent white, and 3 percent Native American. Ages ranged between 18 to over 40 years old. Most writers reported having grown up in working class or middle class families, and a few came from wealthy neighborhoods.

\section{Interviews}

The legal barriers to doing illegal hip hop graffiti usually prevent researchers from conducting a deep and thorough exploration of the subculture, and the illegality of graffiti may make graffiti writers suspicious of researchers and other outsiders (Ferrell 1996; Halsey and Young 2002, 2006). As such, the topic remains only lightly explored in academia and is lacking in consistent theoretical development. With this state of affairs, survey research proves nearly impossible, as obtaining a willing sample of research participants is limited in terms of access. For this reason, the current study originates in the ethnographic methodological tradition, utilizing details from participant observation, semi-structured personal interviews, and conversational interviews done during observations to obtain a deeper understanding of motives and standpoint of illegal graffiti writers. One may, out of a sense of orthodoxy, construct a research agenda having some questions in mind ahead of time, and it may be the case in partially explored or unexplored subject areas that one does not have a clear idea of what those questions are, aside from starting from the unknown and seeking a general exploration and explanation. Sociologists engaged in qualitative studies involving participant observation and interviews must find theoretical meanings ahead of time, but 
inevitably may only identify research questions during the research process (Becker 1958:652; Smith 1987, 2006). It is this position in which I have found myself in the current study.

With a limited body of extant research on graffiti, I explored the motivations for taking the high risks involved in illegal hip hop graffiti, the social organization of the subculture, practitioners' notions of style and other subcultural values, and perceptions and attitudes toward both the illegality of and social opposition to graffiti. Unlike in quantitative studies where researchers typically test pre-conceived hypotheses based on theory and previous research, questions framed from an institutional ethnographical approach take shape during ongoing research, and this is particularly the case in many ethnographic studies (Fetterman 2010). Institutional ethnography begins by fixating upon the daily experiences of excluded and oppressed populations under study, and later scrutinizes key institutional interrelations involved in the process of disenfranchisement. Smith affirmed this in stating that institutional ethnography is not about studying institutions starting from theory. Instead, it explores from the daily experiences of research participants the social and institutional relations affecting individuals, where such governing relations are not directly visible to those who are studied (1987: 2; 2005:1). The institutional ethnographic approach utilized herein similarly seeks to reveal the standpoint of graffiti writers by starting in their routine experiences (Smith 2006:6-7; See also Diamond 2006 and Campbell 2006).

Semi-structured interview questions asked of graffiti writers sought specific information to reveal both standpoint and theoretical connections with the graffiti writing experience, and these questions were both directed and open-ended in format, using emergent probes that arose as answers to the questions were given by research participants. Individualized interviewing often is a superior method over surveys and other non-qualitative methods for gleaning detailed responses from non-random samples of research participants (Charmaz 2006), while probing questions can aid in permitting unanticipated questions to be answered and allowing for a deeper understanding and affirmation of answers. This said, and to keep with the protocol of institutional ethnography (See Smith 1987, 2005, 2006), I began the research process in observing practitioners engaged in their naturalistic environment, as discussed in the previous section, and, given the opportunity to both observe and interview individual graffiti writers, I continued to likewise conduct participant observations prior to semi-structured interviews, if possible, as this having an initial contact through observation sometimes has served to "break the ice" and better facilitate the interview 
process. Preliminary observations also aided the development of the graffiti writer interview guide (See APPENDIX A), based on initial observations and conversational interviews of graffiti writers, and semistructured interview questions often occurred to me based somewhat on events and aspects of participant observations. Additionally, 4 focus group sessions helped me to better direct interview questions I conducted and documented 23 semi-structured interviews and four focus group interviews with graffiti writers. Focus group interviews were carried out with subjects chosen based on the blanket criteria of being 18 or older, and that they actively engaged in writing (also criteria for respondent participation in semi-structured interviews and observations). In recruiting for interviewing and participant observations, I did not pre-screen for experience levels, as it was anticipated that I would be limited in the number of graffiti writers who would be willing to do interviews or permit my observations. Additionally, there is likely a finite number of graffiti writers from which to sample within the metropolitan area selected for study. All interviews were initially stored on an audio recording device and later transcribed, with recordings deleted.

Focus group interviews (which were discontinued in the study at the advice of dissertation committee members) were similarly recorded and stored on an audio recording device and conducted either in the homes of graffiti writers, or at my apartment. Using focus groups is a supplementary interviewing method frequently utilized in multimethod qualitative research and offers benefits to the research process by both encouraging interactive dialogues among interviewees and by generating preliminary data supplementary to participant observation and interviews (Morgan 1997). Generally, in focus groups, I asked research participants to describe their early experiences in graffiti writing, what initially attracted them to graffiti, benefits they obtain from doing graffiti, what motivates them to do illegal graffiti, ideas about potential negative aspects of graffiti, and views on graffiti's illegality and society's reactions to it (See also APPENDIX A). This has proven beneficial in devising semi-structured and conversational interview questions for graffiti writers, as well as in generating questions for semi-structured interviews with policymakers and enforcers (discussed below), according to emergent themes from my analysis of focus group data.

All graffiti writers interviewed in focus groups and semi-structured interviews were encouraged to (and did) make themselves comfortable, often relaxing and drinking beer (which I usually provided), and 
eating pizza or tacos (which I usually cooked or purchased myself). Very often during these interviews, subjects selected music or graffiti videos or sketched graffiti while we spoke.

Interview guide questions assessed the extent of graffiti writers' current and past experiences, preferences for types of environments in which they prefer to paint, whether they are in crews, what their motives are for doing graffiti, whether they have been caught painting graffiti (and details about those experiences), thrill and other benefits they experience from graffiti, their perceptions of why graffiti is illegal or opposed by society-at-large, and their preferences for social policies dealing with graffiti (See APPENDIX A - INTERVIEW GUIDE - GRAFFITI WRITERS). These questions were designed to also assess illegal graffiti writing for aspects of serious leisure and potential for career or income, edgework and practice directed toward experiential benefits as an alternative to alienation, deviant leisure as an alternative leisure practice, and standpoint in terms of written discourse and other institutional constraint.

To keep with the principles of institutional ethnography (Smith 1987), it is necessary to also study the institutions and written discourses involved in the experience of an oppressed population. In order to do so it was useful for grounded theoretical analysis to conduct interviews with key informants involved in these institutional processes and discourses. Sampling key informants is an appropriate and established method in achieving validity within qualitative research studies. (Charmaz 2006; John and Reeve 1982). For this reason, I constructed an interview guide for key officials who were involved with graffiti policy $(n l=5)$, including a city council member, a special projects coordinator for the mayor's office who had been a former parks department administrator, a private individual who started a non-profit graffiti eradication coalition, a director of codes and regulations in charge of the city's two-person graffiti abatement crew, and an arts administrator, also part of the city. I wanted to interview the city mayor, but after an original appointment was made and cancelled, this failed, despite numerous attempts to reschedule. All of the interviewed officials (elsewhere referred to as 'city personnel' or 'policymakers and enforcers') had some part in enforcing policy practices and ordinance related to dealing with legal or illegal graffiti (See APPENDIX E). The interview guide utilized with policy officials provided a deeper understanding of the institutional relations and written discourses that directly shape the standpoints and experiences of illegal graffiti writers. Additionally, and to facilitate the aforementioned task, I also examined the metropolitan 
ordinance (available on the city government website) that is enforced within graffiti policy practices discussed by city personnel whom I interviewed.

\section{Data Analysis}

Grounded analytic research requires intensive comparison of all collected forms of data to highlight repeating themes and patterns and determine when a level of saturation is established in thematic findings (Charmaz 2006; Glaser and Strauss 1967). This study examines audio data from four structured focus group interviews $\left(\mathrm{n}_{1}=5\right)$, semi-structured individual interviews $\left(\mathrm{n}_{2}=23\right)$ and conversational interviews from participant observations of graffiti writing and related unstructured socializing, as well as field notes documenting the latter scenarios (200 hours). (See APPENDICES A and E for IRB-approved interview and focus group questions). These data were then examined against transcribed audio data gleaned from the previously-discussed interviews with city policymakers and enforcers. Participant observational data consist of hand-written field notes of descriptions of said activities, as well as of field notes of direct quotations gathered during these observed painting events, "benching (photographing train graffiti), 6 " and other activities that entail graffiti writers' daily experiences. All notes, recordings, and written descriptions were transcribed shortly after collection in an ongoing basis. The data gathering process was discontinued once it was determined that saturation (or lack of difference in response data) had been reached among the data collected from different research participants, when emergent patterns and themes coded from these data tended to converge.

The process of grounded analytical data analysis used in this study examines field notes collected via audio recording with personal notes and field jottings documented. Recorded and transcribed interview data are compared with supplementary written notes taken during interviews that capture non-verbal and other cues from different interviewees. These data were hand-coded for emergent patterns and themes and in turn were compared for any relationships between data themes from different graffiti writer respondents and those from different interviews of city officials, for which the same coding and theme and pattern identification were used. Emergent patterns and themes obtained from graffiti writer participant observations, interviews, and conversational data were "triangulated" (or cross-checked) for validity

6 "Benching" is a graffiti writer term for photographing train graffiti as new lines go into or out of the chosen or preferred benching location (See APPENDIX F ) 
against patterns and themes in data from interviews with city officials, noting any relationships to the experiences of graffiti writers, to situate the standpoints of graffiti writers within the written laws and policies of the metropolitan area against the rationales of authorities for these policies and practices. Once any consistencies were noted between gathered data and theoretical elements, the most relevant points were used to develop a case for whether and to what degree the data are consistent (or inconsistent) with theory in terms of elements of serious leisure, deviant leisure, and edgework, and how institutional relationships and discourses discovered in research are thought to influence the actions or experiences of graffiti writers. It appeared that graffiti writing was supported by several serious leisure practices that supported an end goal of illegal graffiti in mind. Additionally, graffiti practices associated with skilled writers emerged as a separate form of serious leisure hobbyism directed at an end goal of earning money while increasing their legitimate artistic reputation. All notable conclusions and support for other research are discussed in greater detail in later sections.

\section{Data Storage}

The illegality of graffiti activities carries legal implications for gathered data and the identities of graffiti writers falling into the wrong hands (i.e. legal authorities or the public), and this highlights an utmost priority for preserving research participants' confidentiality. As such, all transcripts, notes, and informational data were preserved in encrypted digital storage, via two-factor authentication, and all recordings were deleted following transcription. These transcripts were stored under lock and key in a bank safe deposit box at an undisclosed location, as has been safely done in past immersive ethnographic research on graffiti writing (Ferrell 1996). As an added precaution, initial interviewing where audio records were obtained occurred in private locations at the consent of research participants, and mentioned, observations occurred in naturalistic environments, which in theory relied on the experience of graffiti writers to select such locations for observations that I was permitted to see. Field notes and photographs7 obtained during observations of graffiti activities were secured via encrypted storage and any copies kept in safe deposit storage along with interview transcripts.

7 Photographs throughout this document do not to contain faces of individuals in the context of doing illegal graffiti, nor do they connect individuals or their identities in any way to illegal activities. Extra care was taken to not utilize pictures obtained during observations that included tags, or "signatures," of sample writers or their crew letters. This was done with an express interest in avoid identifying to outsiders the identities of writers or crews who participated in this research. 


\section{Insider Research Focus}

Some may argue that the current study stands the risk of bias as a result of my immersive methodology and closeness to the processes and practitioners of illegal graffiti, particularly in my serving as a lookout and otherwise aiding in the production of illegal graffiti. I would counter this by saying that due to sampling limitations and access to a criminal subculture, it was necessary for me to place myself as closely as possible to the subject matter and activities. Furthermore, demonstrating my trustworthiness was necessary to encourage writers to include me and share with me the great depth of information and experiences to which I was made a party. It is my belief that in comparison to many past studies, the immersive nature of the current study methodology granted me much greater access and closer proximity to the graffiti subculture and writer experience.

Becoming deeply involved in graffiti research is more than just doing passive observations and formally conducting interviews. I was informed early on, by both graffiti writers and experienced researchers with whom I spoke, that I should become involved in graffiti in no limited way, even trying to do some graffiti myself, in order to fully know and understand the experience. Though this may bias my research, I have, at first reluctantly, and later more freely, acquiesced to this advice, and I have begun an artistic experience of my own, which is not central to discussion beyond my presence as a researcher. I believe this has improved my understanding of and sensitivity to the intricacies presented in my data and research, to some degree prevented "othering” with writers, and it also helped me to garner deeper levels of trust, respect, and rapport with members of the graffiti community under study. Gagné and Austin (2010) noted that being fully involved in riding motorcycles and touring themselves enhanced their acceptance by other riders who they interviewed in research settings. My efforts as a researcher remained open to the capacity for deep involvement, acknowledging the notion that a key goal of qualitative research is in engaging in the process of informed subjectivity, as opposed to that of objectivity.

\section{The Research Process and Edgework}

In addition to the expanded trust and rapport and deeper understanding concerning graffiti, which I have gleaned as a result of being an interviewer, participant, and observer of graffiti writing, I have taken significant risks as a researcher. In the process of weathering these risks, to go along on outings, and to learn what it is like to do a graffiti, I have overcome many fears and become more "street savvy" in ways 
that I previously was not aware were possible. For instance, to do graffiti, or to even to be a lookout, at first was extremely difficult and fear-invoking, largely due to internalized and preconceived notions about being seen, police and bystander practices, and due to what I (somewhat incorrectly) perceived as a ubiquitous police presence. I have learned firsthand and through informal conversations with citizens and graffiti writers, that most people are not "on the alert" for illegal graffiti activity, most police officers are either not present or are perhaps engaged in policing more serious crimes, and that of the people who do observe others in the act of illegal graffiti, few are willing to confront or chase graffiti writers, or to report them to authorities. Nonetheless, there is the constant and ever real possibility of detection and prosecution (or other harm) to those engaged in graffiti writing (and potentially for those who accompany graffiti writers for research or other purposes, such as being a lookout) (Ferrell 1996). It is for this reason that, as a researcher, I have, from the very first observation, been cautiously aware of and subject to these risks while traversing inner city areas, abandoned industrial and residential structures, highway walls, train yards, and dangerous streets where illegal graffiti is usually done. For these and other reasons, one of my research goals was constructed to identify aspects of illegal graffiti that may highlight that it is a form of serious and deviant leisure and edgework, through ongoing practice and skill development, navigating serious risk, and experience of thrill and experiential benefits.

\section{Research Questions}

As was stated before, I utilized an analytic inductive approach to evaluate data, and began this process with initial exploratory observations and interviews. As is commonly done in ethnography, I allowed for research questions to emerge during in process of doing the actual research. As the research unfolded, it became obvious that there is great importance for policymakers and enforcers to know why graffiti writers do what they do in navigating imminent risk in the face of social opposition and the certainty of legal and other repercussions. Additionally, it has become clear that public and institutional audiences may benefit from increased knowledge about the social_organization of graffiti subculture, writer values, perceptions of and attitudes toward illegality and social opposition, and the nuances in practices and motivations of writers of different experience levels. On the policy side of this analysis, it is it is crucial to assess policymaker understandings of graffiti, what forms they most prioritize in removal, and areas for 
potential redesign of policy and discourses concerning graffiti. To address these matters, I pose the following research questions.

1. What is the nature of municipal policymaker standpoints in practices and preferences toward hip hop graffiti and their understandings and views of the subculture?

2. What are writer views, subcultural values, and practices (i.e. standpoints), and their perceptions of social opposition to their pursuits?

3. How does graffiti take form as edgework, leisure, or protest?

4. How do current findings contribute to other research, and what are the policy implications?

5. How can policy officials, publics, and writers benefit from a deeper understanding of hip hop graffiti practices, subcultural values, and the forms that artistic graffiti takes?

To answer these questions, in the next chapter, I discuss significant findings from the interviews I completed with key policy officials and from participant observations, interviews, and focus groups conducted with sample graffiti writers. 


\section{CHAPTER 5}

\section{FINDINGS (PART I)}

\section{Overview: Research on Policy Officials and Written Discourse}

In this chapter, I will present themes and patterns from findings from policy officials' interviews and an examination of written discourse, noting significant contributions to other literature and research. I first present data from the policy side of the current research to assess the ways that written discourse and policy practices construct (and deal with) hip hop graffiti and thus reveal the standpoints of city officials. I suspect that the policy viewpoint of graffiti most closely resembles the general understanding of hip hop graffiti held by most outsiders and non-writers. At the least, it is possible that this conception of graffiti is the one that is most publicly visible. Thus, I believe that presenting the policy standpoint and written discourse first will later accommodate the reader's understanding of the writer standpoint by describing the policy perspective as a frame of reference.. Due to the richness of the data obtained from both samples, the next chapter will separately explore the findings that emerged from semi-structured interviews, focus groups, and participant observations with graffiti writers. In the final chapter I will discuss conclusions based on findings from the current chapter and the next one, highlighting features that are significant to the extant literature and theory to offer potential directions for future research and for revising graffiti policy. Before introducing these findings and others, I first offer a brief revisit to the theoretical framework utilized in this research study.

\section{Theoretical Framework Revisited: Graffiti, Serious Leisure, RST, Edgework, and Policy}

The current theoretical framework was devised to capture the realities of hip hop graffiti writers and their subculture according to related trends in the literature, and the methodology was selected to situate writer standpoints within the institutional order as apparent in policy practices and the written discourse. Thus, describing how daily constraints originating in the policy discourse affect and are 
navigated by graffiti writers (and the ways that graffiti is managed by those who create or administer policy) is a key task to my research. Another goal is to reveal ways that the experiences and practices of writers align with or add to the extant literature and theoretical and conceptual models of edgework, recreational specialization theory, dark leisure, and the serious leisure perspective. To identify these contributions may provide for a deeper understanding of graffiti and writers for policy officials, publics and other stakeholders, and to offer an evidence-based rationale by which policy may efficiently deal with graffiti.

The edgework theoretical perspective posits that there is a real or imaginary "edge" between extremes that edgeworkers deliberately navigate via risky activity and the deployment of specific skills accumulated in practice (Lyng 1990; 2005). Additionally, research explores the ways that edgeworkers increase risk and maximize other benefits from the experience. Lyng's early work posited that edgework offers one a reflexive personal opportunity in "experiential anarchy" (acting in direct contrast to the normalized and ordered habitus of over-socialized post-industrial lifestyles). As recreation, edgework allows practitioners to obtain tangible benefits of thrill, sense of accomplishment, flow, and identity formation by means of the refinement of skills missing from an alienated and largely consumption and service-based modern economy $(1990 ; 2005)$.

The serious leisure perspective posits that, compared to work, leisure activity is becoming an increasingly more prominent way to achieve personal satisfaction where the modern work experience fails to do so (Stebbins 1982). As well, practitioners of serious leisure obtain many personal and experiential benefits (Stebbins 1982), including “flow” (Csikszentmihalyi 1990). Additionally, classic RST theory predicts that different practices and values occur as one "progresses" through a spectrum of skill levels in various forms of recreation (Bryan 1977; Bryan 2008). I will argue that graffiti writing can be conceptualized as a deviant or "dark" form of serious leisure driven by varying motivations according to practitioner levels of experience and skill corresponding to different values, practices, motivations, and benefits. While recreational specialization theory posits that different practices and values occur within a 'spectrum' of skill level and experience within leisure practice, "progression" may occur differently than predicted. Notably, "progression” occurs sometimes in a forward direction of advancement (Bryan 1977, 
2008), but at other times neither progression nor associated leisure identity formation occur (Kuentzel and Heberlein 2006; Oh et al. 2010). As I will argue, the separate ways that practices are arranged within graffiti according to experience level appear to model a "career trajectory" that leads from quantityoriented illegal "bombing" as edgework experience to later earning status and fame. Eventually, writers may significantly improve their artistic abilities, expanding their circle of friends and perhaps eventually securing legal work and paid opportunities using their graffiti talents. This latter professional feature is common in serious leisure amateurism, but in graffiti, this capacity only appears to occur with increasing levels of experience for graffiti writers. Stated differently, in earlier stages, the writer experience involves frequent illegal expression and varying levels of risk; later, practice shifts toward serious leisure hobbyism, and (sometimes) amateurism, with a greater focus on other benefits from writing, while maintaining dark leisure practices, such as tagging.

Based on the current data, at any point in one's graffiti 'career' (an in vivo code designated by writers as the course of time over which one writes graffiti), particularly in the earlier and intermediate stages, practice may take form as edgework. This occurs through regularly creating illegal displays of one's graffiti name, thus establishing one's criminal and artistic reputation in the vein of Mailer's and Naar's notion of the name as "the faith in graffiti" (1974). After recognition is earned from other writers, writing may be done to self-renew or for meditation or peace obtained through practice, or as sometimes is the case, as a legal means to earn money. Generally, all writers reported having painted in terms of some level of response to some alienation or contention with societal values or personal life circumstances.8 I will later highlight the ways that recreation specialization can be used as a guide in distinguishing how beginner to advanced level graffiti practices occur differently, where graffiti can occur both as edgework, deviantserious leisure, and serious leisure amateurism. Additionally, the overlap between designations of criminal and non-criminal forms of tolerable and intolerable deviant leisure forms may offer a better conceptualization of the forms of hip hop graffiti as distinct types of deviant leisure when considered in its separate treatments by policy (e.g. legal versus illegal) (See also Williams and Walker 2010). It is also

${ }_{8}$ See also Lyng (1990) on the Marxian-Median edgework perspective where social psychological experiential benefits gained from spontaneous edgework expression redress the alienation commonly experienced from largely over-rationalized modern lifestyles. 
important to also note Becker's (1963) early research on deviant careers and socialization that occurred for newcomers who had to "learn" to experience the benefits of marijuana (in order to persist); a similar learning may occur for graffiti writers.

Research on urban graffiti and crime policy has shown that municipalities favor standard policy practices of deterrence and removal that include abatement, "hardening the target" (i.e. installing deterrent measures), and increasing penalties to writers. As well, practices justified in "broken windows" reasoning are the most common (and least successful) responses to graffiti (Ross 2016). Additionally, since the 9/11 terrorist attacks, police departments have become more militarized in efforts to maintain order in public space and communities, while municipalities often conduct "wars on graffiti" that attempt to control and regulate public space by using surveillance and "constant vigilance (and resources)" (Iveson 2010:124). Other research has noted public reward programs for reports leading to apprehension of writers and augmented surveillance and increased overt and clandestine police operations sometimes using undercover informants (Ferrell 1996; McAuliffe 2012). Thus, to many, the process of graffiti writing and abatement occur simultaneously within a "moral geography" where control of public space and norms for appropriate uses thereof occurs between dominant power structures and graffiti writers (or other criminalized groups) (McAuliffe 2012; Smith 1997). Perhaps speaking to the interplay between writers and authorities (and the extreme efforts and resources engaged by each) is a well-known incident discussed by Iveson (2010) where federal stimulus money was funded for an $\$ 800,000$ contract in the 2009 removal of football field-sized piece by Saber-AWR along the Los Angeles River (See also Iveson 2010:124-125). Despite persistent reactions such as this one by "the buff," many writers continue to create large feats of illegal graffiti, resisting and (usually) eluding the apprehension of police or other authorities.

Stricter penalties and increased police action in graffiti policy are traditionally accompanied by regular abatement practices (Mailer and Naar 1974; McAuliffe 2012). As I will argue later, relying too heavily on "criminalizing" policy (See also Halsey and Young 2002) may serve to punish the occasionallycaught offender, sometimes making them more savvy. This was the case with a writer forced to abate his work who went back to teach other writers how to adjust their practices to better avoid abatement. At the same time, where policy is constructed in such a manner focused on fines, incarceration, or reparation, 
community members and other stakeholders may continue to be left out of the justice process. Meanwhile, victims of vandalism may be forced to pay for abatement or fines. In such cases, alternative or restorative justice measures may be considered in justice policy, and more legal options may be simultaneously or alternately considered for graffiti writers, as was expressed as a policy preference of writers interviewed in other research (Brewer and Miller 1990; Brewer 1992; McAuliffe 2012). Policy alternatives may show more promise for deterring illegal hip hop graffiti than standard and conventional policy practices, which tend to dedicate resources and funds to "chase" graffiti to other areas or perpetuate repeated graffiti in “quicker” forms where abatement efforts are focused (Haworth, Bruce, and Iveson 2013). Cases of successful implementations of alternative graffiti programs are evident in some Australian studies, as well as in practice since the 1980s in California, where a writer was not considered a real writer unless they also painted legal spaces (Brewer 1992). As I will further discuss, many writers and policy officials in the current sample favor alternative ("legal") policy.

As was established, "moral entrepreneurs" (Becker 1963) often use fear in the media construction of social problem to influence public opinion and mobilize public audiences to address it. For instance, increasing media focus on an issue or presenting it to the in such a way as to blur public understandings of the problem to send the message that hip hop graffiti represents a gang presence (Ferrell 1996). Notably, drawing increased attention to issues, such as graffiti, through moral entrepreneurship and moral panic campaigns often fails to decrease (or may increase) a targeted behavior (Ferrell et al. 2014). This was the case in both research on graffiti abatement (Haworth, Bruce, and Iveson 2013) and in research that examined anti-graffiti campaigns (Ferrell 1996). Studies indicate that "engagement” policies (McAuliffe 2012), essentially what Halsey and Young (2002:178) characterize as "acceptance" policy--such as in the enlistment of writer talent for public murals, or in sanctioning of properly-managed "legal walls" (decriminalized spaces for graffiti), may decrease nearby illegal graffiti vandalism where muralism and hotspot abatement fails to adequately do so (Haworth et al. 2013

Significant connections to theory and literature in the current findings will be revisited in the final chapter to highlight features of results that contribute to the literature and offer directions for graffiti and 
policy research and conventional policy alternatives. Below, I present emergent themes from the current analysis, first from an examination of graffiti ordinance and then from interviews with city policy officials.

\section{Summary of Findings from Graffiti Ordinance and Interviews with Policy Officials}

Several noteworthy findings emerged from the written discourse as framed within the metropolitan ordinances. Specifically, the abatement of non-permitted graffiti must occur on a timely schedule, and local government is authorized to complete abatement independently but first compels owners to do so, at their own cost, before incurring fines and other costs. Additionally, the ordinance authorizes police to serve criminal mischief charges on any individual in possession of or engaging in the use of graffiti supplies (paint, markers, etching instruments) while on public or private property, if lacking permission. While these trends were supported by statements made by all sample policy officials, not surprisingly, the ways in which the ordinance was enforced or upheld varied, as did the viewpoints and perceptions of policy officials about graffiti.

Standpoint theory tells that us our occupations and the regular daily responsibilities and tasks we tend to in our jobs tend to influence our standpoints differently (Smith 1987). As such, the different daily work experiences affecting the standpoint of each policy official can be thought to influence their understandings, views, and conceptions of the problem with graffiti (as well as their ideals of how to address the problem). As such, findings revealed that each policy official "held the line" differently in terms of ordinance and city codes, and in the prioritizing of abatement of the different forms graffiti, based on their separate standpoints. Perhaps a key consensus among policy officials was a commitment to honor the ordinance and other city level policy, but also, to continue recent work in the public arts domain, with some believing that murals might serve as a graffiti deterrent. Further, there was partial consensus among policy officials that using graffiti writers in murals projects and that granting decriminalized graffiti zones was desirable, while several emphasized that "legal walls" had failed as policy alternatives in the past. Thus, where one policy official favored expanding policy by incorporating writer-managed legal graffiti walls and other practices typically are outside of the repertoire of practices of conventional graffiti policy. In the sections below, I present significant current study findings and themes alongside quotes from 
interviewees that give voice to them. First, it is necessary to examine the written discourse in the metropolitan ordinance on graffiti.

\section{Findings from the Written Discourse: Citywide Graffiti Ordinance}

For the geographic location under study, the graffiti-related ordinance can be viewed publicly on the metropolitan government's website (See Appendix B Metro ordinance **1.10 “Graffiti”). According to the website, the ordinance was revised or updated in 2005 and details graffiti-related criminal and civil offenses, enforcement terms, fines, and city timelines for abatement. Generally, the graffiti ordinance sets forth that visibility and lack of permission generally constitute illegality for any public display of graffiti. "Graffiti" is defined by the ordinance as:

"Drawing, inscriptions, or markings...made using aerosol spray paint, etching acid, or other etching materials, or broad tipped markers on a wall or other surface, so as to be seen by the public, placed there by a person other than the lawful owner or occupant of the property, without consent or acceptance of said owner or occupant" (Metro Ordinance **1.10; See Appendix B).

Perhaps worth noting is that the ordinance affects both graffiti writers and property owners in a relationship that essentially punishes property holders by compelling them to eliminate illegal graffiti at their own cost and in a timely manner or face fines and other costs that are assessed for city abatement personnel completing the removal. This system may in effect pit property holders against graffiti writers.

\section{Restriction of Sale of Paint to Minors, Possession and Intent}

The city ordinance also restricts sales of aerosol paint, markers, or other graffiti implements to those under 18 years of age (Metro Ordinance $* * 1.11$ ), and further designates as criminal the possession of such implements by anyone in public or private space (Metro Ordinance **1.13 (A) (1). Criminal possession is outlined as:

"Unlawful conduct or activities by individuals shall encompass the following: No person may possess an aerosol spray paint container, broad-tipped indelible markers, or etching acid, or etching materials with the intent to deface, destroy, or damage any property" (Metro Ordinance **1.12 (A) (1)).

Further, "intent" is defined as possession of graffiti tools: 
“....any possession of such items on either public property, or private property without the express intent of the legal owner shall be prima facie evidence of intent" (Metro Ordinance $* * 1.12(\mathrm{~A})(2))$.

Here the ordinance explicitly outlaws possession or use of specific graffiti tools without having consent of some public or private entity.

\section{Criminal Charges for Graffiti and Terms of Property Owner Abatement and Penalties}

Committing an act of illegal graffiti (or having intent to do so) is described by city ordinance as criminal mischief and is punishable by arrest, incarceration, or fines. 9

"A person who creates graffiti and commits an act of criminal mischief...may be arrested and/or cited for such unlawful activities in addition to the violations set forth herein" (Metro Ordinance **1.12 (2) (C).

Each misdemeanor criminal mischief charge may carry fines or potential jail time (See Appendix B - Metro Graffiti Ordinance).

Terms of property owner graffiti violations are related as follows:

"unlawful activity with regard to property shall encompass the following: "sidewalks, walls, buildings, fences, signs, and other structures or surfaces shall be kept free from graffiti when the graffiti may be visible from the street, or from other public or private property." (Metro Ordinance **1.12 (2) B (1)).

Notably, the ordinance only defines as unlawful instances of graffiti that can be seen from the street. The ordinance also outlines protocols by which the city code enforcement department may fine property owners. When graffiti is reported, abatement must occur within seven days of notice before fines are imposed and abatement by city personnel may occur.

"Abatement or removal of graffiti by the property owner, or responsible party (or signature on a waiver form as set forth herein) must occur within seven calendar days of issuance of any notice of violation, citation, or order" (Metro Ordinance **1.12 (2) B).

\footnotetext{
9 It may be useful to emphasize that while the ordinance defines "graffiti" as markings made without an owner's consent with an array of materials as described, it does not use language designating as illegal the use or possession of "bucket paint," or the oil or latex paint varieties sold in cans and commonly used for conventional applications using a roller or brush (or, in some cases of vandalism, for dumping onto a surface). It is not certain whether this omission is ever argued in criminal proceedings in terms of what constitutes graffiti or graffiti vandalism.
} 
It is perhaps significant to note that, by criminalizing the "site of the crime" and making its clean up the responsibility of the property owner, the design of this feature of the written ordinance may inadvertently pit property holders against graffiti writers.

After a report of illegal graffiti is received, a warning is issued by the metropolitan department of codes and regulations to inform owners of the violation and the potential fines, and to order that abatement must occur at the property holder's cost. Owners may sign a waiver to avoid having to personally remove graffiti, which allows city personnel to enter a property and perform abatement. The ordinance further establishes that if waiver does not occur according to schedule, city personnel may enter a property without permission and with police escort, to abate illegal graffiti (Metro Ordinance **1.14). Non-compliance involves a $\$ 250$ and $\$ 500$ per instance of graffiti appearing on a building or property (See also Appendix B for a full listing of the ordinance). While the ordinance attempts to compel property owners to maintain visible standards to paint over all visible graffiti within given notice, discretion may also be used. An official from city code enforcement indicated using such discretion in enforcing graffiti citations:

"If it's on private property--even when we cite folks--we give them time, and they can have an appeal... We try to work with people... if it's a spot that is frequently tagged, we give.... little more leeway."

Though practicing some discretion by abatement personnel is used to accommodate the property holder in terms of abatement timelines, interviews with city personnel did not indicate if there were ever cases where property holders were permitted to leave instances of illegal graffiti up for extended periods or indefinitely (for instance, if a particular piece or other illegal graffiti carried a positive message or was otherwise desirable).

Aside from any discretion that might be shown on the part of city officials toward removing graffiti, the overarching theme in the ordinance was that all forms of graffiti, absent a property owner's permission (or official city permit), involve criminal charges and fines for graffiti practitioners and civil penalties for property holders who must assume costs and completion of abatement within a designated time. In the next chapter, I will revisit the notion that this discourse places an inherent conflict between graffiti writers and property holders, where the latter have an interest in not having to pay for graffiti removal or fines. Below, I introduce the policy official interviewees.

\section{Sample Policymakers and Enforcers}


All in all, I interviewed four city-level policy officials, and a private individual and anti-graffiti activist who for several years had served as policy advisor to several city policymakers and enforcers. While I did not interview the city mayor or police, these omissions were not deliberate. After several attempts, I was successful at securing an interview with the mayor. However, this appointment was later cancelled by an assistant, due to an unforeseen emergency, and no replacement date was offered. The assistant did offer to have the mayor answer the interview questions and send them by email, but since I agreed to this, I have not been able to get any response from the mayor's office. There is also neither a known police detective assigned to graffiti, nor a graffiti task force in existence at the city level. There had been a graffiti detective in the past who had been involved with criminal gangs, but that individual's job position was reportedly eliminated around the time of the early 2000s recession. The sample thus consists of a city council official of a central city district who has overseen numerous public murals commissions and has past experience in the arts; an official in metropolitan code enforcement who is also chief of the city's one dedicated graffiti abatement team; an official from the public arts department who had also participated in several neighborhood improvement initiatives for the city involving murals and other arts initiatives; a special projects manager for the office of the mayor who had been involved a blight reduction initiative and had conducted graffiti abatement10 as a past official in city parks; and a private individual who was an anti-graffiti activist and had founded and served as director of an anti-graffiti organization that completed a graffiti census of a small section of the city. The anti-graffiti activist said this in terms of the graffiti research he had conducted:

“... the number one thing that I did is... a (graffiti) census, somewhere between 3 to $5 \%$ of the... city...It collected...data...to convince people... what was wrong and who was doing it...."

City policy officials expressed high esteem for the activist's knowledge and ongoing advisory role. The special projects coordinator expressly recommended I speak with the anti-graffiti activist:

“...he's done several abatements and campaigns...and ....research on... mindsets (of graffiti writers)... He has a lot of data...I view (him) as an authority..."

The code enforcement official spoke of the anti-graffiti activist's advisory role,

10 The city's parks department deals with graffiti separately from the abatement team within codes and regulations, where the latter addresses all graffiti in public right of ways and on underpasses within the city limits, as well as performing abatement of city structures, abandoned properties, and, sometimes, on residences. 
“... He's done a lot of research... and we're trying to fit it into our world and try to address it..."

The anti-graffiti activist confirmed this:

"He (the director of code enforcement) has done everything I've told him...he's the number one person in metro dealing with graffiti... a champion that's listened to what I've said and run with it."

The anti-graffiti activist claimed no formal training in public policy, criminal justice, or social research, and he reported that most of his knowledge was non-academic, originating in "things that were told to me." While he had advised and worked closely with several city officials in public and private forums, at the time of our interview, he was not an employee of city government and had no significant background in politics. He had once run for public office, with a platform including graffiti eradication, though he was not elected. Interestingly, upon beginning our interview, the anti-graffiti activist discussed a "San Diego study" that compares recidivism rates from very different types of crimes, one violent (child sex assault), the other non-violent (“career” graffiti writing):

"a study on 10 career vandals...instead of putting them in jail...(authorities) assigned sociologists to study them...and...modify their behavior... career vandals have about the same recidivism... as pedophiles... in the 90 to 95 percentiles... only 10 percent or one percent of the vandals returned to tagging after two years... I call it the San Diego study...I don't know if anyone else does.11"

Though I was promised a citation for this study, to date, I have not received one and have been unable to confirm a "San Diego study" in the literature or other records.

The graffiti activist's daily work experience volunteering in graffiti activism is very specific and distinctly affects his standpoint and views and understandings of graffiti, writers, the nature of the problem with graffiti, and preferences and priorities in best practices for dealing with graffiti. As discussed below, other city level interviewees demonstrated varying views and understandings of graffiti and policy preferences according to their work experiences and responsibilities.

Policymaker and Enforcer Standpoint in Views and Understandings of Graffiti

11 The choice of language and terminology in policy debates--such as this likening of graffiti writers to pedophiles - can be problematic and often unfounded, but this practice does serve a purpose in mobilizing support for graffiti as a social problem (See also Ferrell 1996 on the power of language in graffiti policy narratives). 
Findings from policy official dialogues related a range of views and understandings of hip hop graffiti and the subculture, and the problem faced by the city with graffiti, as well as varying ideals of the best methods for dealing with graffiti. Among these themes was a notable lack of depth of understandings of the styles of hip hop graffiti or how it differs (aside from illegality) from murals and street art, and from other forms of vandalism prioritized in graffiti ordinance and abatement. As well, significant disparity occurred in understandings of the graffiti problem and how it should be best dealt with in policy.

As stated, much of the similarities and differences among policy officials may relate to the differences in their standpoints as related to their work and experiences. Marx tells us that our consciousness is affected by our relationship to the material work we do (Marx and Engels 1978). How work differently affects our values, views, and daily reality (i.e. standpoint) may give context to the nuances in our individualized understandings and views about issues that involve us, which is a key feature in standpoint theory (Smith 1987). As such, policymaker and enforcer stances on graffiti likely vary accordingly by personal experiences and work responsibilities, and by each individual's unique daily reality of involvement with legal and illegal graffiti (i.e. standpoint), As I review the emergent themes below, I will attempt to give voice to these individual standpoints to explain the trends in narratives (and counter-narratives) as they relate to emergent themes.

Study findings indicate that the anti-graffiti activist's views were only partially shared by city personnel who I interviewed. Despite a dedication to activism, a presence in public forums, and a sharing of graffiti census data or other knowledge with local government, his prescribed agenda had apparently not been fully adopted by city policy officials at the time of this writing. As well, the four city personnel were responsible to not only support the graffiti ordinance, but also other priorities, including the implementation of arts and urban renewal initiatives. Further, these city employees and elected officials were also involved in policy protocols and common goals for many larger issues faced by local government, including inequality, poverty, violence, and other social problems. Thus, it is necessary to distinctly examine how the policy officials' standpoints differ.

For instance, the special projects official had worked in the past with city parks, often dealing with artistic and other forms of illegal graffiti. His involvement had entailed closing a city skate park several times and working with paid businesses and volunteers who assisted by painting over obscenity, tagging, or 
other undesirable or excessive graffiti (one of the closures had amounted to a six-figure contract with a professional painting company). While this policy official had reported having thought some of the artistic graffiti he had seen was "cool" and had also worked with commissioning murals, his work experiences and responsibilities forced him to address unwanted graffiti and likely uniquely affected his standpoint having dealt both with abatement and in assisting public murals commissions. Another key task was bringing together different city level departments in several such projects. As will be discussed, his role (and thus viewpoints and understandings of graffiti) differs significantly due to the scope of these responsibilities and how graffiti relates to other priorities. Perhaps best capturing his standpoint in increasing departmental collaboration to eliminate blight, the special projects official stated this:

"I'm kind of a convener of sorts that brings the (city) departments together...in a clean city...there's nothing worse than to say 'that's not my department'...I want people to see something (blight) and not only to see something, do something (about it)."

In another example, a graffiti activist's ideals and understandings of illegal graffiti may be compared with and align to those of a code enforcement officer. Essentially, both individuals' responsibilities are in some significant way tied to the prevention, regulation, and removal of graffiti. While the code enforcement official may personally think some instances of graffiti are aesthetically pleasing or even may occasionally send a positive message, they may also be among most likely of policy officials to stand firm in abatement of all cases of graffiti that are done without permission. The point is that the differences in views and understandings (standpoints) among policymakers and enforcers vary according to how their daily work experience deals with graffiti. Put another way, some individuals may see only one thing (illegal or not) when looking at graffiti, while others may see more than one or hold some value to it.

Findings from interviews with policymakers and enforcers indicated a strong interest in promoting muralism and recruiting artists for public arts projects involving street art or murals. Based on their workrelated standpoint, such individuals may have a "softer" gaze on some forms graffiti (or at least some openness to its artistic value) and may differentiate between forms of artistic and undesirable graffiti. Perhaps illustrating this, when discussing personal views on graffiti, the arts official interviewed in this study said, "I come at it from the arts perspective... sometimes from an artist's or activist's standpoint there can be a positive intent or positive outcome." In all likelihood, if a code enforcer (or graffiti activist) were to take too soft of an approach on illegal graffiti, they may be jeopardizing their reputation, and thus may 
be expected to take a "harder" stance on all graffiti than a public arts administrator or city council official, who may have different priorities.

The code enforcement official emphasized his job requirement, despite a personal opinion of seeing aesthetic value in in some instances of graffiti:

“...if someone didn't have permission .... with the job and the task that I have to do, that is just vandalism...some of it looks cool....and I understand about protesting..."

Despite any aesthetic value he may see, this official's standpoint entails deferring to the city codes and ordinance and the responsibilities he is tasked in maintaining, as was also the case with city workers in Ferrell (1996) and others work, where all graffiti was thought to be blight.

\section{Views of Graffiti and Conceptualizing the Problem with Illegal Graffiti}

City policy officials expressed significant differences in views and understandings of illegal graffiti and its practitioners, and differing conceptions of what is the exact nature or extent of the problem with graffiti. While all interviewees at the policy level defined illegal vandalism as a problem, priority was assigned differently by city officials in terms of the various types of illegal graffiti that occurred. The city council official alluded to polarized understandings of graffiti:

“...depending on who... some people...(when they view graffiti) see 'graffiti' on a scale of one to ten as a ten...other people...see 'graffiti vandalism' on a scale of one to ten, with one being a low, as a one..."

In terms of policymakers and enforcers whose involvement in graffiti policy centered on removal or prevention, the view of graffiti tended to be more directly focused on the terms of its illegality, accompanied by a trend of rapid abatement to prevent more graffiti or send a message of public apathy. Having perhaps a more direct exposure to graffiti in daily work designed toward its eradication, the activist's values may align separately from the four city personnel with whom I spoke. Specifically, the anti-graffiti activist's values appear similar to those of anti-graffiti campaigns and policies that find justification in broken windows assumptions and rational choice theories of crime and criminalization (Ferrell 1996; Ross 2016). It appeared that graffiti was also viewed an indicator of other social disorder in the eyes of policy officials. When asked whether graffiti has any positive value to society, the graffiti activist said “...that's a good litmus test...method of realizing a (social) problem...on a society’s 
organizational ability to fight a nuisance.” Framing all graffiti as a nuisance may align with this individual's standpoint in his long tenure of activism directed to eliminate graffiti.

“it promotes urban blight and decay...decreases property values and...peoples' willingness to invest in the community... people...leave... because we attract graffiti vandals."

This appears to convey the idea that all graffiti is negative and inspires perceptions of apathy. Situating his standpoint according to the broken windows model, he described graffiti an ideology where seeing an instance of graffiti may inspire others to begin doing it.

“... one graffiti vandal will stimulate activity in another graffiti vandal...then that graffiti vandal gets activated. Plus, you have learned behavior."

This statement may suggest that a learning occurs between writers, as well as as stimulus and response.

Several years before our interview, while working on the graffiti census of a small area of the city, the antigraffiti activist was featured in a news article which alleged that the activist had personally called in a majority of the illegal graffiti that had been reported to the city on a public phone reporting system. The graffiti activist spoke on several news features against backdrops of illegal graffiti.

"I am a person who likes the spotlight... using me as the tool to fix the problem. No one else is doing the fight."

This comment is referring to using the media as a platform from to vocalize on issues. It may appear clear that the anti-graffiti activist's actions are consistent with value-based efforts to (further) develop rules by moral entrepreneurs as discussed in research on deviance and labeling theory. Becker noted that enterprising agents of enforcement have in the past contributed to the production and enforcement of marijuana law by assisting the development of local laws and offering data and figures for media and journalists to present to the public (1963:138). These features of moral enterprise are evident not only in the anti-graffiti activist's consistently providing data to the public and local governance, but also in his frequently attending and directing meetings and presentations (for policy officials and the public) on ways to address graffiti. An additional aspect of this individual's "moral enterprising' capacity is evident in his numerous local news appearances featuring instances of graffiti vandalism as visual backdrops to his oncamera dialogues about the negative effects of urban graffiti. Despite several years of "doing the fight" to eliminate graffiti, the anti-graffiti activist left the area shortly after we spoke. 
In contrast to the anti-graffiti activist's values, city personnel whose work deals in some way with the arts had a tendency to look past the negative or criminal aspects of graffiti and see potential value within it. The public arts official emphasized her views about graffiti:

"It goes into a very gray area... Was it intended to add a moment of humor or joy or social commentary?... There is some subjectivity when you're looking at it, what it means...what it's about."

This official appears to be acknowledging a "gray area" within constructions of graffiti as art or crime, where intent is an important factor to consider when viewing graffiti. The special projects official also noted some "distinction" in types of graffiti: "I try to in my mind make some distinction (about forms of graffiti). I think some of the murals they created are pretty cool..." When I asked to clarify, "The illegal kind?" he agreed while reiterating his stance on illegality. "Yeah. But...taking spray cans and writing your name or defacing property for the sake of defacing property — that's a bother to me..." Interestingly, the use of the term "mural" applies to both legal and illegal varieties to this individual. A perhaps blurred distinction between legal and illegal murals appears to be evident in these references, however, for purposes of discussion, generally, "mural" refers to a specific form of permitted street art that addresses a public audience and is utilized by public arts officials. Perhaps for this person a 'mural' is a graffiti "piece." At any rate, illegal productions of graffiti were distinguished by policy officials as separate from valued "murals" or "street art," which were designated by policy officials as desirable and different from "graffiti." As other research has indicated, legal mural productions may use graffiti styling or other non-graffiti stylistic lettering or character forms that are legible to the public, while graffiti is usually a communication among members of the graffiti subculture (Ferrell 1996; McAuliffe 2012).

While still maintaining a stance to preserve or uphold the ordinance to prioritize regular removal of most illegal graffiti, the city special projects administrator, the public arts official, and the city council official all exhibited perhaps what could be called a "softer" view on graffiti and graffiti writers than the anti-graffiti activist or the code enforcement official. This pertained to not only openness to view potential artistic value within illegal graffiti, which was shared by the code enforcement official, but this applied largely in terms of an evident value in utilizing graffiti writer talent to create public murals. This difference may likely be related to the former three officials having backgrounds in the arts or being directly involved in public murals projects, some of which involved several artists and graffiti writers. In a few years, the 
council official's district was able to complete over 20 commissioned murals, often enlisting local artists and sometimes graffiti writers. When discussing illegal graffiti, the city council official hinted at an unfulfilled need for self-expression as a potential motive for doing vandalism:

"Graffiti vandalism...is a signal to much bigger challenges and problems in a community...it's saying that whoever is doing the vandalism doesn't feel that their voice is heard...they don't think they have a voice... don't know ... how to express themselves..."

This individual's work focalizes the importance in the addressing of public concerns and working with multiple stakeholders to find a resolution based on citizen needs. Maintaining graffiti abatement to stop ongoing graffiti vandalism and involving police with citizen property owners who may have suffered damages due to graffiti or code violations were also among top priorities for this official. The arts official's statement perhaps emphasizes this theme of discussing graffiti in terms of the potential for community dialogue, also emphasizing potential impact on community business:

"Graffiti can...force the hand of the community to react... play a role in bringing awareness and... a microscope to an issue, forcing the hand of public officials to address an issue. It can push.... dialogue in their community on an issue. However, it is difficult to condone destructive acts, especially if involving a small business... That is not a positive..."

The special projects official conveyed the Administration's value in artistic mural-style art that is done with permission, distinguishing it from "graffiti." He noted this: "It adds a coolness factor when you can have some street art and murals...to me and the Administration, that's a little different than just the graffiti."

The latter half of this statement may acknowledge the separate forms of intent in legal murals and street art versus forms illegal graffiti. This position was the general consensus of city policymakers and enforcers, and the notion of intent likely goes back to city ordinance which defines criminal intent as doing unpermitted graffiti publicly or privately, or possessing graffiti tools (See also APPENDIX B - METRO GRAFFITI ORDINANCE or this chapter section "The Written Discourse"). Awareness of the separate forms of graffiti may indicate a clearer understanding of intent and of the overall problem faced by a district or municipality.

\section{Policy Officials' Understandings of the Various Forms of Graffiti}

The sample policy officials did not exhibit consensus in understandings of artistic graffiti beyond a common ideal. According to this notion, unpermitted graffiti produces a public nuisance that is prioritized in abatement as slightly less important than obscenity, hate speech, provocative political commentary, or 
gang communications. Thus, being able to identify the different forms of graffiti that occur is likely to be a factor considered by policymakers and enforcers when assessing the overall problem with graffiti.

Nonetheless, the data indicate that these understandings were divided, and separate priorities for abatement (as discussed in the next section) also occurred among different officials. When asked, "Are you aware of any differences in the types of illegal graffiti that appear in the metropolitan area? Are there instances of graffiti that are more tolerated or less tolerated than others?" (See APPENDIX E, Question 8) the city council official's reply perhaps best captured the understandings of city policymakers and enforcers: "I don't know...not well enough to describe eloquently in words." The anti-graffiti activist discussed his understandings of the different forms of graffiti:

“...hate speech... The public... are very intolerant...

religious graffiti...associated with a tumor...that causes profound religious experiences...

Political speech... don't...give it publicity...the way things are polarized... messaging....things that are comical — 'try to keep up'... gang graffiti...has...dropped...

tagging or monikers...makes up...95 percent...I can't think of what else"

I asked to clarify, as the report on the graffiti census also listed "murals" as a form of illegal graffiti. He replied, "Yeah, tags and murals." Again, the use of 'mural' is different than the one referred to by the special projects official. Perhaps most notable is the characterizing of a biological "cause" for doing religious graffiti, perhaps reiterating a view influenced by a background in medical work. Here, he appears to liken graffiti to an illness or sickness:

"The pattern of how graffiti spreads it's an ideology, as well as a habit or vandalism; it has the exact same modeling and equations you would use as with the spread of a virus. you can model it... the growth of...tagging it ends up looking like a colony..."

This statement raises what Ducuyunan noted on her research on graffiti and public space. To paraphrase, depictions of graffiti writers and taggers rely heavily on militarized language and medical metaphors, which depict graffiti as a threat, fueling a "climate of fear" (Ducuyunan 2000:116). Again, this perhaps models this activist's standpoint in terms of taking a tactical approach toward graffiti with an end goal of total eradication.

The lack of consensus in understanding of the distinctions among types of graffiti by city policy officials and the anti-graffiti activist may be further reflected in the relative disparity in their ideals of prioritization for removal for the various forms of graffiti. 


\section{Prioritizing Removal of Illegal Graffiti Forms}

As said elsewhere, there were notable divisions among city officials in terms of prioritizing the removal of different graffiti forms, where the code enforcement and former parks officials first addressed that which was offensive or vulgar as top priorities. The city council official and the code enforcement official suggested that hate speech is most important to address. The special projects and former parks official's focus was more on various city improvement and other special projects including collaborating in urban blight and renewal projects. As a former parks administrator, he remarked on that department's priorities in illegal graffiti:

"... our view of graffiti at that time was: If it was offensive we were taking care of it immediately...24-48 hours was our goal to remove the really offensive stuff."

As a public resource parks where children and adults frequently visit, lewd imagery and profanity would likely take priority, which would likely agree with his work standpoint. While this official's priorities were specifically stated in how graffiti lines up to current priorities, his responsibilities and exposure to graffiti vandalism were reported to have decreased after changing to the current job, while still remaining a priority. The city council official had similar ideals in removal of illegal graffiti:

"...hate crimes...next...profanity...next...gang communications...next ...largescale prolific graffiti vandals...large scale where...the work has caused... abatement exceeding a financial level $12 . .$. that takes it into felony charges..."

This assessment was similar to the code and enforcement official's answer but notably differed from others, who rated political graffiti high among priorities.

The global definition notion of intent in graffiti (whether permitted or not) raises the idea of “moral geographies” (McAuliffe 2012; Smith 1997) which give meaning to spaces navigated by graffiti writers in legal and illegal venues where they paint. Such spatial moralities involve specific power relations and predetermined ideals of "appropriateness" in what forms are taken by graffiti and where it is done. Stated another way, separate moralities occur in graffiti's location, whether graffiti occurs on an abandoned structure or unused space or on a school building, and in the forms it takes (i.e. more or less artistic forms

12 According to metro government officials, graffiti that costs over $\$ 500$ to abate equates to a felony charge. 
such as pieces or less-desirable tagging, or other types of illegal graffiti). The special projects official alluded to distinctions of intent behind undesirable forms of forms of graffiti:

"There has to be sacred cows...there's some political anarchists that don't care...that's a different breed...there have been...bad messages like "kill police" or "Fuck Trump." Yeah, I don't like Trump either, but...that becomes civil disobedience versus civil discourse, to present their view."

While several instances of local amateur graffiti had involved violent or hateful sentiments made about police (and others), politically motivated speech or vandalism were also no stranger to the city. Numerous local places of worship had been vandalized with hate speech, along with public murals, including featuring a widely-respected African American citizen. In recent incidents, the words "kill cops" and "fuck police" and "fuck Trump "had been reported along the interstate and through the city. With regard to this policy official's prior statement, it may be useful to note that differences do exist between civil discourse and civil disobedience that may be separate from hate or racial speech. It is possible (but not certain) that, having overseen abatement at the skate park and recently being involved in muralism and beautification, to this individual, "civil discourse" might entail illegal graffiti statements that may be considered tolerable (perhaps such as illegal graffiti messages like "no bad days" or "heroin kills"). Further, given his standpoint, "civil disobedience" may refer to obscenity, hate speech (i.e. "kill cops"), or politically or racially motivated messages.

\section{Prioritizing Graffiti and Other Crime}

In contrast with differing ideals of prioritization of graffiti, several city policy officials reported similar notions of the levels of priority that graffiti takes in terms of other crime (See question 11 in Appendix F), particularly, some speculated that graffiti was not high on the priorities of police in terms of other crime, given a high volume of violent crime. Again, no police detectives or other officers were interviewed for this study, but it may be notable that several officials had expressed that graffiti was a lower priority when police had dealt with a great deal of homicide and other violent crime in the city. The code enforcement official speculated that graffiti was one of the lowest priorities for police:

“... I don't speak for the police, but...If someone...said, 'there's a graffiti person here,' and they're getting calls of shots fired or a domestic...it's down the totem pole...(graffiti is) a low priority to them."

The anti-graffiti activist referred to a lack of police action or involvement when discussing graffiti policy: 
“... they've been pretty much lackluster... I get a little bit of traction now and then... an officer (police) who decides to do something ...

we don't actually prosecute...for graffiti...we don't have any police training, detectives... a person... whose ass is on the line if there is graffiti... nothing...if police pick them up (cases) they're just tossed out.

This is consistent with the anti-graffiti activist's view that greater controls are needed to address graffiti.

The code enforcement official acknowledged that graffiti was only one among many other priorities:

“... (graffiti is) prioritized in our properties maintenance code...tall grass and weeds is...highest (priority). But...we're out there enforcing and trying to eliminate it (graffiti) if everything works..."

To reiterate, city graffiti ordinance establishes all graffiti is illegal if done without proper permission, and this policy official affirms the ordinance in being responsible to enforce removal of all unauthorized graffiti (along with addressing other code violations). It is also important to note that within the separate public works, department of highways, and metro code enforcement and other authorities who deal with graffiti, the code enforcement graffiti abatement crew was reported to have taken on part of the responsibilities of other departments, specifically the state highway underpasses, which are under a separate authority in terms of abatement. The special projects official noted the centrality of the role of code enforcement in removal:

“'codes and regs' gets the brunt of (graffiti)... responsible for the removal of the big stuff. Parks Department takes care of their stuff. Public Works has some areas they take care of. (the code enforcement official) gets a lot of it because it's in the right of ways... and...private property."

The code enforcement official emphasized this: "I would say on average...the last four years (we spent) 120-160K per years strictly to abate graffiti."

When asked what level of priority graffiti takes in terms of other crime, the city council official said:

"We put $\$ 250,000 \ldots$ into the metro budget ...to put together a graffiti team...our budget shows our fiscal priorities...was it enough...to please everyone? No. But we did take that first step..."

With regular interaction with the public in terms of policies and community preferences and having an interest (as stated before) in the voicing of community concerns, this official's understanding of community satisfaction is likely well in tune.

Remarking on the relative success in his new graffiti crew, the code enforcement official noted:

"Last year we went from 762 work orders to 1259 , but our crews were getting faster. And we began taking care of public right of ways. But we could probably 
do a couple hundred more up to 2000 a year if it wasn't raining as much and we knew where it was."

Making graffiti a greater priority in terms of deterrence, as will be related, was thought to require wider city level involvement and further utilizing murals programs in the hope of improving public space while attempting to discourage graffiti. Here it is necessary to examine another theme, which occurred in views on the effectiveness of current policy and (later) views on best practices for addressing urban graffiti in its various forms.

\section{Perceptions of Efficacy: Graffiti Policy and Practices}

City policy officials conveyed different understandings of metropolitan graffiti practices and their effectiveness. When asked, "Who defines protocols addressing illegal graffiti, how they are developed?" (See Appendix E, Question 6), the city council member discussed who is involved in graffiti policymaking:

"Policies related to graffiti...done at the...department level. For graffiti... in the codes and regulations... in... police standard operating procedures...

legislation... council could enact ordinance...the criminal justice system... a judge on a bench I think will have the authority...to determine what penalties will be...possibly...(state) revised statutes..."

Several public meetings had been arranged and attended by the anti-graffiti activist and city personnel in efforts to make the public and policy officials more aware of ways to successfully address graffiti. When I asked who provides input into graffiti policy and practices, whether graffiti practitioners, police, or property owners (See also APPENDIX E, Question 7), statements were inconsistent. The city council official confirmed her own involvement:

"You'll get lots of different answers...those are developed at the departmental level...includes community inputs...business or property owners can engage in the process... property owners and artists have engaged in the process...I've been involved in those conversations.

When asked if current policies effectively address illegal graffiti, opinions varied. The code enforcement official stated, "I think our policy addresses illegal (graffiti)...we're doing some good to deter folks..."

It was made evident to me that the code enforcement department's prior administrator had visited and spoken with officials in other cities on different graffiti management strategies, after which the city within the past two years began constructing ideas for a city level graffiti management plan that included the recent budget allocation for the graffiti abatement staff and equipment. Adding a graffiti abatement 
crew in support of city ordinance in this official's department may have some role in his view on policy efficacy.

The special projects manager commented on a need to update some current law.

“...there are a lot of laws...that...need to be sunset... people that get arrested ...come out far worse...learn things that aren't positive... marijuana laws in communities that have changed their stance and views on things... some of those communities are printing money.

This last statement appears to indicate awareness of the worsening that can occur when writers get arrested and may suggest openness for modification of the city's repertoires for dealing with graffiti. It is next necessary to explore attitudes toward best practices in dealing with graffiti.

\section{Views and Ideals of Priorities and Best Practices for Addressing Graffiti}

Among city personnel, there was also, as mentioned before, general agreement with the citywide ordinance, which establishes as illegal all graffiti where permission is not granted. Centralizing focus on deterrence protocols in metro ordinance regarding graffiti may align with tenets of the rational choice theory (RCT) and the "broken windows" theory (Wilson and Kelling 1982), the latter of which the graffiti activist and the special projects manager referred to directly in talks. While discussing an urban blight project of a section of the city which he had overseen, the special projects official expressed interest in eliminating disorder, emphasizing the 'broken window': I like to take care of low hanging fruit.... the broken window. I really believe that when people see things...the neglect...(they think) 'oh, who cares.'

The code official and anti-graffiti activist emphasized rapid abatement:

"I do believe that from the consultants we talked to the faster you can get something covered and continue to keep it up, they will tend to stop tagging those areas."

The anti-graffiti activist affirmed, "For every two weeks we leave up graffiti, we will see it increase tenfold."

When discussing graffiti policy efforts, the arts official commented:

"...the effort being made is being used to the best possible effect, but... want...a diverse portfolios investment... what we already have and maybe some art programs. Multiple things, not just one."

This statement captures a consensus among several city personnel for the continued use of public arts alternatives to addressing graffiti. Taking such a binary stance on graffiti may characterize most 
conventional graffiti policy approaches (Ross 2016), but despite a conventional stance on abatement, the policy structure in this study appeared to be leaning toward the ideals of more departmental collaboration for policy alternatives and alternative justice measures. The anti-graffiti activist valued policy alternatives:

“...lots of other ways it can be handled...money to commit to 48 hour removal policy, restorative justice measures, education of the police force, prosecutors, and judge, sentencing guidelines, with evidence-based decisionmaking to back it up."

Perhaps of interest here is that the anti-graffiti activist does not call for increased penalization of writers, but instead advocates for what he refers to as "restorative justice," and "evidence-based decisionmaking" (I will revisit these statements later). From this individual's standpoint as an activist seeking reform of the current policies on graffiti, taking multiple steps such as these may reflect similar measures undertaken in other graffiti control efforts (Brewer 1992; Ross 2016). Implementation of such alternatives would likely require the collaboration of the involved departments and entities. Interviewed policymakers and enforcers shared a value for increased collaboration of city divisions and community stakeholders.

\section{Desire for Increased Departmental and Community Collaboration}

There was unanimous consensus among policymakers and enforcers for needed collaboration from separate departments and other stakeholders in dealing with graffiti and other urban blight in support of administrative interests and city codes and regulations. The special projects official focalized importance on departmental teamwork in everyday practices of combating general blight:

'there's nothing worse than to say, 'thank god that's not my area'... Even...(picking up) cones and...safety barricades... pick em up!...I want people to see something, but not only to see something, do something... a play on Homeland Security's (saying), 'you see something, say something,' but it's: 'You see something, do something!"

This individual's work responsibilities require him to bring together different departments in mayoral special projects, and thus collaboration and teamwork are central to such a role. To him, these are essential aspects of seeing a project through.

When asked, "Do you have an opinion on how graffiti is best dealt with? Can you tell me more about this?" (See APPENDIX E, Question 21), the city council official also emphasized: “collaboration and all voices at the table... because whoever you leave out is going to be the next vandal." 
The city uses a public call in system where citizens can report graffiti and code violations, who log them and address those within their jurisdiction according to their priorities. The council official reported collaborating with police and citizens:

"I...make sure property owners know they can....report graffiti to my office...I will alert (police)....and...officers....meet with property owners...evaluate the property to see if there were any cameras... review the footage to see if that can...lead to....apprehending someone... if it's a business or a property...that has continual vandalism and there are no cameras...(police) can... work with folks to consider if and where...cameras could be installed."

The city council official's taking of this step on behalf of community members coincides with an occupational standpoint as a community liaison.

The anti-graffiti activist reported lacking collaboration among departments and a "war" on graffiti:

"There are the doers... and the obstructionists who won't do anything... They're losing the war...

The Mayor has ... deprioritized (graffiti)... public works won't...meet me...will not participate in a single public forum about graffiti."

Framing the situation as a war captures the standpoint of the activist, who has walked streets counting illegal graffiti, spoken on local news and presented to city government, and attempted abatement in his own neighborhood. It was reported to me that several meetings were led by the anti-graffiti activist and presented to city council, police, and the department of codes and regulations. In these meetings, a detailed plan was outlined suggesting the hiring of a graffiti detective for the entire metropolitan area, as well as forming a committee of individuals at all levels who would meet regularly to discuss budgeting and collaborative approaches to dealing with illegal graffiti.

“... A stakeholder's meeting is something I call for. ... every month ...facilities, maintenance, police, criminal justice, and highway transportation... so they can stay on the same page. Functioning as an island or silo you probably won't get things solved."

The code enforcement director also acknowledged a need for increased involvement:

“...There needs to be...enforcement...from police to go after the folks... we take pictures...we worked with police and sent them (photos taken of abated graffiti)...we had a conviction last year...(metro police) was able to put together a whole packet of that person's work."

These statements reflect the standpoints of policy officials working directly in abatement and prevention, who convey the need for funding as well as combined efforts to reduce graffiti. There was strong consensus on the need for collaboration simultaneously with a desire to continue public muralism as urban 
enhancement and (potential) graffiti deterrent. As well, there appeared among interviewed policymakers and enforcers mixed levels of openness toward other policy alternatives. I will now consider policy officials' preferences in alternatives.

\title{
Alternatives to Conventional Deterrence Policy: Murals and Sanctioned Graffiti
}

As discussed, those whose work involved beautification efforts or public arts were more inclined to convey a "softer" view of graffiti or other forms of public art, while still supporting city graffiti ordinance and emphasizing the harms to the community in potential property damage and costs of mandatory graffiti removal. As stated, several city personnel expressed value in street art and muralism as beautification, and as a graffiti deterrent. The public arts official discussed using murals to deter unwanted graffiti:

\begin{abstract}
"we might...encourage property owners to consider a mural or be part of a program that's doing a mural...sometimes they are resistant...because they feel...it's going to lead to vandalism... some programs have found that it (muralism) deters vandalism."
\end{abstract}

The city council official took a stance in favor of muralism when approached by other district leaders requesting a percentage contribution to a of pooled fund in the tens of thousands of dollars to "abate any graffiti" in their common district areas. The council member noted having been presented a statistical analysis of graffiti occurring within the three council districts. "I politely declined...if I'm going to spend that kind of money, I'm going to pay writers to create beautiful works of art." And that's what I did." Having past involvement with the arts may likely affect this official's standpoint for partially redirecting abatement expenditures to instead seek to visually improve public space.

The special projects official also discussed benefits of murals for beautification, noting one commissioned mural he had overseen for a wall for the city bike and skate park that was also sponsored by the city council. The mural had been designed with block lettering of the name of the city and images of skateboarding and bicycling, and several mural artists and two or more graffiti writers were paid for the project. The public arts official reiterated the consensus value in community and artist involvement in muralism as a community partnership alternative and potential means of deterring graffiti.:

"...murals...can be effective in addressing graffiti...if the project connects with the community as something they are proud of... assuming the vandalism is not coming from outside their community. Perhaps that can deter graffiti..." 
This statement perhaps conveys the standpoint of working with designing and coordinating arts

development projects. This administrator later emphasized a personal role in attempting to increase local graffiti writer or street artist involvement:

“...we've done...different programs...where we try to break down that process (how to be involved in paid commissions) for artists... to help artists...break it down into manageable steps...how to get from $\mathrm{A}$ to $\mathrm{Z}$ and not, haha, be on the wrong side of things (the law)."

One may speculate that the success of the district's muralism program in recruiting graffiti writer talent could extend to other "legal" programs that involve writers. Generally, the city's policy practices held consistently with conventional graffiti policy approaches discussed in the literature, which take shape in binary illegal versus legal constructions of graffiti (Halsey and Young 2002; Ross 2016). Nonetheless, discussion did occur about alternatives, along with various levels of support for these.

It may be useful to reiterate that 'murals' and 'street art' were considered positive by city personnel. Still, some lack of clarity or consensus in understandings of what defines graffiti and street art was also evident. The arts official acknowledged different meanings in the terms 'graffiti,' 'street art,' and 'mural.' "I wouldn't really define (public murals) as graffiti but maybe street art. Depending on how we are using terminology. When asked if there are positive aspects of graffiti (See question 23 in APPENDIX F), the special projects official said, “I'm going to say yes... What I don't like and I think detracts is the tagging. That is why I like to use the terms 'mural' or 'street art." It is uncertain whether "tagged" or "tagging" means the sort of tagging done by hip hop graffiti writers, gang members, those expressing hate or political beliefs, those expressing vulgarity, or others — or if this terminology encapsulates all of the above. By all accounts, this official's statement repeats a general consensus binary approach to graffiti based on the dictates of the ordinance, which constructs graffiti in two categories, as violating established criminal justice and metro building codes, or as an altered permissible form in legal street art and public murals. Nonetheless, certain elements of narratives indicated some openness to both legal muralism and other as yet unused potential alternatives, including "legal" graffiti walls.

\section{“Legal” Walls}

While several murals had been completed in various parts of the city, and the mayor had reportedly allocated funds for many of these projects during recent years, no successful instances of the use of "legal" walls (where graffiti can be painted without legal consequence) were known to exist in the city 
area during the time of my research, aside from a private location provided to writers by a local business person who favored the arts. In terms of city personnel with whom I spoke, there was some interest voiced in completing such a public legal project, while others appeared ambivalent toward such alternatives. Some emphasized past failures at one legal wall attempt.

The city councilmember expressed value in graffiti as crime prevention:

"Art is crime prevention...(it) can be used in the most difficult, challenging times...maybe... graffiti writers are the ones that can bring attention in ways and places that really the media is not......

I look at graffiti writing - I call it graffiti art - it's asking questions, it's begging questions, it's making statements, and it's really a beautiful thing..."

Elsewhere this official shared an idea of interest in a potential legal wall:

"...if the government would allow..." (A legal wall) "that goes throughout the entire downtown... why don't we turn that over to the graffiti artist and ask them to speak to the community... and say what they want to say and do not tell them how to do it?"

The statement appears to reflect interest in involving graffiti writers as community stakeholders, giving them an opportunity to express their voices. Legal walls have deterred graffiti in some areas through legitimate implementations (Craw et al. 2006); however, successful instances of such walls were noted to be professionalized, advertised, systematized, and, generally, credible (See also Ross 2016). Many municipalities have feared that using legal approaches represents a "softening" toward crime, and have been reluctant to use them (Halsey and Young 2006). Mention of the use of legal walls in interviews occurred in two conversations in which it was related to me that the city's history of using legal walls was limited and unsuccessful. The special projects official mentioned one instance at an attempt for using a legal wall at the skate park:

"...at one time there was a graffiti wall that was put up. And it was stolen. The whole thing... it was an ill attempt at trying to 'ok, we'll give you a canvas.

Because that was something you could paint over and redo, paint over and redo. But it didn't work out..."

As discussed, research has shown that allowing writer-managed legal walls (and other legal graffiti exhibitions) has shown preference among many writers by providing more opportunities for writer expression (Brewer 1992). Using these and other alternatives could constitute a modified approach to graffiti policy on enforcement and punishment, and separate interest was also expressed to some degree among some policymakers and enforcers. 


\section{Softening the Approach: Restorative Justice and Engagement Strategies}

Largely, city personnel expressed interest in alternative, sometimes "softer" approaches to criminalizing" graffiti policy features (See also Halsey and Young 2002:177). Such policy measures offer promising alternatives to practices focusing solely on deterrence through abatement and criminalization. The code enforcement official had worked with police and assisted with a case wherein a local graffiti writer who was arrested for graffiti had revealed too much on social media, which alerted police to his identity and led to the building of a significant case after police arrested him in the act of painting a business. The code enforcement official expressed to have generally "understood" people doing graffiti, while again emphasizing its illegality:

"I understand...walking down the street and (you) want to put up your name, or your bomb, or your bubble letters to try and get up, I can understand but I mean that wasn't permission..."

This commentary reflects some graffiti terminology used among writers who participated in this study, language that also occurs in the wider graffiti subculture ('bomb,' bubble letters,' and 'get up') (Brewer 1992; Ferrell 1996; Halsey and Young 2002). These statements may also reflect some understanding of one form of graffiti style (See the current chapter section "Hierarchy of Graffiti Styles"). Significantly, the code enforcement official expressed interest in legal alternatives for writers: "I wish there were...programs where people could go in and show some art talents instead of graffiti or street art, you know?"

Interviewed policy officials not only expressed interest in collaboration with police to apprehend writers, but also favored justice alternatives for apprehended writers (described to me as "restorative justice" where writers own abate their work or that of others). The anti-graffiti activist stated his view on jailing graffiti writers, one share by several other policy officials, "I think it is a terrible waste to put someone in jail..." As such, some interest appeared in restorative (reparative) justice alternatives to jail. During our interview, the city council official referred to the case of an apprehended writer who had been arrested for graffiti, had completed several months in jail, and ordered to pay restitution for the damages:

"...what I would have like to have seen is for him to have had to give several hundred hours of community service work where he would have to pay for and abate everything he had done...then start abating the work of others."

The anti-graffiti activist also emphasized some value in reparative justice measures for apprehended prolific graffiti writers, while noting that such methods had failed in another city: 
“...this is a situation where you have to...be selective...

one (apprehended writer)... (city officials) made him remove it all (his own illegal graffiti)...he went back to all the graffiti vandals and taught them which surfaces and what type of materials to use...to make it (graffiti) harder to remove."

It is important to point out that restorative justice not only involves reparative features such as those discussed by interviewed policy officials but also encourages interaction, apology, forgiveness, and resolution between offenders, victims, and community, via meetings and other forums and alternatives to conventional court and jail models. Participation in processes designed to obtain resolution which are deemed suitable by victims, judges, and community members may better allow offenders an understanding of procedural justice and may empower victims through their involvement in the justice process. A key feature of restorative justice is to restore a sense of harmony among victims, offenders, and the criminal justice system. As Braithwaite noted, restorative justice involves

"restoring victims, a more victim-based criminal justice system, as well as restoring offenders and restoring communities...to restore any lost sense of (victim) empowerment" (1996:451-452).

Restorative justice practices in theory require fewer police, given that the alternative justice system in place can sufficiently shame offenders, without stigmatizing them, resulting in lower crime levels than traditional justice or stigmatization of criminals occurs with a lack of harmony between victim, offender, and conventional justice processes (Braithwaite 1989, 1996). Alternative justice models, including restorative justice practices and redirecting strategies have been used successfully in communities that utilize “engagement” graffiti policy strategies (McAuliffe 2012). These alternatives may lessen consequences for graffiti writers and street artists, instead promoting an urban arts appeal by engaging writer talent.

To summarize, the current study findings indicate significant disagreement among policymakers and enforcers as to what exactly constitutes the problem with graffiti and how to most effectively deal with it. There also appeared to be a lack of clarity in understanding the nuances in the forms of illegal varieties graffiti and street art, or what are effective policy approaches in addressing them. It is worth noting that it may be difficult to resolve a situation that is defined as a problem when it isn't totally clear or agreed what the problem is.

In the next chapter, I will examine the findings from semi-structured interviews, participant observations, and focus groups with graffiti writers, to better identify some of the nuances that distinguish graffiti writing from other forms of graffiti, as a form of recreation having planned benefits. Additionally, I 
will highlight findings that align with the literature on edgework, serious leisure, and recreational specialization. In the final chapter, I will revisit findings from research on writers and policy officials and discuss the ways that acknowledging features of the current findings in practice may be productive to policy and stakeholders. 


\section{CHAPTER 6}

\section{FINDINGS (PART II)}

\section{Overview: Research on Graffiti Writers}

Interviews, focus groups, participant observations, and other interactions with writers in the metropolitan area revealed consistent themes related to the graffiti subculture. Perhaps most notable among these is a necessity to learn and properly demonstrate subcultural values, skills, and knowledge. This process entails perseverance, commitment, socialization, and mentoring with members of the subculture. Where anyone can pick up a marker or a spray can, it appears that, generally through social dimensions, specific practices are learned in legitimate ways of how, when, and where to write graffiti. Distinct subcultural values were evident in research with graffiti writers. These emphasize silence to police, persistently developing one's name and reputation by doing illegal graffiti frequently, risk-taking, building a unique style (and mastering the traditions, or styles of graffiti), and a demonstrating a subcultural ethos of resistance to both norms on uses of public and private space and (often) to the bombardment of commodified images (ads) in the public domain. Through demonstrating acquired skills and knowledge, writers earn the respect and recognition of others in the subculture and continue developing skills and personal style. Thus, a graffiti career trajectory can occur through learning graffiti and developing one's name and street reputation, to potentially attain the status and skill required to sell one's art and earn significant income using learned graffiti skills or related talents. Different factors appeared to be involved in how one's graffiti career develops (or ends) over time. Within the progressive levels of experience one obtains in graffiti, the practice may resemble a form of edgework dark leisure (See also Williams and Walker 2010 on intolerable criminal dark leisure and Stebbins 1996 on deviant leisure). Additionally, writing graffiti over time may resemble forms of serious leisure in legal and paid endeavors, both as a practice resembling hobbyism, and, later, amateurism, with the latter generally occurring at higher levels of experience (See also Stebbins 1982 on forms of serious leisure). 
During many outings, conversations, and interviews, writers reported different benefits obtained from practice and varying motivations for doing graffiti, and for persisting to do so. Motives involved being known or developing one's name, artistic expression, social activity and interacting with friends, protest, subcultural expression, sending a message, to destroy, for distraction, meditation, fun, or thrill. Writers agreed that graffiti is a means to express one's inner potential that involves personal identity. Graffiti was also described as a way of feeling renewed, and a means to getting away from one's problems and allowing self-expression. Other benefits for doing graffiti included accomplishment, flow, thrill, fulfilling time spent with friends, income, making new friends and connections, and enhancing one's image or self-esteem. Graffiti was, by all writers, unanimously viewed as a form recreation having planned outcomes that were personally beneficial in some way. Writing graffiti in various forms and at different levels of experience appeared to occur in a trajectory leading from non-writer to illegal bomber, in turn perhaps leading to "progression" (or specialization per RST) in becoming skilled at piecing and professional wall art. After this time, most writers report having opportunities for being paid for painting graffiti or using their related skills. Evidence from the current research suggests that graffiti should be acknowledged as a legitimate form of recreation and a worthy topic for study under recreational specialization.

The above findings and others will be explored in greater detail after presenting thick descriptions of my observational research (and my researcher standpoint) and aspects of the graffiti subculture, including practices, values, motivations, and rewards (e.g. writers' standpoints). Throughout what follows, I note aspects of the findings and emergent themes from interviews and observations with graffiti writers as they coincide with the edgework framework, serious leisure and dark leisure, and recreational specialization theory. In the next chapter, these features will be revisited in terms of the ways that they contribute to the related extant literature and research. Additionally, I will later relate how these findings interplay with policy discourse and the standpoints and practices of policy officials, and the ways that this knowledge may be utilized in terms of policy modification and future research.

\section{A Day in the Life of Graffiti Research: A "Thick Description"}

In presenting findings from my participant observation experiences and interviews with graffiti writers, it may be useful to visit "a day in the life" of graffiti and the current research. Geertz (1974) posits 
that there is importance in providing a "thick description" in ethnography, to take the reader into the world of those studied, conveying a depth and "thickness" to reported data which superficial analyses may fail to provide.

On a brisk winter evening around midnight, the cold pierced my loosely clad black Mountain Hardwear fleece zip up jacket as I plodded onward to keep even stride on the sidewalk with my new friend, Fred13, whom I had gotten to know in the months before. We were heading through an old section of town away from a bar and grill we were hanging out near where my companion worked part time while attending a local university. I'd gotten to know some regular customers and employees at the bar and grill, and we had met through friends several times before actually talking much. After we had gotten acquainted and had known each other for some time, my acquaintance, Frede mentioned having heard I had planned to do a research project on high risk "BASE" jumping, an extreme sport involving jumping from high surfaces with a fast-deploying parachute worn by practitioners. I expressed to him over a beer that I was canceling my plans to study these risky parachutists for a qualitative research project for a class. I explained my interest in those who do voluntary and dangerous activities, or "edgework" (Lyng 1990). Access was going to be a problem with BASE jumpers ("BASE" is an acronym of the fixtures from which one jumps for recreation: bridge, antennae, structure, earth). Most who practiced BASE lived in places far from our midsized Midwestern city, and I could not afford the investment required in completing much wanted interviews and observations with the members of this high-risk subculture. I had already found out by his own mention that Fred was a graffiti writer, as he had shared once during an after-hours meeting. Weeks after sharing this with me, and after several beers after a shift, Fred slammed down his beer and asked if I wanted to go take a walk and "look out for him." Without hesitation, I agreed, recognizing a rare opportunity when I saw one-most graffiti writers, unlike the BASE jumpers, were probably less likely to make known their outlaw status, much less to invite non-practitioners to be party to their commissions of crime. After ducking into his car for a minute or two, my new friend emerged into the cold and told me we were all set. So, we embarked on our walk, making our way deliberately into the night. I quickened step to keep up through the fairly lit neighborhood, passing under ancient oaks beside venerable brick and board

13 I remind the reader that any assumed names of research participants or graffiti writer or crew names are pseudonyms assigned to protect the privacy and confidentiality of real individuals. 
houses built in the late 19th and early 20th centuries. My companion did not meet the stereotype of one who was about to do illegal graffiti, if there was such an appearance. He carried no backpack or shopping bag. I recall noticing that, donning the usual baseball cap, faded jeans, Vans sneakers, and black North Face jacket, my partner in crime didn't look too different than myself. As the roar of highway traffic got closer, a stillness and cold darkness settled into the air, and I sensed that we were nearing a rough part of town. I wasn't yet to have learned that there were only a few parts of the city writers wouldn't visit or that they considered dangerous. In the wealthy suburban areas, graffiti was thought to be discouraged. I soon found that most places where graffiti was done in the city were similar to areas around Washington, D.C. and outside vicinities where I had roamed as a teenage skateboarder and urban explorer.

The year's first snow had not yet hit us, but the cold had long since made its presence known. We passed down the sidewalk toward the roar of outbound interstate traffic, and Fred pointed to a "throwie" (a bubble letter form of one's spray painted graffiti name) up a sloped cement support under the highway bridge close to the very bottom of the road passing above us. "I did that recently with Early" (another writer). "It was sketch as fuck but we got it done." I nodded as we slowly continued on. We reached the other side of the underpass and a concrete ramp faced us on the left, bordered by an inward-curved chain link fence, the kind that line walkways over highways and along sidewalks crossing bridges that discourage people from throwing objects (or jumping) from the sides. He said in a low voice, "This is it."

Frede pulled a can of Rustoleum from his waist, revealing two more. My companion gave the can a few quick shakes, and the stainless steel ball inside rattled to life_- "clack, clack, clack!" The sounds pierced the roar of speeding cars that hovered above us in the otherwise silent urban night. Suddenly, I noticed my focus had sharpened slightly, the surroundings became a little more pronounced, while I noticed a train track across the street angling under the overpass. "Just let me know if anything's coming," Frede said to me as he secured a pale blue colored spray cap adaptor to the top of his can and gestured toward the road to the right and another pair of roads coming to a fork from the other direction across the railroad tracks, with a fourth road intersecting these across the tracks to the left. I could feel my heart rate starting to quicken and thump in my chest. "Ok," I managed as I sort of instinctively pulled out my cellphone trying to create as innocent a charade as possible to fit my surroundings and time of day. I decided to pretend that I was waiting for an Uber while standing shivering in this not so well-lit spot in a not so nice neighborhood 
at the corner of the walkway that crosses alongside the overpass ahead. I heard my friend's footsteps walk up the ramp behind me, as it gently angles up alongside the foot or so of interstate wall separating us from traffic, before switching back in the opposite direction where it eventually crossed over the road below and the tracks immediately across from my position. “Clack, clack, clack, clack, clackkk!!” I heard Fred shaking cans behind me, wincing at the invasive alien noise and hoping no one heard this and tipped off police to our whereabouts. My mind was creating various potentially bad outcomes to the current scenario as I lingered beside the ominous cement structure feeling like a sitting duck. Suddenly, highway roar was broken by familiar "pffft-pffft-pfffffffft" of paint being expelled from the spray can at my back. I made a silent prayer that no one heard, and after an eternity that was probably no more than three minutes, I heard myself caution my friend from over my shoulder. "Chill! Car! Car!!” I heard the "pffffft" noise stop and a scampering of footsteps as my companion moved to a darker place in the shadows while headlights slowly approached and stopped, pointing directly at me. I recall having become very thirsty at the time, and it was a little harder to breathe, perhaps due to adrenaline and paint vapors clouding the air around me. I fumbled with my phone and turned my head left and then slowly back to the right down the street a couple of times, then looking back to my phone, then both ways down the street, all the while stepping slightly forward from the sidewalk to the street carrying on the charade of acting as if I was expecting someone to pull up. After what seemed like too long, the car moved slowly to the right from its stopped position at the intersection and disappeared into the night. I called out in a hushed tone, "You're good," and I noticed the sound of spray painting had already resumed. This continued a while, punctuated by occasional loud noises clack-clacking of stainless balls sharply to life inside a can to loosen up freezing contents. This ritual repeated a couple of times - me alerting my friend of an oncoming car, him sliding in the shadows, while I was shuffling back and forth in place by the wall, occasionally peering left and right for the ride that would never arrive. Shortly after, my acquaintance again resumed painting. Not long after this, the spraying noises became shorter, more deliberate, and eventually stopped altogether, and I heard my friend step up casually to my left, breath and smoke clouding the air around his face as he drew on his cigarette and at the same time managed "We're good," giving me a fist dap, or bump. My heart felt as if about to explode, and I noticed a dizzying rush of adrenaline surging my body. I had just done my first observation of graffiti in action, and was remotely aware of possibly having broken some laws. I felt a little guilty over this but soon 
also realized that this was part of the cost of doing the research on which I had decided to embark. It must have felt like the sensation in quickly stepping on the brakes of one's car after noticing that state trooper in the median ahead on the interstate, facing your way, and finding out shortly thereafter that the officer was not going to follow you. There was more to it than this, but I could not put my finger on it at the time.

As we backtracked earlier steps, my companion hopped to the street and "tagged" a cursive looking rendition of his name, several times on the pylon supports directly visible to passing cars. "I like the way those turned out," I heard the enthusiasm in his voice as he gestured to the (to me) hardly-legible tags at chest level on the bland salt gray colored cement pillars. I took a quick look and agreed, still not sure we were out of harm's way yet. As we continued, Fred sprayed an occasional tag on dumpsters or garbage cans, partly in order to empty the cans he had. He continued "schooling" me on the various ins and outs of getting one's name up to be known and respected by others in the community, naming off several crews' and other writers' names from the area, who were known and respected by others in the local graffiti community. Many of these were highly respected "OG" writers who had been around the scene for a while, were often known outside the city, and had put in a lot of time in painting graffiti, usually also members of larger crews for whom several other respected writers "repped" or represented by painting together and regularly tagging and doing throwups and pieces of their crew's letters (See APPENDIX F for a glossary of graffiti terms). Frede was a member of a smaller "startup" crew, as one OG had later put it, called STP, and its writers had been becoming more "up" (or having one's graffiti visible) throughout the city. He had said this of his crew in a later interview:

"We had a big crew meeting a while back about what we want our crew to be...we wanna stand out and we wanna do more than other crews...get recognized for doing shit right and are respected, like you know not just doing shitty hollows but doing fill-ins and like crew fill-ins and like running and just .... see it everywhere..."

As we made our way back toward the safety of our cars, the first snow had begun falling thickly and heavily, peppering our dark fleece jackets with fresh white flakes. I later thought back to how elated and frightened I had been. I would later note how I had felt a charge from the experience, and I had eventually become conditioned to fear and the natural 'what if' thought patterns that surge through one's brain while in the vicinity of illegal graffiti. Later I would learn to properly conduct myself in doing graffiti research, and this did not "come naturally"--going for walks involving lurking in shadows and skirting the 
boundaries of the law. The fear of arrest or other dangers one encounters around graffiti are real, perhaps especially for a participant observer. I was left this night with a lasting impression that the same may be said for graffiti - that it appears to be a long and difficult learning process. It was only after many such outings and proving myself as a worthy lookout that I would be allowed to meet and observe other graffiti writers. The question I continue to ask is "Why do graffiti?"

One experienced writer discussed sending a message:

"Somebody that does graffiti may produce some work that speaks to somebody inside of them and maybe it opens up a voice in them or a window to a new idea, or you know a new frame of thought..."

This quote also appears to imply that hearing this message or voice may result in a raised consciousness.

I found in later discussions that an individual who does graffiti goes through a process of socialization in learning subcultural ways to correctly present oneself and legitimate graffiti art, through transgressing dominant cultural norms and values and navigating the risks and consequences that are involved.

\section{Risk in Graffiti Research}

My experience in doing research taught me to avoid certain personal dangers and involved learning to know when a significant risk was present if I encountered someone in the many random and isolated places that my research following graffiti writers took me. I was once approached by an individual while walking past a section of homeless camps near the railroad tracks who appeared to be in an altered state, intoxicated, or mentally ill, or possibly some combination of both. While I was passing by along the railroad tracks, he offered to sell what he called marijuana as he pulled out a quantity of some dirty soot colored substance in a large sized Ziploc bag and tried handing it to me. I politely declined, and he then asked for a ride. I again did not agree, sensing something was off and apologizing that I didn't know him well enough. Learning to navigate risky situations such as this one may serve as a form of edgework in one's experience as a researcher, as I often did, attempting to be closer and more immersed in the writer experience by visiting the places where writers go, or to go on my own to photograph graffiti in remote and often abandoned spaces within the otherwise densely occupied urban area. Overall, the risks involved in graffiti writing permeate into the world of the researcher or anyone else getting close to the action of everyday forms of resistance that occurred within graffiti writing. 
In one observational encounter, several writers and I had been attempting access an abandoned industrial building in order to paint a roller "lineup" (a production with several writers" names adjacent to one another, often in similar styles and color schemes). As we arrived, a very loud individual was yelling violent statements and expletives into the darkness across an empty lot of overgrown weeds where we had emerged while entering the complex. After some hesitation in discovering his proximity to us, my companions paused only a moment and chose to continue. An intermediate writer said at the time: "I'll take my chances. I'll spray him in the face with a spray can if he comes at me. Be like, 'Now, look, buddy!'” This instance may hint at the notion that writers may adopt a variant of the "code of the streets" (Anderson 1999), where respect is commanded in the ways one carries oneself in the struggle to avoid conflict but also maintain decency. As such, writers were in some sense outlaws operating according to their own constraints, norms, and values within a larger system of contrary norms, values, and practices, where hostility was common.

\section{Socialization, Mentorship, and Identity in the Graffiti Subculture}

An additional thick description of the graffiti subculture, values, and standpoint of writers is offered here to detail the socialization that is required in order to learn and improve necessary skills to continue to do graffiti as an "everyday form of resistance" (Scott 1984; Collins 1988), while conducting oneself properly, developing style, and earning respect from other writers. This narrative is organized to present the ways that members of the subculture, through mentoring, establish consensus in approval and respect among other writers, sometimes exercising social control, shaming, or ousting to preserve subcultural values and practices.

Lachmann (1988) and others found that among writers, entry into the subculture and development of one's skills and knowledge were dependent upon social dimensions and mentorship. Similarly, in the current study, a key factor influencing progression and to some degree connection to the graffiti subculture was in friendships and associations with other writers. Going from novice to respected writer appeared to involve practice and learning that occurred largely in social interactions. A common theme was that crewmembers were like friends or family to writers. Some established crew membership from friendships outside of graffiti. One advanced writer noted the importance of early shared connections and identity, referring to an initial encounter with one of his closest writer friends: 
"He did some graffiti on my skateboard...prolly like the wackest shit ever...BUT...from that day on, me and Brothr were graffiti writers. We weren't just skateboarders anymore."

An intermediate writer reported identifying closely with their graffiti crew, in a familial sense:

"we are about...authenticity and family. Just try to be as pure as we can to who we are as people... And it's just all the friends and family we been hanging out with together since we were 9-10 years old."

Another member of the same crew, affirmed, saying: “...they're like family and are about like being there for each other and like keeping each other from like getting down in the dumps."

Where graffiti did involve common values and support for friends and crew members, graffiti identity could remain known to other writers, while one's real identity remains confidential. A writer of an intermediate experience level discussed graffiti identity.

“In a sense it's like your alter ego. People know you, but they don't know who you are. They just know you by your name and your reputation and what you've built for yourself."

Many practiced graffiti primarily alone or with one or two fellow writers, often close friends or crewmembers. One advanced writer noted this: "I tend to paint by myself most of the time... and... It's more of a thing that I do when I'm in a particular zone."

On several occasions, writers expressed value in always having a marker: "Just like a goddamn wallet. Just like a goddamn phone, just like money —I'm gonna keep a marker on me if I have one." Where anyone can possess or use a can or marker, becoming a member of the graffiti subculture appeared to require mentorship in learning proper values, self-conduct, and notions of style before acceptance, trust, or respect were earned from the community.

A writer of intermediate experience who identified as non-binary female discussed the difference between 'writing graffiti' and 'being a writer' where a true writer uses cans:

“I don't use cans....I just got into that in the past month, but I've been writing...for about 10 years... I've just been using streaks and markers and stuff like that."

"Like what is the difference?" I am asking what distinguishes 'being a writer' from 'writing graffiti':

“I just feel like I don’t (identify as a writer); I get up...I tag...I did a roller the other day and a piece and like a little straight (straight letter)... with (the crew leader)...I just didn't want to put anything on the walls just yet. Because I don't feel like I practiced enough or nearly as much as everybody else...I just don't have the confidence to get out there and actually put it on the walls...I'm just really hard on myself and that's why I haven't done it." 
This individual and others reported that mentorship was an important part of learning and progressing to use of cans, as had reportedly occurred recently for this individual. This is consistent with other research, including Ferrell's (1996) where beginners often worked directly with more experienced crew writers before gaining the confidence and skills.

An active intermediate writer strongly identified with graffiti in his everyday life, and reported seeing and later check-listing potential spots while engaged in daily work routines, and also reported regularly "catching tags" while at work. He explained how graffiti and skateboarding are related in the way he views the everyday world:

"It (graffiti) gives me a lot of ideas. Everything I compare to graffiti...skateboarding is a good comparison... once you start looking at spots, skate spots, all you can see is where you can skate everywhere. And now (after he started doing graffiti) it's like, (I see) things (spots) I can skate everywhere and paint everywhere."

The latter half of this statement perhaps reflects a parallel to the body of research of socialization in deviance (See also Becker 1963 on learning to smoke marijuana). Prolific writers often approached painting as a mission, emphasizing planned elements of practice and preparedness, highlighting the 'resistance' theme throughout writing activities as consistent with other research (See Ferrell 1996 on resistant and anarchic elements of graffiti writing and Ferrell and Weide 2010 on "spot theory"; also note Halsey and Young 2006 on desire and resistance in doing illegal graffiti). The practice of check-listing or previewing potential spots ahead of time, prior to doing graffiti--described by writers as "doing homework" or homework - may reflect a dark leisure supportive activity consistent with deviant/"dark" leisure conceptual frameworks (See also Smith and Raymen 2016 and Stebbins 1996).

Perhaps expanding on the previous writer's statement about the different gaze one takes after developing as a graffiti writer, once I was engaged in a "day spot” observation with an advanced intermediate writer piecing a back wall of an abandoned business adjacent to a raised railroad track. On this occasion, we suddenly noticed what sounded like a charged chorus of secondary school-aged inner city children, singing what sounded like pop culture theme songs coming from the direction of some residences located on the other side of the tracks. At the time, the singers were out of our sight, and my associate and I were busy alternating from hiding in the weeds to resuming a relaxed standing position beside the wall, as the rumbling locomotive alternately passed backward and forward along the tracks, apparently being 
loaded with additional freight cars. This spot was within a mile of a train yard. My writer friend noted at the time:

"We wouldn't see all this hood shit if we were just simple ass white boys from suburbia. We wouldn't even be going into the hood at all..."

This statement emphasizes the fact that graffiti takes the practitioner into worlds unseen by many, and in the process, it shapes one's standpoint through an alternative identity, ethos, and practice of subcultural values. My companion later summed this up, facing me as we squatted below the tops of patches of weeds to avoid being seen by the engineer in the low-rumbling train drifting past us:

"Once you're painting so long...you honestly feel like a part of the neighborhood...like 'Yo, what's up! I'm broke as fuck; I'm out here doing illegal shit.' It's like, we are one and the same..."

This closeness or 'with these alternative environments in which one places oneself as a writer must also be learned in real time, as my perspective as close up participant observer similarly changed with experience.

\section{Subcultural Values and Practices and The Hip Hop Orientation in Graffiti}

Numerous subcultural studies have emphasized a subculture's musical preferences and modes of dress or other style (Snyder 2016). Urban "hip hop"-style graffiti is a product of the hip hop movement, which emerged in the 1970s and 1980s and includes music, fashion, dance, graffiti, and skateboarding (MacDonald 2013; Ferrell 1996). In the current study, writers did not indicate specific musical preferences or styles clothing, though many writers reported being or having been avid or occasional skateboarders. Notably, all research subjects persistently and illegally painted their graffiti name in improved representations and in different prohibited spaces. As well, certain personal standards applied to how one writes graffiti, and how one should conduct oneself in various situations in which graffiti is done.

Early research on West Coast graffiti writers used the descriptor hip hop in "hip hop graffiti" (Brewer and Miller 1990). Ross and others argue that, despite its association with hip hop culture (and despite the latter's influence on the development of artistic graffiti since the early tag and throwup forms) graffiti and hip hop are not intricately connected (2016:139). Current study findings also indicated that "graffiti writing" did not necessarily carry the "hip hop" descriptor in regular conversation, though it may be implied. I was never corrected by writers while using the term in interviews or conversations, and my use of the descriptor throughout this writing references the notion that graffiti is considered by many, including several sample writers, to be one of the "pillars" of hip hop culture. Most writers with whom I 
spoke reportedly enjoyed hip hop music but did not claim any single musical or other stylistic preference specifically centered around the hip hop or any other singular culture or movement. One experienced writer described how his graffiti is compatible with his music:

"I love hip hop; I've always been into rap music and the whole culture of hip hop; If I'm not in my basement making beats, I'm drawing, working on color schemes, looking at letters. It's pretty evenly split 50/50; I draw a lot of inspiration from the sounds, etc.

This individual and others who I interviewed spent a great deal of time practicing sketching pieces on paper or other media before they went up on a wall. This process practice included working with colors, shapes, patterns, and styles in writing graffiti, often at the same time as listening to, or, in this individual's case, creating beats. Interestingly, and as noted in other research, graffiti and hip hop music do have in common the notion that neither form requires a great deal of equipment: graffiti flows from markers and spray cans, while rapping or "beatboxing" can be done without equipment; scratching records and sampling are done with record players and some additional equipment of limited cost (Ferrell 1996).

\section{Efficiency Norms: A "No-hollow Zone"}

Many writers of all experience levels painted risky "hot" spots, which are highly-visible in the daytime, including highway walls or "street" spots (bombing) where graffiti throwups, tags, or pieces will get a great deal of public exposure. Incidentally, these spots often were abated quickly and frequently. Where advanced writers often sought spots where graffiti tends to "ride" (last) longer, this did not occur by accident (See also Ferrell and Weide 2010 on "spot theory" and the skilled selection of graffiti spots by writers). As such, a key value that emerged from observations and interviews was in making the most of the risk one exposes oneself to by utilizing a spot to its fullest, including painting as much as possible in the time that is available without detection. In other words, there is a certain amount of time one may reasonably expect to spend in painting any spot before being noticed by passersby or police, and often where it was possible to do a quick tag, it was also possible to "go bigger" with a larger hollow, throwup, or piece (See section below "Hierarchy of Graffiti Forms"). One night while going out to observe a research participant "taking a walk" (or going out to do graffiti), we encountered a style "rule" of practice set up in terms of the current city by a former king (a highly prolific and well-known writer). My

companion and I stopped at a bar, and while ordering, we encountered another local writer, who my friend 
spoke with for a moment. He later told me after we left: "I told him we were going out to catch some throwups. He reminded me that a respected local writer had said "the (current) city is a "no hollow zone."” It was explained that this meant that in the metro area, as compared to others, it was considered relatively "low" (safe) enough to generally get up by painting throwups (rather than just hollows or tags) without police detection. This was according to a well-known Midwestern graffiti "king" (a prolific and highly respected writer who by consensus, and had gone "all city" or had extensively painted their writer name or crew letters in all areas of a city). Everyone in the graffiti community appeared to deeply respect this writer for his demonstrating an exceptional level of dedication, his willingness to face arrest and court, and for displaying work in his ubiquitous pieces, blockbusters, throwups, and tags. My present company echoed this writer' statement, "If you have time for a hollow, you have time to do a throwup (a filled in outline of one's tag name)." A throwup is a filled in and outlined hollow of bubble" lettering style (or other style) that is an outlined rendition of one's writer or crew name (See next section and Appendix F). Throwups are one level in a hierarchy of graffiti traditions, or styles. This wisdom, echoed in the words of a style king, also originated in the graffiti ethos that was discussed as passed on through guidelines from past leaders. As a value, this directive could also be expressed as "going big" (making a painting as big as possible, given the circumstances). Another related and consistent theme among writers was consensus on an unspoken "hierarchy" of graffiti styles (traditions) consisting of increasing size and complexity. The hierarchy consisted in ascending order of handstyles or tags, bombing styles (i.e. hollows and throwups), and piecing (presented below). These guidelines were conveyed to me in my early observations, and the same knowledge was confirmed by many senior writers in the subculture throughout my research. These traditions or styles (not referring to artistic style) in which graffiti takes shape have an implicit code of practice related to their separate forms, and varying levels of time or skill involved in their execution. This finding is consistent with other research (Ducuyunan 2000; Ferrell 1996; Hawarth et al. 2013; Lachmann 1988).

\section{A Hierarchy of Styles of Graffiti}

What I describe as a hierarchy of styles of graffiti traditions or forms was explained to me in my earliest observations and conversations and has remained fairly-consistent over time and may align with other literature, which noted graffiti being done in various forms for different motives, with tagging and 
throwups done for "burning" (fame and destruction) and piecing as expression of artistic talents (Brewster 1992). Though this "hierarchy" often implies increased skill, time, and labor (and thus respect) in the production of tags, throwups, or pieces, it is the case that all sample writers used (or practiced using, as was the case with less-skilled beginners) each tradition or form of graffiti in order to get their name up. As has been demonstrate in other research, it was imperative that these traditions were practiced by writers of all levels. Also affirming other studies, proper learning of style and quality in graffiti occurred in the presence of one or more skilled writers who "educate" the newer members of the subculture (Brewer 1992:188; Lachmann 1988), and regularly coach them on proper graffiti (See also Ducuyunan 2000:115-116 where writers shared a culture of sharing information, graffiti supplies, and knowledge).

\section{Handstyles, Tags, and Tagging}

Different levels of graffiti writing styles occur in less and more complex productions, as might occur in a hierarchy, with more complex instances on the higher end, and the simplest at the lower one. Tags (the practice is designated 'tagging'), or "handstyles," are executed in a quick process called "tagging," consisting of a stylized rendition sometimes resembling calligraphy, is usually done in large volumes to display one's graffiti name or crew letters to earn fame through public exposure. Tags may be done with added tildes, ticks, arrows, underlines, or other add-in effects. Tags are executed with various drawing implements, including aerosol spray paint (usually Rustoleum brand, but often whatever is available), art supply grade paint markers, "streaks" (paint markers designed for metal and other applications), inexpensive markers, white out pens, felt-tipped pens, or sometimes shoe polish or other pocket sized applications. These features were also consistent with other research (Brewer 1992; Ferrell 1996; Gomez 1993; Halsey and Young 2002) in terms of the applications and uses of tagging and the materials chosen for their use. Notably, during earlier research, Krylon was often the brand of choice (See

Ducuyunan 2000 and Ferrell 1996). One veteran writer told me that after the early to mid 2000s, Rustoleum products could be used with adaptors and different types of caps, including wide spray nozzles or ones having high-pressure caps suitable for fast applications like tagging or throwups. 


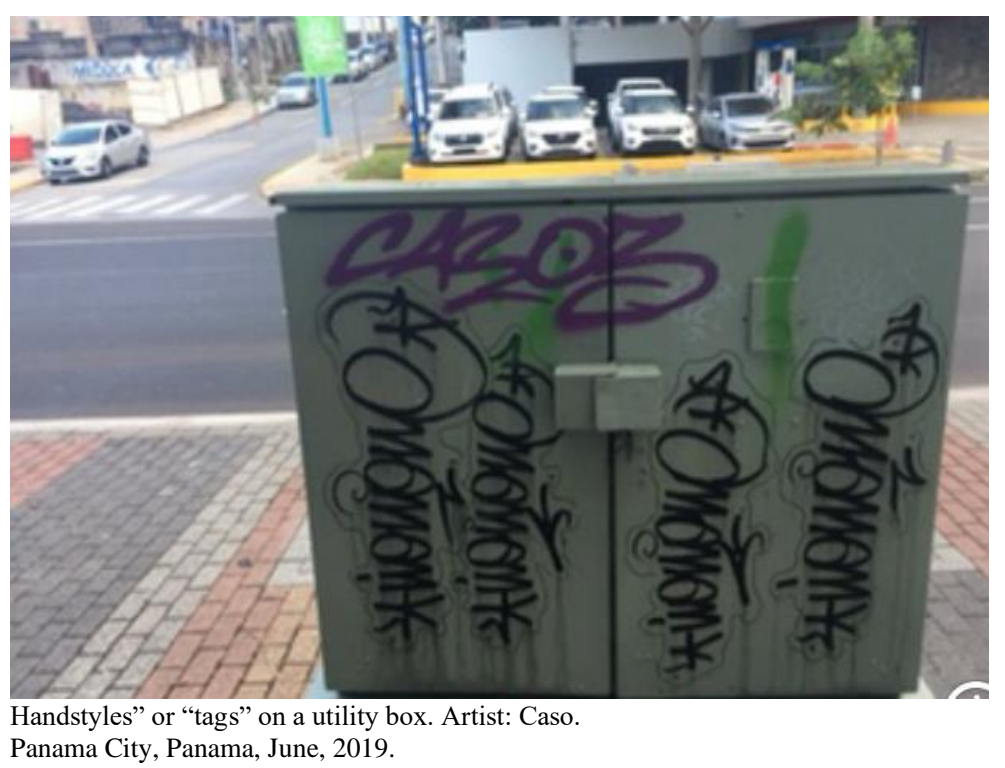

An array of different types of products are used and sometimes marketed by producers of art supplies for graffiti or related applications. Below are some commonly acquired tools for tagging:

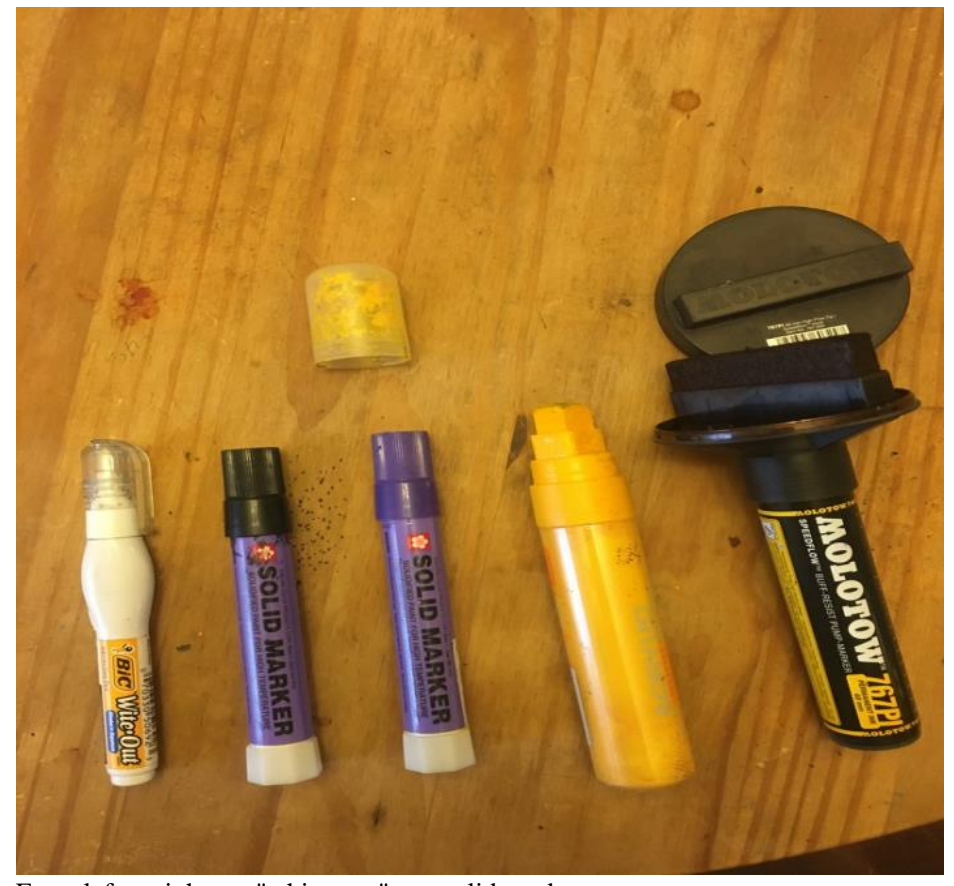

From left to right are "white out "pen, solid markers, wide-tipped, refillable markers. .

The types of markers above (and others) were frequently used by writers in the current study for getting up with tags on street signs or other public places and were also used for drawing train "monikers," or renditions of one's tag name, graffiti crew letters, an alias, or some symbol or graphic with or without a slogan on sides of train cars. Monikers were thought by some to have been historically written by hobo 
subcultures for communicating about sources of work, friendly locals, food sources, or traveling and railroad conditions, such as places to look out for the railroad police (Lennon 2016; Ferrell 2019). Modern train monikers in their pre-aerosol original form were "written" with railroad tar or oil paint, or done as carvings, a precursor to modern hip hop graffiti. Monikers were tailored to wooden box cars as a canvas, and among the most known of such hobo train artists were Bozo Texino and Herby, who sent thousands of these monikers across the country on freight lines (Lennon 2016:31). On many of my research excursions, graffiti writers often pointed out several modern style train monikers, some of which I found later were done by transient subcultures, graffiti writers, or local rail workers. I later often noticed the same writers' monikers in my travels to other parts of the country, and many writers remarked about this in conversations.

Though accessible to even total beginners, tagging, or writing "handstyles," is thought to be an entry way to graffiti for amateurs who may write for a variety of reasons, perhaps becoming active "taggers" and "bombers" (who paint tags and larger renditions of their graffiti name) before potentially beginning to "piece" (discussed below), perhaps sticking with graffiti long enough (or not) to reach an advanced or elite writer status. It is important to reiterate that tags (and other traditions or styles in graffiti) formed a necessary basis of subcultural communication and development among current study writers, as was also the case with past studies (Brewer 1992; Ducuyunan 2000; Ferrell 1996).

Tagging was historically done for reasons of "power" or "fame" (gaining territory and reputation as a writer), "burning" to express artistic skills, or painting with intent to get fame or, to a lesser degree, to deliberately destroy property, known as "bombing” (Brewer and Miller 1990). This trend was also consistent in the current research in terms of generalized motives for doing graffiti reportedly being related to ego and thrill, centered around tagging to establish one's name and reputation during the early career, versus later when graffiti was generally more associated with creating more complex “pieces” or masterpieces (as will be discussed in later sections). Part of earning respect and being accepted in the community involves being up, or having one's name seen and recognized by others in the subculture. This involves tagging, as well as the other traditions in graffiti styles. Consistent with other research, writers in the current sample noted that tagging is a social activity and part of the subculture, a tradition to be 
respected, and as such authorities will never eradicate it (See also Halsey and Young 2002:173 on tagging's centrality of importance to graffiti subcultural members).

A variation of tagging known as "scribing," or sometimes called "scratchiti" (McAuliffe 2012), is done using a sharp object or "scribe," to etch one's mark or name sometimes using an etching acid product for inscribing mirrors or other glass surfaces. I sometimes was present where an acquaintance scribed their graffiti name, and familiar graffiti writer names appeared to be visible on many mirrors and other surfaces in public places in the city limits. One intermediate writer noted: "scribes are like one of the best ways to get up because they ride for a long time...not often do they replace mirrors."

\section{Hollows, Throwups, and Bombing}

A next form of graffiti in a hierarchy of styles consists of hollows, and throwups, "throwies" or sometimes "bubble letters" (a graffiti lettering style where parts of letters may resemble inflated bubbles). Hollows are generally larger than tags, and are hollowed outline renditions that may be done in "bubble" style lettering of a graffiti name or crew letters. Hollows have a lack of color fill and consist of generally an outline, sometimes having 3D effects built in (the color of the wall may be used as the "fill" color).

Alternately "throwups" are filled-in forms of hollows outlined with a contrasting shade against an interior fill color. Hollows or throwups may be done in square or rounded, sometimes in sharp edged letter styles.

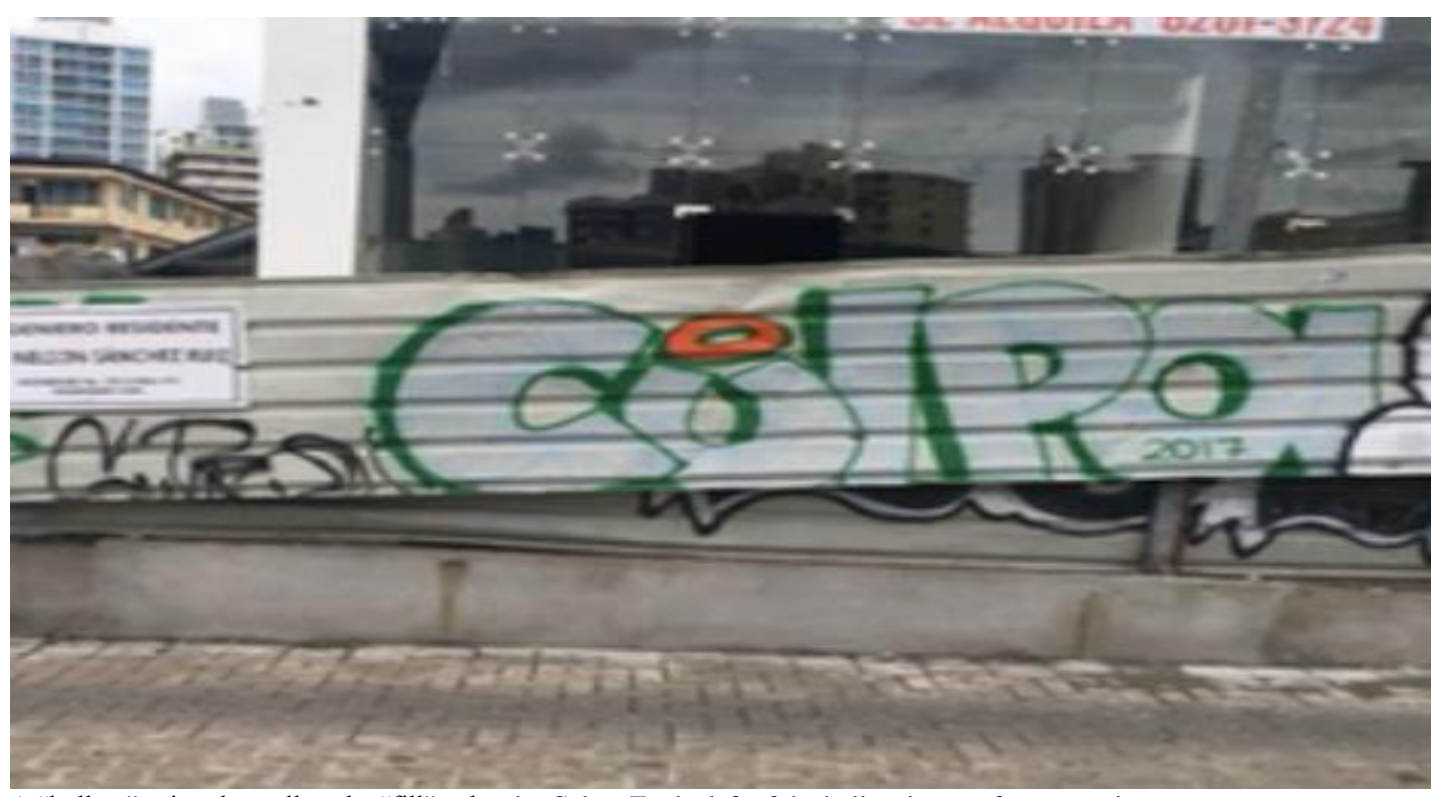

A "hollow" using the wall as the "fill" color, by Culpa. To the left of the hollow is a tag for comparison. Panama City, Panama, June, 2019. 
A throwup may also include an outside border of color that makes a production pop from the background color. Throwups and hollows may be done with additional features, exclamation points, dollar signs, faces, or characters to add flair to the production, as is often similarly done with tags. "Bombing" may refer to a collection of practices that involves getting one's name up in the street and may include tags, hollows, or throwups, which is a term that appears to remain consistent in modern graffiti culture as reported in earlier works on "wars on graffiti" (See Austin 2010 on bombing forms often being more common in response to militarized graffiti policy; Also see Brewer 1992 and Ley and Cibriwski 1974 for historical references to bombing). There is an implied risk in bombing, which current sample writers reported to be a quantity-oriented practice (as opposed to quality), meaning that the intent is to get one's name up frequently (and quickly). Bombing may include piecing in the streets, but pieces done while bombing were generally done very quickly and less elaborately, due to the risk, lacking the same detail as one would dedicate to piecing under less risky circumstances. Consistent with other research, throwups were often produced as less elaborate versions of pieces (See also Ferrell 1996:83) and were often the choice of writers in areas that were considered high traffic or "hot spots" (See also Haworth, Bruce, and Iveson 2013 where writers faced by increased abatement often resorted to "quick and dirty" forms of writing that includes throwups or tags).

In matters of respect, in the current research, going over a tag was usually avoided if the tag was especially stylized or done by well-known, prolific, or deceased writers, also consistent with Ferrell 1996 and others' research where going over kings was usually avoided. Additionally, if going over a tag, one was expected to do a larger and more complex production using paint. It was considered appropriate if going over a tag to paint either a "hollow" (a hollowed rendition of lettering) or a filled-in hollow known as a "throwup," or perhaps an even more complex "piece" (masterpiece). Going over" someone else's work can be considered respectful or disrespectful (or sometimes irresponsible as will be discussed), and was expected to be done by "burning" the original work (painting a better production) to lessen chances of conflict and convey a "proper" execution of going over. Displaying the correct skills and styles in this way while writing graffiti involved practicing according to a consensus of what is appropriate in "going over" other graffiti (according to the hierarchy of graffiti styles), while at the same time "going over" was one of 
the most taboo actions one could make, due to it often resulting in confrontations. An intermediate writer discussed a general guideline on respect and going over:

“...if you don't see their stuff that often, and it doesn't look that great...you could probably go over it and not get too much shit for it...that person's not really respected."

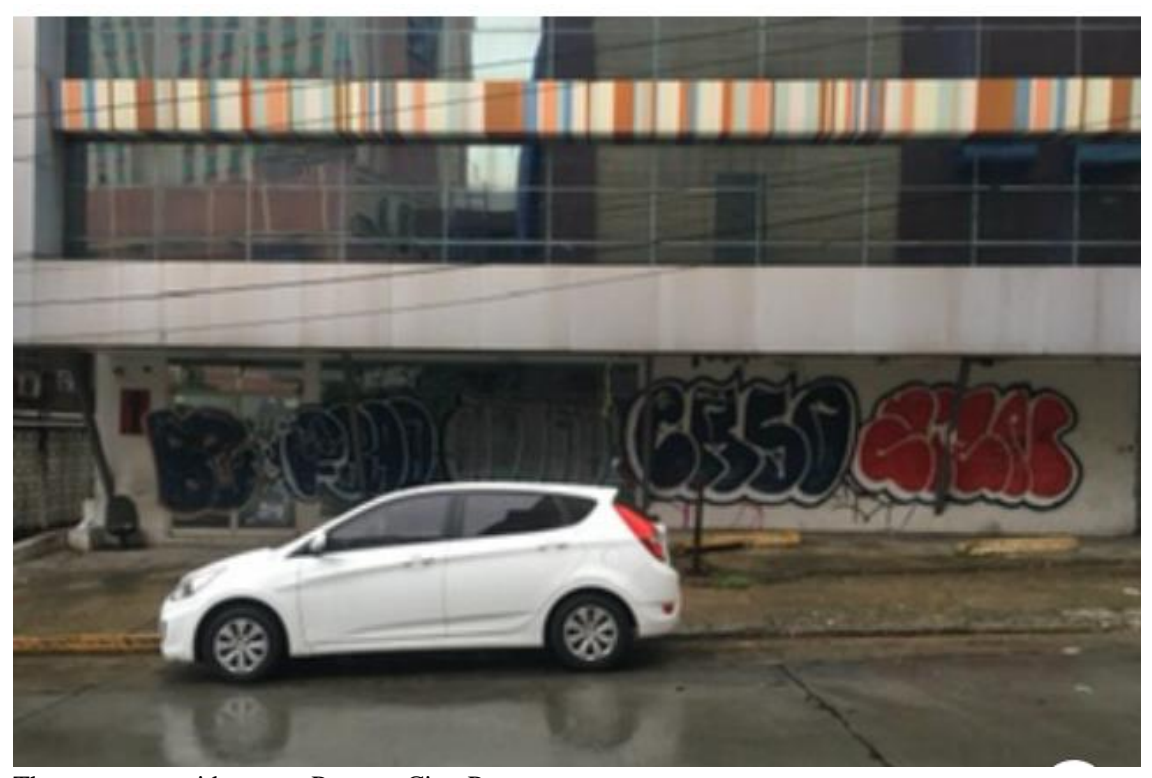

Throwups on a side street. Panama City, Panama.

While a throwup was the accepted graffiti style choice to use in getting up quickly, and perhaps in going over a tag or a hollow, it was considered good etiquette when going over a throwup to do so with a more skilled "piece."

\section{Pieces and Piecing}

The third level in the hierarchy styles involves pieces (or the practice known as "piecing"), generally from simple and less-stylized to more artistically aesthetic and more complicated or stylistic versions of names or crew letters. It was agreed that pieces usually include at least two colors, a fill and an outline color, contrasting the fill color to create "3D" shadowing effects, giving a sense of movement to letter forms and using other depth effects. The entire production of a piece often has a single or multicolored background and sometimes a shell color or "force" going around the other part of the letter shadowing. Pieces may contain stars or arrows as extensions of the lettering, and use elaborate color fades within the fill or 3D, sometimes "coins" or patterned effects using patterned lines of color inside edges of letters in shadowing. Pieces may have a comic book or 3D appeal and appear to be "coming out of" the surfaces on which they are painted. This characteristic of piecing is consistent with other studies on graffiti 
subcultures and practices (Ducuyunan 2000; Ferrell 1996; Halsey and Young 2002). Also consistent with other research, pieces could take several hours or less than an hour by skilled writers (See also Ferrell 1996 and Ferrell and Weide 2010 on piecing).

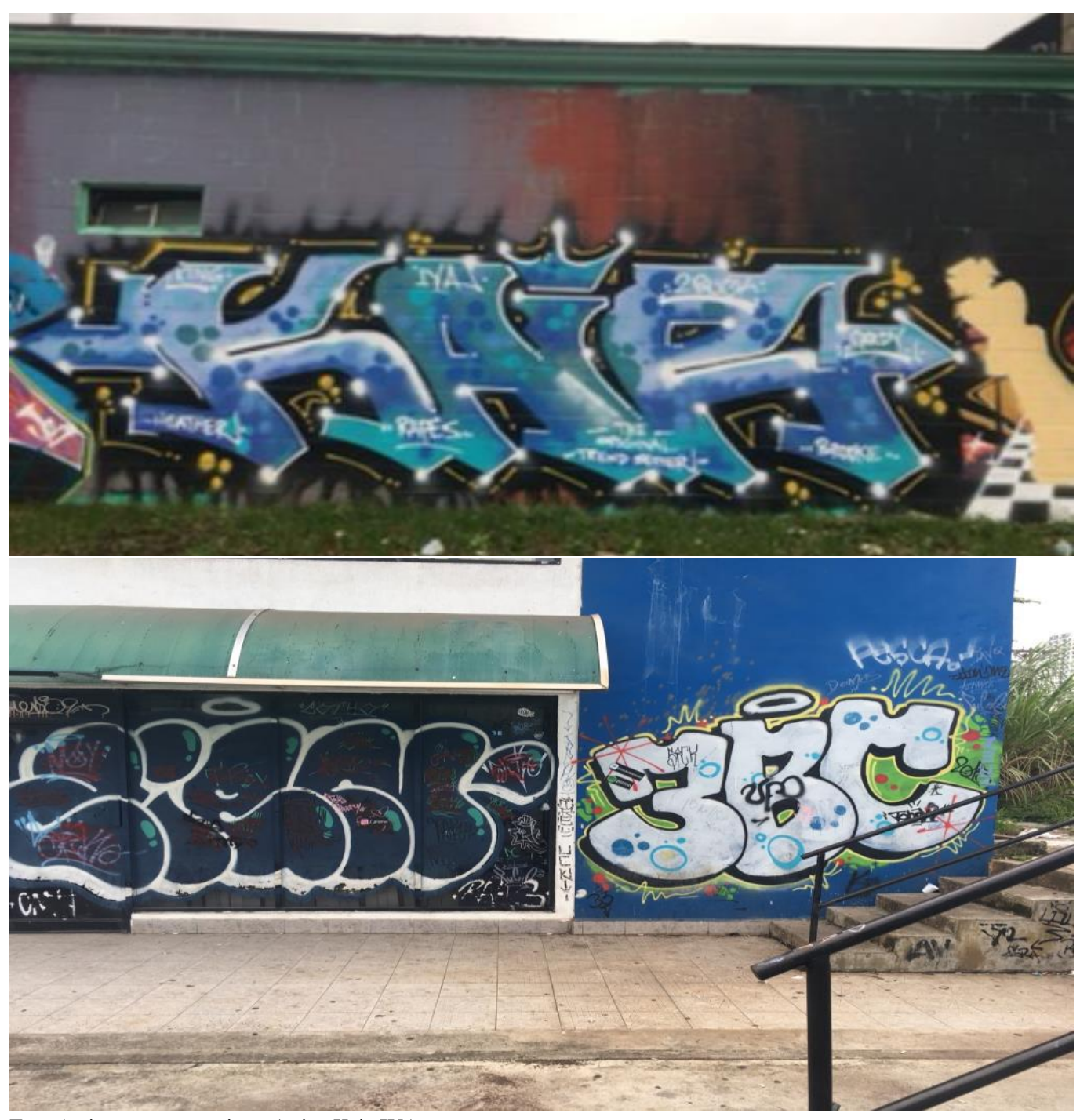

Top: A piece, or masterpiece. Artist: Kair-IYA.

Below: A throwup (left) and a three-letter piece in Panama City, Panama. Note the additional effects in the foreground and background of both the pieces and the outer shell (yellow) and overall crispness of the lines, shadowing, halo, crown, and other effects.

Pieces may be gone over, either on walls trains, or other surfaces but in my research, going over was usually considered respectfully done if first using a "roller" color to buff out the piece with a base color for a new piece, or at least care is usually (not always) taken to completely go over the previous writer's 
work14. Alternately, creating group "productions" was acceptable if going over, given the original is "bodied" (gone over larger).

Within piecing as a form or style of writing, there are also styles evident in one's graffiti, such as the "old school" style that is reminiscent of earlier (1970s to 2000s) pioneering lettering elements of stars, arrows, handles, flares, and other lettering manipulation. Additionally, "wildstyle" or highly adapted visual exaggerations on letters, often rendering the entire piece illegible to all but the initiated. One veteran described styles of graffiti:

"Style would be just be like fonts I guess... different lettering... Like old school shit, wildstyle shit, block letter shit, bubble shit, bomb shit, throw up shit. Style. Fucking handstyles, tags, all that shit. Top to bottoms, end to ends, would follow that."

Styles, including wildstyle or "old school" or styles in forms like bubble lettering from throwups, can be incorporated into every different element of one's writing, whether pieces, throwups, hollows, tags, or characters (Also see APPENDICES C, D, and F for additional descriptions of wildstyle, piecing, and other related terms).

\section{Rollers and Blockbusters}

Where some pieces may "burn" others in quality and presentation, higher levels of precedence over pieces in the hierarchy of styles discussed by writers was not usually encountered, aside from in some instances of capping or dissing. Stated differently, pieces did not often get gone over, but if they did it was by something larger and more stylistic, or perhaps more so by roller pieces. Rollers may include largest varieties in the graffiti styles, and often occur in over-sized and stylistic block letter, or "blockbuster" (square letter), pieces constructed using buckets of paint and paint rollers, often affixed to long roller sticks and extensions, particularly in "heaven spots" or highly visible locations where graffiti could be seen from multiple and far off vantage points and tended to avoid "the buff" longer, due to the difficulty in reaching the spot. Heaven spots often involve a greater level of risk, both physical and psychological (See also APPENDIX F). Letter fills in roller pieces are either outlined with other colors of roller or aerosol paint, and may contain various letter bending effects of pieces, but usually always having a $3 \mathrm{D}$ effect to create

\footnotetext{
${ }^{14}$ As mentioned already, higher status writers didn't always completely go over others they may not respect, or sometimes those of less status went over others for various reasons.
} 
realism and depth to the letters, often with backgrounds and multiple color shades, and, occasionally, animations or characters. Blockbusters and pieces may convey the willingness to "go big" (paint as big as possible or completely fill the canvas chosen in the spot or wall) in order to get up, as well as showcasing one's artistic talents. Commenting on style and going as "big" as possible, one writer said: "You gotta let "em know." A prime example of "letting them know" may be evident in the potential to "go big" with roller pieces as demonstrated by ones such as the famous 1997 block letter piece by Saber-AWR that spanned nearly three hundred feet in length along the Los Angeles river. This same writer described this practice as a key part of "aggressive styles" common among prolific West Coast graffiti crews.

For writers in the current study, claiming the status of 'writer' involved earned respect through continued practice and mastery of the hierarchy of styles. Generally, pieces (and sometimes throwups) were gone over with (or less often without) permission granted (writers may give a call to friends who are writers or more experienced ones to ask before going over specific instances of their work). Most writers did not go over other respected writers' pieces (either living or, even less frequently, the deceased). Exceptions may regularly occur in cases of civilian non-writers looking for a place to paint, in accidents (for instance picking a spot to paint when in darkness and not looking carefully where choosing to paint), or in deliberate "beefing" (feuding) for various reasons. Such instances converge on notions of comparative skill, proper execution, and respect (or disrespect), which must be learned in order for one's graffiti career to develop. Practicing the correct code of conduct and painting styles appears to be fundamental to maintaining the levels of subcultural respect needed to progress. It is also important reiterate here that many writers emphasized that, in order to respect the traditions of graffiti, one must continue to tag throughout their graffiti career along with doing other styles. Additionally, learning' did not equate to 'graduation' from one form to the other, but instead indicated mastery of different graffiti traditions or styles. While OGs and intermediate writers tended to specialize in piecing, and while beginners first focused more on bombing practices, no single tradition of graffiti was necessarily practiced exclusively by writers of any given experience level. 


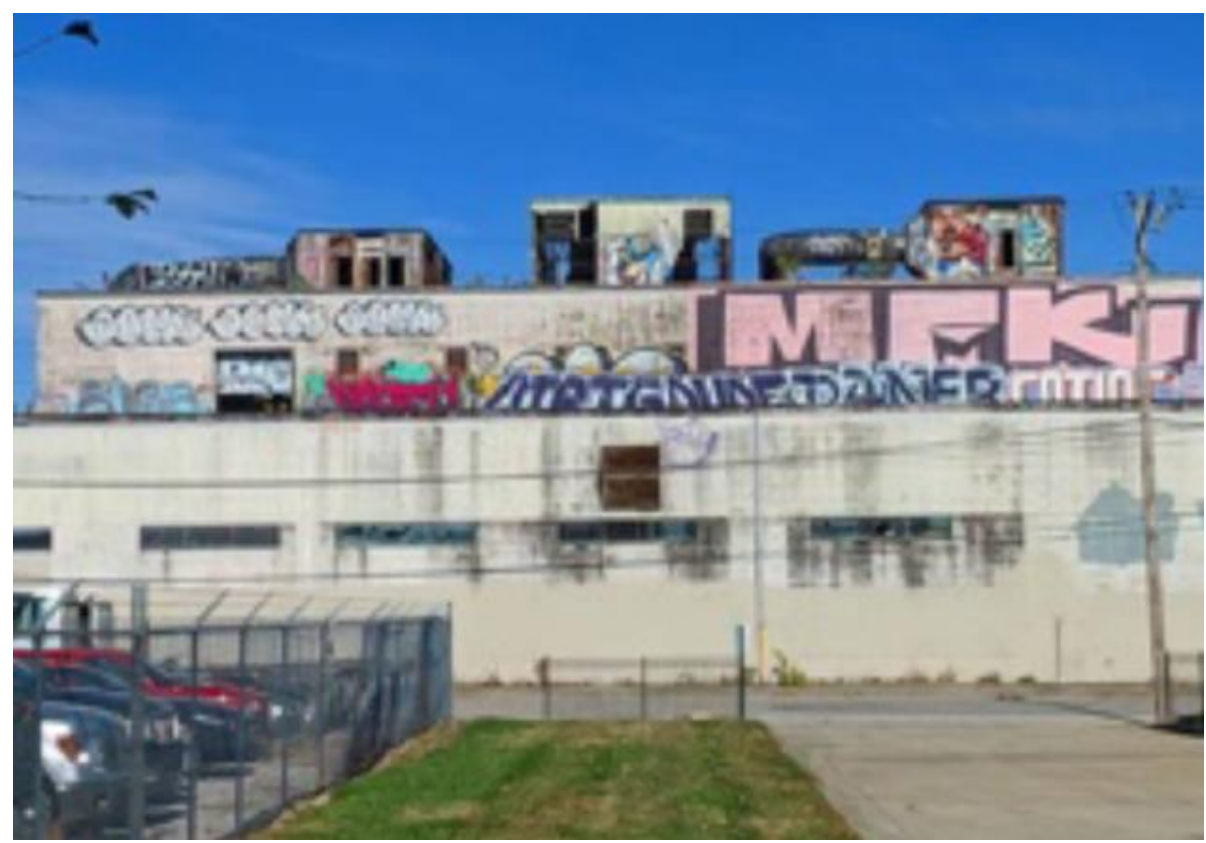

Roller pieces (top right and below), January 2020

\section{Experience Levels, Mentorship, Progression, and Social Control in Graffiti Subculture}

A frequently reported ideal of advancement appeared to be earning respect and was a key feature distinguishing writers of different levels, often the difference between beginners and others. Central to this was the demonstration of correct personal conduct and carrying oneself with respect and responsibility, such as when going over another writer (as discussed above). Thus, learning and mentorship were usually central to the "progress" of writers, as is consistent to other studies on graffiti subcultures (Ducuyunan 2000; Ferrell 1996; Halsey and Young 2002). Mentorship (and sometimes shaming) appeared to serve an important role in guiding the uninitiated on proper behavior and practices that maintain subcultural standards such as proper executions of style and styles of graffiti. As such, there existed more experienced writers, intermediate ones, and beginners, having varying levels of experience, dependent loosely on years of involvement and perhaps more specifically on degree of commitment and involvement. These different experience levels were related to me as in vivo codes. "Toy" or beginner writers had little or no artistic style, skill, or knowledge of graffiti, and were usually in their first year or two of practice. "Intermediate" writers, or sometimes simply “writers." attained the 'writer' status by demonstrated dedication and notable levels of artistic style and continued to establish their graffiti name through several dedicated years on the street as "bombers" who eventually begin to "piece." "Veteran" or "OG" writers, were advanced in skill and had been around the scene for a decade or more, usually since the early 2000s or before (See also 
APPENDIX F for a definition of "OG" and other graffiti terms). As will be discussed throughout what follows, these different classes or designations of ascending status and skill in graffiti writing appeared to occur along a graffiti career trajectory of specialization wherein writers typically begin writing as toys and progress through levels of advancement. Many writers eventually attain the high levels of skill possessed by veteran writers, who potentially may potentially "go legit" or cease writing illegal graffiti and embark on legitimate careers based upon their artistic or other graffiti skills.

\section{Figure 1 Total Sample Writers by Class / Experience Category}

Generally, Toys had 0 to 1.5 years of experience, Intermediates reported between 2 and 10 years, and Veterans had 10 or more years of experience (See sections above for a definition and discussion of experience levels/classes of writers.

\begin{tabular}{|c|c|c|c|}
\hline $\begin{array}{c}\text { Interviewed/Observed Writers } \\
\left(n_{l}=31\right)\end{array}$ & Toy (beginner) & Intermediate & $\begin{array}{c}\text { OG } \\
\text { (Veteran) }\end{array}$ \\
\hline $\begin{array}{c}\text { Writers per Category } \\
\text { (Percentage of sample) }\end{array}$ & 6 & 13 & 12 \\
& $(19.4)$ & $(41.9)$ & $(38.7)$ \\
\hline
\end{tabular}

Figure 1 displays frequency distributions (and percentages) of writers who were assigned to each specialization level. It is also useful to acknowledge that, as also discussed elsewhere, not all writers progressed at the same rates. Additionally, the data did not reveal much granularity among writers of different progression levels regarding self-reported levels of perseverance or commitment in writing. That is to say that most writers reported to have persevered over time with periods of inactivity corresponding to other major life events. Nonetheless, as also is discussed elsewhere, a shift appeared to occur between painting with a high "quantity" orientation in the beginning and middle of one's writing career. Later, at some point in their progression, writers tended to have reported to have accumulated status and skills and began to paint with a more "quality" orientation, including in many instances using these in paid and professional pursuits.

Since a time-series comparison of data was not possible in the current research design, I utilized several questions and prompts about level of time, resources, and money invested in graffiti as compared to other recreational pursuits (See APPENDIX A, Questions 18 and 29). Data indicate that, taken as measures of involvement and centrality of importance to other life pursuits, one's level of investment in graffiti and related activities increased notably over time. This occurred during the specialization between the toy and intermediate classes and increased for veteran writers (See Figure 2). Questions also probed respondents for 
how personal levels of investment and involvement changed. Generally, intermediate and advanced writers reported a significant increase in personal involvement and investment "since the beginning" (being a beginner), offering additional support for recreation specialization occurring in graffiti writing (See Figure 2 below for trends in self-reported investment in graffiti compared to other recreational pursuits).

Figure 2 - Relative Graffiti Investment by Writer Class/Specialization Level (See also APPENDIX A - INTERVIEW GUIDE - GRAFFITI WRITERS, Questions 18 and 29).

\begin{tabular}{|l|c|c|c|}
\hline \multicolumn{1}{|c|}{$\begin{array}{c}\text { Interviewed Writers } \\
(n 2=23)\end{array}$} & $\begin{array}{c}\text { Toy (beginner) } \\
(4)\end{array}$ & $\begin{array}{c}\text { Intermediate } \\
(10)\end{array}$ & $\begin{array}{c}\text { OG (Veteran) } \\
(9)\end{array}$ \\
\hline $\begin{array}{l}\text { Reported levels of time, } \\
\text { money, resources } \\
\text { invested in graffiti as } \\
\text { compared to other } \\
\text { recreation }\end{array}$ & $\begin{array}{c}\text { Less than (2) } \\
\text { About the same (1) } \\
\text { More than (1) }\end{array}$ & $\begin{array}{c}\text { More than (2) } \\
\text { Much more (8) }\end{array}$ & $\begin{array}{c}\text { More than (1) } \\
\text { Much more (7) } \\
\text { No answer (1) }\end{array}$ \\
\hline $\begin{array}{l}\text { Percentage (range) of } \\
\text { investment in graffiti } \\
\text { compared to other } \\
\text { recreational pursuits }\end{array}$ & $25-50$ & $50-90$ & $60-100$ \\
\hline
\end{tabular}

Figure 2 displays counts (and percentages) interviewed sample writers according to class/category (experience level) and frequencies of reported comparison categories of level of graffiti investment relative to total investment in all leisure/recreational pursuits. The percentage ranges in the bottom row reflect selfreported level of investment (money, time, and other resources) in graffiti related activities as a percentage of one's total recreational activities (for example, 100 percent indicates zero investment in other leisure/recreational pursuits). Designations of class or experience/specialization level (according to in vivo codes) were either self-reported, or were rated as such by other writers, including several OGs with whom I spoke. Though 'intermediate' was (like “toy” or "OG”) a term I adopted from conversations with numerous writers, generally, if a writer was not a veteran and was not a toy (or self-proclaimed beginner), they were assigned to the intermediate designation. Being at the intermediate level of writer was confirmed by a frequently reported preference for bombing, maintaining their name and their spots, dedicated to improving piecing styles and skills such as advanced can techniques, painting methods, and design features (in all cases learned from advanced writers), and in being current or past crew members. Intermediate writers were still engaged in developing and advancing their styles, skills, and reputations, sometime after having earned writer status beyond the beginner or toy designation. This appears to be consistent with other 
research where different classes of writers reported corresponding variations in philosophies, associations, or motivations for doing graffiti (See Ducuyunan 2000 on taggers, writers, and gangsters and Brewer and Miller 1990 on taggers and elites).

Earning writer status for one intermediate level writer involved going from a "wack tagger" to “actually being good" eventually obtaining writer status, beginning with few social connections.

'I've always written on peoples' shit... used to be really fucking toy and ... was just like a wack tagger...didn't understand that I could actually be good...I didn't know people or use the internet...only knew a few people... maybe like 3 actual writers, and...didn't hang out with them often..."

Earning writer status involves more than just getting up, but also knowing people. Here an intermediate writer describes what is required in earning writer status:

"having a well-established name, ... be up enough...have good...multiple (styles) preferably. Definitely have tags down (perfected)...pieces, for sure."

It appears that mastering the hierarchy of styles described above, as well as utilizing these different traditions of graffiti in getting up lead to writer status for this individual.

Veterans or "OGs" (“original gangster" referring to "old school” writers) were respected for having a long history in the graffiti scene, typically painting prior to when the internet and social media emerged strongly, noted by one writer to be the period from around 2006 to 2009 . Veteran or "OG" status writers were known and respected for painting skilled pieces and "going big" (covering a wall completely or as much as possible), for their reasoning and values, and knowledge coming from long experience. The veteran or OG level in the current research most closely compares to Brewer's (1992) “elites."

As mentioned elsewhere, an OG or other experienced writer might mentor “younger” (lessexperienced) writers to assure proper learning occurs, and that that person will demonstrate it in their practices, and (hopefully) share it with others. This was necessary before writers could progress, earn status, and eventually be welcomed at annual gatherings for graffiti and in painting in train yards (both events from which toys and many intermediate writers were excluded). Some consensus was evident among veteran writers for a value for the culture supported by teaching other graffiti writers. One veteran writer said:

"I don't want to paint with every single person in the game... will meet them... If there's somebody new... and I see they have potential, by all means I'll help 
them...take them under my wing...tell them what they're doing wrong...guide them in a new direction. I feel like you need to do that for the culture."

Mentorship generally occurred when OG or intermediate writers might "take in" a "younger" (less experienced) writers out to show them proper conduct and norms on the ways to paint different spots. This might sometimes involve "guiding them in a new direction," as the veteran writer mentioned here noted, again consistent with other research (Gomez 1993; Ferrell 1996; Halsey and Young 2002). An instance of this occurred when two intermediate level writers went out to a train yard with an experienced writer who had allowed the two to come along to photograph train graffiti and perhaps to demonstrate proper train writing. I was not present on the outing, but one writer recounted that, while leaving, the three were approached by another experienced writer who immediately expressed disapproval toward the younger writers' presence. Ultimately, the dissenter was answered by the senior veteran writer, who told the former in not so many words that it was ok and to back off, which the other did willingly. It appeared that painting in valued train yards carried responsibility for not bringing in others who may bring careless behavior to attract unwanted outside attention.

Within the culture of hip hop graffiti there appears to be a "structure," however loose, that determines who becomes an insider and who stays an outcast. Whether or not one begins to graffiti at one's own behest or that of a friend, accepting advice from more advanced writers (or anyone better than oneself) seemed to be key to earning trust and respect and becoming part of the community. Graffiti was thus not a solo endeavor, but a collective one, dependent on social approval (or social control) on which learning and continued acceptance in the subculture may largely depend. In this sense, individuals who are accepted must show and earn respect and follow the established subcultural norms, again consistent with much of the literature on graffiti (See also Lachmann 1988 and Ferrell 2006).

Many writers in the current study reported having a "day one" (a person who first influenced them to write). One advanced writer reported the bond one often makes with their personal writer influences.

"Jair, he's my 'day one,' he literally was there before anyone else and was the person that first inspired me to write. We'll always be tight, forever be homies."

The early (and ongoing) establishment of friendships one with other writers appears to be key to the continued socialization and accumulation of contacts and mentors that occurs in one's graffiti career. Additionally, based on current findings, it appeared that some level of respect was earned in utilizing the 
advice of more experienced writers, who may offer some specific help or critique or create a "sketch," in their own style, of a less-experienced writer's graffiti name. In some cases, if such advice is not taken or a sketch not practiced, offense may be taken by the more advanced writer. This occurred in one instance that I observed where an OG writer told me he had given a sketch to an intermediate writer, who had reportedly not used it. When asked about this, the veteran writer said, “I told him he needs to paint bigger. He hasn't used my sketch I gave him, either." This writer appeared to take offense by the failure of the other to practice the advice he had provided. While we were discussing this on one occasion, the other writer acknowledged: "I used his E, but I refuse to do the whole sketch."

Though it was not totally clear why he rejected the experienced writer's guidance, the newer writer reported to me that the veteran made him feel very demoralized over time, continually chiding him for painting too small. The alienated writer at one point stopped actively doing graffiti, though it is uncertain how this interaction may have affected his decision to stop. To my knowledge, this writer has continued to paint since taking a break.

Another instance where an experienced writer offered advice to a beginner occurred when I met with both of them one afternoon near the downtown area of the city. They had been talking about possibly going to paint graffiti, but this was never decided. After we met, rain had become imminent, so we decided to drive to my apartment to decide what to do. After we settled in on my back porch, Bcool (the advanced writer) had started working on a sketch, and Gear (the toy writer) was pacing around and urged that we "go paint a spot." Ultimately, I was too tired to do much and was also wary of maneuvering in the rain, and Bcool also declined, giving no reason as to why. Instead, he spent upwards of one hour talking to Gear, carefully explaining his understandings about style, getting up, and how to improve one's graffiti productions, his voice caring and passionate as he discussed these things in depth, listening whenever questions arose. As I looked over my notes over a cup of coffee, I noticed this conversation later took a turn and became a disagreement, as Gear, who was a bit older, declined the advice of Bcool, which had been to improve his work by "going big" (painting bigger productions) and to focus on simple straight letter pieces instead of what he had been doing. Gear said he didn't understand how to do straight letters, and soon found a reason to leave. Bcool went on a tangent of discussion, venting to me about how it's hard to teach people, and that he had been giving golden advice, but was frustrated because Gear clearly hadn't taken 
well to it. "I don't know about that guy. What do you think? I don't trust him." Bcool appeared to be notably disturbed by the other writer. I acknowledged that I didn't know and wasn't sure why the other had so adamantly rejected his advice. It is not known whether the "younger" writer has since accepted this advice or that of others, since this occurred, or whether he has continued writing. These instances may stress the importance of mentorship among writers, and reiterate that young writers may face conflict or lose respect if they resist or disregard help that is offered to them by the more experienced.

\section{Snitches Get Stiches: “A Blue Line of Silence,” Ousting, and Respect Lost (and Regained?)}

Perhaps central to the fact that graffiti is usually illegal, a consistent theme was that all writers maintained a blue line of silence to police and other outsiders or "civilians." "Snitching” (informing) was highly discouraged by every writer to whom I spoke, and was perhaps the most discouraged acts of graffiti. One writer had been "ousted" simply for suspicion of snitching. This individual had in a previous incident been caught by police while "painting carelessly" (according to statements made by various other writers), and in possession of drugs and a firearm while out painting. In regard to the incident, an OG writer said:

"Never take a gun with you when you're doing graffiti. If you get caught, that's just a whole other consequence you have to deal with."

It was thought that, after being apprehended, this writer had mentioned other acquaintances' names while being questioned by police. Several writers and some of his crewmembers later took part in seeking to rid the city of the writer's name after the incident. Though his informing was (to my knowledge) never officially confirmed, by all indications, and according to several other writers, this individual has long since discontinued his writing career.

When graffiti writers do "get caught up" or "catch a case," they may become informants to police to save themselves from harm, as may occur in any collective criminal enterprise. If this occurs (or is thought to occur, as the previous discussion makes clear), usually most or all respect for good style, "being up," or treating people well may be lost. Some writers may meet with physical violence for jeopardizing the safety of others from prosecution, as one snitch was known to have been assaulted by an unknown individual for informing on a friend. On a social media post of one of this writer's train graffiti pieces I noticed, someone had commented: “Somebody cross him out!” I soon discovered that some writers' graffiti does get ' $\mathrm{x}$ '-ed out, sometimes alongside various labels, such as "toy" or "snitch." This appeared to be a 
common practice in cases of suspected informants, and ousting appeared to carry the highest consequences of shame. Many writers had been "going over" or crossing out every one of the previously mentioned writer's pieces, throwups, stickers, and tags, whether in the city, on train cars, or in other cities. It was conveyed to me that this writer's work was all but erased, despite his having long ago earned a reputation as being a prolific and talented artist. Despite new instances of this writer's graffiti, a tag or throwup appearing, these would also be defaced by others. Thus, being ousted in graffiti was in a sense being stigmatized as being known to have behaved in ways that are deemed unacceptable in the subculture, as might occur in victimizing elderly people or child assault.

Sometimes, perhaps in less severe circumstances, respect may be lost and later regained. When discussing respect, another veteran writer stated,

“...people who are not respected... get shit on ... people have totally been ousted, and then they continue to keep coming back and it's mind blowing..."

I checked for more here and asked, "Do you think they can regain that respect when they lost it?"

"I do... It just depends on what you did ... and ... how...you handle it ... Did you snitch on your crew...? You're probably never going to be cool again... Or did you make a mistake and steal something ... and you lost some respect? And you kind of laid low for a while and then you regained some respect."

It appears that what he described here was a temporary loss in respect, perhaps according to a less severe violation than snitching. Snitching can also occur by indirectly alerting authorities or outsiders to illegal activities through “dry snitching” or carelessly revealing a writer's legal identity or otherwise jeopardizing one's own or others' safety level in terms of being discovered or arrested.15 In some cases, personal "beefs" (feuds between writers) can attract unwanted attention of police or others. This may have been the case in a situation of a dispute between several writers basically taking turns "dissing" (disrespecting by painting over or crossing out) each other's work. This exchange ended after one writer had crossed out the other's piece, leaving a message that used the legal name of the other writer, which led to accusations of "dry snitching." The final incident in this beef involved my writer acquaintance going over another throwup, this

15 As a researcher, I implicitly posed a threat to being a "dry snitch," either in discussing illegal activities or events or jeopardizing writer confidentiality. Confidentiality was my central concern in doing this study, and am I ethically obligated to continue to prioritize the confidentiality and safety of all research participants. This includes limiting discussions of observations I witnessed in research, including in the current work. 
time leaving their crew name and names of two members of the crew, who wanted nothing to do with the beef. I received a phone call and was asked to go and buff their names and the crew name. I accompanied another writer to do so in broad daylight, around 1:00 PM (fortunately unseen), using nearly an entire can of Rustoleum flat black paint. This incident again raises the importance of mentorship in imparting knowledge and conduct standards of the subculture, which appears to include some preference to stay out of personal beefs.

\section{Everyday Forms of Resistance: Contesting Use of Space, Private Property, and Advertising}

According to Scott (1988) and others, "everyday forms of resistance” include things like dragging one's feet at work, faking ignorance, or other forms of deliberate and defiant acts. Further, these forms of resistance are primary modes of rebellion where other methods might result in violence or severe consequences. Thus, everyday acts are subversive yet subtle in nature (Scott 1984), and it may be argued that the graffiti writing is also an everyday form of resistance. For instance, it was reported to me that graffiti is often motivated specifically to do illegal vandalism to evoke a charged response. One OG writer summed it up this way:

“....sometimes, I just feel a little funky...like 'fuck you.' It's just, you know. it's not something I do all the time. But every once in a while... gotta take a shit!"

Doing hip hop graffiti in its purest form appears to be a bold and resistant activity, wherein a central norm of the subculture is in doing frequent illegal acts in order to get one's name up or send some other message in public or private spaces. To do so is inherently transgressive in nature, and ordinarily, leaving one's mark or message costs money, as in renting sign space. While we were discussing external constraints to writing, one intermediate writer said this:

"It's like this: I've always disliked the way government is, and that's why I do it (write). It's like they have their own idea or way they want the city to look. And I say 'fuck that!' I want to put my mark there because that's how I want it to be. It's about leaving my mark."

Whether done as an outlet or as a form of revolt or resistance to authority or convention, graffiti may also be attractive to practitioners because it can be done relatively cheaply (See also Mailer and Naar 1974 and Ferrell 1996 on this notion of low cost and accessibility in doing graffiti). "All you need is a marker and a can of flat black 'rusto' (Rustoleum brand spray paint)," an OG writer once said to me. Perhaps more 
significantly, most writers admitted that the fact that graffiti is nearly exclusively illegal makes it fun or thrilling. One intermediate writer noted this while discussing the reasons why writing is illegal: “... (graffiti) is illegal because it (involves) other peoples' property—it's not yours...But it's fun!” Another intermediate writer of the same graffiti crew remarked to me while discussing illegality and doing graffiti: "Like, I get this high. You felt it." These notions of fun and thrill sensation for writers, as associated with the illegality of graffiti appear consistent with other research on graffiti subcultures (Brewer 1992; Ferrell 1996; Halsey and Young 2006; Lachmann 1988) and may also align with the notions of fun and thrill in edgework (See also Lyng 1990, 2005).

Aside from the code discussed elsewhere and other guidelines and structures within graffiti, writers did not appear to feel any remorse over violating ethics of private or collective space; in many instances, the opposite was the case. Though most writers were aware that illegal graffiti challenges consensus notions of appropriate use of space, many stake a claim in using public or private space as they see fit, some emphasizing 1st Amendment and taxpayer rights, and others a need to beautify ugly city walls. Most public places and many private ones were considered fair game for getting up, and different locations appeared to be popular for varying reasons involving municipal controls such as abatement or police monitoring, again consistent with other research (See Ferrell and Weide on "spot theory"). A veteran writer expressed value in graffiti as resistance to government and to a bombardment of billboard advertisements:

\footnotetext{
"I hate the fucking government and I hate how it's ran...how the whole world is ran...everybody's manipulated like robots...some big ass billboard saying 'come and get this cheap ass fucking couple burgers for like two dollars' and it's killing you. Like what the fuck?! There's nothing cool about that...someone puts a... hard fire assed piece on the billboard and people be looking at it like 'hey that's cool you know what I mean, that's art...instead of let's look at a goddamn cheeseburger and go kill ourselves."
}

An intermediate writer also expressed resistance toward advertising, and a desire to send his own message:

"I am destroying people's property...there's just rules to it...it's huge corporate business...everybody writes...I mean if somebody can have a billboard, and I can't just because I didn't pay for it? I think that's bullshit. Just because I don't have enough money to spread my message."

Whether as fun, to reclaim space, to destroy, or to boldly resist norms of public and private property, governance, or advertising, graffiti appears to be an ongoing and everyday form of resistance, which agrees with themes of findings in early and ongoing research (See Ducuyunan 2000; Ferrell 1996; Halsey and 
Young 2006). This may emphasize the notion that as long as space is contested and property privately owned and managed under municipalities and governed according to local ordinance, there will also coincide contestant practice, such as graffiti writing, which pose an imminent threat to the norms and values embedded in hegemonic discourses that designate appropriate uses of public or private space.

\section{Beautification}

In addition to other motives, many writers expressed a belief that writing graffiti beautifies otherwise plain space. A veteran writer emphasized: “...(graffiti) is making a really boring cityscape colorful." An intermediate writer said this: "We go out at three in the morning and beautify the city. And we pay for the paint." An advanced intermediate writer also noted graffiti improving the city environment.

“...when you paint graffiti, it's adding some color, some life to the area...it's a beautification process." (Graffiti) opens people's eyes, and it's a very creative and inspiring thing to see. Because it's art. It's different, and in city landscapes...urban areas - a lot of things look the same."

This again reiterates the notion of "moral geographies" (See also McAuliffe 2012) that are defined and contested in notions of the "creative city" and quality of life matters. To some writers, their graffiti may serve improve the days of outsiders who see their intended positive message, while hopefully avoiding abatement. One intermediate writer aptly noted: "if it (graffiti) has a positive message, a lot of people probably won't buff that." In a significant sense, graffiti, in the eyes of writers, does not detract from the urban atmosphere, but instead adds to the collective public visual aesthetic. Some reported sending a positive message for the occasional outsider to notice alongside their graffiti. A veteran writer discussed adding messages in this way:

"I always throw in a line or caption that has underlying meaning-I am a very 'pro' the people type person, so a lot of the messages I include in graffiti are very ah, people-based."

Perhaps in a similar spirit, an advanced writer described graffiti as "comforting the disturbed and disturbing the comfortable." He explained that what this means is that graffiti can either send a message such as "fuck you" or alternately, "hey that's art." For him this is involves a conscious decision on the part of the writer, and depends on their mood. Later, he discussed piecing as being more pleasing to "haters" of graffiti.

"Say I go out and paint a very beautiful piece of art, not a tag but a piece...that looks good to someone who hates graffiti.... so (they) look at it ... like 'wow, that...does look good... make em think ...this isn't...bullshit destruction. It's...art...even make somebody smile or ... have a little better of a day." 
In addition to creating different content within their graffiti, all writers generally reported choosing graffiti spots (locations) strategically, for both visibility and longevity, as is also consistent with other research (Ferrell and Weide 2010).

\section{Choosing Graffiti Spots, Risks, and Constraints}

In terms of choice of spots, there did appear to be some value in longevity, despite significant risk in executing a given spot. One intermediate writer noted:

"I don't know, it's like, I'd rather hit a spot that's going to ride forever and have like a bigger chance of getting caught. Not necessarily a bigger chance of getting caught but a bigger penalty if I do get caught.... Like I'd rather have that than a spot that's going to get buffed tomorrow. Every time." Like, I'd rather take the risk for it. But that's just me, I guess.”

Here a key value appeared in being willing to risk a certain consequence in order to get up in a spot where one knows ahead of time that they will remain undisturbed for a long period. As such, writers reported sometimes vigilantly selecting from and choosing different ways of getting up according to environmental conditions. Night time was often dedicated to painting highways, street spots, or other "bombing." An intermediate writer noted his different activities according to day or night:

"if it's daytime, I like to paint 'day spots' (low risk tagging, bombing or piecing) or wait it out and just draw (sketch) or tag or scope shit out (for later)..."

In terms of recreation, this writer reported "bombing" at night and "productions," or high quality piecing usually at "low walls" or train spots with friends during the day (called "day spots" by writers):

“there's nothing like... having a night out and just drinking a bunch and going and bombing or doing whatever - catching crazy spots...or in the daytime going to do some serious productions."

This was often the case in most observations being done in the day, and writers often chose abandoned industrial locations or walls beside railroad tracks or under highway bridges, as well as in municipal drainage systems ("channels"). At night was when much of the freight train piecing or street and highway bombing, tagging, or piecing was done by many. Some writers had faced severe danger in painting certain areas (and continued to paint afterward, if somewhat more carefully):

I've been held at gunpoint... painting a 'bando' (abandoned building)...It was very scary.... I had to talk dude out of shooting us... He was on meth or something...like...'this is my trap spot... and we were like 'we thought this place was abandoned, and I'm sorry.'...he's like 'what do I get out of this?'... finally he was just kinda like 'Go.' I thought I was gonna get shot... after that I really second-thought things... painting in the hood." 
An OG writer involved in the graffiti scene during the early 2000s had noted that anti-graffiti efforts at the time involved "subversive" tactics like those discussed in Ferrell's (1996) and others' research. This included a graffiti task force and detective, who also dealt with drug gangs and had a similarly militant approach in dealing with graffiti. This writer had been injured after being (allegedly) deliberately struck by a police vehicle driven by an officer who had evidently observed him attempting to flee the scene of a graffiti spot. Despite having been fully run over by the cruiser and having a broken leg, the writer managed to elude capture by hoisting himself over a fence and escaping into the woods. These themes raise findings from research that cautions the enforcement of graffiti ordinance and intensified policing that has occurred along with a militarization of municipal police forces in recent decades (Iveson 2010). Though not officially verified with police or other governmental officials who I interviewed, the injured writer noted to me that this incident occurred at a time when the graffiti task force that was in place was also reportedly connected to an anti-gang policing unit.16

In addition to other constraints, including hostile residents, "heroes" (vigilantes), or "the buff," writers choosing spots had to consider whether other writers or, in many cases, civilians will "diss" or go over their graffiti, often with sloppy handstyles, renditions of male or female anatomy, or other non-skilled writing. On one observation, while having a difficult time deciding on where to go to paint during the day time, an intermediate writer asked a veteran, "You wanna just go paint at (name of the wall)?" The advanced writer declined, emphasizing the likelihood of being gone over: "Not really. Stuff usually gets dissed or gone over there. I would rather not waste the paint."

Certain spots were easily accessible and fairly safe, chosen for practice or to get out to paint where the concern was not wanting a piece to ride or to avoid "the buff" (abatement crews) or other writers of all skill levels who paint there. Only pieces placed correctly may "ride" (or last) longest. An OG writer said this about valuing spots that avoid abatement:

"I don't want my graffiti to piss people off. That's why I paint trains.... abandoned (spots); I paint stuff that belongs to the city sometimes, but it gets buffed...I want my graffiti to last - where the sun has bleached it off the wall. I don't want it to get painted; as long as it can possibly last, I want it there."

${ }^{16}$ As Bloch (2016a) noted, sometime after the 1990s murder of a graffiti writer, Insta, by a local vigilante, a shift occurred in public perceptions of graffiti in Los Angeles, and hip hop style graffiti writing became less a gang affiliated phenomena and more one having to do with quality of life. 
It was conveyed to me that it is good form to not paint places that anger outsiders, "the buff," or police and other authorities. As such, one does not leave a tag by a road side where there is a secret entrance to a graffiti spot. Similarly, during gatherings, one does not paint nearby personal property or bomb the neighborhood where private citizens from the community volunteered their personal property in the form of clean walls during large communal piecing events that sometimes occurred. On one such occasion, several veteran writers painted a building near where writers had gathered to paint. This later angered some other writers who felt that it was disrespectful to the community to come there and paint illegally, considering the community was not objectionable to the private walls being painted piece by piece down a wall spanning the block. I was told second hand that eight or more writers were ready to fight with one of the veterans and others who were part of a group of four or five who had decided to paint the nearby building without permission. Though violence had evidently been imminent, the confrontation was defused, but it appeared that the group's behavior had generated some notable concern in choosing that spot. Taken together, these findings suggest that choosing graffiti spots is a careful and dynamic process of selection dependent on numerous constraints, subcultural norms, and matters of etiquette, as other research has also demonstrated (Ferrell and Weide 2010; Haworth, Bruce, and Iveson 2013), and, furthermore, it involves learning a set of skills that, as one intermediate writer emphasized, “...you and no one else has control over."

\section{Getting Up and Off Limits Space}

Most writers found spaces somewhere to get their name up, whether on highway walls, billboards, highway signs, street side walls and bridge underpasses, abandoned buildings, or on walls of industrial complex structures and runoff channels. Significantly, to paint over another writer, especially kings or the deceased, was considered unnecessary, and if not done legitimately could result in conflict. It was my experience that most of the graffiti writers I met and observed were extremely kind, generous people. Nonetheless, "beefs" (disputes) among writers could and did apparently occur at any time, over space or other matters concerning respect, and sometimes, "dissing” (disrespecting) each other's work by "capping" (going over) it. Sometimes beefs resulted from one writer "clipping" (cutting into, usually on an edge or shadowing) another writer's work, or "side busting" (painting too close beside someone). Sometimes 
matters were handled by individuals according to skill level, but sometimes beefs became ongoing conflicts if one writer offended another or caused harm to the scene.

Train yards in the metropolitan area under study were generally "off limits" to most beginner or intermediate writers. Freight trains provide perhaps the most valued of canvasses, as noted in other research (Ferrell 2006; Being able to properly paint trains was done by some, but generally reserved for those capable of producing quality graffiti, without causing damage to the equipment, and without being reckless or being seen or confronted by anyone who may not disapprove of the activity. Trainwriters had usually earned a high level of status and respect in graffiti, and typically veterans had painted actively for over five years, but sometimes more, before being "allowed" by other writers to paint trains in yards. To do so alone may risk confrontation with individuals who may disapprove of a "newbie" presence. Another veteran writer took me along to paint a train spot in another city but emphasized that I was only allowed to return alone or with him and was never to show the spot to anyone else, who may risk showing it again, or the spot end up getting "blown" (noticed by authorities).

Some spaces appeared to be "sacred" to many writers, and these included schools, playgrounds, places of worship, memorials, occupied homes or personal property, non-commercial vehicles (in most cases), or small businesses. Painting at one of the above locations may cause a loss of respect from other writers. This also is generally consistent with other studies on graffiti subcultures (See also Halsey and Young 2006). One highly skilled writer was ridiculed for having been extremely intoxicated and painting over church doors. He had discovered it the next day, not realizing what he was doing at the time. This writer is no longer active, though it was not known whether this instance had anything to do with it.

Notably, public murals were not always considered off limits, and many writers did throw ups and tags, or sometimes even pieced, over murals, but to my knowledge this type of writing did not include hate or political messages, simply disregard for the primacy of murals in occupying public space, similar to findings in other research (See also Bloch 2016b). Sample writers did not report having vandalized historical properties or monuments, though several very active writers known to create large volumes of graffiti had been apprehended during the time of my observations and interviews.

Many graffiti writers expressed some desire for and willingness to utilize more legal spaces, if offered. When discussing hypothetically 'what if graffiti were legal?" An advanced writer said: "If the laws 
were changed on it? Yea, I'd be painting a lot more." Elsewhere, he said: "There should be more spots where we are able to do it (graffiti), but I do agree (with illegality)" This writer, like many others, acknowledges the public's objection to graffiti and its illegality, but welcomed the idea of more legal spaces to do graffiti, a finding consistent with Brewer and Miller 1990).

\section{Style in Hip Hop Graffiti, Developing Individual Style, and Learning from Others}

Style was a valued and essential subcultural element in creating and displaying one's uniqueness in graffiti, and in ones' character. This sense of 'style' is separate from that related in the hierarchy of styles of graffiti traditions that includes tags, throwups, pieces, and so on (as discussed in the previous section, “A Hierarchy of Styles of Graffiti"). Style was described this way to me by an OG writer:

"Style? ...it can be defined in a few different ways ...coming up 2002 is when I really started um looking at graffiti. There wasn't much to go off of in the city I live in...looking at LA shit... because that's where the dopest shit was.... where MSK was. Revok, there were writers here, but they all had different styles that they had copied from someone else. Or else they were all very basic, general styles."

Unique style was a key element of doing quality graffiti in any of its traditions. Style appears to be an artistic skill that can be developed as in conventional visual art. Within graffiti, as in any art form, there are different styles, which find roots in the artists and the times and circumstances in which they paint. Notably, one's unique artistic style was thought to develop over time, as they practiced perfecting the different styles of graffiti. As a writer, one's improved style was expressed in their art. Style was not always limited to graffiti, though was thought to be a "visible" (or sometimes tactile when style was described as a feeling) in one's art. When discussing style, an experienced writer noted:

"It's (style is) your mojo...the outward manifestation of your inner being...the essence of who you are-your soul...projected out in some physical form. Whether...something you projected on a wall, how you walk, how you talk, how you dance... how you dress... it's a vibe"

Another writer noted this, saying "Style? Sometimes you can feel it when you look at a piece. It's that uniqueness of a writer, their vibe." Another intermediate writer summed up the similar styles notable among different members of their graffiti crew:

"It's just cool to see like the generations of style, like the grandfather when people start teaching people how to do graffiti. How their style is translated into other peoples' style." 
It appears from these statements that style is a quality thought to be unique to one's own identity, but can also "rub off" on others who one teaches. Essentially, style is unique but reportedly develops through learning from others. As such, learning to produce respected and quality graffiti and practicing letter basics in creating increasingly skilled productions that convey developed style is not typical of the work of beginners. Respect may be earned from demonstrating one's graffiti quality and style, as is often originally learned from others. Additionally, one is respected in being known for doing high quality graffiti that is learned and demonstrated through proper lettering and style. An advanced writer discussed having developed his own style and letter quality earlier in his career from an experienced writer.

“...my style is unique to me...also... kinda came from when I met this guy... a couple years older than me, and he had it figured out. and....he was like 'this is how you draw letters... stop what you think you know...forget everything and listen'... and he taught me some letter structure... he did it with everyone from that time period...teaching all of these wack ass writers how to make their graffiti look better..."

The person spoken of here had mentored several notable writers of his time period, and was still an active writer for a larger graffiti crew. This instance raises the importance of social control in recreations, where other researchers reported that veteran edgeworkers often observed and advised others in the appropriate ways to engage in edgework, often in subtle or direct and constraining manner (Laurendeau and Van Brunschot 2006).

Graffiti writing appears to be a structured and often internally regulated social activity with a unique subcultural ethos and unique norms and values, sometimes enforced by more experienced members of the subculture. A subcultural ethos appeared to be carefully learned through mentorship and practice over time. Significant value was attached to a writer's demonstrating respect and responsibility to other writers and the subculture in their graffiti practices, maintaining a code of silence with police and outsiders, and committing frequent acts of illegal graffiti displaying artistic skill with unique and hard-developed style. An intermediate writer commented that style is:

“...originality...it's your way of making letters look crazy...it's what makes it original and like...'style-icious' (laughs loudly)...haha I don't know if that's a word...it's my word."

While style is an important and valued element in doing graffiti, respect comes from the recognition gained demonstrating that style publicly in repeated illegal acts (See 


\section{Respect and Doing “Consistent, Quality Vandalism”}

Once while I was with an OG trainwriter painting at a permission wall (free wall where one could legally paint graffiti) owned by a private citizen who also maintained an art gallery, we were confronted by another writer who walked by. We had my acquaintance's vehicle, a black sedan with tinted windows, backed up along the side of the graffiti wall with the car doors and trunk open, playing music while the engine puttered through straight pipes. After talking over a cigarette in the brisk 40 degree temperature, my acquaintance showed the other writer a piece of paper with a couple of prototypes of his different styles of pieces, saying he was out of practice. The other writer replied: "You always put up quality stuff, every time I see it."

This individual appeared to imply that the other was known for his reputation for producing quality graffiti. Another OG writer emphasized important elements of developing one's name as a writer when asked what is required to earn writer status:

"Consistent, quality vandalism --- hahahaha coupled with, I guess you would say, a good criminal reputation... you know? In technical terms, I guess..."

Another experienced writer told me that while learning to write graffiti, it is very important in the first two years to practice and perfect straight lettering and legible styles in order to truly familiarize oneself with letter structures. The reasoning was that after this occurred, one would be able to properly begin bending letters and adding effects, flares, and other dimensions to create more complex and artistic "pieces" (masterpieces). This raises the serious leisure notion of developing a propensity for learning skills and specialized knowledge (Stebbins 1982), if also maintaining the levels of perseverance required to do so.

One advanced intermediate writer said:

"for while, for a couple of years...graffiti was my life...all my time and effort...I was just chasing after something. It felt so good to be recognized as somebody when... you've always been the outcast."

Whether recognized or still attempting to gain renown in the graffiti subculture, writing was practiced as regular and serious transgressive expression, and appears to resemble forms of serious and dark leisure practice, according to several common features.

\section{Serious Leisure in Hip Hop Graffiti}


Learning to become a graffiti writer, and progressing in skill and experience level require serious leisure commitment and a motivation (compulsion) to learn greater levels of skill and knowledge and to improve those skills and utilize knowledge through one's experiences. Some writers believed that there were no benefits in the first year, though whether that is true is unlikely, as thrill was a consistent feature to every writer's experience, whether it was a current aspect or something generally experienced in the past, which was typical to veterans. Based on semi-structured interview data, writers of all levels of skill reported receiving benefits from writing, similar to what Stebbins (1982) described as durable benefits available in serious leisure. Writers of all experience levels practiced to some degree according to what Stebbins describes as serious leisure hobbyism, and many advanced writers had graffiti careers that involved both illegal and legal graffiti, with the latter practiced in some professional capacity. This professional capacity was an institutional relationship for some writers involved in city muralism projects designed to rejuvenate some lower income neighborhoods, with some city officials expressing some hope or expectation that these murals would deter graffiti (See Also CHAPTER 5).

As assessed from semi-structured interview questions, many sample writers agreed that they experienced benefits similar to those reported in serious leisure research. These included "selfactualization" (bringing out some inner potential), "self-enrichment" (feeling they had improved their lives through a unique experience), "renewal of self" (particularly as it pertains to being restored or renewed after "needing to paint"), "feelings of accomplishment" [this was reported to me as similar to the affective accomplishment experienced by writers in the research of Halsey and Young (2002; 2006)], "enhancement of self-image" (this had to do with seeing oneself progress artistically and otherwise), "self-expression" (evident in the ability to assert one's name and presence and in painting to contest conventional use of public space), "social interaction" (occurred for all writers with friendships, mentorship, events and gatherings, and otherwise), and "lasting physical products of the activity" (in the case of canvasses, murals, pieces that were photographed and shared physically and in digital media, an in legal and illegal artistic works that avoid abatement. Additionally, all writers exhibited the six characteristics of serious leisure in their practices and as assessed in semi-structured interview questions (See also in APPENDIX A). These included having the potential for a career in the pursuit (in paid or unpaid productions), a unique (subcultural) ethos, having fun and self-gratification, a means to social interaction, having the need to 
persevere at the practice, identifying strongly with the pursuit, and investing significant personal effort into the pursuit. Additionally, as with serious leisure practitioners, graffiti writers consistently reported experiencing nine durable benefits, as mentioned above) (See Stebbins 1982:254-258; Stebbins 2006).

These key aspects of serious leisure appear to be part of the experience of learning to do graffiti and developing over the course of one's graffiti career (here 'career' does not relate to an income generating pursuit but instead to the tenure of one's graffiti practices over time). When asked if he had ever felt compelled to improve his skills and experiences as a graffiti writer (See APPENDIX C, Question 34), a veteran writer replied:

“Always...if you don't...you suck as a person, like in any walk of life...I can't say that... I know some people ... just the fact that they got to go out and paint something...makes them happy. It helps them deal..."

One may write graffiti for six months or ten years, but advancing beyond simple letters that lack style (characteristic of beginners) appears to be a learned and dedicated process of achieving mastery of letter structures by repeated drawing and painting, where letters themselves are works of art, each having varying visual effects and color presentations. This again resembles what other graffiti research has found regarding improving skill and knowledge through consistent practice (Gomez 1993; Ducuyunan 2000; Ferrell's 1996; Lachmann 1988).

\section{"Flow" and Writing Graffiti}

Csikczentmihalyi (1990) researched the experiential benefits of "flow," a deep sense of connection and satisfaction gained through personal pursuits. A beginner writer explained to me the importance of getting a sense of flow in writing graffiti while learning to make her letters look better. A beginner writer noted:

"After I painted like ten times. And after I understood the flow and what to do... at first I was just like 'ok what the fuck do you do with this??' ... when I understood flares. And I still don't exactly... hold the can far away....and then move it and try to shape the line."

Flow was thought to occur in practice as a benefit as skill development and mastery occurred. An intermediate writer spoke of a peaceful quality from doing graffiti, despite the danger:

“...I feel that bliss, I'm not thinking anything, I'm feeling divine, when I'm doing it. I'm just free. I'm in a moment. Of those cold nights, warm nights...just beautiful. Stars are in the sky...those other...crazy nights, people are throwing two by fours at you...shooting guns in the air because you're in a bad 
neighborhood. It's still peaceful...once that paint touches the wall, you're just on Mars."

An OG writer reported his motives in terms of getting up changed over time to ones of a therapeutic nature:

"Uhh, in the beginning shit was fucking...Just to get up and get my name out. That was it. Now, it's more of a meditative state. More of some peace, peace of mind, release of worry."

A veteran writer spoke of speed, quantity, and quality in doing graffiti:

"something that I'm always working on is quality and...speed as well...if I can paint fast and have it be a clean piece... the faster and cleaner I can paint the more quality pieces I can complete. So it ties everything together: speed, quality, and quantity... the trifecta that I'm trying to achieve."

It appears that this experienced realized flow through efficiency in producing quality pieces quickly. The learning of speed, quality, and style appear to require serious commitment for writers, and thus writing graffiti appears to occur both as specialization process and as product.

\section{Serious Leisure Commitment and Producing "Saleable" Graffiti}

In this research, I did not note any newcomers quickly becoming able to produce high-quality graffiti, though many displayed impressive levels of quality and skill during and after the first year or two. Those having highly-skilled mentors in some cases often had continuous careers and displayed their work with other esteemed and up writers. Most writers described having passed through stages in becoming a graffiti writer, involving varying levels of commitment. I was told by several "older" (more experienced veteran writers) that many people "fall off" after trying their hand at graffiti, most lacking the extreme drive required to persist in the face of learning to present respected graffiti and face extreme risks early in the graffiti writer career. Another writer emphasized the commitment in putting in work to earn writer status and to progress: "The work has to be done in the streets."

Many interviewees reported to have reached a point where they had been able to generate income with their graffiti skills, perhaps aligning with the serious leisure notion of utilizing learned skills for professional purposes or to engage with the public or professional entities in a "professional amateur public" (See also Stebbins 1982:258-259). However, this was not common for newcomers, at least until dedicating extreme commitment and skill development occur for progression to the level of having a known street reputation (or "doing consistent quality vandalism coupled with a good criminal reputation" according to one OG writer) and a following of people who appreciate one's graffiti style. Most writers 
beyond a beginner level reported to have sold their art to others or purchased art from others via art shows, social media or word-of-mouth. As such, these graffiti practices appear to resemble what Stebbins (1982) designates as serious leisure hobbyism. Also recalling Stebbins, amateurism pursuits, chosen for their strong appeal, become an "avocation" for practitioners of leisure only when significant seriousness and commitment are put forth by practitioners (1982:258-259). On this note, it is important to highlight the fact that several writers in the current sample noted the importance of "pushing oneself in order to get up, which is "the whole point of graffiti" as other interviewees also emphasized. Thus, the seriousness and commitment displayed by writers during the beginner level (and beyond) to a significant extent determined whether they endure in the pursuit and later specialize to develop marketable skills that may also become the basis of paid professional pursuits. This finding and others related in Figure 2 suggest evidence that, graffiti appears as both serious leisure and as recreation in which specialization appears to occur, which will be revisited in detail in the section following the next one.

\section{Auxiliary Activities: Social Media, Blackbooks, Benching, and Homework}

Several supportive and related graffiti activities were also engaged in by writers, in addition to the actual painting of graffiti spots. For instance, other research has emphasized the fact that modern and recreational subcultures often create media in physical and digital representation which are distributed to a global digital audience, and this may translate documented experiences into social capital through "likes" and positive comments (Snyder 2016). Every graffiti writer I interviewed or spoke with about it reported being both socially active in some way with other writers and used social media either to network with other writers and learn, as an intermediate writer related:

“...like that's kinda how I learned a lot about (graffiti) is from like Instagram...how I connected with a lot of people I know today is through social media."

Social media was also used to post one's own graffiti or view works posted by others, while sometimes this was done in excess. One OG writer commented: “I don’t need to post 900 pictures of my graffiti but someone else can...." While this individual did not feel the need to post his work, many writers of different skill and experience levels were often legitimized by more experienced writers, who commented on or "liked" their social media posts. One writer recollected the feeling when a local and internationally known "king" (prolific writer), had posted a picture of his own graffiti: 
"Yo, back in the day he posted my graffiti. Yeah, somebody showed me like he posted my graffiti back in the day. It was kind of flattering..."

As also noted above, many practiced writers valued selling their work both through word-ofmouth, at graffiti events or gatherings, at art shows, and often via social media, by posting pictures to which individuals both inside and outside the subculture can interact in accumulated 'likes' or comments of approval or in interest of purchasing art. As discussed throughout this and the next chapter, mastering graffiti style takes time, and several years of being "on the streets" and doing illegal graffiti must occur first.

Taken together, several deviant and non-deviant legal or illegal activities are usually done by members of the hip hop graffiti subculture, in most cases with illegal vandalism as the end goal in mind. Auxiliary graffiti activities also involved writers practicing future tags, throwups, or pieces in a sketchbook (or "blackbook") (See Ferrell 1996 where these are referred to as "piecebooks") or creating pieces or other graffiti on painter's canvasses or on scrap pieces of wood, metal, traffic signs, or other objects that can be acquired cheaply and easily while exploring graffiti spots or driving through the city. A writer known for creating very elaborate and wildly popular canvasses (usually featuring cartoon or comic book characters) frequently sold his works on social media. In a conversation during a participant observation with this writer, he advised me: "Get yourself a blackbook, and practice for a month. You'd be surprised how much that helps you get better" (at doing graffiti). Such activities may equate to what Smith and Raymen (2016) described as related dark leisure activities whose mastery may be key to success in dark leisure pursuits, such as where street racers had to also learn to be proficient with welding and engine mechanics.

In a sense, doing graffiti in sketchbooks or blackbooks (or on canvasses) in the current research was done both as a recreation in itself, and as a supportive or preparatory stage that occurs prior to painting a wall, train, or other 'real world' surface. Canvasses were often done to showcase one's artistic skills, and, if produced by a reputable graffiti writer, canvasses were often sold with great success, and for respectable prices (from as low as $\$ 10$ to upwards of $\$ 300$ per item). An intermediate writer reported earning hundreds of dollars a week selling canvasses, sometimes completing sellable pieces during down time at work.

"I have a little side hustle-I sell canvasses on the side, mainly for like peoples" kids or whatnot. I'll like draw their name in cursive and do dinosaurs all over it or whatever... on a daily basis...like today, I drew two pieces and...finished a canvas while I was working..." 
A recurring theme among all writers I observed or interviewed was "benching" (or viewing and or photographing) train graffiti, either one's own work or that of others, sometimes capturing and reposting photographs of rare instances of graffiti done by deceased "kings" (very prolific and known writers). It was revealed to me in conversations that train graffiti may "ride" for long periods of time but does get "buffed" fairly commonly, and to be present to see one's own or others' works offers a photo opportunity. "Benched" trains or other "flicks" (pictures) of graffiti taken in person were often shared through text messaging or posting on social media by every graffiti writer I observed.17 Similarly, most individuals also regularly or semi-regularly searched social media "feeds" to discover pictures of their own graffiti or that which is posted by others for entertainment or inspirational value. A veteran writer summed up social media's role in making graffiti more publicly available: "since like social media and the internet has infiltrated graffiti by storm...you can pretty much look up any writer you want..."

An intermediate writer commented on this:

“...if I get some spare time I'll look through the hash tagged benched pieces and see if anything popped up. You know, that's while I'm at work."

In addition to viewing graffiti from afar via social media, some writers reported spending a great deal of time going out and physically looking at the work of other writers to figure out how certain techniques are performed in their tags, throwups, pieces, or characters. An intermediate writer described "consuming" graffiti in this manner:

"A lot of times I just like drawing (sketching)...going to spots to look at shit, and think about how they did it...like consuming graffiti, just like eatin it up... and just like wondering what I can do...to take it to the next level..."

Such practices, may reflect a level of hobbyism within graffiti, where some described “doing homework," or driving or walking around areas off highway sides or often in industrial complexes or along railroad tracks to find spots. This usually entailed trespassing and personal danger in finding an appropriate spot to paint graffiti, or in looking at other graffiti.

\section{RST in Graffiti Writing: Experience Levels, Progression, and the Career Trajectory}

\footnotetext{
17 It was pointed out to me by my committee member, Dr. Ferrell, during a review of a draft of this paper, that the term "benching" predated the process of actively photographing train graffiti. It is possible that this term's meaning has evolved as writers practice of photographing and exchanging photographs of graffiti developed.
} 
Interviews, casual conversations, and observations revealed that different motivations and rewards occurred for graffiti writers according to specialty types chosen and levels of skill. These distinct and overlapping groups or classes among writers appeared to be consistent with different groups designated by other research on graffiti (See Brewer 1992 and Ducuyunan 2000, among others). A frequently reported ideal of advancement was that of earning respect and was a key feature distinguishing writers of different experience levels, a difference between "toys" and other writers. Central to this was demonstrating correct conduct and carrying oneself with respect and responsibility, and thus learning and mentorship were often central to the "progress" of writers. A caveat from recreational specialization theory is that early research suggested specialization involves a spectrum of progression from lower levels of experience to higher levels, but as RST matured as a theory, some studies revealed that progression is not always "linear" or indicated in a "forward" direction toward advanced skills or levels of practice (Kuentzel and Heberlein 2006; Scott and Shafer 2001), and progression can vary according to life contingencies (Oh et al. 2010; Scott 2001b). The current findings similarly reveal not all writers advanced along the continuum of experience or career trajectory, or, in many cases, writers did progress to greater experience and skill levels but continued with the full spectrum of graffiti practices, from illicit tagging or "sticker bombing" (placing stickers with tag name to public fixtures) to legal forms of graffiti (i.e. selling canvasses, commissions, and muralism). In some cases, writers continued tagging, with markers or paint, after many years of writing and reportedly did not move on to throwups, piecing, trainwriting, or other practices associated with experience, despite many having periods greater than five years invested in graffiti. These trends appear to be consistent with RST research in terms of specialization not always occurring in a consistent linear direction of progression.

In addition, in terms of the benefits often occurring in changing graffiti practices over time, different benefits and motivations occurred among writers of different levels of experience. Some advanced writers and several intermediate ones reported painting primarily in either quantity (usually bombing streets with tags and throwups, often for thrill and recognition), or quality (reportedly for motives of social origin or for therapeutic or meditative reasons, with benefits in demonstrating artistic ability) or sometimes both, with some writers bombing, piecing, trainwriting, and painting murals and canvasses, 
Many successful muralists started as illegal "taggers", and to paraphrase a prolific L.A. graffiti writer, Toomer, speaking in the graffiti movie Infamy (2005): Doing illegal tagging and piecing are necessary starting points in order for graffiti writers (including himself) to be able to learn how to be good enough to paint street murals. In other words, you can't have one (professional quality murals) without the other (illegal graffiti in its less elaborate forms). As stated before, tagging and all traditions of graffiti must be honored, again consistent with other graffiti research (Ferrell 1996; Halsey and Young 2002).

Throughout, I discuss the "career" trajectory of graffiti writers that involves developing skill through different styles and artistic improvement over time, leading from tagging to eventual piecing, and (often) commissioning of paid muralism and street art, as well as professional pursuits centered on graffiti related skills. Notably, this does not occur for every graffiti writer. In the current study, no beginners appeared to have mastered all (or in some cases) any styles of graffiti, or presented a well-developed style from the start. The trend in graffiti practices was toward advancement over time, but some exceptions occurred in writers familiar with graffiti over a long course of 8 and 9 years and had not reported producing large amounts of illegal graffiti beyond occasional throwups, pieces, or tags. Trainwriting, muralism, and commissioned graffiti usually are other extensions of highly artistic "piecing," which may be sold on graffiti canvasses or HO scale train cars, though usually only after at least an indeterminate level of experience is gained and considerable amount of time, generally years, is committed to doing graffiti while expanding one's personal reputation and repertoire of skills. Many writers engaged in professional pursuits wherein they used graffiti skills or skills that "branched off" in their legitimate endeavors. Among sample writers, these included professional tattooing, custom auto painting, professional sign painting, custom mural design, business painting and typography, graphic design and printing, digital media, custom car design, and other pursuits wherein skills related to graffiti were used frequently. This ability to make money, and perhaps make a living, from graffiti fits with Stebbins's ideas about moving from serious leisure to a career. In my research, such pursuits were usually done exclusively by more experienced writers, whereas often less-experienced ones and often intermediate writers tended to focus on "bombing," which typically involves painting “quick and dirty” (See also Haworth, Bruce, and Iveson 2013) tags, hollows or throwups, or sometimes quicker piecing, which together generally may take far less time in executing. Thus, the early writer's focus is on illegal graffiti that (if done correctly) occurs, unit for unit, in 
greater quantities than one might achieve in painting larger and more elaborate pieces that is a common practice, if not the predominant one, of more advanced writers.

\section{“Quality” and “Quantity” Orientations in Graffiti, Supplies, and Paint Spot Preferences}

Beginner writers often tended to focus on producing large quantities of graffiti, rather than highquality graffiti, as their skills or style are not well-developed. Getting up, or doing higher volumes of the "quick and dirty" versions of graffiti helps a writer to improve their skills and display style. This focus on quantity (as opposed to quality) among beginners is consistent with much of the extant literature on graffiti subcultures (See also Brewer and Miller 1990; Ducuyunan 2000; Ferrell 1996; Lachmann 1988).

Discussing this in terms of his own understanding of a difference in roles between graffiti artist and writer, an intermediate writer said:

\footnotetext{
“'A graffiti 'writer' ... just vandalizes everything. I kinda do that in a sense. I do do that...some people that do quality and quantity, but there's some people that just do quantity...they just tear shit up."

I consider myself a graffiti writer, and I can't stress the word 'artist' enough... an artist is somebody that ...does it for the love of it."
}

This generalized difference in practices appears to best capture the trends in different specialization and experience levels among writers, who may progress. "Tearing shit up" was characteristic in resistance practices occurring at all levels of graffiti, though many less-experienced writers and many intermediate writers) often tended to primarily focus on high quantity bombing, as opposed to lower quantities of higher quality artistic displays. In contrast, veteran writers conveyed mastery in all traditions of graffiti, while continuing to bomb but also specialized in stylized piecing. Thus, more experienced writers generally tended to focus on style and elaborate piecing more so than beginners, displaying a notably high level of quality in all their productions (as opposed to quantity).

Additionally, intermediate writers might bomb or paint pieces (masterpieces), usually outside of train yards and in "low spots" such as abandoned buildings, tunnels, drainage ditches, and other places where one can take their time. On the other hand, several advanced intermediate and many veteran writers typically painted in train yards. As already stated, this was an unspoken rule of privilege for established writers, where others had to put in the work and earn the recognition and status of others in the community before painting freight trains. 
Perhaps relevant to classic recreation specialization research, many advanced writers in the current used deluxe and higher quality paints for train pieces. This was also the case in paid productions and sometimes on wall pieces that one expected were going to ride. These cans of aerosol paint ranged in price from $\$ 4$ to $\$ 10$ a can, where conventional paints for city walls (and often for train applications) range in price between $\$ 3$ and $\$ 4$ per can, depending on where one shops. Specialty caps are available for all deluxe brands, and both caps and paint were purchased at local art supply stores. Additionally, most writers using Rustoleum paint also purchase after marked adaptors with specialized caps with different pressure releases and spray patterns. It appeared that most toy writers only acquired these with knowledge from other writers. I was referred to a local art supply by my initial research respondent, where I purchased a variety of brands and colors of paints and adaptors. Notably, many of these paints were not yet manufactured in much of earlier graffiti research. Nonetheless, the evidence suggests that a part of specialization in graffiti writing involves the use of different specialty paints and supplies, which appears to be consistent with RST theory (Bryan 1977, 2008).

An intermediate writer told me this about bombing with spray paint:

"I can usually get a couple of throwups out of two cans. For a fast piece take a can for the fill and one for the background. Three cans will get me a couple of throws and a piece."

From what I observed, this entailed a throwup between four by six feet, or a piece about five by eight feet in size.

On the other hand, the typical train graffiti piece may vary in size, though usually is as larger or larger than a piece or throwup done while bombing; again the focus on the latter is on quantity, where quality is implicit in train piecing. The average train car consists of a significantly larger canvas surface to cover. This may be a space on an autorack panel about six-feet-in width, or one may create a fifty-foot wide production spanning the length of an entire core, or a production referred to as an "end to end." Train graffiti are thought to stay intact for some time before being gone over by other writers or railroad workers re-stamping the train car with weight and capacity specifications. I was told separately by intermediate and advanced writers why one should avoid disturbing railroad informational stamps on sides of train cars: 
"You gotta leave those numbers alone. They're less likely to buff your piece as fast. Sometimes you get lucky and they stamp over them (the covered numbers). Sometimes they just buff your whole piece. I even go around the reflectors."

Another caution was expressed to me that before painting or tagging a train car that transports vehicles, the contents should be verified as empty to avoid damaging cargo with one's overspray that can get inside the freight car. Damaging the contents of train cars can lead to a criminal case being built based around instances of one's graffiti. If one is caught painting the same letters on a train, they could end up with extensive criminal charges. An experienced writer told me:

“Don't ever paint a loaded autorack (freight car designated for automobiles). If the paint goes inside and ruins the paint job on those brand new cars, you can guarantee they (railroad police) are going to build a case on you."

Not a week after hearing this, I was with an intermediate writer who reported never having tagged an autorack before. He walked away from me on the gravel road and went up to the train, spraying an oversized tag of his name in bright green paint. I could see from where I was standing that there were trucks or SUVs inside it, directly behind the perforated thin metal where he was painting. As he returned beside me, he stated plainly, "I don't care."

Writers can paint train cars spanning great lengths (according to railroad specifications listed on websites), and excepting twenty feet of ladders and end panels, creating an intricately designed and multicolored piece over the sides of the car panels. I was not granted access to witness many trainwriting productions, though on one occasion a veteran writer painted a sixty-foot long piece along a transit structure wall, and another time I watched the creation of an "end-to-end" train piece in another city where words were created by each letter of the writer's graffiti name to make a saying along the side. While he did this, another writer painted several pieces of his graffiti name on several panels of another freight car.

One veteran writer reported to me that each end to end train car production could consume fifteen or more spray cans in a combination of standard or deluxe quality brands, depending on the complexity of the piece, number of colors used, and whether using characters (cartoon style figures or effects common to graffiti piecing; See also Ferrell 1996). Often writers climbed ladders leaned on the train car and typically also used extension poles on paint rollers to apply bucket paint to create true "whole car" productions, sometimes making train cars appear as objects like the end of a pencil. I noted two or three writers to take a 
roller and "bucket" paint to a laid up train to paint crew letters on the side, working on it the night before and later returning the next morning to finish their styled two-color blockbuster piece.

Another veteran writer reportedly switched hobbies from painting large quantities of train graffiti pieces to buying, working on, and restoring import cars. He told me this about the ephemeral quality of doing train graffiti:

"For me, getting into cars was something positive because I can see where my money's going. If you do...trains, you...don't get to see a lot of them because they get re-stamped, gone over...some of em are around, but a lot of em get restamped...like you do a train or a handful in one night, you better get that picture."

Where most veteran (and intermediate) writers enjoyed trainwriting and other piecing, as well as doing commissions, getting paid may devalue the experiential benefits of the freedom in pursuits as a shift occurs from recreation to occupation, as reported by one veteran writer:

"If I had to do it all day every day or just do the stuff that someone wants to pay me for, and I wasn't getting any enjoyment out of it I'd get burnt out on it."

Thus, it appears that some level of enjoyment occurs in doing graffiti recreationally that may not similarly occur in paid activities. Since most writers in the current study did engage in illegal graffiti, this research did not direct focus on or separately explore the world of muralism and "legal" graffiti. However, as I will discuss in the next chapter, I believe that future research directed toward the legal aspects of writing may assist in contrasting standpoints of writers of the illegal and legal persuasions.

\section{Investment and "Side Bets" in Graffiti Writing as Recreation}

Investment in recreational pursuits may involve time, money, resources, and to some degree, penalties endured, fill a category one may consider as part of "investment," in other literature known as "side bets" (Buchanan 1985), or levels of investment in serious leisure in terms of the loss one would incur by discontinuing practice. An OG writer reported having so much time, money, and other resources invested in his graffiti career over several decades that it only made sense to continue raising the notion of side bets, which may compel further practice, rather than desistance.

"I've invested more time in it, even over the years that I wasn't doing it at all. I would say I've invested way more in it than in my other hobbies. It's totally overshadowed it. But... it's stupid because...the only real payoff a majority of people are going to get is an emotional payoff. It's something non-tangible." 
Another veteran writer who earned money from professional muralism described graffiti as a lifestyle, and reported having spent large sums on graffiti related costs, restitution, and court fees. "Hundreds of thousands of dollars...you could (say) 200 grand."

As stated before, despite its illegality and the costs involved in serious graffiti practice, a common theme among many writers was that it would take significant limitations to stop them from writing graffiti. This trend appeared in the various ways one may be willing to increase personal investment in graffiti.

Generally, arrest did not stop most writers, but it did sometimes get in the way of other life responsibilities. Some writers may "slow down" after arrests or while involved in court matters. This was the case with one beginner who had been in trouble for "non-graffiti" reasons and had not wanted to continue writing while facing the matter at hand. "I can't really paint right now because I'm in trouble for other things, non-graffiti related."

Many writers likened jail time as "paying membership dues" just as with golf one might to pay membership fees or buy new golf clubs now and then (as is discussed in the next section). Overall, most writers appeared committed to the illegal painting of graffiti, despite threats of legal consequence. As one advanced crew member said on commitment in the face of consequences:

"nowadays, I really wait for someone to get popped for their first time...to see if they're going to stick around. Cuz otherwise this is kind of a hobby, you know?...There are... a massive amount of people who...painted and are really good but they got popped once and they're too scared to do it anymore...

Thus, it appears that the RST notion of commitment occurred also in terms of one's willingness to continue practicing graffiti, despite arrest, jail, fines, and other consequences of being apprehended by police, which appear as part of one's “side bets” (See also Buchanan 1985). When asked, "What would stop you from painting (graffiti),’ (See APPENDIX A, Question 16), many writers acknowledged that jail may sometimes interfere with other life aspects, particularly in terms of intimate relationships, reputation, and continued employment, but would not stop them. A veteran writer reported to me that he devoted his time to bombing, piecing, and trainwriting, and reported continuing to write after being involved in criminal cases and being ordered to pay thousands of dollars in fines and court fees for several graffiti cases. Many indicated that only death or disability or extreme incarceration would stop them from painting (See APPENDIX C, Question 16), or as one veteran replied, "Nothing.” Another intermediate writer answered: "Probably death. Or being paralyzed." 
Many writers confirmed that, for different periods of time over their graffiti careers, they either slowed down or stopped doing graffiti completely, but later resumed. As such, individual levels of commitment and other life factors may increase or decrease one's engagement in the subculture over time. One advanced writer reported having experienced varying levels of commitment over time:

“...don't get me wrong there were like entire years where I just didn't paint. And... The less I do it and the more I'm just like a square...like a carrier pigeon, get up, go to work, come home, eat...bed. Repeat. You know what I mean? I can't do that."

In sum, doing graffiti over time may or may not lead to a development of one's graffiti career in the same ways for all writers, and serious leisure commitment and perseverance (both qualities of recreation specialization) appear to be key in this process. In addition, graffiti as an everyday form of resistance involved and required facing a certain degree of risk, which, if navigated correctly, could lead to benefits in thrill, "flow," fun, and improvement as a writer.

The current findings offer mixed support for research on recreational specialization using the adventure recreation model, where specialization predicts increased practice, skill, higher risk, and increased sense of control (Ewert et al. 2013:92-93). Specifically, experienced writers did report having increased their involvement and skill in recreational pursuits over time, and many noted more control, particularly in risk management; in contrast, highly experienced and intermediately experienced writers generally valued flow and restorative benefits from graffiti more so than seeking out risk (or thrill). Additionally, writers of intermediate and veteran levels of "progression" had generally invested much more in terms of time, money, resources, efforts than their other forms of recreation (See Figure 2 above, which relates ranges and percentages of variation among writers of toy, intermediate, and veteran levels in terms of self-reported level of investment in graffiti). Furthermore, this investment was noted to significantly increase over the course of writers' graffiti careers, as noted by intermediate veteran writers. Taken together, these findings garner notable support for graffiti writing as a recreational form from which planned benefits are obtained through regular practice, and that specialization appears to occur in the different levels of progression among writers. Another key finding in the current study consistent with specialists at all levels in numerous recreational pursuits (See also Ewert et al. 2013:10) was that writers of 
all classes reported value in social rewards and motives, including being part of a group, making friendships, and interacting with other writers.

\section{"Paying Dues": Deterrence Policy, Jail Time, and Writer Commitment}

Though not consistent among all policymakers and enforcers, there was a commonly reported notion among several officials that illegal graffiti is destruction of property which invites more frequent and severe crime. Increasing abatement, surveillance, and police involvement were considered keys to reducing graffiti by the anti-graffiti activist, and these efforts were presented to city administrators in public meetings where it had been declared that the graffiti problem is getting worse. Whether this declaration is true or based on reliable data (there had been no known graffiti census done since the 2015 pilot study discussed elsewhere), this thinking raises the tenets of broken windows theory, which assumes that a rational choice is made by writers who exploit an easy opportunity to paint graffiti. The anti-graffiti activist perhaps affirms this: "People come to (the city) to do graffiti, and they take up residence here because it's something they can do.” Later, he stated: “...we don’t actually prosecute people for graffiti...that's one of the reasons why it's so bad here." Here he implies that writers regularly can paint graffiti and escape prosecution, and that the city is not doing anything about it. Thus, increasing the efforts against graffiti is perhaps the most logical strategy to the anti-graffiti activist. Nonetheless, it is uncertain whether prosecution would effectively deter writers. The data in the current research reveal that most writers had not been arrested for graffiti, or had not been in serious trouble if they had, and several who had been arrested and done jail time indicated it hadn't been that bad and was part of paying dues. One intermediate writer noted:

"I always feel like it (jail time) wasn't actually that bad. Somebody pointed it out to me as like paying dues... if my hobby was golf I would have to buy new clubs or like pay membership fees. So, like every once in a while, I have to pay the court some money and like spend a night in jail for all these spots that I get away with."

It thus appears that the "logic" behind graffiti writing is in some sense as the anti-graffiti activist implied, that is to do illegal graffiti because one can do it and avoid prosecution. Nonetheless, "getting up" for many intermediate writers, is a competitive process where being willing to face the risk of jail was just one of several factors in graffiti that one had to face, along with receiving numerous benefits. Yet, to get those benefits is not a passive process. As another intermediate writer put it: 
"You have to push it to get up...to get known...because there's so many writers now...it's hard to compete...Y You gotta prove that you're the best..."

Those who had "pushed" their illegal graffiti, despite the risks, appeared to get more respect and other benefits, along with improved graffiti skills. Pushing oneself in this manner is to compete for space not only with other writers, but also with "the buff," as discussed in the next section. Additionally, writers changed their painting styles to quicker tags or throwups when repainting over walls where abatement efforts were directed. Many writers also continued to illegally paint over murals that were completed on walls where illegal graffiti frequently occurred, as was also the case in other research (Bloch 2016b;

Haworth et al. 2013). Beginner and intermediate writers reported that they similarly adapted to abatement, often in their own words, taking it as a "challenge."

\section{Abatement as a Challenge}

To repaint urban space (abatement) offers an illicit and clean canvas to individuals who are looking for something to paint. Several sample writers reported that it is fun and challenging to engage with "the buff," and many early and intermediate writers largely concerned with fame viewed abatement as a challenge. An intermediate female writer who I spent a great deal of time with on observations perhaps best summed this up:

“For some reason I feel like it's kinda fun to keep up (with abatement), like if that makes sense? We (she and another writer) did a highway spot and it rode for a while. And (then) they buffed it, and like we went back and did that spot again! It was a good spot. We did it like four times! Yeah you were there twice!" (mutual laughter)

Similarly, writers in the current study expressly reported enjoyment from thrill and flow from doing graffiti, where many valued painting spots often serially, as abatement served as a regular eraser for the same canvas to artists. Writers also valued illegality and equated abatement to necessary jobs for city workers or, in some cases, as necessary for toy writers to improve. An OG explained the value in abatement as he sees it:

"I think the buff's great. It's cool (mutual laughter)...Dude, some peoples' shit's so whack. It's good to see someone take it out... Without me having to go over there and cap 'em... you know? I'm getting old, man! I'd have a full time job cappin these toys... you know? They paint a lot of garbage!

To this writer, "the buff" (See also APPENDICES D and F) is an essential part of the process of toy writers improving, as also was the case with legendary writer Espo (Stephen Powers), who, while a graffiti writer 
with epic paint overs of public grates and other surfaces in New York, often repurposing walls and billboards for paint-overs to advertise for his graffiti zine and book (See Iveson 2010, Snyder 2009).

Writers reported to have improved their skills and became more savvy about doing graffiti in response to abatement practices. One intermediate writer said this while discussing a spot getting buffed several times after she painted it: "Fuck that spot, haha, cuz like if you're gonna buff it I'm gonna go do something else." The anti-graffiti activist also acknowledged that writers adapted and pointed out that one neighborhood abatement organization would only paint over instances of illegal graffiti that are greater than one foot square in size,

"They adapt very quickly. So say you start replacing stop signs. 48 hours, the stop signs get replaced. Along with the graffiti. Vandals start doing something else. The sound walls on the freeway. They (abatement crews) are doing anything 8 feet and below... So the vandals just moved everything above 8 feet."

It may be useful to note a change in the discussion and use of words at this later point in the interview. The word "vandals" is used in this discussion about writers adapting to abatement. This again raises the standpoint of the anti-graffiti activist using language appropriate to his purpose in relating an important aspect of abatement, namely that it is an ongoing policy practice on which his role as an anti-graffiti activist is largely dependent.18

Several writers painted highway spots in strategic places so that they didn't get "buffed" by abatement crews, whose jurisdiction excluded highways running through the city, which fall under state and federal highways' abatement territory. Instances of graffiti were placed high up on backs of highway panel signs and were generally said to be irremovable or 'involve excessive funds and resources (i.e. shutting down multiple interstate lanes and running special equipment). The city council official confirmed this:

"...on the highways and the interstates...is.... a very expensive abatement because the state or the fed has to shut down those highways... have to decide... are they going to spend that kind of money to do that."

18 Ferrell (1996) also reported that it is useful for policy officials and city administrators to use unflattering language, characterizations, or narratives when referring to graffiti (in the style of moral entrepreneurism; See also Becker 1963 and Cohen 1974). It is thought that to degrade certain behavior and label its practitioners better serves moral entrepreneurial objectives. 
Interestingly, many writers practiced with a knowledge of these and other policy protocols and utilized them in order to be more up and obtain more long lasting spots that avoid abatement for a longer period of time. This finding perhaps offers additional support for the research of Ferrell and Weide (2010) on "spot theory" and writers making informed and skillful decisions on spot selection. Sometimes, as one veteran writer noted, the motive for doing illegal graffiti is to provoke a negative response:

There's been times where I've painted things just 'cause I knew intentionally that it would invoke some emotion in the people that have a distaste for it. but that's just me being a smartass..."

Whatever one's reason for doing graffiti, illegality, abatement, and other forms of opposition were key aspects of thrill, continued challenge, and getting better as a writer.

\section{Edgework, Thrill, "Crowding the Edge" and Improving Skills}

As noted above, thrill appeared to occur differently for writers at different times during their writing careers. As such, some may gravitate to it as edgework, while others may eventually avoid risk or thrill in graffiti practices. Where advanced writers (including some at the intermediate level and higher) focused more on quality and more detailed piecing than newer and other early intermediate writers, a majority of veteran and OG writers reported being motivated to write graffiti less for the thrill or developing one's name and more for "peace and meditation," or for therapeutic reasons.

When asked if he obtained benefits in thrill from doing graffiti, an intermediate writer acknowledged that thrill is a fixture in graffiti:

"Every time. Every tag, every throw-up, every piece. Piecing's the best. Heaven spots. Always the best...you're just like: 'how did I get away with that?' Especially if you run from police; you know that's an extra thrill, if you get away."

Of note, the reference to "heaven spots" (or "heavens") (See also APPENDICES C and F) refers to highly visible locations chosen by writers. Heaven spots earn respect from other writers for the implicit risk involved in their production, and in the fame one accrues in their visibility. As one individual noted, "A heaven is where you have no choice but to see the piece." Heavens are also valued for (often) remaining undisturbed by "the buff" longer. This may be especially so when closing highway lanes is required for their abatement, as was affirmed in the discussion by the city council member. Additionally, heavens imply a greater level of thrill experienced, both in their production and in later seeing one's work (or being seen). 
with graffiti:

“...it's just like really exciting when you do a tag and walk around and are like nobody saw that but it's going to be there a while..."

This perhaps raises a notion of accomplishment and affective dimensions of writing, as indicated in other research (Halsey and Young 2002, 2006). Notably, on several observations, I noticed writers often to have reported feeling better after doing graffiti spots. This often motivated an enthusiasm to do more spots, based on a sense of deep connection and "flow" (an in vivo code).

“...(graffiti) gives you that drive, that rush...it's like the seduction; it gets you going...When you're young: doing it for the thrill or ego... Later graffiti becomes part of you, so you do it by mood."

This reference to a seduction raises the notion of desire and an affective dimension of doing illegal graffiti for a feeling of accomplishment, as reported in other research (Halsey and Young 2006). Nonetheless, when questioned further, thrill remained the main benefit for this writer, overall. In contrast, when asked if he experiences thrill, an OG expressed a different value:

"...thrill in terms of the excitement of what I did after the fact yeah. If something happens that causes me to...feel in danger or...excited. ...That type of thrill doesn't appeal to me, anymore. At one time it did. I loved it...walking the line of disaster.... when I experience that now, I don't enjoy it... at all. That adrenaline rush or whatever...

I attempt to clarify: "Why do you think that's changed?"

"Because I don't have a necessity for it - there's no necessity to feel that way."

It appeared that this writer's motives had shifted over the years, at least in terms of thrill.

An advanced intermediate writer discussed other benefits related to thrill: “...running from the cops, adrenaline. It's a much better feeling than drugs...graffiti is fun, therapeutic, and an escape from reality for me." Perhaps extending this idea, an intermediate writer reported pursuing thrill in graffiti like a drug, and a willingness to sustain personal injury.

"It's like that rush of endorphins...something to keep you sharp...but then like I'll get home...and some of my other dudes hit a spot...it's time...so I'll go do that...it's like a drug, it really is...I'm not going to OD on it, but I am going to break my wrist running through the woods, right?"

In some research, factors are altered by edgeworkers to increasing the stakes or risks and dangers involved, a process described as "crowding the edge" (Lyng and Snow 1988). This conceptual pattern 
appeared to emerge among graffiti writers, who similarly crowded the edge of danger by deliberately acting to increase the stakes in their practices, and as a result, many experienced an increased thrill, while some reported improving their skills. Crowding the edge may occur in choosing higher profile graffiti spots that, or attempting to push one's abilities in terms of how spots are generally painted (i.e. with either tags, throwups, or pieces) in terms of the time available, visibility, likelihood of police stopping, and other factors that are involved in a location chosen for graffiti. An intermediate writer emphasized increasing the stakes and progressing:

“...I end up, getting better, progressing... Doing shit to...push myself and things I didn't think I could do before.... push the spot. If someone does a throw up there and you do a piece there, it's like some one-up shit."

One beginner writer described going over the edge while pushing her own physical and psychological risks in increasing the risk:

"I tried to climb a billboard and literally cried...there's no bigger thrill... and you cry ... thinking you're going to die or break a leg...I mean -it's not really worth it; I guess it was worth it at the moment, but that was some pretty sketchy stuff... pretty thrilling, I would say."

It appears this beginner admitted to stepping too far out of her comfort zone by trying to climb the billboard, and perhaps went over the edge in terms of doing something beyond the established physiological threshold of fear. This writer has since has greatly improved her skill and has continued to write, though it is unknown if this includes painting in extreme environments such as on billboards or other situations.

Other "edge crowding" scenarios may involve higher than usual potential for detection by police or others, as might occur in a high traffic or busy pedestrian area where police may regularly patrol. One may also choose to paint highway signs, walls, or overpasses that require climbing over moving traffic or walking onto narrow ledges over drops to paint highly visible locations. Additionally, "edge-crowding" was accomplished in painting during busy times of the day, which was the case in "day tagging" (painting tags publicly during daylight hours). Once while tagging to get his name up at a gas station, one individual reported having the police later show up at his home for tagging dumpsters and gas pumps. Evidently someone who had seen him had reported his license plate number to the store manager or police, reaffirming the ongoing potential for discovery through unnoticed surveillance measures as an additional risk for modern writers. 
The notion of safety or a sense of control appeared to be evident while writers exploring the limits of one's environments in edgework practices were engaged in highly dangerous pursuits. During one such instance while on an observation painting highway walls at around 2:30 AM, with, cars passing "at speeds in excess of 70 or $80 \mathrm{mph}$," it was pointed out to me by an intermediate writer to relax and try to not draw extra attention:

"Most people are so focused on the road that, if they even notice you (painting) in the dark, it either doesn't register, or they are too occupied...to reach for the phone and call."

Despite any reassurances, the risk of being struck and killed while pushing the edge in graffiti remains, as one veteran pointed out: “.... there's always that chance of a tractor trailer unhitching... or that one cop just feeling frisky enough that day" (to stop you). Graffiti appeared to be consistently practiced by writers of all levels of experience in environments where there is no choice but to face some imminent danger, whether it is an oncoming tractor trailer, a vigilante citizen, a roof collapsing underfoot, an oncoming train, or many such potential hazards. This notion perhaps is significant to edgework studies and research on high-risk recreation, as will be discussed later.

Another writer discussed his skill level limiting his abilities as a "younger" writer:

"Early on didn't have the skill necessarily to go with my desire to be able to paint what I'd like to paint...so you know, the breaking of the law...there was a territorial thing, too. You know, claiming territory. All that appealed to me...but now, the only reason I (write) just like to create...And the adventure is fun...sometimes."

In this sense, it appears that edgework and taking more illegal risks was a natural part of doing graffiti in the earlier part of one's graffiti "career," though risk (or "adventure") still was part of this writer's experience after many years writing ("sometimes"). This statement raises the notion of the different theoretical and conceptual forms that graffiti may take, at least to some extent according to one's level of skill and experience.

\section{Career Trajectory: Dark Leisure Edgework Recreation to Professional Pursuits}

Most writers agreed that graffiti is a form of recreation with planned positive outcomes and also requires that writers learn and demonstrate many skills and rules of engagement. There was a tendency for all writers to have reported they had persevered in graffiti over time, displaying a desire to extend their skills or graffiti career by continuing to write as a dedicated practice, independent of skill level. 
Nonetheless, less-experienced writers had the tendency to paint certain areas with greater frequency than other writers, either street signs, abandoned structures, or in other places such as in the city channels where littering and public safety were a concern with homelessness and drug use that might have occurred there. This again may raise the notion that writers chose environments based on a key criterion of being able get up, without being arrested or otherwise hindered by outsiders, whether painting in public view or not. This may be significant to the dark leisure aspects of graffiti, where choice of places to write (and the associated risks involved) were evidently dictated by policy and discourse which construct all non-sanctioned graffiti as vandalism. As will be discussed further in the next chapter, this finding also has potential implications for implementing legal graffiti policy.

Making money by selling one's graffiti or doing murals usually later in one's graffiti or was noted in intermediate and more experienced writers and were not practices associated with beginners. While cases may occur where less-skilled writers do tap into commissioned work, my research revealed no such instances. In one of few cases of this that I was aware, a newer writer was commissioned by a business owner and later "gone over" when the owner changed his mind and commissioned another more experienced writer to reproduce the image in the same location. While discussing this with me, the original artist acknowledged that the second version was of better stylistic quality, but was not discouraged by this and later commissioned a wall at another business. Another less-experienced writer helped in this piece by creating a simple collection of shapes used as backdrop to a highly stylized lettering of the business name with customized cartoon character alongside the letters. Nogo, an intermediate writer discussed selling one's graffiti and "cashing out."

"As long as you're like, not trying to 'cash out' on this shit--or if you put in enough work, go ahead and cash out! But...if it's your first couple months writing, I definitely don't wanna see you selling your shit.'

This writer did not report making much money from commissions, only "a couple I sold for ten bucks." Though writing for 9 years, he clearly had not "cashed out" on graffiti and did not appear to push as much as many writers who did regularly sell their art. Nonetheless, he is recognized by other writers, presents his own unique style, and continues to get up.

Several OG or advanced writers reported selling many canvasses and other items with their graffiti name and crew letters or customized sayings and characters. A veteran writer noted selling many of his 
artistic canvasses to both other writers and non-writers, and had once sold dozens of HO scale trains in a specialty show, raising funds to help some friends in need. An advanced intermediate writer known for intricate piecing and a member of a national graffiti crew, started writing with no art background but reported supplementing his professional sales income selling canvasses and doing commissioned murals. "I make at least a couple hundred dollars a week off my canvasses... the end goal is to make money off this." It appears consistently that before being able to sell one's art, some respect must be earned, and one has to be experienced, at least at the intermediate level. This individual's crew members reportedly also working professionally using graffiti related skills:

"...we (his crew) got...guys that have a mural business and are getting paid to do fine art on the side of hotels... and tattoo shops and really wherever else they want to be..."

Earning money using one's graffiti know how appears to align with the serious leisure perspective in terms of career in making of money from skills and knowledge related to the pursuit (Stebbins 1982). In terms of specialization, higher skilled graffiti writers tended to sell their work somewhat regularly, either on commissioned canvasses or in other forms (e.g. mural businesses), while several artists also sold works through galleries, at the same time doing illegal graffiti in their other time. As I will discuss further in the next chapter, graffiti appears to occur both as a form of edgework dark leisure in its illegal forms, and resembles forms of serious leisure occurring differently in specialization levels.

\section{Discontinuing the Writing Career}

The writers who I interviewed and observed spanned from 18 to over 40 years in age. It is uncertain when or whether aging out occurred in this sample, though some writers reportedly had been very active with large graffiti crews and yet hadn't written graffiti in several years, aside from an occasional train or a wall at a legal gathering. Some writers fell out of practice for long periods of time. One OG writer I spoke to reported not painting anything notable since 2016 but had been in one of the most well-known graffiti crews in the region and the state.

Discontinuing practice in graffiti may apparently occur at any level of experience. One ten-year veteran writer said new writers experience no benefits the first year, are not good enough to be recognized, and that even after building a reputation, they may have a "shelf life" (i.e. eventually stop painting). This 
shelf life appears relate not only to one's social status in the community, but also significantly to their level of commitment (or the decrease of it, perhaps as occurs due to other life constraints).

Life commitments may as such serve to constrain one's graffiti practices. One very active writer reported to me that his significant other had entered a professional career, and that he had not been painting. At least one other writer in the same crew had reportedly had stopped painting graffiti for some part of the past two years due to unknown reasons, though he had mentioned a very negative series of interactions with another writer, which decreased his desire to paint.

Laub and Sampson (1993) noted that significant work status change, marriage, or other "turning points" occur to determine whether and how criminality persists, or, perhaps, even one's criminal status. Being on bond, probation, or under some other court order can constrain one's writing. A veteran who was asked what would stop him from painting graffiti noted, "My wife! Hahaha.... You know, my legal status, you know what I mean? I'm out on bond...there's quite a few things." While none of the writers in the research sample reported to have aged out, many of the more experienced writers experienced other significant lives events or commitments that tended to precede the importance of their practice of graffiti. It appears that there may be some importance for research on this topic in terms of graffiti writing, to establish trends in how writers continue or discontinue practice over the life course.

\section{A Caution to Alternative and Legal Graffiti Policy}

Based on conversations with several writers in the current sample, it appeared that only a few had been hired for public arts projects in the metropolitan area. Most writers were unaware of how to get involved. One intermediate writer I interviewed noted a need for legal spaces to paint:

"Yeah if the city would grant me permission to do murals. Then they wouldn't have to buff. And...it would help a lot with graffiti. It would be like a skateboarder needing a skate park.... I could ride around all day on a skateboard and destroy dudes' property. Either give us a place to skate, or we're going to grind on your shit. In an analogy-sense."

Where creating "free" spaces for legal graffiti may be beneficial to writers, policy officials, and public, writers who were interviewed in this research indicated no plans to intentionally desist in writing graffiti illegally. Brewer and Miller acknowledged this in their early research, yet they posited that "Giving writers greater access to legal arenas, for their writing is the key to reducing illegal HHG” (hip hop graffiti) 
(1990:364). The city council official interviewed in the current study appeared to be aware of this value,

noting that:

"I would much rather see more funding available...to be used to pay for...graffiti writers to create collaborations that would include...known vandals and then let them create.... and implement the plan that would produce work that is considered...generally acceptable by society."

While discussing the idea of implementing a legal wall, the same city council member expressed interest in utilizing a mile-long section of river flood wall and "...turn that over to the graffiti artists...to speak to the community... say what they want to say, and...(authorities) not tell them how to do it." Given that writers of all skill levels in the current research expressed interest in painting legal spaces and that there was potential interest in sanctioned legal spaces as expressed by policy officials, the use of such alternative graffiti venues may be viable directions for current policy. Nonetheless, as is emphasized in other graffiti studies, neoliberal efforts to allow graffiti also tend to attempt to control it by diluting its potency (Lombard 2013). Further, such policies that "co-opt" writers in legal muralism are often argued as "revanchist" efforts to retake the city from graffiti writers and other "undesirable influences"; these efforts may be backed by moral entrepreneurs and growth machines to attract middle class residents (Walters 2019:148, 167-168; See also Kramer 2016). As such, writers in the current study may become suspicious and resist legal efforts if such attempts are made. Thus, this caveat to legal graffiti policy raises the notions of moral geographies and the implicit conflict imposed by graffiti's illegality, implicit power relations, and other differences between writers and municipalities in the control over public and private space.

\section{Policy Standpoint and Conflicting Images: Quality of Life and Illegal Graffiti}

The key issue for policy officials in this research is that graffiti is illegal because, despite any aesthetic value it conveys, it conflicts with the image of the city that many wish to project through promoting an atmosphere free of blight as necessary to increased quality of life. In order to expand this city level vision and enhance quality of life, several policy officials conducted revitalization projects and promote the ideal that murals and other permitted street art add a certain "coolness" value to public space and deter unregulated tagging and other graffiti, which conflict with the image.

The city personnel's and anti-graffiti activist's different standpoints and ideals regarding graffiti converge on continuing with public arts alternatives along with developing collaboration with other departments to explore alternative justice options. Some policy officials and the anti-graffiti activist desired 
funds and support for 48 hour abatement, collaboration and regular meetings among departments, education of police and the hiring of a graffiti detective and or task force, and "restorative justice" measures (making apprehended writers paint over other graffiti). Some value was expressed in helping the police to build criminal cases on writers and sometimes working with police and community installing surveillance equipment in graffiti hotspots. It is worth reiterating here that in other graffiti research such practices have become synonymous with place-based policing (Ferrell et al. 2014), militarized "wars on graffiti" (Iveson 2010). Given the specialized practices and orientations of writers at different specialization levels as evident from the current findings, policy officials may consider viable alternatives to conventional and place-based urban graffiti policies. To do so may acknowledge the non-instrumental and expressive nature of much of graffiti, as will be further explored in the following chapter. 


\section{CHAPTER 7}

\section{DISCUSSION AND CONCLUSIONS}

\section{Synopsis}

In this chapter, I further discuss significant findings that relate to the extant research and theory on urban graffiti, the serious leisure perspective, dark leisure, recreational specialization theory, and edgework. In addition, I explore some recommendations for alternative policy practices based on findings that indicate a potential fit for interviewed city officials' preferences. I conclude with a discussion of limitations of the current study and potential directions for future research.

It is important for policy officials and planners to recognize the nuances that distinguish hip hop graffiti from other forms of illegal graffiti. Doing so may broaden limited public understandings of artistic graffiti that construct it either as a destructive pastime of criminal vandals, or as a sanctioned form of art in city-funded muralism that uses writer talent. It is my position that graffiti should also be recognized as a legitimate type of recreation involving high levels of skill, practice, and resulting benefits for practitioners. As Austin noted, a whole different city is made available by taking graffiti and "art in the street" (2010:33) seriously.

I will also argue in what follows that illegal graffiti is important largely because it sends a bold and resistant message that offers a glimpse of the realities of unheard individuals whose experiences escape the understanding of most outsiders. Providing a more coherent glimpse of the hidden writer standpoint offers to increase public awareness and reduce confusion and misperceptions about hip hop graffiti, while also potentially lessening its association with other more intolerable graffiti. It is 
my position that celebrating the artistic voice and standpoint of hip hop graffiti through alternative practices that may enhance an element of diversity to openly contribute to the urban aesthetic and improve outsider awareness, understandings, and reactions to graffiti. Thus, I believe, as do Zieleniec (2016) and others, that graffiti offers an opportunity to create a more just urban social space.

I begin this discussion by recapping current findings related to progressing along the writer career trajectory and the contingency that writers must "come correct" and preserve subcultural norms and values if they are to be respected as a writer. Later, I will bring in policy findings to demonstrate the ways that municipal abatement (and occasionally, the law) confronts writers, and how this relates to varying motivations for painting both legal and illegal graffiti. Specifically, I will review the ways that many beginners center their focus on thrill and fame, while the more experienced may more generally value flow, meditation (or peace of mind), social connections, and demonstrating artistic mastery. Notably, and as was also the case in other research, graffiti emerged as a social process for writers at all levels, including beginners, whose progress often appeared to rely on making social connections. Thus, writing graffiti emerged as a highly social, bold, and resistant subcultural practice for which motives include expressing transgressive values and alternative notions of the urban visual aesthetic, to beautify public or private space, to communicate with others within the subculture, to demonstrate artistic ability, to earn money, or sometimes to send a message to outsiders. Current findings indicate that writers engaged in an ongoing pursuit of risk, edgecrowding, a notion of abatement as a challenge, and taking extreme precautions in revealing one's official identity. Taken together, these highlight the resistant nature of hip hop graffiti, as has been reported in other research (Ferrell 1995, 1996; Halsey and Young 2006; Snyder 2016).

Additionally, when considering features of the current findings in terms of recreational specialization theory, it becomes evident that specialization occurred in the differences among the practices, preferences, and views of writers of different classes. Notably, serious leisure, dark leisure, and edgework appear in the experiences of writers of the overlapping specialization categories. Below, aspects of these theoretical intersections are further explored, followed by a discussion of implications and policy recommendations.

\section{Subcultural Influences and the Graffiti Career Trajectory: From Toy to OG}


Writing graffiti appears to involve a process of socialization in which writers learn to value different aspects and outcomes to the experience over time, in a career trajectory moving from toy to veteran. This process appears to be similar to classical research on socialization and subcultural membership of (See also Becker 1963). Success as a writer appears to be largely dependent on earning the acceptance, respect, trust, and guidance of others who collectively regulate the subculture and its organization. Thus, within the graffiti community, both actively legitimizing subcultural norms and values through practice and learning via mentorship may occur contingent to the process of successfully moving through the career trajectory, while increasing one's skill and experience in doing graffiti. Significant in terms of earlier graffiti research, the current study located subcultural aspects surrounding different practices of experienced and beginner writers (See Brewer and Miller 1990 on "elites" and "taggers"). Notably, the current study defined a third class of intermediate writers, whose practices fall between (and sometimes overlap with) those assigned to beginner and elite classes of toy and OG (See also CHAPTER 6 for a description of specialization levels of writers based on the current data). Also consistent with Brewer's and Miller's (1990) work that reported writers motivated by "rebellion" against conventional norms, earning fame, demonstrating artistic ability, and, to a lesser degree, destroying property, writers in the current study were similarly motivated, and also valued flow, escaping one's problems, and the risk experience associated with the thrill obtained in evading apprehension by police and other authorities. Perhaps also consistent with edgework research, and to some extent that of tests of the adventure recreation model in RST studies (See also Ewert et al. 2013), most writers in the current study reported to have embraced and pursued the thrill that is obtained from doing illegal graffiti, particularly at the beginner or intermediate levels while developing one's name and reputation. Additionally, several intermediate writers wrote graffiti with the intent of going "all city" (being up throughout the city), despite the dangers and risks associated with becoming a prolific writer. At some point, however, a shift toward a focus on painting for meditative and artistic benefits appears to occur, sometime around the intermediate level of specialization, especially after one has become significantly up and recognized by other writers. Additionally, after years of painting illegally for thrill or fame, many writers shifted focus to artistic and stylistic expression in an orientation of producing quality (rather than quantity) in their graffiti. As such, heterogeneous practices appeared within graffiti writing, revealing a process more diverse than one that can 
be designated simply as simple art or vandalism. Progressing from beginner to experienced levels as a writer involves developing one's unique subcultural identity, correctly practicing subcultural norms and values, being respectful, and earning the respect and acceptance of other writers. This entails perfecting one's tagging, throwup, and piecing style, and eventually creating graffiti that is shared, traded, bought, and sought after by other writers and outsiders, alike. This sharing of graffiti often occurs through various media forms, including sketch book tagging or piecing, the trading of stickers, partnering on painting canvasses (or in producing murals), or creating and selling individualized wall art, signs, album art, and other custom applications (such as in digital media design and production). Much of the legal graffiti observed in the current study aligns with the serious leisure perspective, particularly as serious leisure hobbyism (Stebbins 1982) throughout much of one's graffiti career, where generally producing illegal graffiti may also be aptly described as “dark” leisure edgework. In the case of many intermediate and veteran writers who do public and private commissions or work professionally using skills centering on their graffiti experiences and skills, writing may more resemble serious leisure amateurism. Despite having and taking advantage of often paid legal graffiti opportunities, writers in the current sample inevitably continued to paint illegally, while facing inevitable risk, which is consistent to what the research of MacDiarmid and Downing (2012) and others also found. The implications of these subtleties and theoretical aspects of graffiti writing are discussed further below.

\section{Policy Implications: Dark Leisure, Serious Leisure, and Recreational Specialization in Graffiti}

Writing graffiti for all writers in the current study was supported by several auxiliary leisure "subpractices" geared toward an end goal of producing illegal graffiti (or earning money). These and other supportive practices within graffiti align with the auxiliary activities done in conjunction with other "dark" leisure pursuits (See also Stebbins 1996; Williams and Walker 2010). To recall Williams' and Walker's (2010) deviant leisure typology and Stebbins's (1996) categories of deviant leisure, in the current study, graffiti was only constructed as tolerable if it did not harm public welfare. This means that graffiti that was done without advanced permission was generally deemed intolerable according to written discourse and practice. At the same time, as sample policy officials emphasized in interviews, many members of the public still viewed sanctioned street art (or graffiti) as intolerable on some level, or at least undesirable. Additionally, all five interviewed policy officials interpreted graffiti that is not granted advance permission 
as intolerable because of the damage to private individuals' property may occur both physically and in fines and abatement costs. Interestingly, in some instances, certain forms of graffiti were permitted to "ride" by city abatement officials, which points to a "gray area" of discretion that may further confound public and municipal understandings of hip hop graffiti and its distinction from other types of graffiti. This finding appears to be consistent with Stebbins's theoretical discussion of dark leisure in the sense that there will always be overlap in notions of tolerable and intolerable dark leisure forms, differences that are spatiotemporally contingent (1996:19). This intersection may be better distinguished in the administration of legal graffiti policy alternatives and in the redrafting of graffiti policy language and narratives.

As the sociology of language and policy research both show us, our choice in words used in specific situations conveys a great influence on the meanings constructed in terms of what is being described. Dark leisure and notions of what are tolerable behaviors derive some potency from what may be conceived of as unhealthy features of dark leisure or recreational practices. For instance, much of the antipathy toward graffiti that was related by policy officials in the current study appeared to focalize on features of the activity that involve high personal risk and edgework. Specifically, the code enforcement official emphasized the dangers in writers painting of billboards and roadway signs crossing over highways, noting that someone may eventually be killed or injured. This policy official and others preferred for writers to engage in other practices, such as painting in abandoned warehouses, or painting at legal gatherings and productions. From the standpoint of the policy officials and others, these separate instances likely lie outside of the "intolerable" category as a function of their being (usually) semi-private and away from the public, and less of an immediate threat to community welfare.

To better frame graffiti as a legitimate recreational form that may be acknowledged by publics and municipal policy, it is useful to revisit the serious leisure aspects as the current findings suggest they appear to occur over the course of one's graffiti career trajectory and in specialization. Based on study findings, for writers, graffiti and related practices resembled serious leisure hobbyism throughout a significant part of writers' careers. Notably, after significant skill development and accumulation of experience, one's writing practices in many cases more closely resembled those of serious leisure amateurism. In the latter case, if writers eventually become employed professionally, or for city arts projects or in other public or private arts commissions, they essentially capitalize upon their graffiti skills to engage more directly with the 
public, organizations, or businesses, (See also Stebbins 1982:258-259 on "professional-amateur-publics"). This was the case with many advanced writers who had either obtained paid work or formed businesses (or in one case an arts cooperative specializing in muralism) providing professional artistic productions either in graffiti style or otherwise using their graffiti-related skills and experiences. Additionally, on occasion, numerous intermediate writers had begun to similarly market their skills by providing services to private individuals and businesses. Notably, all writers beyond the intermediate level generally bought, sold, or traded art with others in a non-professionalized market consisting of other writers and non-writer enthusiasts or friends, again affirming aspects of serious leisure hobbyism that appear in practice throughout significant part of one's graffiti career.

Current findings also suggest that graffiti writing has characteristics consistent with serious (dark) leisure (See Williams and Walker 2006 and Stebbins 1996), and specialization appears to occur in separate and overlapping classes of writers, carrying implications for RST research in terms of incorporating unconventional forms of recreation into future studies. It is important to highlight that the current study findings are also consistent with Scott's (2012) research, which found heterogeneity in levels of seriousness and quantifiable numbers of participants in different classes, as well as diverse practices and views according to each class. Additionally, past experience and centrality of importance of a recreational practice relative to other pursuits were key features of all classes of writers, and consistent with the results of the research of Lee and Scott (2013), commitment in doing graffiti appears to lead to one's writer identity formation, career potential, invested effort, and perseverance.

As mentioned before, writers did not always progress beyond a certain level after attaining writer status, and writers described motives differently according to level of specialization. As such, one may or may not continue writing for years, becoming recognized as a known and skilled writer or (eventually) a veteran (OG). Several "cases in point" occurred where a small number of intermediate writers either had not developed a throwup or piecing style, or had not dedicated a great deal of effort in getting up, even after several years of writing, though both individuals had become known as prolific taggers or bombers. This was again consistent with other studies on RST where specialization does not always occur in a forward direction of "progress" (See also Kuentzel and Heberlein 2006; Oh et al. 2010). 
Also, similar to other research findings, as specialization increased among writers in the current study, many reported to substitute their primary recreational form in painting graffiti for other activities. Specifically, experienced writers more often reported substituting paid activities for illegal graffiti, frequently painting model trains ("HO scale) or canvasses (or sometimes commissioned art). In contrast, less experienced writers frequently reported seeking out spots for later (“doing homework”) or practicing sketching in black books as primary substitution activities over doing illegal graffiti. Writers of all skill levels infrequently utilized legal walls (aka "free walls" where graffiti can be painted freely), though only a small number of these were known to be available in the metropolitan area under study; many writers traveled outside the city to paint freights. Alternately, beginner and intermediate writers frequently sought out unused or abandoned buildings, barrier walls, or sewer runoffs to practice or otherwise "get a spot," whereas more experienced writers most highly valued painting in train yards. This practice was limited to the veteran or established writers and was regulated by many who wished to keep the inexperienced out of yards to avoid compromising access to more experienced writers, which had happened in the past.

To highlight other findings that are consistent with RST research, among writers in the current study, flow, substitutional recreational practices, identity, multi-directional progression, and addiction all reportedly occur as one becomes more experienced and progresses along the graffiti career trajectory (See also Needham et al. 2013 for similar findings). Notably, the graffiti career trajectory for the most part did not lead to successful legal endeavors among writers of the current sample, though in many cases did, particularly as was the case with several OGs and intermediate writers. Additionally, flow (See also Csikczentmihalyi 1990) was experienced differently by intermediate (or toy) writers to whom bombing was usually the primary outlet, whereas more advanced writers most frequently valued trainwriting and the sense of meditation and accomplishment associated with it. Intermediate writers valued flow, but more frequently reported experiencing thrill, rush, and, in some cases, addiction when discussing motives and benefits, the latter of which are typically associated with "quick and dirty" tags and throwups (McAuliffe 2012), which in turn are more associated with (generally) higher risk street spots. For many, the rush from doing illegal graffiti was better than any drug and was also addictive, compelling one to paint increasingly more over time after one had learned to enjoy a "seduction of crime" (Katz 1988) within doing illegal graffiti, or a "desire" (Halsey and Young 2006), also consistent with findings in other deviance studies and 
edgework research (See also Lyng 1990). On the other hand, advanced writers tended to less often seek out "hot" graffiti spots where a greater risk or likelihood of arrest might occur, and thus, on average, thrill was reported to be less desirable to more experienced writers. Additionally, the more highly-experienced writers reported experiencing flow, relaxation, or meditation more frequently than rush or thrill. This finding differs significantly from other recreational specialization research, where more experienced rock climbers and other edgeworkers did tend to value thrill increasingly over time (Ewert 1988), and many others deliberately raised the stakes and "crowded the edge" (Lyng and Snow 1988; Lyng 1990) to maximize thrill.

When considering the varying practices, attitudes, and views of writers of different writer specialization levels, the consistent features of writing with other RST research, and the fact that writers acknowledge the planned rewards obtained through regular practice, graffiti writing appears to be a legitimate form of recreation. Additionally, writers of all levels of experience unanimously agreed that graffiti is a fun and rewarding form of recreation having features common with edgework and serious leisure, and features rewarding positive outcomes like flow, thrill, socializing with other writers, and other benefits. To acknowledge that within graffiti writing there are distinctive classes of practitioners and recreational features, including different attitudes, practices, and behaviors may allow a better understanding of urban artistic graffiti. To acknowledge graffiti as recreation, along with the nuances and differences within graffiti and its related practices is important for publics and city officials. to better justify the investing of time, money, and resources into legal graffiti policy alternatives.

These and other findings may better inform policy practices of the positive potential in the use of discretion in both justice and abatement practices, and in the development of properly operated legal walls and other venues. In such locations, writers may exhibition their works in an unconstrained environment, and positively interact with writers of different experience levels and backgrounds. Additionally, such legal spaces may be placed in ways that offer a public view of artistic graffiti that increases exposure and awareness, and may thus serve to decrease misunderstanding or fear about hip hop graffiti. Additionally, other alternatives may serve community interests.

\section{Policy Recommendations: Expanding Practices through Alternatives}


As implied throughout much of the current discussion, most municipal abatement efforts are far outpaced by the desires of writers to get up and be consistently and persistently known (See also Bloch 2016b). It is my position that, binary policy constructions consistently miss out on significant and mutually beneficial legal opportunities for artistic expression that are enjoyed by many writers, some of whom maintain legitimate lifestyles and seek out economic benefits from legal graffiti productions, consistent with other research (See also Kramer 2016 and Brewer 1992). Conventional policy also fails to address the non-instrumental, expressive nature of illegal graffiti, as was alluded to by several city officials who were dedicated to maximizing the creation of public art and potentially considered offering legal spaces as expressive outlets to be managed by writers. Graffiti writers did express value in such legal opportunities, and it is worth considering whether offering permitted alternatives would correlate with a decrease in tagging that is targeted by the $\$ 160,000$ annual expenditures on abatement in the city currently under study. Offering legal venues to writers may be a fruitful means to also reducing unwanted forms of graffiti, though attention must be paid to proper implementation of such legal alternatives (Ross 2016).

Furthermore, policy officials should not expect illegal artistic graffiti to disappear, or for writers to "change their ways" and go legal. Such policies are only suggested for allowing free space for writers in the interest of raising awareness, reducing fear, and potentially involving writers for more paid opportunities, not for gentrifying neighborhoods or attempting to attract the middle class with street art.

Additionally, and despite its persistence and seeming success (if limited), abatement as a mainstay in graffiti policy fails to eliminate the serial and repeating occurrence of illegal graffiti because it does not address the reasons behind writing on walls (See also Gomez 1993; Halsey and Young 2002). Some argue that abatement and writer commissioned muralism is a concerted policy effort to retake the city from graffiti, and to instill increased notions of quality of life and safety among residents and outsiders (Walters 2019). Policymakers must on some level reconceptualize abatement as an ongoing enterprise that is in many ways encouraging to illegal graffiti, and it may be sensible to take a proactive stance to repaint other city walls where writers can regulate legal space (as opposed to solely utilizing costly abatement or murals as "spray and pray" graffiti deterrents. Further, to continue the city's desire for muralism and given some veteran writers' desire to teach or mentor those less-experienced who show promise, it may be possible to 
utilize alternative mural programs that enlist city youth talent, allowing for experienced graffiti writers to teach those who show interest.

As was mentioned, I was made aware during interviews that several non-affiliated citizens in neighborhoods throughout the city had at times conducted their own graffiti abatement. Some success may be realized in boosting community ownership and involvement in graffiti policy through "adopt a wall" programs on highways and streets (See also Ross 2016) where community ownership might be opted for rather than relying on the installation of surveillance cameras or adding to the responsibilities of overtasked police whose focus is on more prioritized crime involving public safety. It may also be useful to conduct further community preference surveys to utilize data in organizing such programs. In such scenarios, private citizens could opt to co-adopt walls or otherwise take ownership in matters involving public space, perhaps in cooperatively adopted walls between neighborhood members and graffiti writers. This raises the important notion that future policy and research on graffiti culture and policy might also attempt to better assess the standpoint and experiences of community members and other stakeholders, perhaps assessing perceptions of fear before and after attempts at alternative graffiti policy.

Significantly, as the written discourse generally pits property owners against writers inherently by nature of the fine and abatement ordinance, it may be that policy officials could benefit from using the same discretion as is extended to property holders (by the code enforcement official) in cases of frequently targeted graffiti spots. Notably, other councils like stART program in Toronto have begun to allow property owners to choose not to abate graffiti from their properties, should they so desire. Additionally, such programs allow land owners to commission writers or street artists to decorate their buildings. To exercise discretion in this way may contribute to the graffiti writer-property holder tension that is implicitly constructed by policy

The current data suggest that modifying graffiti policy according to themes revealed in interviews with policy officials and in data gathered on writers could serve the consensus desire for increasing community and other departmental involvement in ways complementary to the preferences of policy officials who are intent on expanding an urban artistic aesthetic throughout the city. Findings also indicate that there is some degree of consensus between policy makers and hip hop graffiti writers within this aesthetic. Essentially, there should be more space available for murals and more free space where writers 
can "get up" without fear of legal penalties. This may be achieved through further developing public murals programs to more inclusively involve community stakeholders and graffiti writer talent, while also furthering other alternatives that redefine public spaces.

An awareness of the distinctions in practices among writers of differing levels of experience may also serve useful in implementing legal alternatives in graffiti policy. For instance, if city-provided legal walls are attempted in policy measures, experienced writers may offer support or mentor newer writers who are intent on bombing as their primary focus in graffiti. In other words, if there were venues where experienced writers create highly skilled art and socialize with other writers (as was desired by many), it may be the case that less-experienced writers may shift their primary focus from fame excessive tagging and bombing to more artistic displays where they may experience flow and other benefits from learning to develop their piecing skills through exposure to experienced writers. In this way, the needs of both writers and policy officials stand to be served to some extent.

Given the significant variation in the motives and experiences of writers of different skill levels and the heterogenic practices within it, graffiti crosses a line of legality that occurs somewhere between illegal dark leisure edgework and legitimate and tolerable serious graffiti leisure forms. In theoretical terms, it is my belief that different levels of specialization in graffiti better describe the practice, one which carries the potential for every writer to create from illegal graffiti a legitimate career related to their skills and experiences. As well, as writers gain skill and experience, they appear to alternate between legal and illegal graffiti writing, similar to the process described by MacDiarmid and Downing (2012) of drift occurring between criminality and legitimate practice. It appears that this drift also underscores the power of written discourse to exclude the voice of non-dominant and diverse individuals and groups (Collins 1988; Smith 1989, 2005). Further, graffiti writers drift between whatever environments are available for the practice of their art, sanctioned or not. A knowledge of the drift between legality and illegality among graffiti writers may be emphasized in policy. For instance, policy change could expand legal opportunities and lessen criminal consequences for writers by offering accepted alternative spaces where they may practice legally. This form of alternative could also serve to diversify the benefits of municipal arts administration by offering public locations where the graffiti aesthetic can be better understood and appreciated as art and 
expression. As per labeling theory, allowing such an alternative expression of graffiti could serve to avoid the master status of 'graffiti vandal.'

\section{Alternatives in Restorative Justice}

Interestingly, where most policy officials desired more collaboration and funding to address illegal graffiti, some ideas of how these efforts should take shape included increasing police involvement and shortening abatement timelines. Several officials noted that jail was not a favorable alternative, and reparative measures should instead be employed. Some officials desired to have places where writers could go to do graffiti, rather than illegally on underpasses, highway signs, and other structures and walls. It is likely that the disempowerment that restorative justice theorists posit is present in conventional criminal justice models may be reversed by no longer excluding victims and others impacted by crime from participation in overseeing justice. Such measures, combined with expanded legal opportunities for writers, may also be worth incorporating into policy design and implementation.

The alternative practices desired by the policy officials for dealing with apprehended graffiti writers may more aptly be described as reparative, than restorative, justice measures. Nonetheless, utilizing true restorative justice policies along with reparative measures may be incorporated alongside legal graffiti forums to more efficiently serve policy preferences to encourage artistic graffiti and reduce unskilled tagging, while also creating a more holistic justice process for apprehended writers, victims, and community.

If success could be realized through managing illegal graffiti in these and other alternative measures, conserved funds and resources might be utilized for public welfare programs or other areas of need, another key desire of policy officials. It is likely that allocating legal walls and other forums where writers can showcase their skills (and exercising discretion in enforcement situations, where applicable) may divert resources or perpetual monies funneled into abatement. If managed correctly, a writer-operated legal wall program might also generate tourism and value from local and outside interest. Feature events could perhaps generate opportunities for community artists and youth to paint in public art graffiti mural exhibitions or competitions. Artist talent thus may potentially be capitalized upon by municipalities in the interests of accumulating alternative community capital through utilizing the arts and increasing tourism, youth involvement, and other initiatives. On the other hand, if mismanaged or used in policing to 
apprehend writers, such projects will likely fail, lose writer support, and potentially result in greater losses. Thus, any changes must be carefully planned and evaluated in design and in ongoing implementation, as classic policy implementation models specify should occur in policy research, design, and implementation (Pressman and Wildavsky 1984).

\section{“Mainstreaming” Graffiti and Writer Resistance}

As other research noted, modern neoliberal policy design uses legal graffiti to make illegal activity docile and watered down. Writers may resist participating or granting too much legitimacy to legal policy programs, which may be suspicious and not motivated to reveal much about their identities or illegal activities (Lombard 2012; Bloch 2016a). The current research holds consistently to other studies where, despite having legal opportunities to do graffiti, often for economic benefits, writers reported fully planning to continue to write illegally. This affirms a non-instrumental and resistant intent that perhaps lies at graffiti's core. As such, though legal opportunities are usually widely valued and appreciated by writers, policy officials should be cautioned to avoid setting their expectations too high in terms of "converting" writers or unrealistically foreseeing a total elimination of illegal graffiti. Instead, practices should engage writers in the legal opportunities to exhibit their artistic skills (or practice them). This may result in gaining writers' respect to some degree, which may potentially result in a lessening of some instances of illegal graffiti.

Another caution is that public arts opportunities may appear risky to graffiti writers in the sense that revealing their legal identity may occur when following up on or attending public callings. The fact that some writers have taken this bold step in arts projects overseen by city policy officials speaks to the fact that several writers commissioned for public arts projects created an arts collective specializing in murals and street art, shifting focus from illegal to legal art. While this may be a theoretical end destination in the graffiti career trajectory, a full emergence from illegality did not occur for writers in the current sample, as was consistent with other studies (MacDiarmid and Downing 2012; McAuliffe 2012). Nonetheless, many sample writers did have legitimate professional pursuits wherein they used graffiti skills, and most writers used their graffiti skills creatively and for ways to accumulate monetary benefits. Additionally, most writers were aware of the potential for highly paid careers, and many expressed an interest in making something legitimate from their graffiti knowledge and skills. Though not likely for 
many writers, this was the case with many well-known OGs including, but not limited to Risk-MSK, Revok-MSK, Espo, Norm-AWR, Mike Giant, and others whose many years doing illegal graffiti eventually led to lucrative legal pursuits and international renown.

A caveat to policy redesign is that many advanced writers reported that graffiti posed constraints on personal relationships, and it is unknown whether or how utilizing legal outlets for graffiti may affect these constraints or personal limitations among experienced writers. It is unknown, but possible that giving already taxed writers more outlets or responsibilities related to their writing hobby may further add to personal constraints and hence potentially limit involvement in legal initiatives.

Lastly, it should also be noted that, if the establishment of a graffiti task force is prioritized in future budget plans (as per the recommendations of the anti-graffiti activist who consulted with the city personnel on this and other matters), in addition to the creation of legal venues for graffiti, measures should ensure that police do not target legal graffiti gatherings or direct investigations to such venues, as this resulted in past legal policy failures (Lachmann 1988). Such approaches also move in a direction toward zero tolerance municipal graffiti policies that tend to militarize police, publics, and policy officials in a “war on graffiti” approach having negative results for communities (Iveson 2010). Additionally, it may be the case that protest, hate, and political forms of graffiti stand the risk of appearing when municipalities sanction legal spaces for graffiti. For legal walls or other writer-managed forums, writers may need to devise ways to self-regulate to discourage obscenity, hate speech, or touchy political graffiti that are targeted in priority over artistic graffiti and which were noted to precipitate the failures of past efforts at using legal walls by the city under study. To determine the best ways to unfold such a policy program redesign, and in order to give ownership to writers in legal spaces, it would likely be useful to assess and consider the ideas of writers themselves on how to successfully design and operate legal walls and other forums. This process would require the conducting of focus groups, interviews, or questionnaires to pose specific questions and obtain detailed and balanced feedback on how writers are willing to coordinate the design and implementation of the project. Where collaboration among large groups of writers may be difficult, it is likely that most would take interest and offer valuable feedback. Based on the findings in the current research, it is likely that numerous members of the graffiti community would be willing to participate in focus group and other interviews to assist the process of effectively designing and 
implementing legal spaces for writers. This could be facilitated with the assistance of a liaison such as this author or other writers or artists who are currently or have been involved in the city arts and murals initiatives.

\section{Limitations and Directions for Future Research}

A key limitation to the current research involves sampling. In terms of the policymaker and enforcer sample, it would better serve future research to interview a knowledgeable police official or graffiti detective who can provide greater knowledge of the views, priorities, practices, and policy preferences of metropolitan police. Graffiti researchers also have noted a predominance of males in modern day graffiti subcultures (Bloch 2016), and to recall, the current study sample is also over-represented by whites and males, with 27 males to two females and one individual who identified as "non-binary female." 28 writers reported being white or Caucasian, one "biracial" Black, and three Native American. It is unknown what percentage of the national or international writer population of graffiti writers are female, transgender, or of a non-white background, though other research indicates diversity in writer populations that were traditionally Black or Latinx. It is possible that my being a white male could have influenced the sample selection of writers referred to participate in my research. I believe that future graffiti research conducted by those of other genders and in other regional locations will likely reveal a more diverse population of writers doing hip hop style graffiti, generally and will also identify more nuances within the standpoint and practices of writers. In terms of diversity and demographics, utilizing alternative graffiti practices might increase the involvement of beginner writers, females, people of color, transgender, and other minorities. Such individuals may become empowered by participating in legal graffiti wherein they may also interact with other and more experienced writers who may facilitate their learning of new skills and techniques.

Notably, the current research contributes to literature on graffiti writing by providing an up-to-date analysis of graffiti subculture in a Midwestern American city. This may allow conclusions to be made about policymaker understandings, practices, and preferences (e.g. their standpoints), and the standpoints of graffiti writers: their practices, preferences, and perceptions of society's reactions. I believe that it would also be worthwhile to the body of extant graffiti literature to conduct a more comparative analysis of writers' standpoints by accessing willing writer research participants from cities in regions outside of the 
American Midwest. A caveat to this and other findings regarding expanding the diversity of a research sample of writers, is, of course, research access to a willing sample of graffiti writer research participants.

The current data indicate an extreme level of commitment among writers with only one (unconfirmed) case of a writer in the current sample who is thought to have discontinued practice since being interviewed. Since this research did not definitively identify or examine cases of writer desistance, a continuation of this research may examine the perspectives of writers who quit doing graffiti or transitioned into legal work that uses significant skills, learned through the ongoing practice of illegal graffiti. Given an accessible sample of research participants, future research may be designed to more closely examine specialization and desistance as they occur for different graffiti writers over time. Additionally, future graffiti policy research may also utilize municipal level abatement data, where available, to perform GIS or spatial analysis of the frequency and types of graffiti to better evaluate the effectiveness of abatement, which may be a baseline for alternative graffiti policy practices.

It is significant to also point out that several sample writers emphasized the importance of "pushing oneself in order to get up and be known, which (to many) is "the whole point of graffiti." To recall Stebbins, amateur pursuits, chosen for their strong appeal, become an avocation only when significant seriousness and commitment are put forth by practitioners (1982:258-259). Thus, in the current research, the seriousness and commitment displayed by writers during the beginner level (and beyond) determined whether they endured successfully in the pursuit and later specialized in piecing, muralism, and marketing their graffiti skills, which in many cases then became the basis of paid professional pursuits.

It is important to also reiterate that Bryan $(1977 ; 1979)$ conceived of specialization as a continuum of attitudes, practices, and views held among recreationists, and also as the process through which individuals improved their skills and experiences in recreation. On the other hand, Scott and Shafer (2001a) saw specialization as the ways that recreationists view and participate in their pursuit over time (See also Tsaur and Liang 2008). Significantly, from the current data, in vivo codes for experience levels refer to classes of writers that are distinguishable by the varying practices, views, attitudes, and in some cases the materials used as one becomes more experienced and practiced in doing graffiti with different media (i.e. progressively using and mastering the use of markers, scribes, aerosol paint, "bucket paint" as one masters the different traditions in graffiti; See also CHAPTER 6). As such, this analysis presents notable evidence 
suggesting that graffiti writing occurs in a process of specialization. Future research may more deeply explore specialization within artistic graffiti.

Additionally, as noted before, a unanimous consensus was evident among writers that graffiti is a form of recreation having planned positive benefits, and writers of advanced and intermediate specialization levels reported receiving durable benefits as per serious leisure amateurism (See also Stebbins 1982 on distinguishing amateurism from hobbyism and volunteerism serious leisure forms). On the other hand, writing during the earlier stages (generally un-paid or non-professional practices) of one's career may be likened to a form of serious leisure hobbyism in that writers are serious and committed with a potential market base for selling their skills (e.g. social media or word-of-mouth networks), but lack an established institutional professional arrangement (as in serious leisure amateurism). On the other hand, if writers become involved in public or professional exchanges for their work, graffiti may be more aptly distinguished as akin to serious leisure amateurism. It may be useful to recall that Tsaur and Liang (2008) determined that serious leisure was common among recreational specialists. The current study offers some evidence that, as recreational pursuers, graffiti writers consistently exhibited all characteristics of serious leisure. Additionally, all sample writers, when asked, confirmed receiving lasting benefits from doing graffiti, and there was compelling evidence suggesting that those benefits, views, and practices varied significantly enough by each class of writer to establish that graffiti also occurs as recreational specialization. These are important points for policymakers and other stakeholders to consider when weighing options with policy alternatives. If graffiti can be viewed as legitimate recreation and sanctioned in public legal spaces, this may serve to lessen the confusion, misconception, and stigmatization of graffiti that occurs due to muddled definitions of hip hop graffiti, gang graffiti, racial speech, political, or "civilian" amateur graffiti. Utilizing legal graffiti policies may as such serve to increase public exposure to and awareness of hip hop graffiti, thus potentially lessening perceptions of fear that may be inadvertently assigned to all graffiti due to a widespread lack of understanding or confusion about its different forms and their meanings. To measure the efficacy of this feature in alternative policy implementation, future research may also be designed to assess public understandings and perceptions of fear associated with graffiti in its various forms both prior to and after incorporating legal graffiti policy initiatives. It is also suggested that, given adequate sampling and access, future research may more closely examine serious leisure 
characteristics among writers of different experience levels, ideally using some of the more qualitative approaches consistent to other serious leisure and RST research.

Lastly, since the graffiti career trajectory aligns with aspects of edgework, serious and dark leisure, and recreational specialization, other research might be directed to the study of "legal" graffiti writers who specialize in paid or volunteer legal graffiti or street art projects. As stated before, many veteran writers of the American West Coast, including Risk-MSK and others, are known to have shifted their focus to the legal sphere, and their art has often been featured in gallery settings and commissioned in street art projects. Understanding the commonalities and differences among legal and illegal writers may assist in a deeper understanding of whether and how writers transition from the illegal graffiti career to legal endeavors.

\section{Concluding Statements}

Described in terms of recreational specialization, serious and dark leisure, and edgework, the practice of graffiti reveals ways that can benefit conventional policy. To make the interests of graffiti writers and policy makers come together best, sensible alternatives may be used to add cultural capital to the community, increase stakeholder involvement, increase cultural awareness, decrease confusion and potentially reduce perceptions of fear about graffiti, and provide an expressive outlet to artists. To give every writer what they desire--walls and canvas on which to paint--could add a valuable dynamic for writers and garner community appreciation of the visual aesthetic in hip hop style graffiti.

If one examines the nuances within graffiti writing, the writer standpoint becomes evident in the transgressive practices and everyday forms of resistance in which writers engage in getting up. Graffiti writing continually crosses and re-crosses the edge of legality and extreme danger, perpetually guided by an internal drive to create. As one experienced writer aptly noted about graffiti, there is...

“... something spiritual about painting... graffiti is...spiritual ...because ultimately you have to have something inside yourself, whether disdain for authority, whether you're rebellious. There is something inside you that you are trying to get out. Like painting a wall. There is something inside of you that is driving you to do that... You're taking something where you didn't have anything and creating something out of nothing."

To create "something out of nothing" in this way, writers channel an artistic and rebellious energy, in a voice telling of exactly who they are and of what their experience entails. We can choose to encourage this 
voice, or continue to muffle its sound by painting over it. Regardless, the resonance of the visual expressions of graffiti writers resists opposition and demands to be heard.

It is my sincere hope that this research illuminates the deeply creative nature and nuances of graffiti writing, and the extreme dedication, risk taking, investment, and skill acquisition that precede its ubiquitous and ephemeral appearance. 


\section{REFERENCES}

Adler, Patricia and Peter Adler. 1987. Membership Roles in Field Research. Newbury Park, CA: Sage.

Akers, Ronald L. 2012. Criminological Theories: Introduction and Evaluation. 2nd ed. New York: Routledge.

Alonso, Alex. 1998." Urban Graffiti on the City Landscape.” Presented at the Western Geography Graduate Conference, San Diego State University, February 14, San Diego, CA.

Alonso, Alex. 1999. “Territoriality Among African American Street Gangs in Los Angeles.” Master's Thesis. Department of Geography, University of Southern California.

Allman, Tara L., Bruce M. Mittelstaedt, and Marni Goldenberg. 2009. "Exploring the Motivations of BASE Jumpers: Extreme Sport Enthusiasts.” Journal of Sport and Tourism 14(4):229-247.

Atkinson, Rowland and John Flint. 2001. "Accessing Hidden and Hard-to-Reach Populations: Snowball Research Strategies." Social Research Update 33. Retrieved August 21, 2019 (https://www.researchgate.net/publication/46214232_Accessing_Hidden_and_Hard-toReach_Populations_Snowball_Research_Strategies)

Austin, Joe. 1998. "Knowing Their Place: Local Knowledge, Social Prestige, and the Writing Formation in New York City." Pg. 240-252 in Generations of Youth, edited by J. Austin \& M. N. Willard. New York: New York University Press.

Austin, Joe. 2001. Taking the Train: How Graffiti Art Became an Urban Crisis in New York City. New York: Columbia University Press.

Austin, Joe. 2010. "More to See than a Canvas and a White Cube: For Art in the Streets." City 14 (1-2):3347.

Austin, D. Mark and Claudia Sanders. 2007. "Graffiti and Perceptions of Safety: A Pilot Study Using Photographs and Survey Data." Journal of Criminal Justice and Popular Culture 14(4):292-316.

Austin, D. Mark, Furr, Allen L. and Michael Spine. 2002. "The Effects of Neighborhood Conditions on Perceptions of Safety. Journal of Criminal Justice 30(5):417-427.

Avico, U., Kaplan, C., Korczak, D. and K. Van Meter. 1988. Cocaine Epidemiology in Three European Community Cities: A Pilot Study Using a Snowball Sampling Methodology. Brussels: European Communities Health Directorate.

Baird, J.A. and Claire Taylor. 2016. "Ancient Graffiti.” Pp. 17-26 in Routledge Handbook of Graffiti and Street Art, edited by J.I. Ross. New York: Routledge.

Becker, Howard. 1963. Outsiders: Studies in the Sociology of Deviance. New York: The Free Press.

Bloch, Stefano. 2016a. "Challenging the Defense of Graffiti, in Defense of Graffiti." Pp. 440-451 in Routledge Handbook of Graffiti and Street Art, edited by J.I. Ross. New York: Routledge.

Bloch, Stefano. 2016b. "Why Do Graffiti Writers Write on Murals? The Birth, Life, and Slow Death of Freeway Murals in Los Angeles." International Journal of Urban and Regional Research (2016):451-471.

Braithwaite, John. 1989. Crime, Shame, and Reintegration. Cambridge, UK. Cambridge University Press.

Braithwaite, John. 1996. "Restorative Justice and a Better Future." Pp. 448-454 in Classics of Criminology, 4th, edited by J. Jacoby, T. A. Severance, and A.S. Bruce. Longrove, IN: Waveland..

Brewer, Devon and Mark Miller. 1990. "Bombing and Burning: The Social Organization and Values of Hip Hop Graffiti Writers and Implications for Policy. Deviant Behavior 11:345-369.

Brewer, Devon. 1992. "Hip Hop Graffiti Writers' Evaluations of Strategies to Control Illegal Graffiti." Human Organization 51(2):188-196.

Hobson. 1977. "Leisure Value Systems and Recreational Specialization: The Case of Trout Fishermen." Journal of Leisure Research 9:174-187.

Bryan, Hobson. 2008. Conflict in the Great Outdoors: Toward Understanding and Managing for Diverse Sportsmen Preferences. Tuscaloosa, AL: University of Alabama Press. 
Bryan, Hobson. 2000. "Recreation Specialization Revisited." Journal of Leisure Research 32(1):18-21.

Bryce, Jo and Jason Rutter. 2003. "Gender Dynamics and the Social and Spatial Organization of Computer Gaming." Leisure Studies 22:1-15.

Buchanan, Thomas. 1985. "Commitment and Leisure Behavior: A Theoretical Perspective." Journal of Leisure Research 7(4):401-420.

Castleman, Craig. 1982. Getting Up: Subway Graffiti in New York. Cambridge, MA: MIT Press.

Celsi, Richard L., Randall L. Rose, and Thomas W. Leigh. 1993. "An Exploration of High-Risk Leisure Consumption Through Skydiving." Journal of Consumer Research 20(1):1-23.

Chalfont, Henry and James Prigoff. 1987. Spraycan Art. London: Thames and Hudson.

Chambliss, William J. and Aida Y. Hass. 2012. Criminology: Connecting Theory, Research, and Practice. New York, NY: McGraw-Hill.

Chang, T.C. 2018. "Writing on the Wall: Street Art in Graffiti-free Singapore." International Journal of Urban and Regional Research 2018:1046-1063.

Charmaz, K. 2006. Constructing Grounded Theory: A Practical Guide to Qualitative Analysis. Thousand Oaks, CA: Sage.

City of Sydney. 2010. "Inquiry into Effects of Graffiti on Public Infrastructure, Submission to NSW Legislative Assembly Standing Committee on Public Works Inquiry into the Effects of Graffiti on Public Infrastructure.” Retrieved August 15, 2018

(http://www.parliament.nsw.gov.au/Prod/parlment/committee.nsf/0/bb6b816809

$7 \mathrm{a} 24 \mathrm{f}$ 7ca25774400ba3f9? \$FILE/46\%20-\%20City\%20of\%20Sydney.pdf)

Cohen, Stanley. 2002. Folk Devils and Moral Panics: The Creation of the Mods and Rockers. London: Routledge.

Collins, Patricia H. 1989. "The Social Construction of Black Feminist Thought." Signs 14(4):745-773

Collins, Patricia. H. 2000. Black Feminist Thought. 2nd ed. New York: Routledge.

Conal, Robbie. 1992. Art Attack: The Midnight Politics of a Guerrilla Artist. New York: Harper Collins.

Cooper, Martha and Henry Chalfont. 1984. Subway Art. London: Thames and Hudson.

Craw, Penelope J., Louis S. Leland, Michelle G. Bussell, Simon J. Munday, and Karen Walsch. 2006. "The Mural as Graffiti Deterrence." Environment and Behavior 38(3):422-434.

Csikszentmihalyi, Mihaly. 1990. Flow: The Psychology of Optimal Experience. New York: Harper and Row.

Curtis, J. E. 1988. "Purple Recreation." SPRE Annual on Education 3:73-77.

Desmond, Matthew. 2007. On the Fireline: Living and Dying with Wildland Firefighters. Chicago: University of Chicago Press.

Dilley, Rachel E. and Sheila J. Scraton. 2009. "Women, Climbing, and Serious Leisure." Leisure Studies 29(2):125-131.

Ducuyunan, Faye. 2000. "Governing Graffiti in Contested Urban Spaces." Political and Legal Anthropology Review 23(1): 103-121.

Durkheim, Emile. 1979. Suicide: A Study in Sociology. Edited New York: The Free Press.

Emerson, Robert M., Fretz, Rachel I. and Linda L. Shaw. 2011. Writing Ethnographic Field Notes. Chicago: University of Chicago Press.

Ewert, Alan W. 2001. "Playing the Edge: Motivation and Risk Taking in a High Altitude Wilderness-like Environment." Environment and Behavior 26(1):3-24.

Ewert, Alan, and Steve Hollenhorst. 1989. "Testing the Adventure Model: Empirical Support for a Model of Risk Recreation Participation.” Journal of Leisure Research 21(2):124-139.

Ewert, Alan, Ken Gilbertson, Yuan-Chun Luo, and Alison Voight. 2013. "Beyond 'Because It's There': Motivations for Pursuing Adventure Recreation Activities." Journal of Leisure Research 44 (1): 91-111.

Ferrell, Jeff. 1995. "Urban Graffiti: Crime, Control, and Resistance.” Youth \& Society 27(1):73-92.

Ferrell, Jeff. 1996. Crimes of Style: Urban Graffiti and the Politics of Criminality. Boston: Northeastern University Press.

Ferrell, Jeff. 1997. “Criminological Verstehen: Inside the Immediacy of Crime.” Justice Quarterly 14(1):223.

Ferrell, Jeff. 2006. "Freight Train Graffiti: Subculture, Crime, Dislocation.” Justice Quarterly 15(4):587608.

Ferrell, Jeff. 2016. "Graffiti, Street Art, and the Politics of Complexity." Pp. xxx-xxxviii in Routledge Encyclopedia of Graffiti and Street Art, edited by J. I. Ross. New York: Routledge. 
Ferrell, Jeff. 2018. Drift: Illicit Mobility and Uncertain Knowledge. Oakland, CA: University of California Press.

Ferrell, Jeff and Mark Hamm. 1998. "True Confessions: Crime, Deviance, and Field Research.” Pp. 2-19 in Ethnography at the Edge: Crime, Deviance, and Field Research, edited by J. Ferrell and M. Hamm. Boston: Northeastern University Press.

Ferrell, Jeff, Keith Hayward, and Jock Young. 2014. Cultural Criminology: An Invitation. Los Angeles: Sage.

Ferrell, Jeff, Dragan Milovanic and Stephen Lyng. 2001. "Edgework, Media Practices, and the Elongation of Meaning: A Theoretical Ethnography of the Bridge Day Event." Theoretical Criminology 5(2):177-202.

Fetterman, D. 2010. Ethnography: Step-by-Step. Thousand Oaks, CA: Sage.

Feyerabend, Paul. 1975. Against Method. London: Verso.

Fletcher, Robert. 2008. "Living on the Edge: The Appeal of Risk Sports for the Professional Middle Class." Sociology of Sport 25:310-330.

Forsey, Caitlin. 2012. Men on the Edge: Taking Risks and Doing Gender among BASE Jumpers. Winnipeg: Fernwood Publishing.

Foucault, Michel. 1974. The Archaology of Knowledge. London: Tavistock Publications.

Gagné, Patricia and D. Mark Austin. 2010. "Playing with the Guys: Women's Negotiation of Gendered Leisure and Space." International Journal of Motorcycle Studies 6(2):1-23.

Gomez, Marisa A. 1993. "The Writing on Our Walls: Finding Solutions Through Distinguishing Graffiti Art from Graffiti Vandalism." University of Michigan Journal of Law Reform 26(3):633-707.

Gould, James, DeWayne Moore, Francis McGuire, and Robert Stebbins. 2009. "Development of the Serious Leisure Inventory and Measure." Journal of Leisure Research 40(1):47-68.

Graffiti Management Plan. 2017. "StreetARToronto (StART) Partnership Grant Recommendations." Retrieved April 18, 2018. (https://222.toronto.ca/services-payments/streets-parkingtransportation/enhancing-our- $\quad$ streets-and-public-realm/graffiti-management/)

Granter, Edward, Paresh Wankhade, Leo McCann, John Hassard, and Paula Hyde. 2019. "Multiple Dimensions of Work Intensity: Ambulance Work as Edgework." Work, Employment, and Society 33(2):280-297.

Griffiths, P., M. Gossop, B. Powis, and J. Strang. 1993. "Reaching Hidden Populations of Drug Users by Privileged Access Interviewers: Methodological and Practical Issues.” Addiction, 88:1617-1626.

Halsey, Mark and Allison Young. 2002. "The Meanings of Graffiti and Municipal Administration." Australian and New Zealand Journal of Criminology 35(2):165-186.

Halsey, Mark and Alison Young 2006. "Our Desires are Ungovernable: Writing Graffiti in Public Space." Theoretical Criminology 10(3): 275-306.

Hastings, Donald W., Susan B. Kurth, Monika Schloder, and Darrell Cyr. 1995. "Reasons for Participating in a Serious Leisure Career: Comparison of Canadian and U.S. Masters Swimmers." International Review for the Sociology of Sport 30 (1):101-119.

Haworth, Billy, Eleanor Bruce, and Kurt Iveson. 2013. "Spatio-temporal Analysis of Graffiti Occurrence in an Inner-City Urban Environment." Applied Geography 38:53-63.

Heckathorn, Douglas. 1997. "Respondent-driven Sampling: A New Approach to the Study of Hidden Populations. Social Problems 44:174-199.

Heckathorn, Douglas. 2002. "Respondent-driven Sampling II: Deriving Valid Population Estimates from Chain-referral Samples of Hidden Populations. Social Problems 49:11- 34.

Heo, Jinmoo, Robert A. Stebbins, Junhyoung Kim, and Inheok Lee. 2013. "Serious Leisure, Life Satisfaction, and Health in Older Adults." Leisure Sciences 35(1):16-32.

Heo, Jinmoo, Youngkill Lee, Brian P. McCormick, and Paul M. Pederson. 2010. "Daily Experience of Serious Leisure, Flow and Subjective Wellbeing of Older Adults." Leisure Studies 29(2):207-225.

Hinkle, Joshua and Sue-Ming Yang. 2014. "A New Look into Broken Windows: What Shapes Individuals' Perceptions of Social Disorder?" Journal of Criminal Justice 42 (1):26-35.

Iveson, Kurt. 2010. "The Wars on Graffiti and the New Military Urbanism.” City 14:115-134.

Jaehyun, Kim, Michael Ferguson, Benjamin Hickerson, and Andrew Mowen. 2019. "The Association of Constraints, Negotiation, and Social Influences with Recreation Specialization among Recreational Baseball Participants." Journal of Park \& Recreation Administration 37(1):40-58.

Jaques, David. 2017. "Why is Graffiti Legal in Bogota?" Retrieved Online January 12, 2019 (https://theculturetrip.com/south-america/colombia/articles/why-is-graffiti-legal-in- 
John, George and Torger Reve. 1982. "The Reliability and Validity of Key Informant Data from Dyadic Relationships in Marketing Channels." Journal of Marketing Research 19:517-524.

Jones, Ian. 2000. “A Model of Serious Leisure Identification: The Case of Football Fandom.” Leisure Studies 19:283-398.

Jorgensen, D. 1989. Participant Observation: A Methodology for Human Studies. Newbury Park, CA:Sage.

Jung, Carl. 1964. Psycological Types, Or, the Psychology of Individuation. New York, Pantheon.

Kaplan, Charles D., Dirk Korf, and Claire Sterk. 1987. "Temporal and Social Contexts of Heroin-using Populations: An Illustration of The Snowball Sampling Technique." Journal of Mental and Nervous Disorders 175(9):566-574.

Katz, Jack. 1988. Seductions in Crime. New York: Basic Books.

Kelling, George H. and Catherine Coles. 1996. Fixing Broken Windows: Restoring Order and Reducing Crime in Our Communities. New York: Simon and Schuster.

Kidder, Jeffrey L. 2006. "It's the Job that I Love: Bike Messengers and Edgework." Sociological Forum 21(2006):31-54.

Kidder, Jeffrey L. 2011. "Bike Messengers and the Really Real: Effervescence, Reflexivity, and Postmodern Identity." Symbolic Interaction. Retrieved August 25, 2018 (https://doi.org/10.1525/si.2006.29.3.349)

Kim, Hyounggon and Chi-Ok Oh. 2013. "Applying the Theory of Recreation Specialization to Better Understand Recreationists' Preferences for Value-Added Service Development." Leisure Sciences 35 (5):455-474.

Kramer, Robert. 2016. "New York City's Moral Panic Over Graffiti: Normalizing Neoliberal Penalty and Paving the Way for Growth Machines." Pp. 404-415 in Routledge Encyclopedia of Graffiti and Street Art, edited by J. I. Ross. New York: Routledge.

Kuentzel, Robert F. and Thomas J. Heberlein. 2006. "From Novice to Expert? A Panel Study of Specialization Progression and Change." Journal of Leisure Research 38(4):496-512.

Lachmann, John. 1988. "Graffiti as Career and Ideology." American Journal of Sociology 94(2):229-250

Laub, John H. and Robert T. Sampson. 1993. "Turning Points in the Lifecourse: Why Change Matters to the Study of Crime." Criminology 31 (3):301-325.

Laurendeau, Jason. 2006. "'He Didn't Go in Doing a Skydive': Sustaining the Illusion of Control in an Edgework Activity." Sociological Perspective 49(4):583-605.

Laurendeau, Jason and E. G. Van Brunschot. 2006. "Policing the Edge: Risk and Social Control in Skydiving." Deviant Behavior 27(2): 173-201.

Lee, Jin-Hyung and David Scott. 2006. "For Better or Worse? A Structural Model of the Benefits and Costs Associated with Recreation Specialization." Leisure Sciences 28 (1):17-38.

Lee, Sunwoo and David Scott. 2013. "Empirical Linkages Between Serious Leisure and Recreation Specialization Theory." Human Dimensions of Wildlife 18: 450-462.

Lemert, Edwin. 1951. Social Pathology: A Systematic Approach to the Theory of Sociopathic Behavior. New York, USA: McGraw Hill.

Lemert, Edwin. 1967. Human Deviance, Social Problems, and Social Control. Englewood Cliffs, NJ: Prentice Hall.

Lennon, John F. 2016. "Trains, Railroad Workers, and Illegal Riders: The Subcultural World of Hobo Graffiti." Pp. 27-35 In Routledge Handbook of Graffiti and Street Art, EDITED BY J. I. Ross. New York: Routledge.

Lewisohn, C. 2008. Street Art: The Graffiti Revolution. New York: Abrams.

Ley, David and Roman Cybriwsky 2010. "Urban Graffiti as Territorial Markers." Annals of the Association of American Geographers 64 (4):491-505.

Lombard, K.J. 2013. “Art Crimes: The Governance of Hip Hop Graffiti.” Journal for Cultural Research 17(3):255-278.

Lyng, Stephen. 1990. "Edgework: A Social Psychological Analysis of Voluntary Risk Taking.” American Journal of Sociology 93(4):851-886.

Lyng, Stephen. 1998. "Dangerous Methods: Risk-Taking and the Research Process." Pp. 221-251 in Ethnography at the Edge: Crime, Deviance, and Field Research, edited by J. Ferrell and M. Hamm. Boston, MA: Northeastern University Press.

Lyng, Stephen. 2005. "Edgework and the Risk-Taking Experience.” Pp. 3-14 in Edgework: The Sociology of Risk-taking, edited by S. L. Lyng. New York: Routledge. 
Lyng, Stephen and David A. Snow.1986. "Vocabularies of Motive and High Risk Behavior: The Case of Skydivers." Advances in Group Processes 3:157-179.

MacDiarmid, Laura and Steven Downing. 2012. "A Rough Aging Out: Graffiti Writers and Subcultural Drift.“ International Journal of Criminal Justice Sciences 7(2):605-617.

McNamara, Robert. 1994. The Times Square Hustler: Male Prostitution in New York City. Westport, CN: Praeger.

Mailer, Norman and Jon Naar. 1974. The Faith of Graffiti. New York: Harper Collins.

Martín, Favian. 2016. "American Indian Graffiti." Pp. 124-136 in Routledge Encyclopedia of Graffiti and Street Art, edited by J. I. Ross. New York: Routledge.

McAuliffe, Cameron. 2012. "Graffiti or Street Art? Negotiating the Moral Geographies of the Creative City." Journal of Urban Affairs (34) 2, pages 189-206.

McDonald, Fiona. 2013. The Popular History of Graffiti: From the Ancient World to the Present. New York: Skyhorse.

Mead, George Herbert. 2015. Mind, Self, and Society, The Definitive Edition, edited by C. W. Morris. Chicago: University of Chicago Press.

McCoy, Liza. 2005. "Keeping the Institution in View: Working with Interview Accounts of Everyday Experience." Pp. 109-125 in. Institutional Ethnography as Practice, edited by Dorothy L Smith. Lanham, MD: Lowman and Littlefield Publishing Group, Inc.

Messner, Steven F. and Richard Rosenfeld. 2001. Crime and the American Dream. Belmont, CA: Wadsworth.

Miller, Eleanor. 1989. "The Second Step in Double Jeopardy: Appropriating the Work of Female Street Hustlers." Crime and Delinquency 35(1):109-135.

Mitchell, Robert. 1983. Mountain Experience: The Psychology and Sociology of Adventure. Chicago: University of Chicago Press.

Morgan, David L. 1997. Focus Groups as Qualitative Research. 2nd ed. Thousand Oaks, CA: Sage.

Needham, Mark D., David Scott, and Jerry J. Vaske. 2013. "Recreation Specialization and Related Concepts in Leisure Research.” Leisure Science 35:199-202.

Newman, Oscar. 1972. Defensible Space: Crime Prevention Through Urban Design. New York: MacMillan.

Oh, Chi-Ok, Michael J. Sorice, and Robert B. Ditton. 2010. "Exploring Progression Along the Recreation Specialization Continuum Using a Latent Growth Approach." Leisure Sciences 33(10):15-31.

Orr, Noreen. 2006. "Museum Volunteering: Heritage as 'Serious Leisure."' International Journal of Heritage Studies 12:194-210.

Pabón, Jessica. 2016. "Ways of Being Seen: Gender and the Writing on the Wall." Pp. 78-91in Routledge Handbook of Graffiti and Street Art, edited by J. I. Ross. New York: Routledge.

Phillips, Susan A. 2016. "Deconstructing Gang Graffiti." Pp. 48-60 in Routledge Handbook of Graffiti and Street Art, edited by J. I. Ross. New York: Routledge..

Police Foundation United States of America. 1981. "The Newark Foot Patrol." National Criminal Justice Reference Service: 1-143. Retrieved April 18, 2018(https://www.policefoundation.org/ )

Pomfret, Gill and Bramwell. 2016. "The Characteristics and Motivational Decisions of Outdoor Adventure Tourists: A Review and Analysis." Current Issues in Tourism 19(14): 1447-1478.

Rodriquez, Amardo and Robin Patric Clair. 1999. "Graffiti as Communication: Exploring the Discursive Tensions of Anonymous Texts." Southern Journal of Communications 65(1):1-15.

Romotsky, Sally and Jerry Romotsky. 1975. "Plaqueaso on the Wall." Human Behavior 4:65-69.

Ross, Jeffrey Ian. 2016. "How Major Urban Centers in the United States Respond to Graffiti/Street Art." Pp. 393-403 in Routledge Handbook of Graffiti and Street Art, edited by J. I. Ross. New York: Routledge.

Ross, Jeffrey Ian and Benjamin S. Wright. 2014. "I've Got Better Things to Worry About: Police Perceptions of Graffiti and Street Art in a Large Mid-Atlantic City." Police Quarterly 17(2):176-200.

Sales, Stephen M. 1971. "The Need for Stimulation as a Factor in Social Behavior. Journal of Personality and Social Psychology 19:124-134.

Sampson, Robert and John Laub. 1993. "Turning Points in the Lifecourse: Why Change Matters to the Study of Crime." Criminology 31(3):301-325.

Scott, James C. 1984. Everyday Forms of Peasant Resistance. New Haven, CT: Yale University Press. 
Scott, David and C. Scott Schafer. 2001a. "Recreation Specialization: A Critical Look at the Construct. Journal of Leisure Research 33 (3): 319-343.

Scott, David and C. Scott Shafer. 2001b. "A Rejoinder to Reviewers' Comments." Journal of Leisure Research 33:357-61.

Scott, David and Geoffrey Godby. 1994. "Recreation Specialization in the Social World of Contract Bridge." Journal of Leisure Research 26 (3):275-295.

Sheng-Hshiung Tsaur and Ying-Wen Liang. 2008. "Recreation Specialization and Serious Leisure." Leisure Sciences 30 (4):325-341.

Shillington, Kevin. 1989. History of Africa. New York, NY: St. Martin's Press.

Silver, Tony and Henry Chalfant (Producers). 1984. Style Wars. New Day Films.

Sinnreich, Helene. 2004. "Reading the Writing on the Wall: A Textual Analysis of Łódz Graffiti." Religion 32(1):53-58.

Smith, David M. 1997. “Geography and Ethics: A Moral Turn?” Progress in Human Geography 21:583-590.

Smith, Dorothy E. 1987. The Everyday World as Problematic: A Feminist Sociology. Boston: Northeastern University Press.

Smith, Dorothy E. 2005. Institutional ethnography: A Sociology for People. Walnut Creek, CA: AltaMira Press.

Smith, Dorothy E. 2006. Institutional Ethnography as Practice. Lanham, MD: Rowman \& Littlefield.

Smith, Oliver and Thomas Raymen. 2016. "Deviant Leisure: A Criminological Perspective. Theoretical Criminology 22(1):63-82.

Snyder, Gregory J. 2006. "Graffiti Media and Perpetuation of an Illegal Subculture." Crime, Media, and Culture 2(1):93-101.

Snyder, Gregory J. 2009. Graffiti Lives: Beyond the Tag in New York's Urban Underground. New York: New York University Press.

Snyder, Gregory J. 2016. "Graffiti and the Subcultural Career." Pp. 204-214 in International Handbook of Graffiti and Street Art, edited by J. I. Ross. New York: Routledge.

Stebbins, Robert A. 1982. "Serious Leisure: A Conceptual Statement." Pacific Sociological Review 25(2):251-272.

Stebbins, Robert A. 1992. Amateurs, Professionals, and Serious Leisure. Montreal: McGill-Queen's University Press.

Stebbins, Robert A. 1996. Tolerable Differences: Living with Deviance. Toronto: McGraw Hill Ryerson.

Stebbins, Robert A. 1997. "Casual Leisure: A Conceptual Statement.” Leisure Studies 16:17-25.

Stebbins, Robert A. 2007. Serious Leisure: A Perspective for Our Times. New Brunswick, NJ: Transaction Publishers.

Stone, Phillip R. and Richard Sharpley. 2013. "Deviance, Dark Tourism and 'Dark Leisure': Towards a (Re) Configuration of Morality and the Taboo in Secular Society" in Contemporary

Perspectives in Leisure: Meanings, Motives and Lifelong Learning, edited by S. Elkington and S. Gammon. Abington, Oxon, UK: Routledge.

Stone, Deborah. 2012. Policy Paradox: The Art of Political Decision Making. 3rd Ed. New York: Norton \& Company.

Stout, Brian, Dadich, Ann, Hosseinzadeh, Hassan and James Herbert. 2018. "Living on the Edge: Juvenile Justice Work as a Form of Edgework." Crime, Law, and Social Change (69) 3:71-384

Taber, Nancy. 2010. "Institutional Ethnography, Autoethnography, and Narrative: An Argument for Incorporating Multiple Methodologies." Qualitative Research 10 (1):5-25.

Thompson, Hunter S. 1966. Hells Angels: The Strange and Terrible Saga of Outlaw Motorcycle Gangs. New York: Penguin Books.

Thompson, Hunter S. 2003. The Great Shark Hunt: Strange Tales from a Strange Time. New York, NY: Simon and Schuster

Trahan, Adam. 2016. "Research and Theory on Latrinalia." Pp. 92-102 in Routledge Handbook of Graffiti and Street Art, edited by J. I. Ross. New York: Routledge.

Vanderveen, Gabry and Gwen van Ejik. 2015. "Criminal but Beautiful: A Study on Graffiti and the Role of Value Judgments and Context in Perceiving Disorder." European Journal on Criminal Policy and Research 22 (1):107-125.

Virden, Randy J. and Richard Schreyer.1988. "Recreation Specialization as an Indicator of Environmental Preference." Environment and Behavior 20(6):721-739. 
Vogt, W. Paul. 1999. Dictionary of Statistics and Methodology: A Nontechnical Guide for the Social Sciences. London: Sage.

Waclawek, Anna. 2016. "Pop Culture and Politics: Graffiti and Street Art in Montreal." Pp 247-257 in Routledge Handbook of Graffiti and Street Art, edited by J. I. Ross. New York: Routledge.

Weide, Robert Donald. 2016. "The History of Freight Train Graffiti in North America." Pp. 36-47 in Routledge Handbook of Graffiti and Street Art, edited by J. I. Ross. New York: Routledge.

Wellman, Rogenbuck, and Smith. 1982. "Recreation Specialization and Norms of Depreciative Behavior Among Canoeists." Journal of Leisure Research 14 (4): 323-340.

Wexler, Mark N. 2010. "Financial Edgework and the Persistence of Rogue Traders." Business and Society Review 115 (1):1-25.

Wharton, Jane. 2018. "Banksy Picture Self-Destructs in Shredder Moments After It Is Sold for $£ 1,000,000$ at Auction." Retrieved April 2, 2019 (https://metro.co.uk/2018/10/06/banksy-picture-self-destructs-in-shredder- momentsafter-it-is-sold-for-1000000-at-auction-8011424/).

Williams, D.J. and Gordon J. Walker. 2010. "Leisure, Deviant Leisure, and Crime: Caution: Objects May Be Closer than They Appear." Leisure 30(1):193-218.

Wilson, James and George Q. Kelling. 1982. "Broken Windows.” The Atlantic Online. Retrieved May 3, 2019 (http://www.theatlantic.com/doc/print/198203/broken-windows ).

Wozniak, Jesse. 2014. "When the Going Gets Weird: An Invitation to Gonzo Sociology." American Sociology 45:453-473.

Wu, Tsung-Chiung (Emily), David Scott, and Chun-Chieh Yang. 2013. "Advanced Online Game Addiction." Leisure Sciences 35(3):203-217.

Xu, Yii, Mora L. Fiedler, and Karl H. Flaming. 2005. "Discovering the Impact of Community Policing: The Broken Windows Thesis, Collective Efficacy, and Citizens' Judgment.” Journal of Research in Crime and Delinquency 42:147-186.

Young, Alison. 2010. "Negotiated Consent or Zero Tolerance? Responding to Graffiti and Street Art in Melbourne." City 14(1-2):99-114.

Young, Alison. 2014. Cities in the City: Street Art, Enchantment, and the Urban Commons." Law and Literature 26(2):145-161.

Young, Jock. 2003."Merton with Energy, Katz with Structure: The Sociology of Vindictiveness and the Criminology of Transgression." Theoretical Criminology 7 (3):389-414.

Yenchken, David. 2013. "Creative Cities." Space, Place, and Culture 2013:1-21. Retrieved April 5, 2018 (http://www.futureleaders.com.au/book_chapters/pdf/Space-PlaceCulture/DavidYencken.pdf).

Zieleniec, Andrzej. 2016. "The Right to Write the City: Lefebvre and Graffiti." Urban Environment $10: 1-21$

Zuckerman, Michael. 2007. Sensation-Seeking and Risky Behavior. Washington, DC: American Psychological Association. 


\section{APPENDIX A - INTERVIEW GUIDE - GRAFFITI WRITERS}

(1) Do you consider yourself a graffiti writer? How long have you been doing graffiti? How old are you, and what race do you identify with most?

(2) Are you part of a crew? If so, can you tell me about your crew and what they are about and what makes them different and why you choose to represent them?

(3) Tell me about the first time you realized that you are or could be described as a graffiti writer.

(4) What are things people specifically do that in your view define them as being graffiti writers? In other words: What would someone have to do before you would consider them to have acquired the status of writer?

(5) What are your top reasons for writing graffiti? Is there a number one reason?

(6) Would you say that most of your friends are also graffiti writers? How many or what percentage of your friends also write graffiti? Has that change $d$ over time at all?

(7) How do you define style?

(8) What is the difference between a respected writer and one who is not?

(9) What is outside (wider) society's viewpoint on graffiti writing? What do you think makes outsiders think or feel this way?

(10) How does your family feel about you writing graffiti? What about your friends who do not write graffiti?

(11) Why do you think what you do is illegal? Do you agree or disagree with illegality and why?

(12) If graffiti were legal would you still do it? Please elaborate. (Probe: This could mean 'what if' graffiti became legal or if it were legal all along)

(13) How do you feel about buffing by municipal workers? Do you think they could do their work in an alternative way? If so, how? 
(14) Please tell me more about what you think of larger society objecting to graffiti and how your views of society influence your writing. (Probe: How, if at all does the fact that society objects and your perception of this influence your writing?)

(15) Have you ever been in trouble with the law over writing graffiti, and if so, can you talk about what happened?

(16) What would stop you from painting?

(17) Do you ever or have you ever racked paint?

(18) Would you say that you practice graffiti or related activities as much as, more than, or less than your other hobbies or pursuits? (Probe: If you could give it a percentage of how much you do graffiti or related activities out of the total free time you spend on other personal interests/recreation, etc. i.e. 20 percent out of my total free time)

(19) Do you work professionally with any of the skills you have obtained by doing graffiti? How?

(20) Have you ever had (or do you anticipate) gaining other income or benefits from utilizing your skills related to graffiti? If so, please tell me more.

(21) Do you think people who are not graffiti writers approve of your graffiti? Why?

(22) Do you believe graffiti has damaging effects to society? Please tell me more about this.

(23) Does graffiti have any beneficial aspects for society? Pleas elaborate.

(24) Do you ever obtain a thrill from doing graffiti or graffiti-related activities? If so, please tell me about this in detail.

(25) Does graffiti give you any benefits that you know of from doing it? Please explain. Have these benefits always been the same?

(26) Are there personal dangers in doing graffiti? If so, please explain as much as possible, if so.

(27) Are there risks in doing graffiti? If so, could you tell me more about these? Were your perceptions of risk involved in doing graffiti ever different than they are now?

(28) What motivates you to continue to do graffiti (despite any risks or dangers, if applicable)? How have these motives changed for you over time, if at all?

(29) Do you have much invested in time, money, and/or other efforts in your experience of doing graffiti? How much would you say you have invested compared to other hobbies or recreation (as much, more, much more)? Has this amount ever differed? How?

(30) Do you ever take vacations to do graffiti or for art/graffiti purposes? If so, how often? Has this changed at all over time, since you started painting? 
(31) Have you or would you change residences to somewhere having better conditions for doing graffiti or greater access to quality graffiti spots?

(32) Do you ever do graffiti-related or other activities instead of painting a spot (for instance if you are too tired or unable to paint a preferred spot)? Please explain.

(33) If you ever do more than one type of alternative to painting, can you talk about the different reasons that you might do one graffiti-related activity instead of another?

(34) Have ever felted compelled to improve your skills and/or experiences as a graffiti writer? Has this ever been different for you?

(35) Would you say that doing graffiti has anything to do with one's identity? Explain.

(36) Are you motivated to do graffiti for being part of a group? Making friends? Making personal connections? Has this changed over time?

(37) Would you describe graffiti as a form of recreation? How so? Has it always been this way?

(38) Is graffiti at all a release for stress? A way of feeling restored? If so, explain.

(39) How much would you say you have persevered at doing graffiti over time? Have you always put in the same level of perseverance? How?

(40) Would you say graffiti is personally enriching? Self-actualization? Self-expression?

(41) Is there anything else we haven't discussed previously that you think is important to my research regarding graffiti writing that I need to consider in my analysis? (Probe: Or is there anything else you wish to discuss?)

Thank you very much for your time and valuable insights. Do you have any questions for me? 


\section{(FOCUS GROUP) - GRAFFITI WRITERS -}

1- Initial question (10-20 minutes):

"Tell me about the time when you realized you wanted to be a graffiti writer."

2- Allure to writing graffiti (10-20 minutes):

"I am interested in hearing you talk about what it is about graffiti writing that draws you to it.

What can you tell me about that?"

3- Personal values about graffiti writing (10-20 minutes):

"Tell me about the reasons you continue to write graffiti and how it may benefit society and yourself (if at all)."

4- Views about illegality of hip hop graffiti writing (10-20 minutes):

"What are your thoughts about the fact that graffiti writing is illegal in most places?"

5- Views of society's objection (10-20 minutes):

"Tell me about why (most of) society objects to graffiti writing; in other words, laws against it, attitudes that it is destructive, etc.?"

6- Efficacy of anti-graffiti social policies and attitudes (10-20 minutes):

"Is society going about it the right way with laws, attitudes, objections to graffiti: In other words, what are your thoughts on police and social discouragement of graffiti?"

7- Final question - open ended discussion (10-20 minutes):

“We've discussed a lot of interesting things today that I think will be invaluable to my research.

This all makes me want to learn more about how to write graffiti myself. Let's talk briefly about some things you consider important that we have not talked about today. 


\section{APPENDIX B 19 ** METRO AREA GRAFFITI ORDINANCE}

\section{GRAFFITI}

**1.10 DEFINITIONS ... the following definitions shall apply unless the context clearly indicates or requires a different meaning.

BROAD-TIPPED INDELIBLE MARKER. Any felt-tip marker or similar implement containing a fluid that is not water-soluble and which has a flat or angled writing surface one-fourth inch or greater.

ETCHING ACID. Any liquid, cream, paste, or similar chemical substance that can be used to etch, draw, carve, sketch, engrave, or otherwise alter, change, or impair the physical integrity of glass or metal.

GRAFFITI. Drawings, inscriptions, or markings, of whatever kind, character, or description, made using aerosol spray paint, etching acid or other etching materials, or broad-tipped indelible markers on a wall or other surface, so as to be seen by the public, placed there by a person other than the lawful owner or occupant of the property, without consent or acceptance of said owner or occupant.

\section{**1.11 SALE OF ITEMS COMMONLY USED FOR GRAFFITI.}

Any person selling, or offering to sell aerosol spray paint, broad-tipped indelible markers, or etching acid or other etching materials must keep such items in a place that restricts public access within the retail establishment.

\section{**1.12 ILLEGAL ACTIVITIES.}

(A) (1) Unlawful conduct or activities by individuals shall encompass the following: No person may possess an aerosol spray paint container, broad-tipped indelible markers, or etching acid or etching materials with the intent to deface, destroy, or damage any property.

(2) For purposes of this section, any possession of such items on either public property, or private property without the express consent of the legal owner, shall be prima facie evidence of intent. (B) Unlawful activity with regard to property shall encompass the following: (1) All sidewalks, walls, buildings, fences, signs and other structures or surfaces shall be kept free from graffiti when the graffiti is visible from the street, or from other public or private property. (2) Abatement or removal of graffiti by the property owner, or responsible party (or signature on waiver form as set forth herein) must occur within seven calendar days of issuance of any notice of violation, citation, or order. (C) A person who creates graffiti and commits an act of criminal mischief as set forth in ... *** Penal Code...***, may be arrested and/or cited for such unlawful activities in addition to the violations set forth herein

$19 * * *$ denote where city or county names were omitted out to maintain the confidentiality

** denote truncated ordinance numbers

... indicates omitted text to maximize confidentiality 


\section{**1.13 ENFORCEMENT.}

(A) (1) The provisions of $\S \S * 1.11$ and $* * 1.12(\mathrm{~A})$ shall be enforced by any law enforcement officer.

(2) The provisions of $\S * * 1.12$ (B) shall be enforced by the *** Metro Code Enforcement Division, in accordance with all laws, regulations and ordinances pertaining to public nuisance and/or property maintenance, and shall be considered a civil offense, punishable as set forth in $\S * * 1.14$.

(B) A notice of violation, citation, or order shall be issued to the owner of private property and shall include the following: (1) Identification/location of the property. (2) Location of the graffiti. (3) A general description of the graffiti.

**1.14 ABATEMENT.

(A) (1) Within seven calendar days of issuance of any notice of violation, citation, or order, the property owner or responsible party must:

(a) Abate the graffiti according to Metro Government's policies and procedures using materials furnished by Metro Government; or

(b) Sign a waiver form that will allow Metro Government to proceed to abate the graffiti with the cost of abatement done on the part of Metro Government being borne by the owner/responsible party.

(2) If a waiver form is not signed within the seven-day period, Metro Government may proceed with the abatement according to its policies and procedures for such abatement, and bill the owner or responsible party for the costs thereof. In any event, Metro Government shall bill the owner or responsible party for the costs of any work done on the part of Metro Government on such owner or responsible party's property to abate graffiti. In the event the bill is not paid for work done by the Metro Government to abate graffiti within 90 days of its issuance, a statement of the account shall be certified, and Metro Government may proceed with judicial action to collect the fine, along with interest at the rate established by law.

(3) By appropriate order of the *** Metro Code Enforcement Board, Metro Government, or its authorized contractor, is expressly authorized to enter private property and abate graffiti thereon, in accordance with this section. *** Metro Police Department may assist in the enforcement of this subchapter.

(4) If Metro Government performs the abatement, either upon receipt of waiver form, or by means of seven-day elapse of time without other abatement, the property owner or responsible party is put on notice that abatement shall occur by standard means, which may or may not meet with the subjective standards of said property owner or responsible party. Metro Government shall not be liable for any damage to the property, or decline in its value by reason of the abatement performed.

**1.15 PENALTIES. (A) Any person violating $\S * * 1.12$ (A) shall be deemed to have committed a misdemeanor, and shall be subject to a fine not to exceed $\$ 500$ for each offense.

(B) A violation of $\S * * 1.11$ shall be classified as a civil offense and shall be enforced through the Code Enforcement Board ("Board") as provided in ***.275 et seq., or as it may be amended.

(C) Any person violating $\S * * 1.11$ shall be fined a minimum civil penalty of $\$ 250$ or a maximum civil penalty of $\$ 500$. Each day that a violation continues after a citation has been issued or notice has been served shall be deemed a separate offense.

(D) Any person cited in accordance with subsection (C), directly above, may pay the minimum civil penalty within seven days from the date of issuance or request a hearing regarding such penalty to the Board in accordance with **.275 et seq. If the person fails to respond to the citation within seven days as referenced above, the person shall be deemed to have waived the right to a hearing. In this event, the Board 
shall enter a final order determining that the violation was committed and impose the maximum civil penalty set forth in the citation.

**1.16 APPEALS. (A) Appeals of civil penalties may be made by filing a written notice of appeal with the Board, as provided *** as such sections may be amended. (B) Appeals of criminal citations may be made to a court of competent jurisdiction. 


\section{APPENDIX C \\ TYPES OF HIP HOP GRAFFITI}

\section{"Tagging" (or "handstyles")}

Tagging was among the first forms of graffiti, especially in Philadelphia and New York (Mailer and Naar 1974; Halsey and Young 2002). Tagging is a key part of "bombing" and consists of quickly executed and often stylized versions of one's graffiti name. Bombing (and tagging) is geared toward getting one's name "up" as much as possible (Brewer and Miller 1990) and also consists of sticker bombing and throwups.

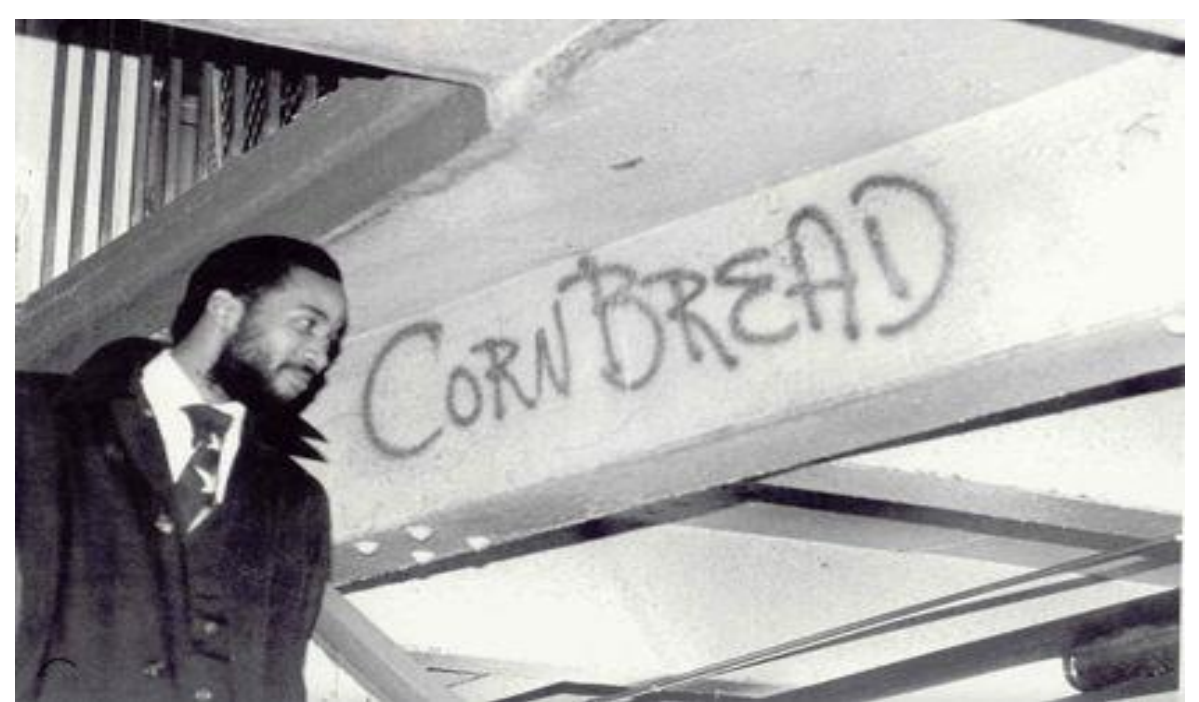

Writer legend, Daryl "Cornbread" McCray, often credited the founder of graffiti, next to an original tag

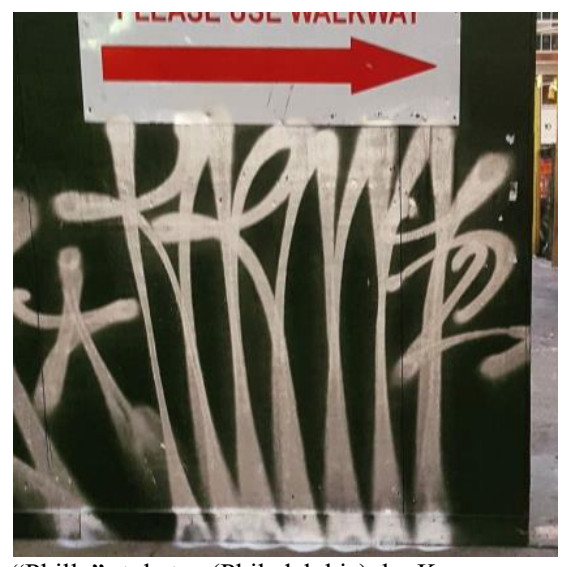

"Philly" style tag (Philadelphia), by Karma

\section{Stickers, or "Slaps"}

These "sticky" alternatives to tags are usually created at home or in privacy, and are carried in quantity, along with markers or spray cans, to "slap" onto public surfaces. Graffiti writers' stickers are sometimes used by street artists, and it is unknown whether or not the two related art forms overlap with stickers. 
Many graffiti writers create stickers for bombing or to trade with other writers, often coming in multiple shapes or sizes, and traditionally exchanged in person, at gatherings, or via snail mail as "sticker packs."

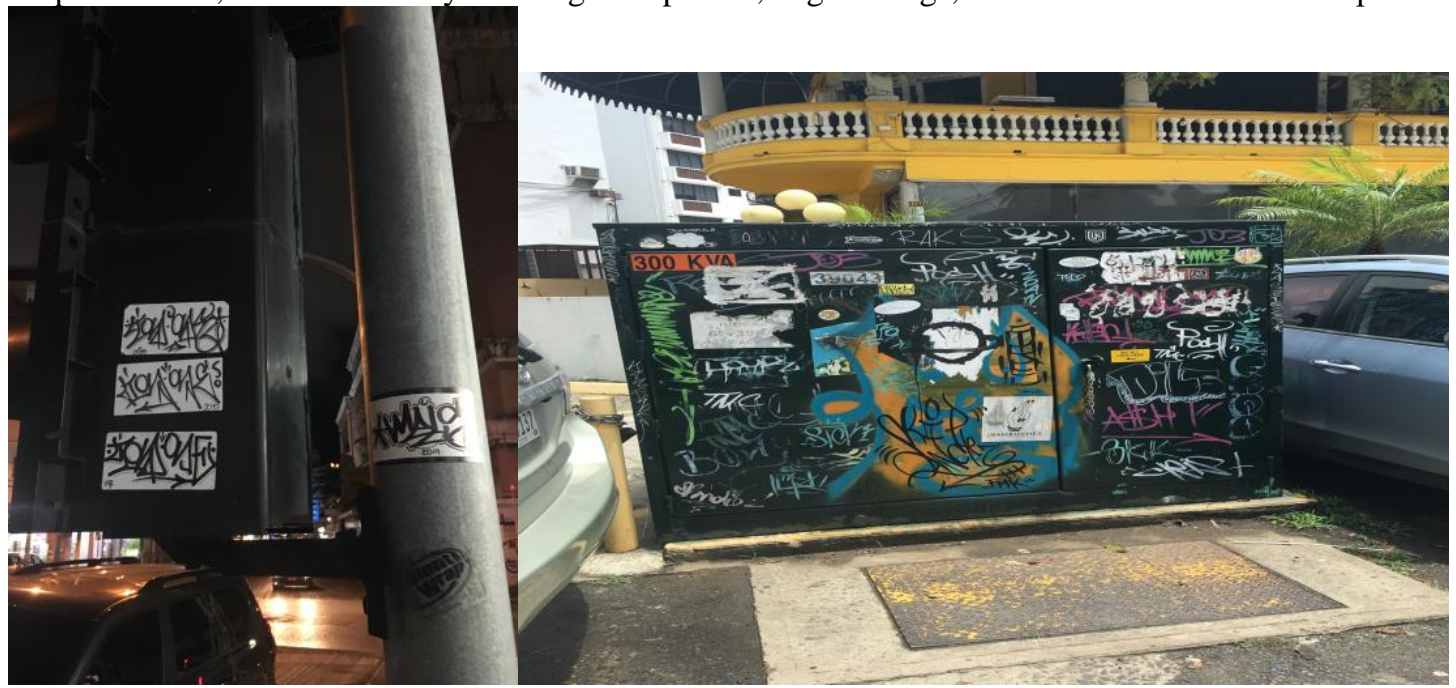

Professionally made and handmade stickers and a variety of handstyles decorate utility boxes, Panama, June 2019

\section{Throw-ups, also called "throws," "throwies" and "bubble-letters"}

Throw-ups, also called "throws," "throwies," or "bubble letters," are more complex renditions of one's graffiti name than tags or "hand-styles" and are often quickly executed in high quantities, as an important aspect of "bombing" to gain fame or notoriety. Throwups are larger and more visible than tags and may be described as hollow or filled-in, or called "fills," or "fill-ins," (colored-in) or "hollows" (simple outlines of a larger connected-letter fill or throw-up).

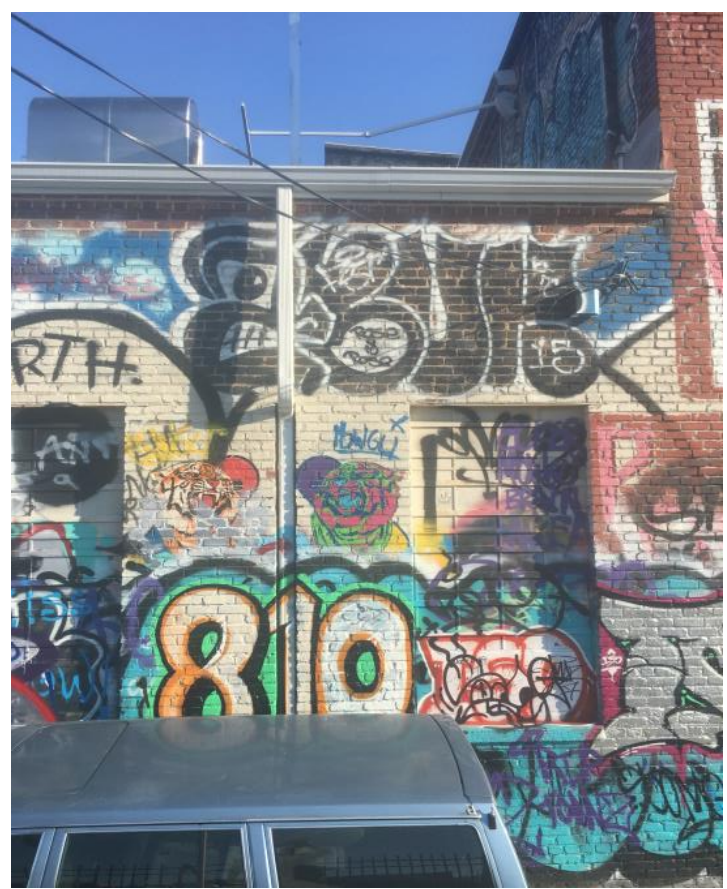

A throwup (top) by 2Buk-NK-FST, Baltimore, Maryland, May 2020. 


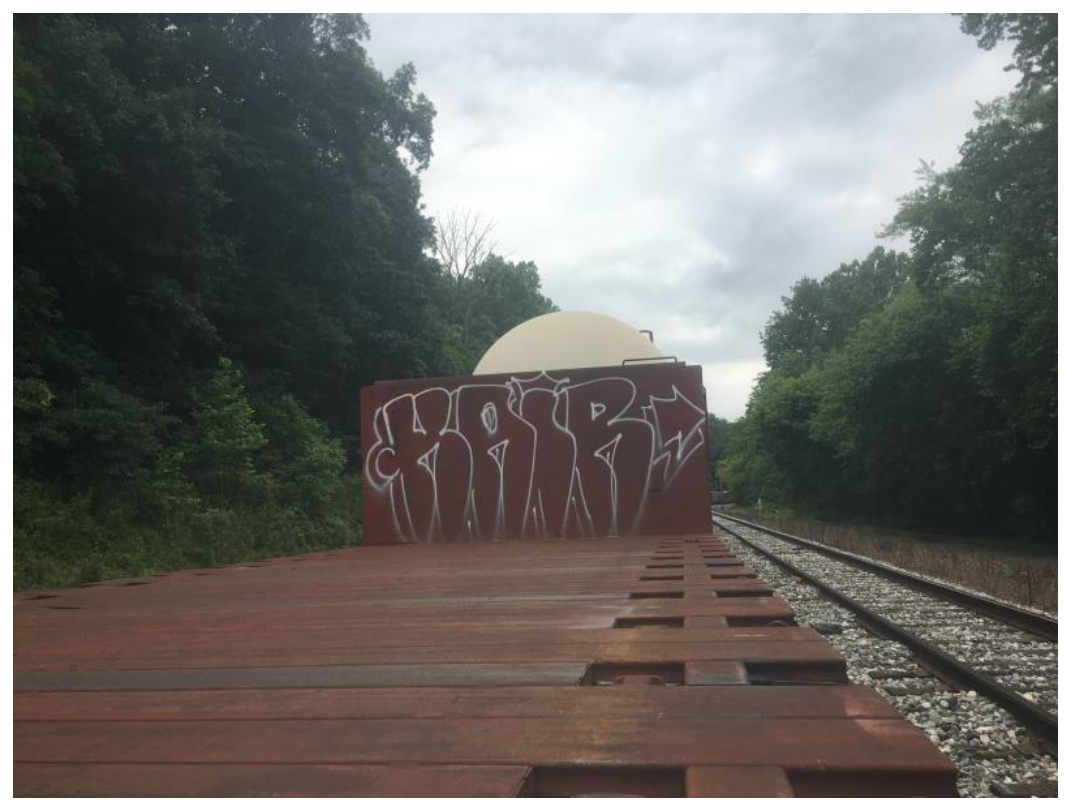

A stylized hollow by Kair-IYA, Maryland, July 2020.

\section{Straightletters (or "blockbusters")}

Straightletters are large pieces using simple letter style but can vary in skill, complexity, and size.

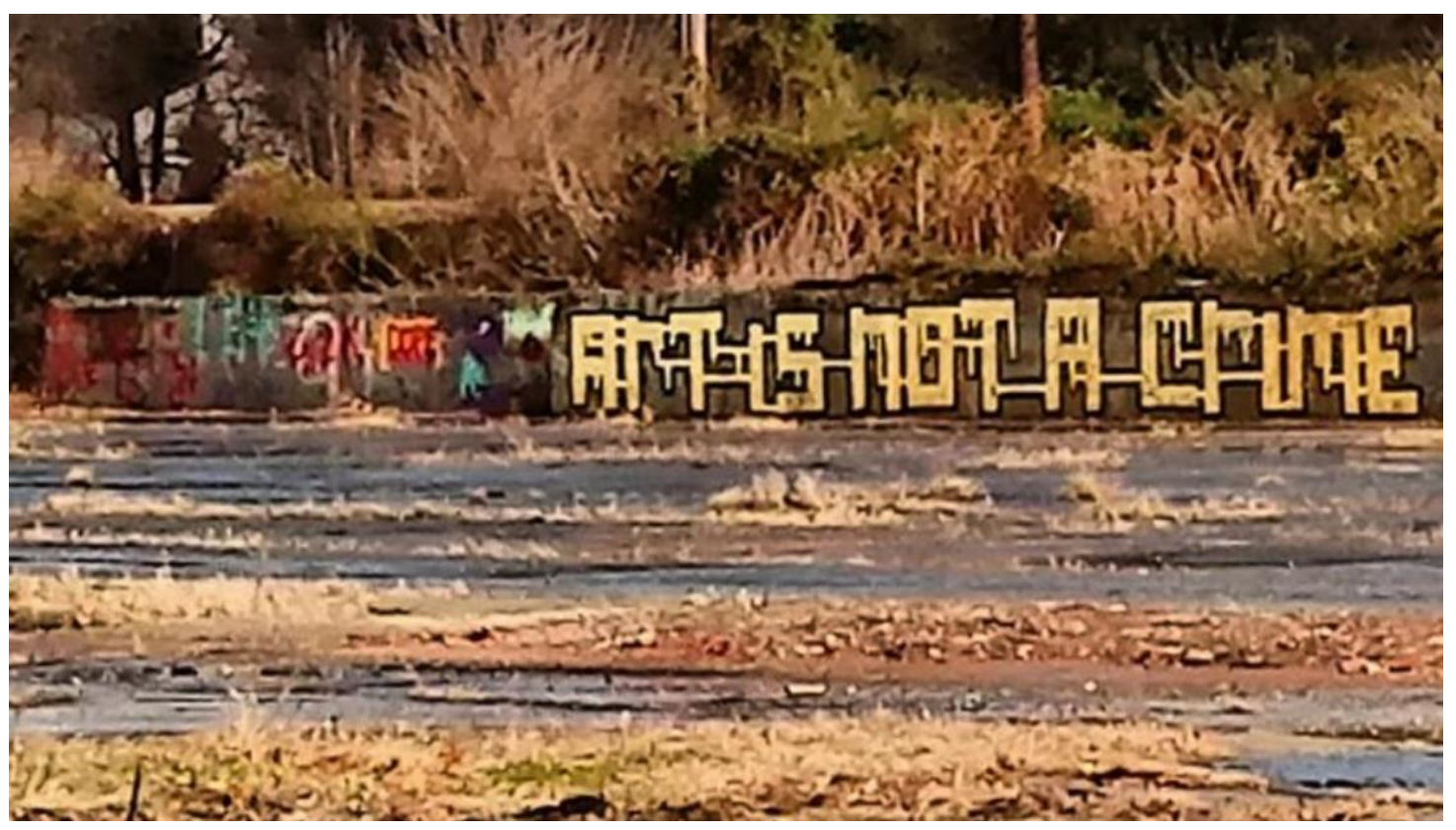

(Top) Art is not a crime", a stylized "straight-letter" piece on a trackside wall near Hagerstown, Maryland. 


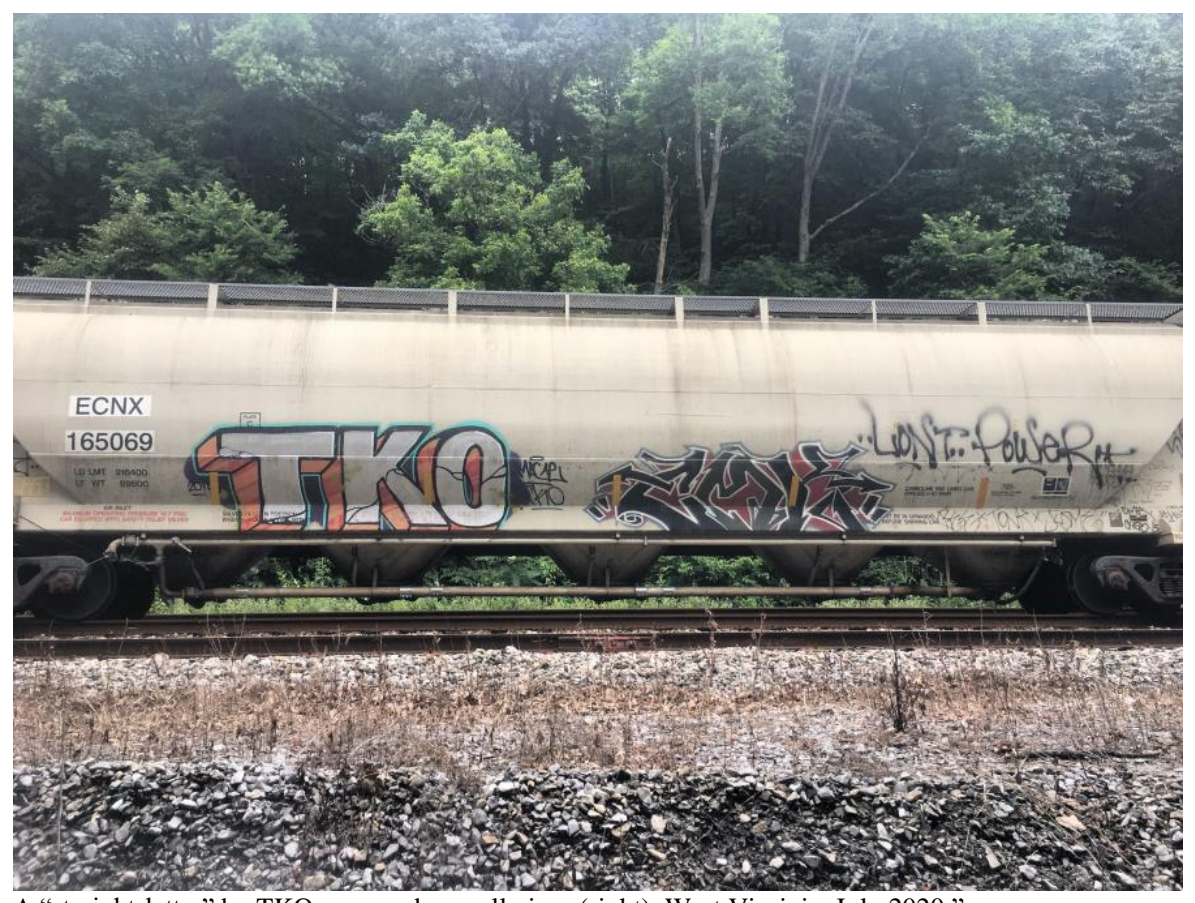

A "straight-letter" by TKO crew and a small piece (right), West Virginia, July 2020."

\section{Roller Piecing and Heaven Spots}

Rollers are performed with bucket paint and rollers, often in straight letter style, but also frequently incorporate various lettering and piecing styles. Doing rollers in highly visible places is "the name of the game. "Rollers often gain writers fame or notoriety by their sheer size and locations in which they are placed. Often rollers are the chosen medium in what "heavens" or "heaven spots"- these are locations where one's gaze naturally falls as they pass by highway signs, tops of buildings, or on walls and other structures directly in sight of roads or thoroughfares.

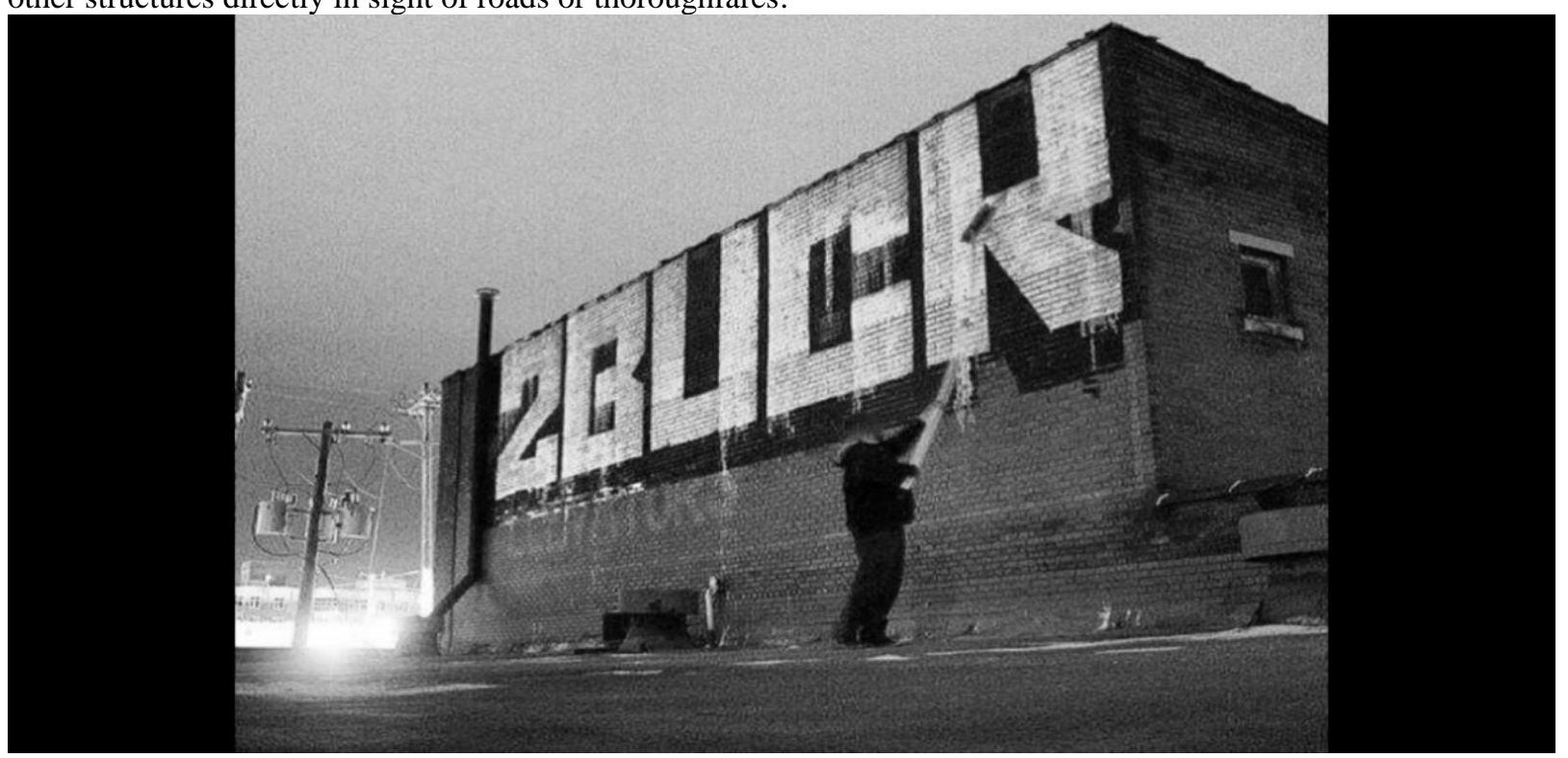

Internationally known and deceased writer Jon Brown, aka "2Buck," (above) painting a famous roller at a "heaven spot." 


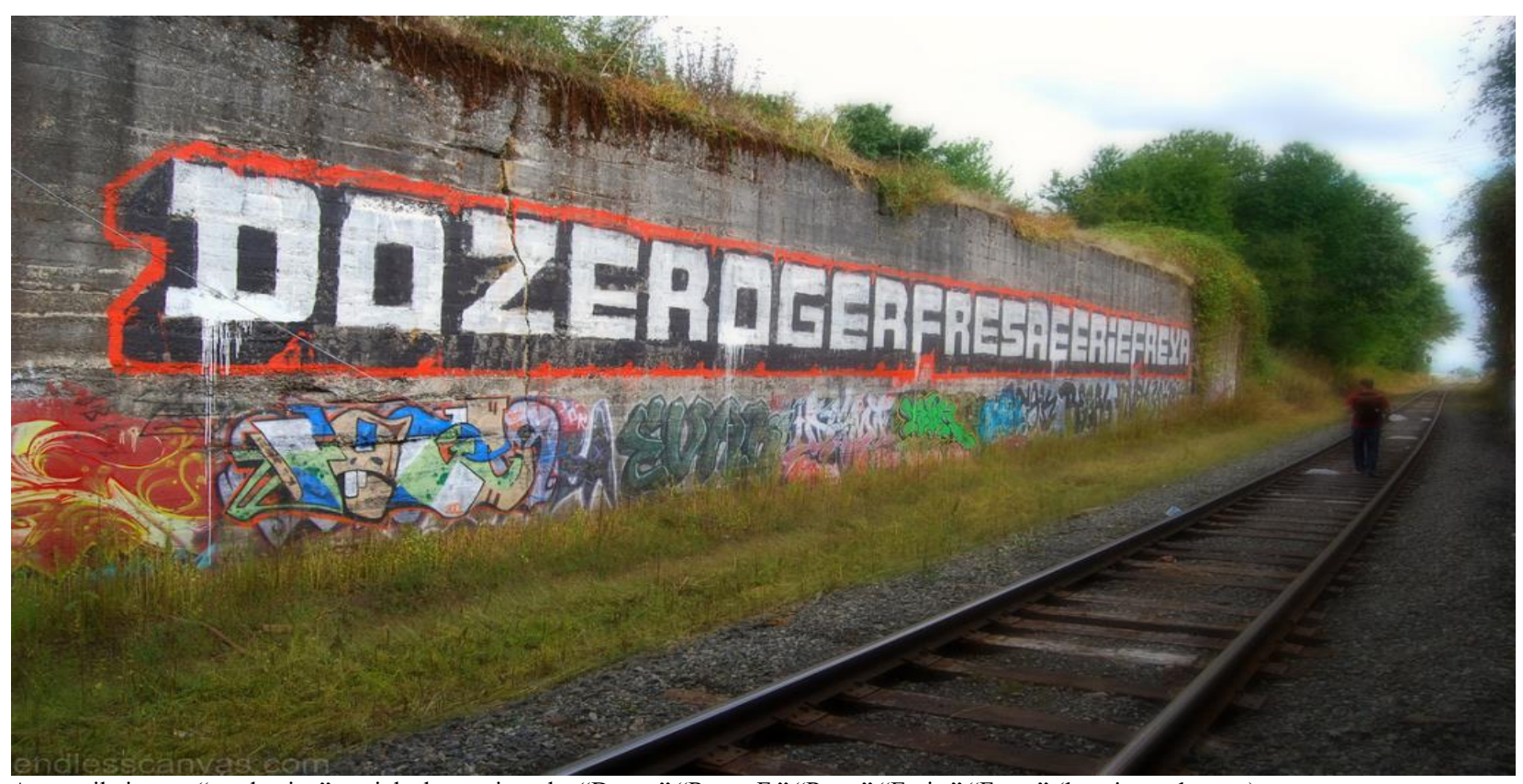

A compilation, or "production" straight-letter piece, by "Dozer," "Roger F," "Resa," "Eerie," "Freya" (location unknown)

\section{Aerosol piecing and Wildstyle}

Pieces are often the choice of elite writers and those who value artistic expression. pieces are arguably the most skilled and labor intensive forms of hip hop graffiti, and include productions composed in "wildstyle" (refers to a highly artistic form of piecing, usually unappreciated by outsiders and difficult for them to "read" or understand). These pieces usually consist of exceptional coloring schemes, and often writers use deluxe paints in their execution.

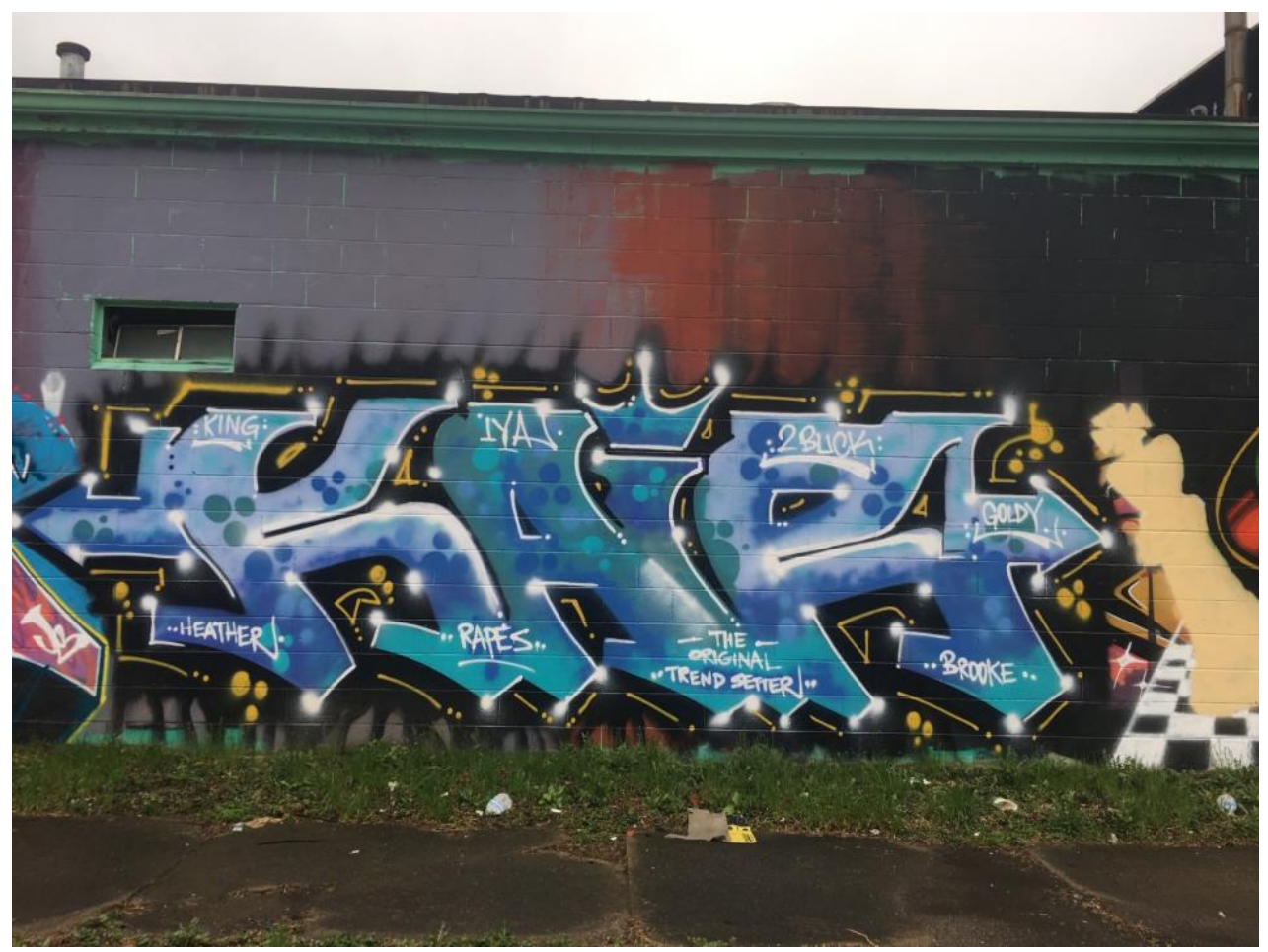

Top: "The Original Trend Setter"; a highly stylistic piece by King Kair-IYA. 


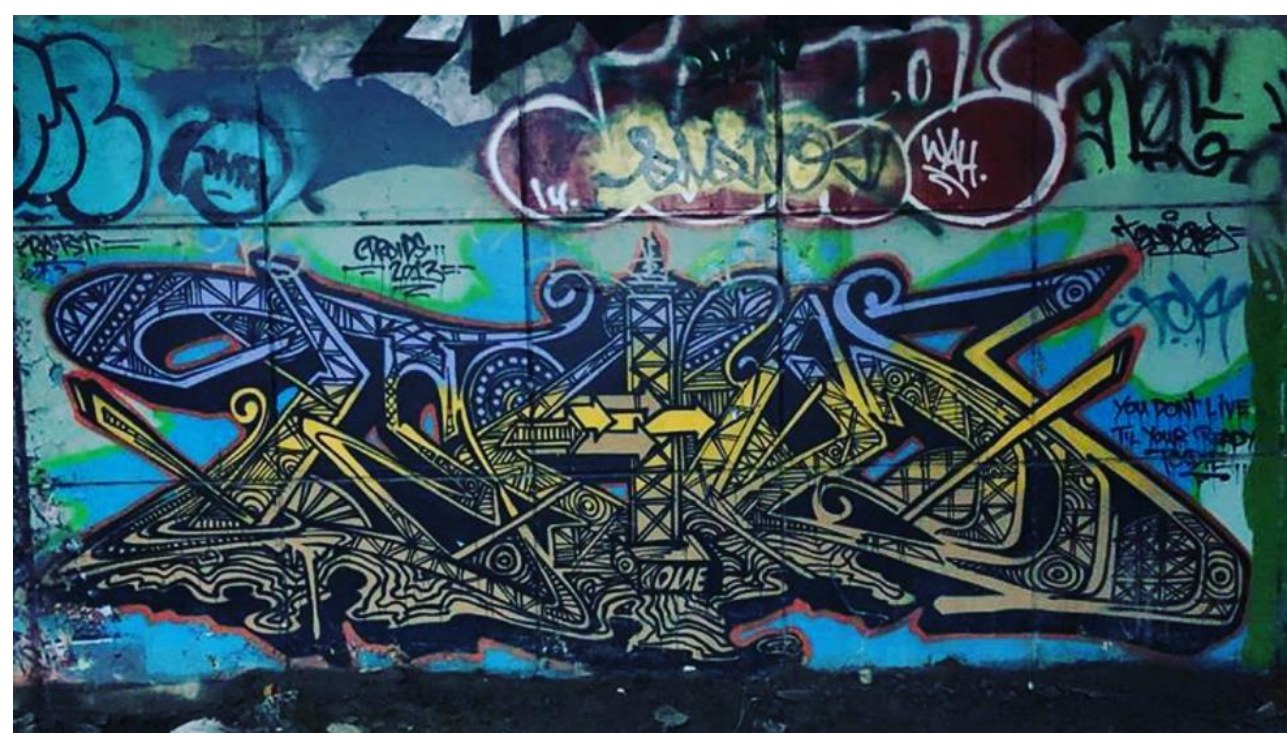

A wildstyle piece by Tead, location unknown

\section{Train writing and Monikers}

Often elite writers are known to prefer painting freight trains, either in railyards or at some unknown "stop line" locations (where trains temporarily park). Many writers use between 2 and 8 spray cans to paint small to large sections of sides of train cars or panels. Some writers will use 15 or more cans of spray paint, or several gallons of "bucket paint" to paint a train car with their name, a crew name, characters, or some combination of these. Train writing may be simple or intricately designed monikers or tags, throwups, or pieces, which may cover the entire train car (or in some cases several cars).Train piecing may span from one end of a car to the other (referred to as an "end to tend"), or from end to end and top to bottom (a "whole car"- -see below).

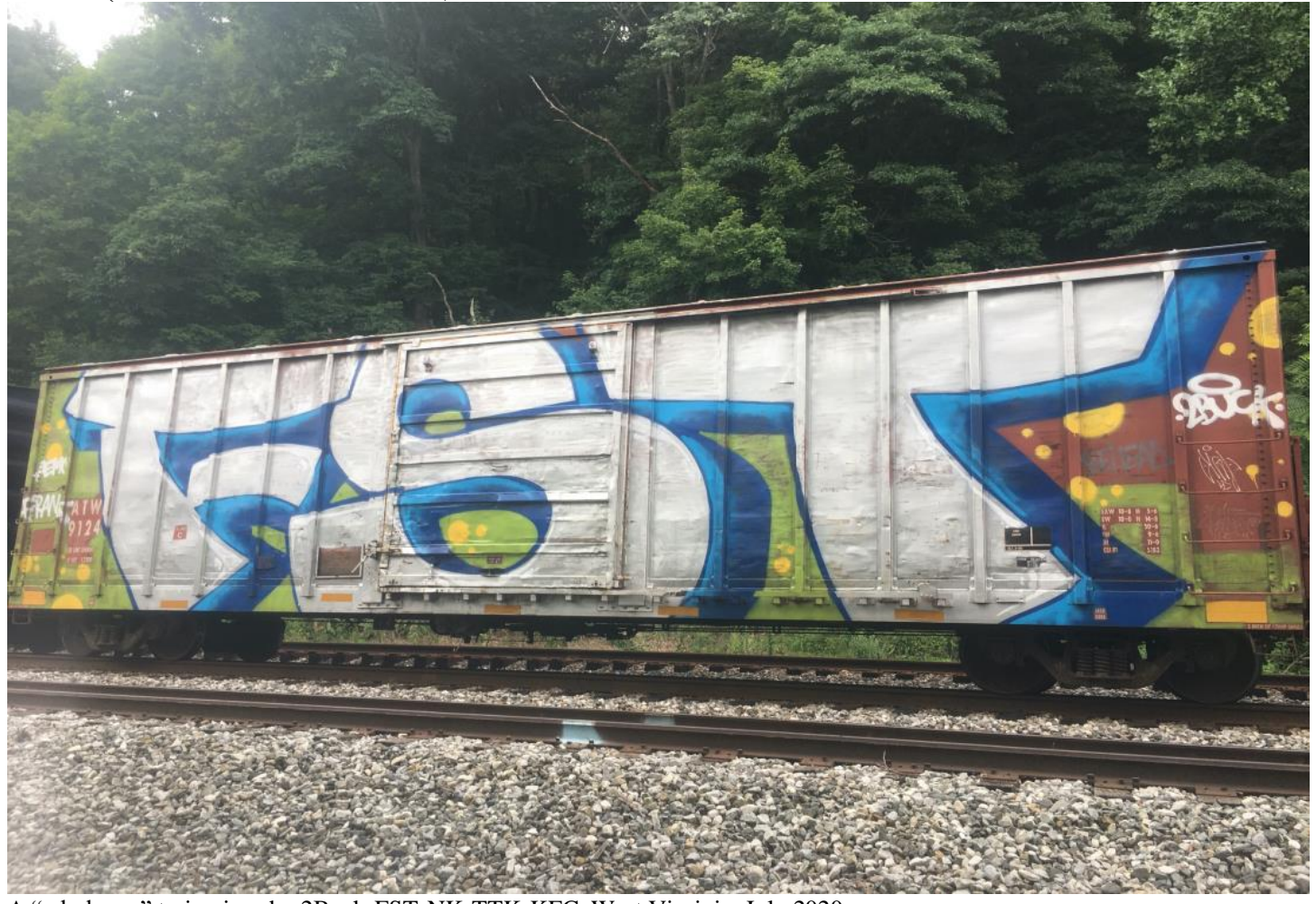

A "whole car" train piece by 2Buck-FST-NK-TTK-KFC, West Virginia, July 2020. 


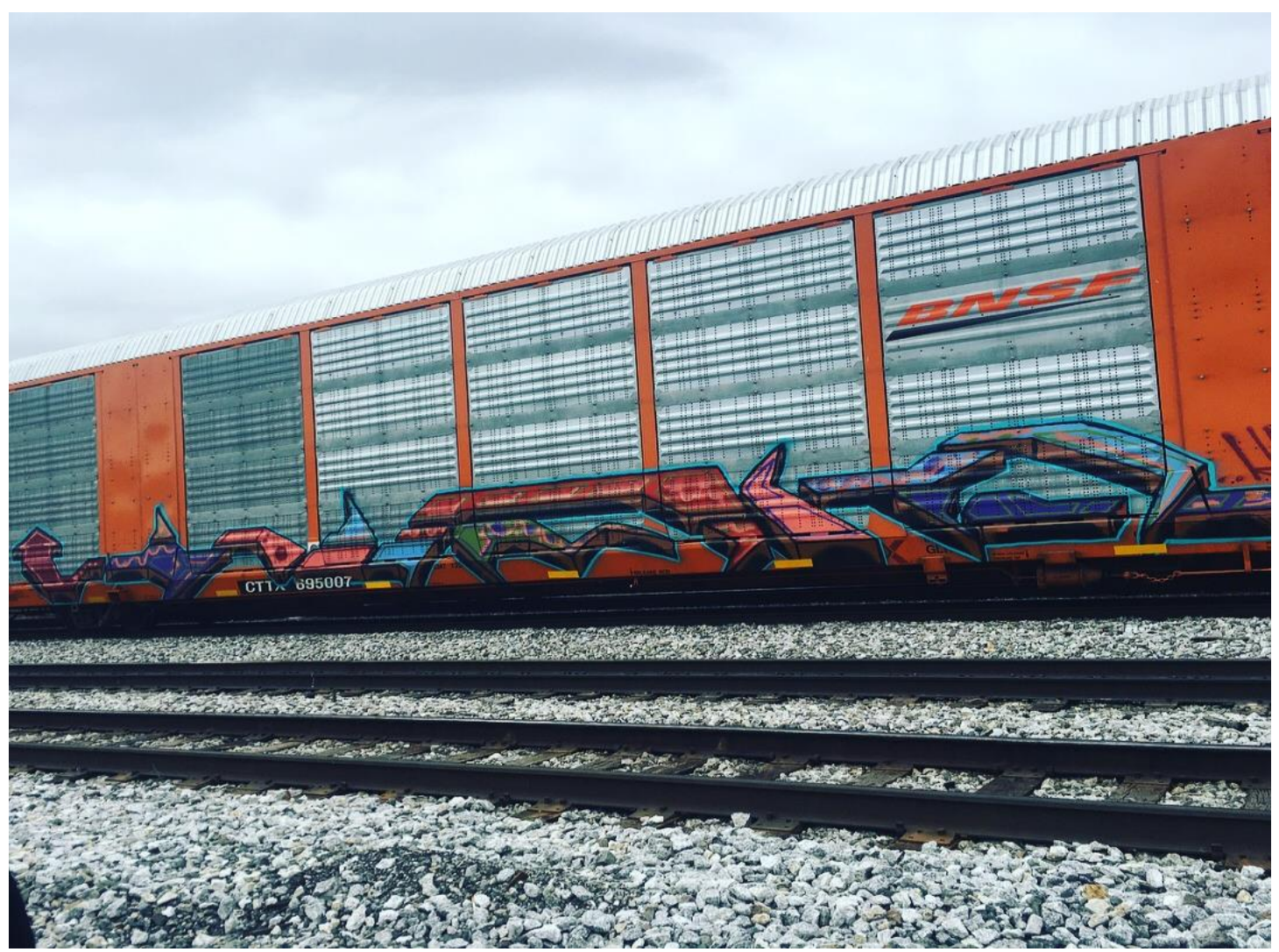

A “wildstyle 'end to end' train piece, done in three letters, by Kar-IYA, Baltimore, Maryland, July 2018

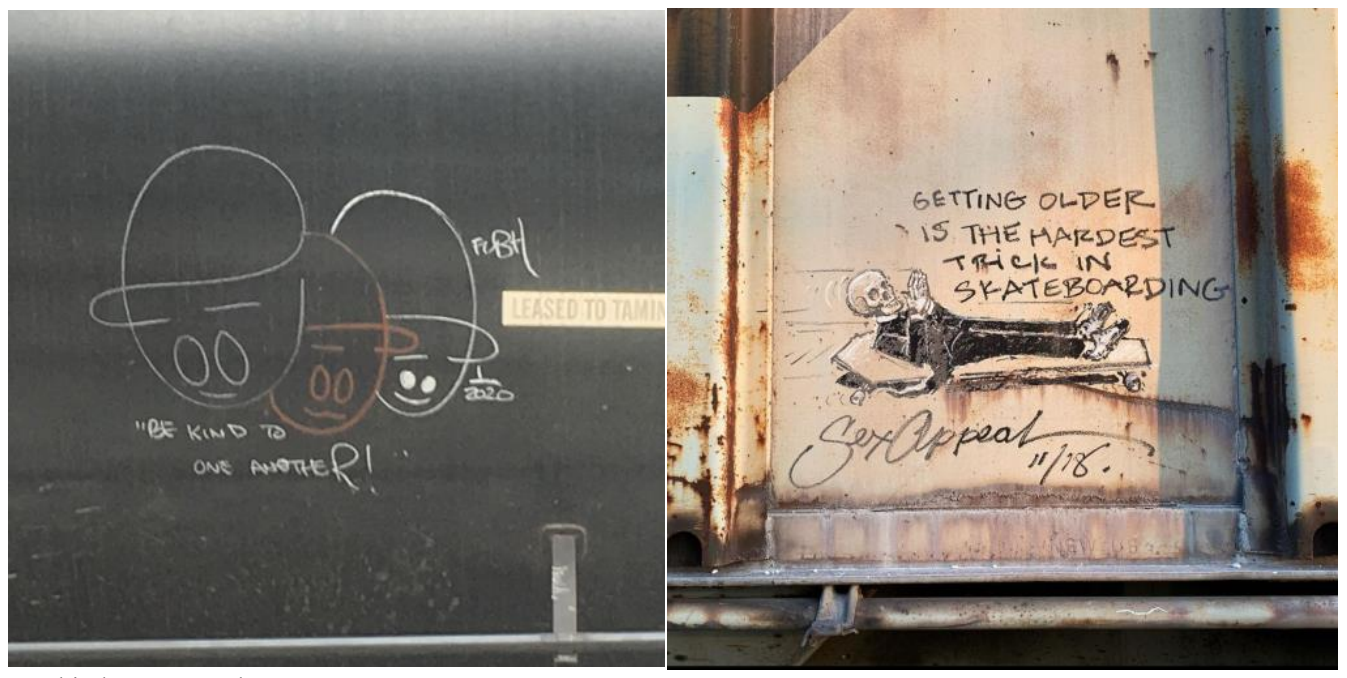

"Be kind to one another,” Western Maryland, July 2020. (Right) Moniker spotted Portland, Oregon, photo: IG: (@train monikers)

\section{Political Graffiti}

Political graffiti may or may not be done in the style or artistic flair of hip hop style graffiti, but many instances of political graffiti have been executed in highly-skilled and stylistic artistic often in street art mural or having elements of hip hop graffiti style. 


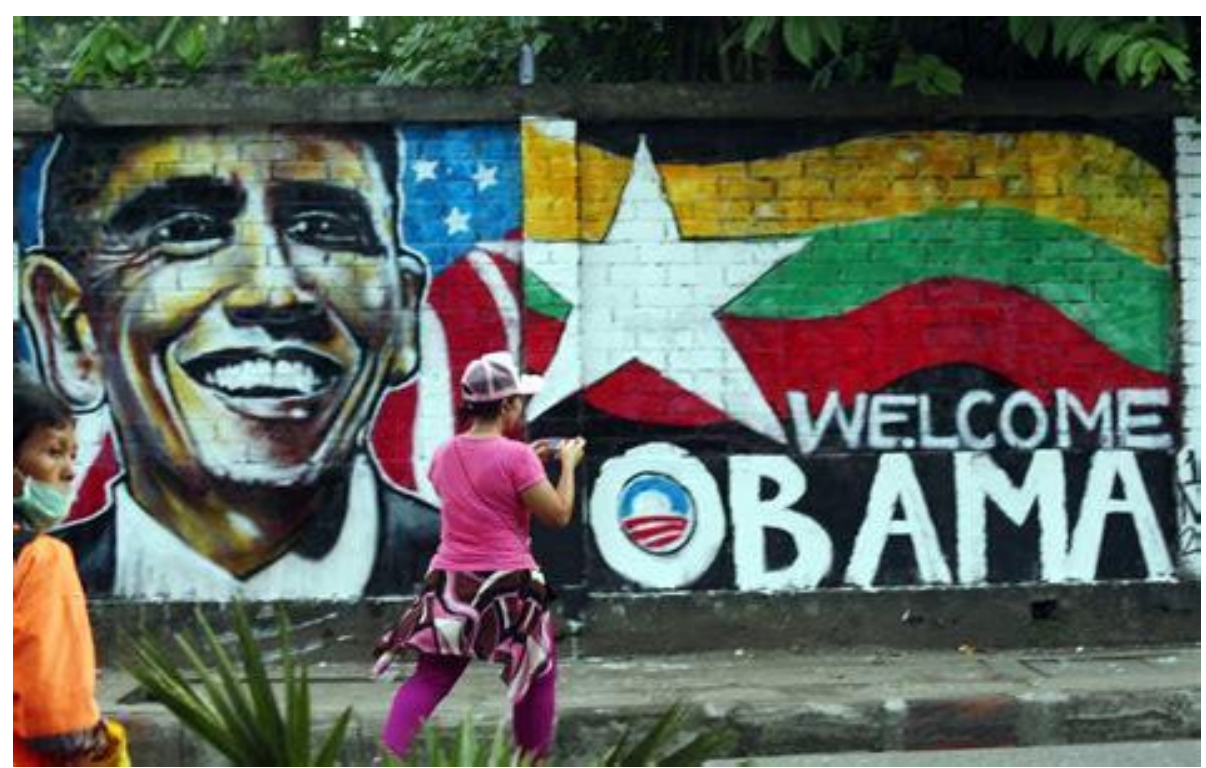

A non-graffiti style political mural celebrating the 44th US President, Barrack Obama.

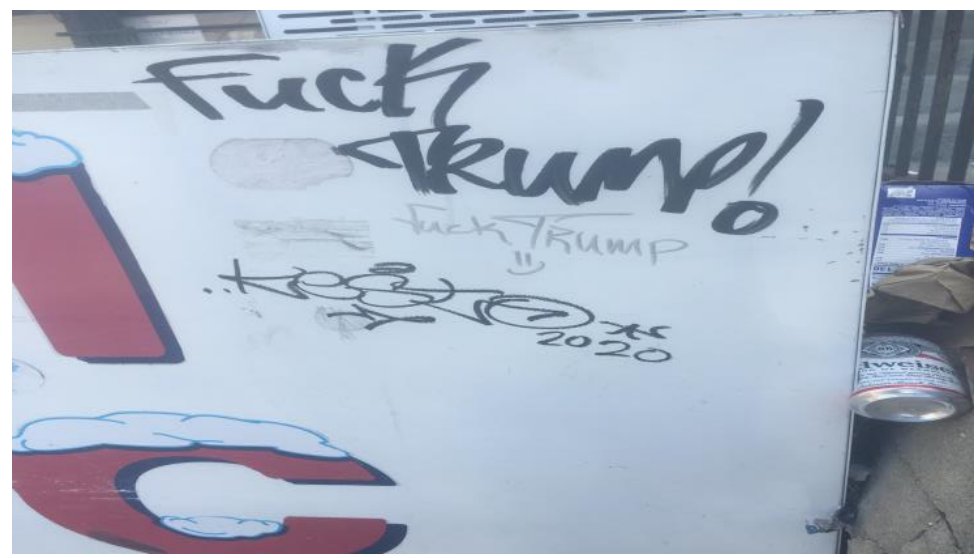

Political graffiti alongside a tag (Kesto), Washington, DC, June 2020

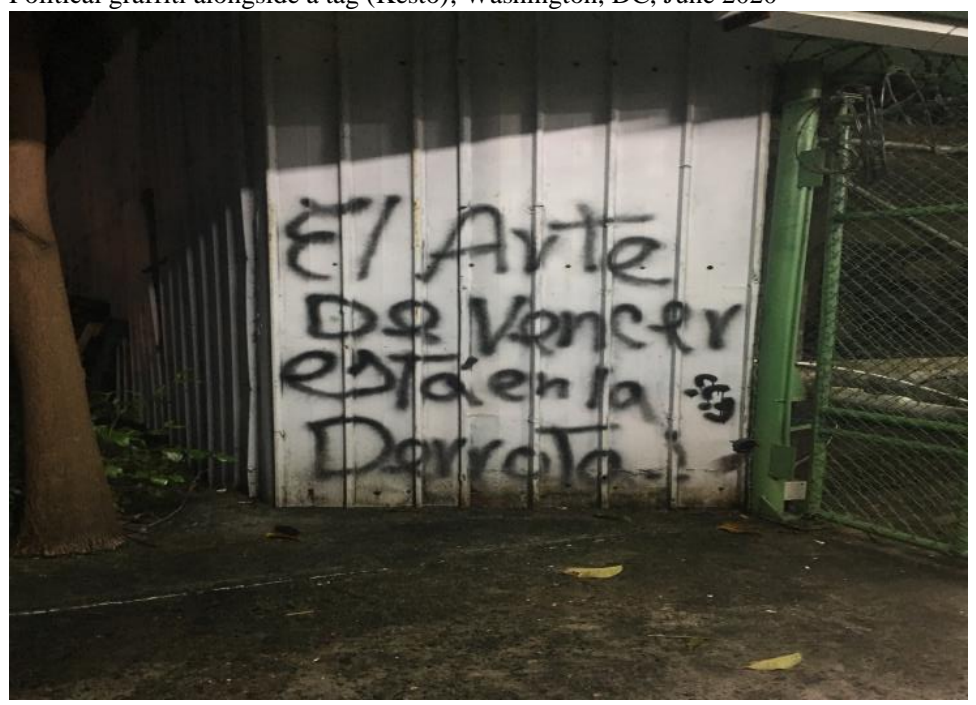

Political graffiti: "The art of victory is in defeat" (Simon Bolivar), June 2019, Panama. 


\section{APPENDIX D \\ OTHER PRACTICES IN HIP HOP GRAFFITI}

\section{"Dissing"}

This may be a form of aggression or of social control within the graffiti subculture wherein someone marks or paints-over (or partially covers) another writer's work. Dissing also may occur when a writer loses respect within the community, or is otherwise not respected, such as with unknown or unskilled writers.

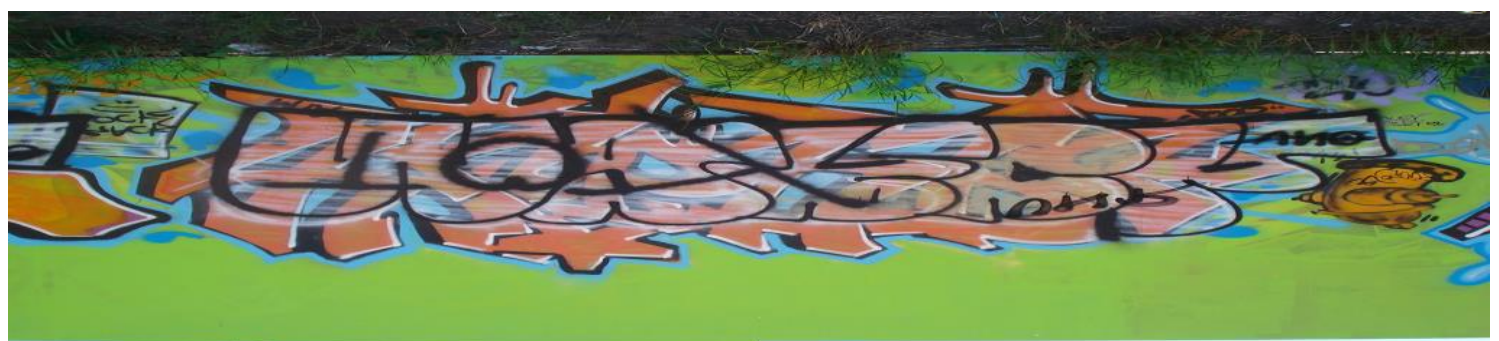

A "dissed" piece that was gone over with a throw-up, which was in turn gone over with the word, "toy," a common insult to unskilled beginners, or to those who have lost respect in the community.

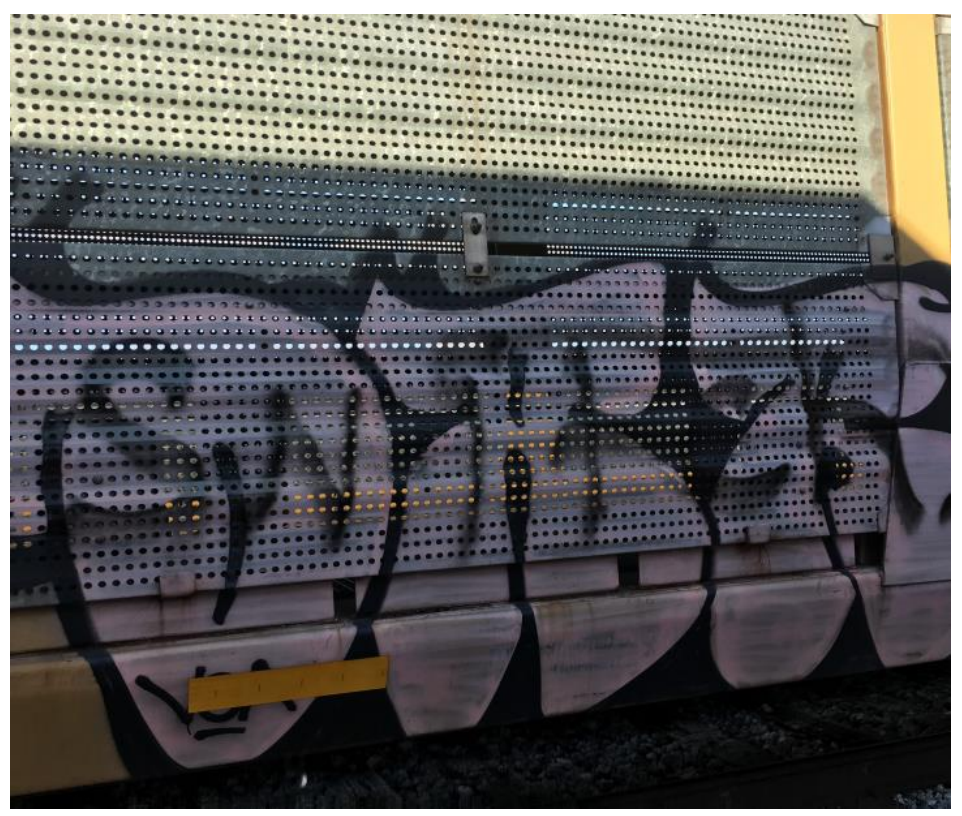

A dissed train piece, June 2017

\section{"Going Over"}

Related to "dissing," going over refers to generally painting over someone else's art. It can be done with respect, where the other person's art is completely covered, or it can be done disrespectfully; either leaving enough of the other individual's art showing that others can tell who got "gone over." One may also diss another writer as discussed above. 
"The Buff"

This term refers to abatement by municipalities (generally), but may also apply to volunteers or to vigilante anti-graffiti actions taken by private citizens.

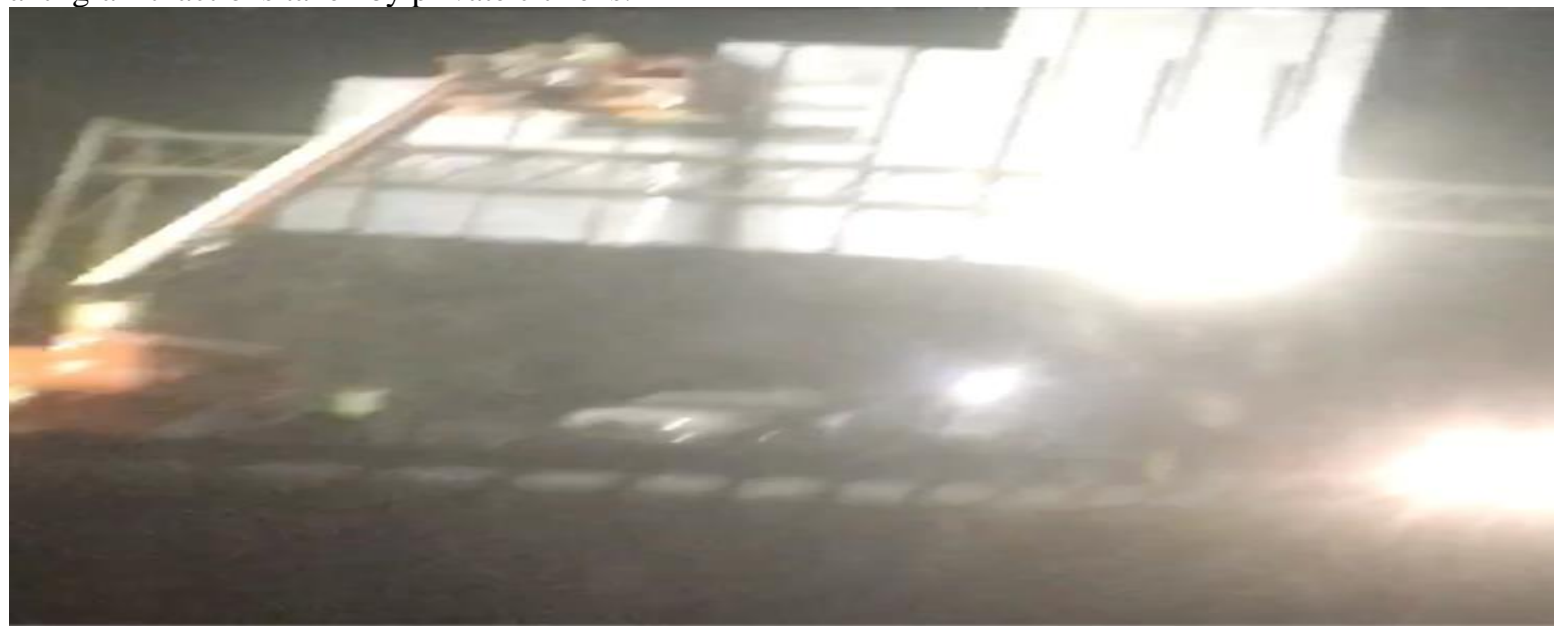

State highways (or possibly municipal) abatement crew conducting 3AM graffiti abatement on a large highway sign, September 2018. 


\section{APPENDIX E INTERVIEW GUIDE - POLICYMAKERS AND ENFORCERS}

(1) What is your job description? Do your responsibilities involve dealing with Illegal graffiti? How so? Can you explain this in further detail?

(2) What is your role in terms of dealing with illegal graffiti? Do you deal with legal or permitted graffiti? If so, how so?

(3) How long has your job involved dealing with illegal graffiti? Was there anyone who did this before you? How did their role differ, or was it the same?

(4) What is your responsibility in dealing with graffiti (i.e. parks, the metropolitan area, districts within the city)?

(5) Who else is involved in dealing with illegal graffiti?

(6) Who is responsible for defining the city protocols addressing illegal graffiti? Can you explain how these are developed?

(7) Who is involved in providing input for the designing city protocols for graffiti? (i.e. Property owners? Police? Graffiti artists? If so, to what extent are each involved?

(8) What types of illegal graffiti are of highest priority?

(9) What are your views on illegal graffiti, in general?

(10) Would you say that graffiti is a problem in the LMA? How big of a problem is it?

(11) How is illegal graffiti prioritized in terms of other crime?

(12) Are you aware of any differences in types of illegal graffiti that appear in the metropolitan area? If so, please explain. Are there instances of graffiti that are more tolerated or less tolerated than others? Please tell me more.

(13) Is all graffiti treated the same under policy? Does this vary at all in practice (either abatement or policing)? 
(14) Approximately how money much is spent on illegal graffiti in the metropolitan area (or in the city)?

(15) Do you believe this is money well spent? Are you aware of how this could be changed or improved?

(16) Do current policies effectively address illegal graffiti? Please explain.

(17) Have there been times when the city "clamped down" or alternately escalated the handling of illegal graffiti? If so, can you discuss this with me in more detail?

(18) Have there been times when the city "loosened up" or de-escalated policy practices that deal with illegal graffiti? If so, can you tell me more about this?

(19) If you haven't already answered this, what determines when there is a decrease or increase in city actions on illegal graffiti?

(20) Are you aware of other ways that illegal graffiti could be handled than is being done? If so, can you discuss this?

(21) How do you think graffiti is best dealt with? Can you tell me more?

(22) Does graffiti have positive aspects? If so, can you talk about this?

(23) Do you know of any the historic processes of dealing with illegal graffiti or municipal practices in other areas and cities? If so, do these have a bearing (or could have one) on policies in Louisville?

(24) Can you discuss the details of any city practices that at any point allowed graffiti or dealt with it in some way other than ordinance enforcement and abatement?

(25) Is there anything else we haven't discussed that you believe is relevant or would help my research?

(26) Is there anyone you would refer to me who also deals with illegal graffiti and whose feedback you think would be valuable to my research?

Thank you for your valuable insights. Do you have any questions for me? 


\section{APPENDIX F GLOSSARY OF TERMS}

Acid bath

"All city"

Background

Bars

Biting

Black book

Blockbuster

Bombing

Bubble letter

Bucket paint

Burner a chemical used for "scribing," or "scratchiti," in etching one's name onto a glass or plastic surface, often in public restrooms or on gas pumps

high status among writers who are prolific in a city area and have demonstrated that they can occupy a vast amount of space but also demonstrating various styles and mastery of skill

refers to complementary or contrasting colors painted "behind" one's graffiti name, usually some patterns of color that, along with 3D structure in lettering or characters, presents a multi-dimensional effect

basic structures of lettering that create individual letters. For instance, an uppercase ' $h$ ' has two vertical and one horizontal bar. In piecing, one can create a piece by painting bar by bar and letter by letter, or they can sketch out all the bars in all the letters and fill them

refers to stealing" someone else's style by reusing it in one's own art. Opinions vary among writers, where some believe biting is necessary for progression, while others say it is an inevitable part of learning one's own unique style

refers to a collection of sketches of tags, throwups, or pieces, and may include stickers or other drawings one trades with other writers; often used as a social activity and for writers to share outlines of other writers' names

large and usually legible square-letter form of piece that often occupies a larger amount of space than average pieces painted with aerosol; often utilize conventional paint applied with rollers and brushes

refers to a form of writing, street or highway walls, signs, postal boxes, and so forth. Bombing can include tagging or doing throwups alone or together with piecing (less frequently)

a general term referring to a traditional style of hollows or throwups that have curved letters with features sometimes resembling bubbles

refers to conventional paint that is applied with rollers or brushes; often used in "rollers" and "blockbusters"

or sometimes "banger"; refers to an exceptionally artistic or stylized piece 
Cap

Diss

Fill

Fill-in

Force

Handstyle

Heaven spot

Hollow

King

Mural

OG

Outline either an aerosol can cap or the process of going over (to cap) or "capping" other graffiti; may originate in Style Wars (1983) movie that featured a writer known for going over other writers with his name "CAP" 20

originates in hip hop culture (to disrespect) and describes the process in graffiti of deliberately disrespecting another person's art, either by partially going over them or sometimes crossing out the "dissed" writer's name and leaving a tag with one's own graffiti name

the filled in part of a throwup or piece; refers to the general color scheme of the filled letters and can vary in patterns, colors, and may have its own style separate from the lettering style

is another term for a "throwup" and basically indicates that it is a hollow but filled in.

an outer layer (or layers) added around one's piece once the 3D shadowing or other effects and background are added; sometimes referred to as a "shell"

typically refers to a tag

this is a location where graffiti is painted and is highly visible, usually high spots such as highway signs, ledges of overpasses, water towers, or high walls of buildings and rooftops. "Heavens" usually involve a high level of risk, either for their being physically dangerous, or sometimes for their involving a higher level of risk of being apprehended in the process

simple precursor of a throwup; usually an outlined rendition of a graffiti name, often bubble-style lettering. Hollows utilize the wall background color and sometimes have 3D effects built into their line structures

perhaps the highest status a writer can obtain, usually applied to deceased writers who was "all city" or become prolifically up in a city area

can refer to graffiti pieces, though not typically within the subculture; refers in this study to the legal forms of pictorial and typographical street art employed by city policy officials, sometimes with an interest in deterring graffiti

term referring to advanced writers in this study. OG writers in the current sample had all written for a minimum of ten years. Consent was applied by other writers in the scene that 2Buck was an OG writer, as were other writers with around ten or more years of experience. Writers who were considered "OG had also for the most part been around the graffiti scene since prior to the inundation of graffiti by social media (prior to 2005). "OG" is thought to denote "original gangster"

either a rendition of someone's graffiti name done on paper and sometimes produced by experienced writers for their peers or for less-experienced writers to practice (sometimes referred to simply as a "sketch"). 'Outline' also describes a process of piecing where one first sketches out the bars or major pieces of letters, which are latter filled in with a "fill" color

20 The writer "CAP" later went on to exhibit works in galleries, and did work for Ride Snowboards and Dragon Optical, both of which are big names in the outdoor sports world. 
Piece

Piecing

Scribing

Scratchiti

Shell

Sidebust

Sketch

Sketch book

Street art

Structure

Style

Tag a highly stylized letter-based signature, often produced as writers progress beyond being able to produce a handstyle (tag) or throwup; sometimes "masterpiece"

the process of creating a piece (masterpiece). Two ways of piecing include "bombing" style and otherwise. If piecing while bombing, one may prefer to utilize the bar-by-bar, letter-by-letter method, which is generally faster and may skip the step of outlining one's piece before painting

a form of tagging done on glass or plastic surfaces, usually done with a pointed metal object referred to as a "scribe," though some veterans used a product called "acid bath" which is an industrial grade abrasive chemical that requires using proper protective equipment (i.e. heavy duty gloves)

a way of getting up that deals with scratching one's name into metal, wood, plastic, glass, or other surfaces (See also McAuliffe 2012)

refers to the outermost color (or colors) in a piece; also called a "force" or "force field"

to paint graffiti close beside another writer, often without leaving a continuous space between the two; can be done while two writers are painting together or (more often) one writer paints a tag, throwup, or piece, and another writer later does so in close proximity to the original writer's or writers' work

the process of practice or developing different styles of graffiti that usually precedes the production of a piece; a vast majority of writers reported sketching prior to doing a piece or before practicing a new style of tag or throwup; a sketch may refer to an "outline" done by one writer for another, sometimes by OGs for toys or intermediate writers to practice

another name for "black book" which composes a collection of a writer's work or that which others shared

legal or illegal artistic productions, usually geared toward the generally public; legal street art is similar to graffiti in the respect that both are usually frowned upon if lacking permission;

refers to the general letter structure of one's graffiti; good structure refers to letters in which bars that are in proportion, or if proportions are deliberately distorted in some letters, these distortions are artistically consistent or coherent

an abstract notion referring to one's unique artistic style, personal style, one's mojo, or life force; style also refers to the different styles of graffiti: wildstyle, bubble lettering or blockbuster, regional letter style, and so forth; a hierarchy of styles in this writing describes the precedence in skill which one form of graffiti takes over another (i.e. tags versus throwups or pieces)

perhaps the simplest rendition of one's graffiti name, tags can lack style or be highly stylized; practiced by writers of all levels; tags are often written beside pieces or throwups and are part of a larger practice known as "bombing" in order to get one's name up in large volumes 
Tagger

Tagging

Throwie

Throw up

Toy

Up

Writer one who specializes in tagging; often a derogatory term applied to graffiti writers by outsiders; sometimes associated with beginner graffiti writing practices

the practice of painting tags; was least desirable form of graffiti by policy makers in the current study

another name for "throwup" or a quickly performed rendition of one's graffiti name, which may have square-edged or bubble-style letters; throwies are part of a process of "bombing" or painting large volumes of one's name in order to get up

a two (or more) colored rendition of one's graffiti name, often using contrasting outline and fill colors. Throwups are a more sophisticated version of a hollow and are generally quick but more complicated ways of getting up. Throwups are often associated with "bombing" to get one's name up in quantity

a beginner writer, usually within their first year or two of painting graffiti, while attempting to generate respect; Toys generally lack skill or style until a great deal of work is done in "bombing" to get one's name up. Not until later one is acknowledged as a writer, and may be considered generally a 'writer' or an intermediate level writer

or "getting up" is a state of having a great deal of one's graffiti visible in the city area; "getting up" was said by most to be the point of doing graffiti

shortened form thought to originally denote graffiti writer. Most individuals primarily used this term (writer) to describe themselves or others, though occasionally some also used 'graffiti writer.' 


\section{CURRICULUM VITAE}

Theodore Malone, Ph. D.

(484) 509-7875

tcmalone@pm.me

\section{Objective}

I am seeking an assistant professorship in Sociology that grants me a balanced teaching, research, and service and the freedom to contribute to departmental and institutional outcomes by expanding my current research agenda and by using my skills and knowledge in teaching, social policy, deviance and criminological theory, and research.

\section{Education}

Ph.D. Applied Sociology (August 2020)

University of Louisville (Louisville, KY)

M.A. Applied Sociology (2015)

B.A. Sociology \& Anthropology (2002)

West Virginia University (Morgantown, WV)

\section{Employment}

Graduate Teaching Assistant (2017-2019)

Part-Time Lecturer (2019)

Sociology Department, University of Louisville

- Independently taught Sociology 336 (Criminology) at University of Louisville/Quality Leadership University in Panama City, Panama

- Independently taught two sections of Intro to Sociology; team taught, curriculum design, assessments, and grading (D.M. Austin, Brandon Schmidt, Jon Phoenix)

- Assisted teaching online Intro to Sociology (with Dr. Mark Austin)

- Assisted teaching Sociology of Volunteerism (with Dr. Mark Austin)

- Team taught Sociology 336 (Criminology) and Sociology 330 (Juvenile Delinquency) with advisor and mentor, Dr. Ryan Schroeder

Graduate Research Assistant (2016-2017)

Center for Environmental Policy \& Management at University of Louisville

- Conducted quantitative research for social and environmental justice via policy research and co-wrote, co-edited annual report Louisville Metropolitan Housing Commission

- Conducted program analysis, database management, and data analysis and supported the director, Dr. Lauren Heberle in projects with partnered organizations including US EPA superfund brownfields reclamation

- Assisted with community environmental justice projects and co-presented research at various state and local conferences 
Graduate Teaching Assistant (2014-2015)

West Virginia University Department of Sociology

- Assistant to full professor for Intro Social Inequality, Race Relations, Cyber Crime [(Dr. A. Dasari, John Kane (FBI)]

Writer/Editor (2013-2014)

- Coordinated transcription, editing, and ghost writing of a book about an individual's life and prison experience earning GED then master's degree while incarcerated (project overseen by WVU advisor, Dr. Patricia Rice)

Mathematics Teacher and Remediation Specialist (2009-2013)

West Virginia Department of Education, Morgan County Schools

- Taught Mathematics students from grades 7 to 12, assisted in achieving Annual Yearly Progress for middle/high schools

- Served as remediation specialist to Geometry \& Algebra students

- Served as district-level representative for curriculum development to organize state required senior transition mathematics courses

Mathematics Teacher (2007-2009)

Virginia Department of Education, Winchester City Public Schools

- Independently taught Algebra 1 and 2, C++ programming

- Conducted data analysis for standardized state testing and assisted in increasing test scores above prior years' rates for Algebra I and II, helped achieve annual progress; my student's VA SOL scores: 70-93\% average

\section{Research}

Deviant subcultures and dark recreation; edgework and recreation; policy analysis, urban space and graffiti policy; alternative research methods; institutional ethnography; litigant court advantage

\section{Publications}

"State of Metropolitan Housing Report: Living in Community: Housing for People Living with Disabilities and Our Aging Population.” Metropolitan Housing Coalition, Louisville KY. Heberle, Lauren, Brandon McReynolds, Adam Sizemore, Steve Sizemore, Theo Malone, Jamie Beard, C. Fosl. 2016

"You Can't Fight City Hall: Organization and Legal Success in West Virginia." Master's Thesis. West Virginia University. 2015.

\section{Presentations}

"Hip Hop Graffiti as Bold Expression and Act of Resistance"

(Presented 2020; Wilson College Humanities Conference, Wilson College,

Chambersburg, PA)

"Don't Look Up: Social Media and Digital Consumption of Graffiti" (Presented 2019; Wilson College Humanities Conference, Wilson College, Chambersburg, PA)

"Principles of Ethnographic Research and Graffiti Art"

(Presented Spring 2018; Guest Speaker Talk - Sociology 405/605 Voluntarism, University of Louisville; Louisville, KY)

"Getting Up: An Ethnography of Hip Hop Graffiti Writers, Their Art and Their Perceptions of Society's Reaction" 
(Presented Spring 2018; Guest Speaker Talk - Sociology 618 Qualitative Methods, University of Louisville; Louisville, KY)

"Becoming an Efficacious Teacher"

(Presented May 2009, Shepherd University Department of Education,

Shepherdstown, WV)

\section{Service}

Senator - Student Government (2018-2019)

Student Government Association (University of Louisville)

Student Government Association Representative (2018 to 2019)

Graduate Network in Arts and Sciences Representative (2018)

Sociology Graduate Student Association (University of Louisville)

Speaker Recruiter and Coordinator (2018-2019)

John Rieger Academic Speaker Series, UofL Sociology Department

Graduate Network in Arts and Sciences Representative (2018)

Sociology Department (University of Louisville)

Sociology Graduate Association Member (2017 to 2019)

Sociology Department (University of Louisville)

Search and Rescue Specialist, Medic (2016-2018)

Jefferson County Search Dogs Association, Louisville, KY

Search and Rescue Specialist, Medic (2010-2011)

Shenandoah Mountain Rescue Group (Vienna, VA)

Trail Overseer (2010-2015)

Potomac Appalachian Trail Club (Vienna, VA)

Patient Advocate (1999-2000)

Ruby Memorial Hospital (Morgantown, WV)

\section{Memberships}

American Sociological Association (2015 to Present)

Jefferson County Search Dogs Association (2016-2017)

National Education Association (2007-2014)

Potomac Appalachian Trail Club (2010 to Present)

Shenandoah Mountain Rescue Group (2010-2011)

\section{Professional}

Goals

Sociology teaching, service, and continued research related to current focus

Social policy research and development

\section{References}

Patricia Gagné, Ph.D.

Ryan Schroeder, Ph.D.

Jim Nolan, Ph.D.
Professor, University of Louisville patricia.gagne@louisville.edu

Dean, Georgia Southern University rschroeder@georgiasouthern.edu

Professor, West Virginia University Jnolan2@wvu.edu 